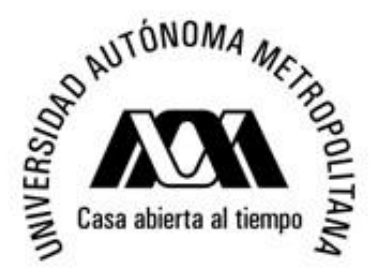

Universidad Autónoma Metropolitana Unidad Iztapalapa

División Ciencias básicas e Ingeniera

Departamento de Química

Área de Química Analítica

30-10-2014

\title{
Evaluación de métodos de inmovilización de enzimas para la construcción de biosensores.
}

\author{
Tesis que presenta \\ Erika Rodríguez Sevilla
}

Para obtener el grado de

Doctor en Ciencias (Química)

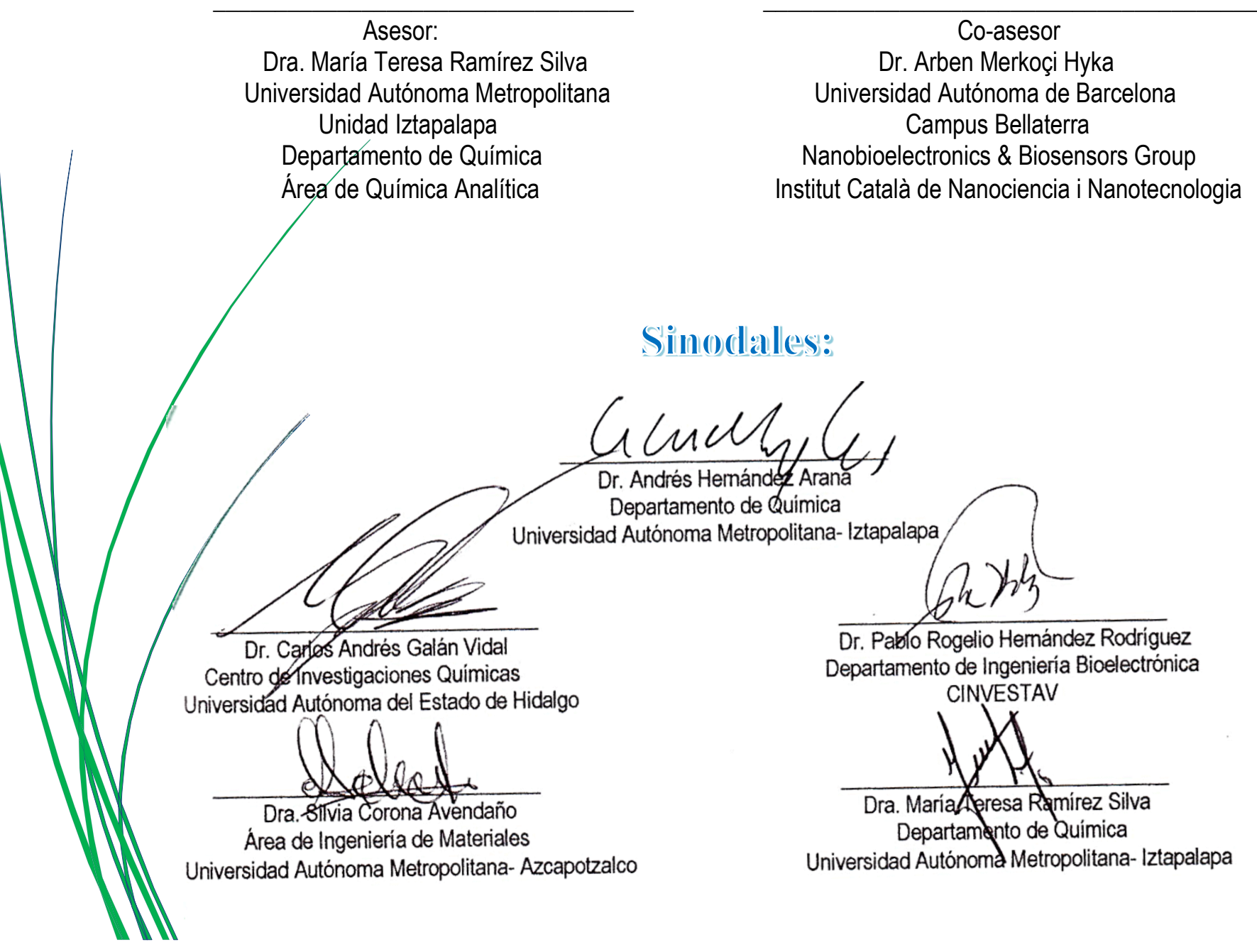




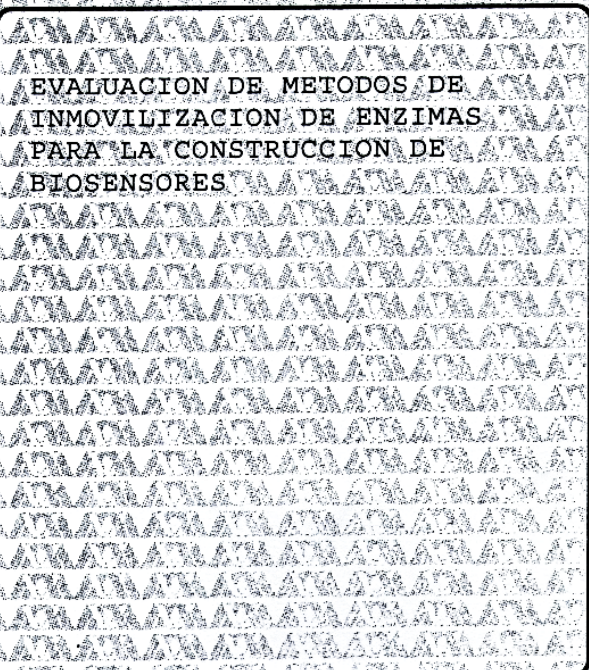

S

and

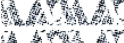

What

Whis

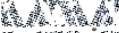

W.

antas

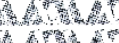

H.t.

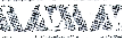

andis:

WWH.

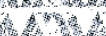

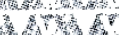
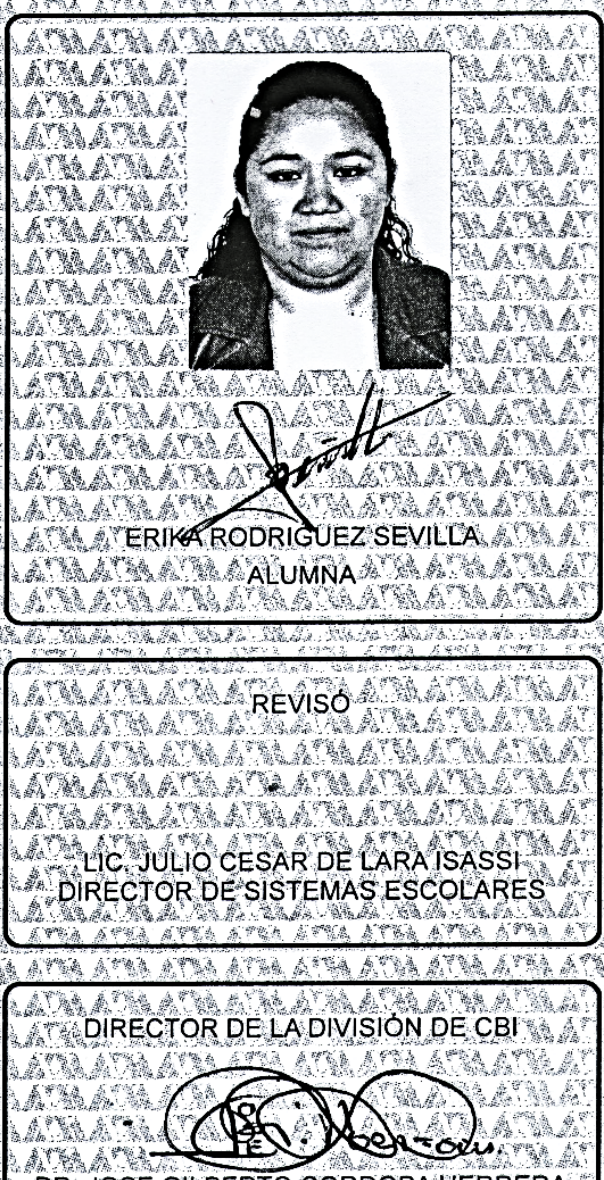

DR JOSE GILBERTO CORDOBA HERRERA

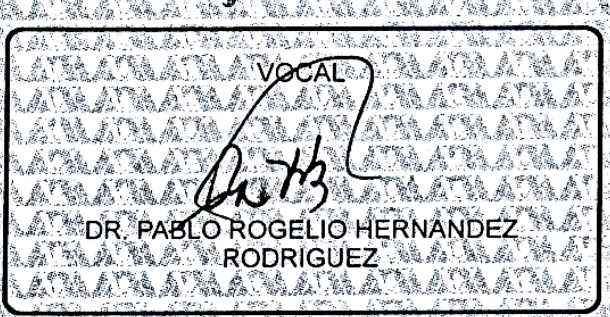

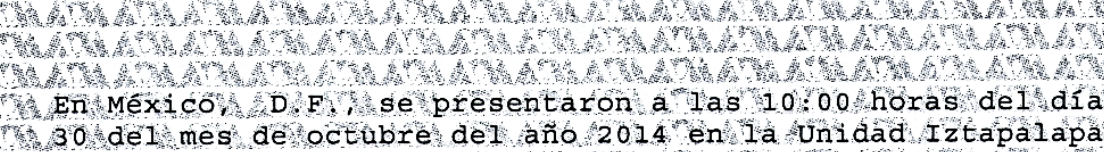
de la Universidad Autónoma Metropolitana, los suscritos miembros del furado:
\end{abstract}

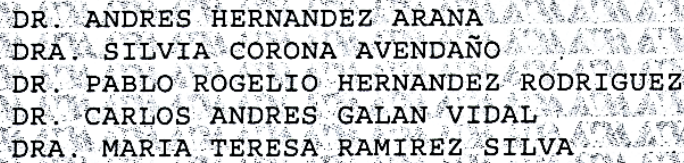

Bajo la presidencia del primero y con carácter de Secretaria la última, se reunieron a la presentación de la Disertación pública cuya denominación aparece al margen, pararla obtención del grado de:

DOCTORA /EN CIENCIAS (QUIMICA)

T. DE \& ERIKA RODRIGUEZ SEVILLA

Y de acuerdó con el artículo 78 fraccín IV del Reglamento dêtestudios Msuperiores de la Universidad Autónoma Metropolitana, $10 s$ miembros del jurado resolvieron:

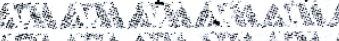

\section{A probar}

Acto continuo, el presidente del jurado comunicó a 1 a interesada el resultado de la evaluación $\mathrm{Y}$, hen caso aprobatorio, le fue tomada la protesta.

$\mathrm{Na}$

Whath 


\section{Índice}

Índice

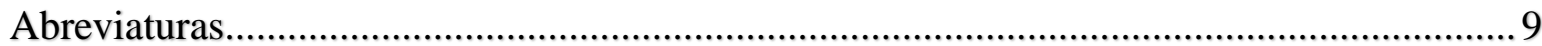

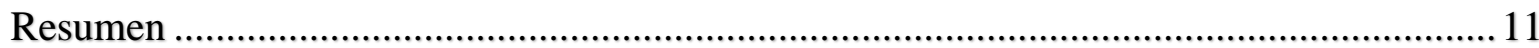

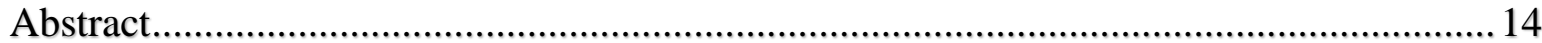

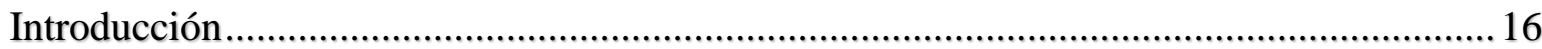

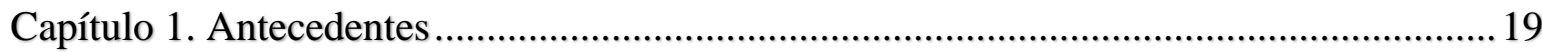

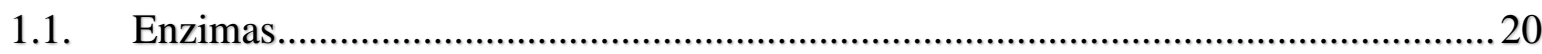

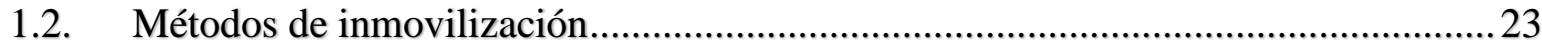

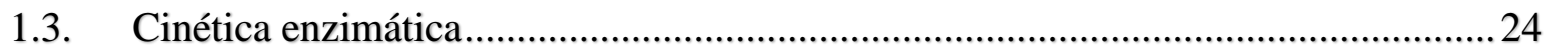

1.3.1. Factores que afectan la velocidad de la reacción enzimática. ..........................26

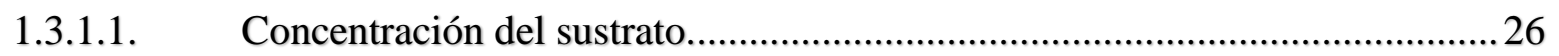

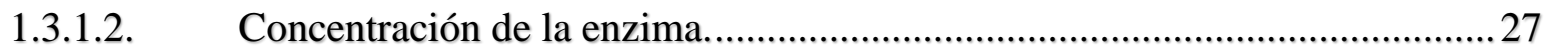

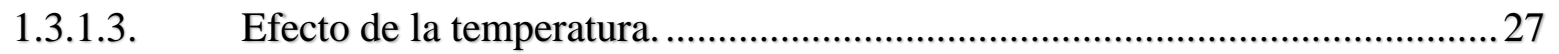

1.3.1.4. Efecto del $\mathrm{pH}$

1.4. Constante de Michaelis-Menten en solución .............................................................28

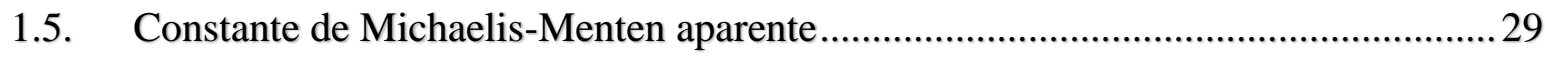

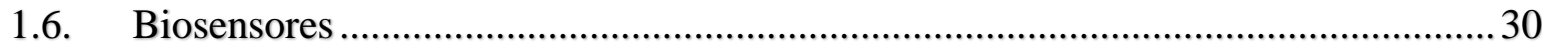

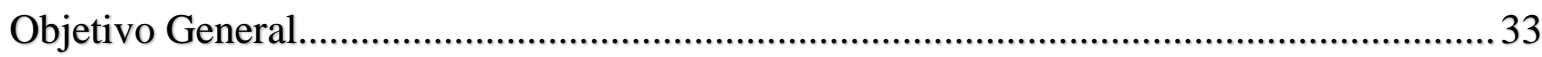

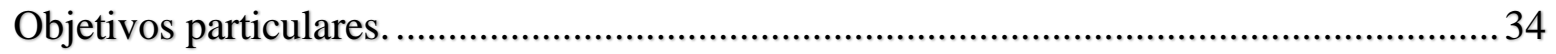

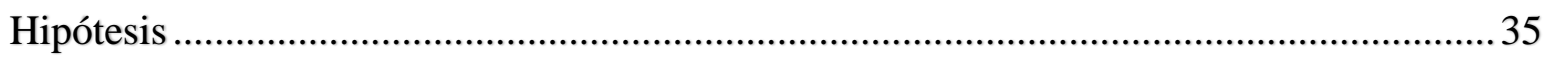




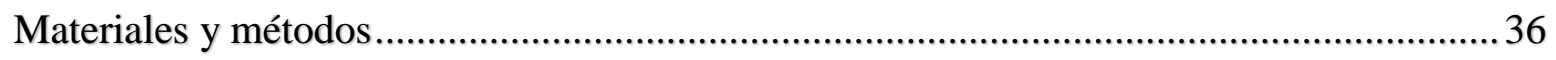

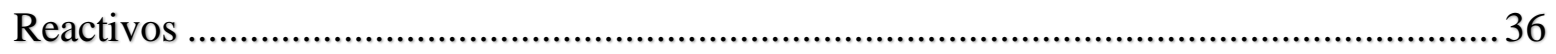

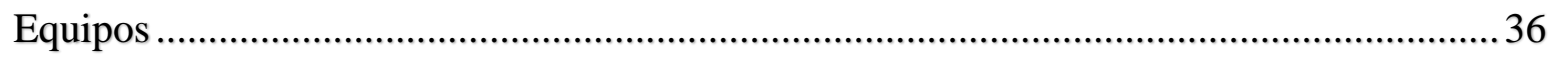

Caracterización espectrofotométrica por UV-vis del sistema laccasa de Trametes versicolor

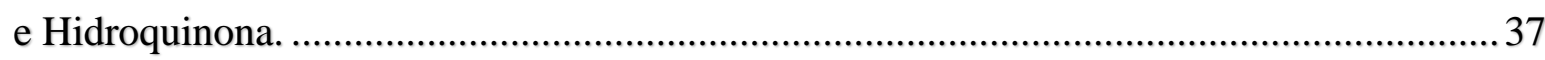

Caracterización espectrofotométrica de tirosinasa mushroom...............................................

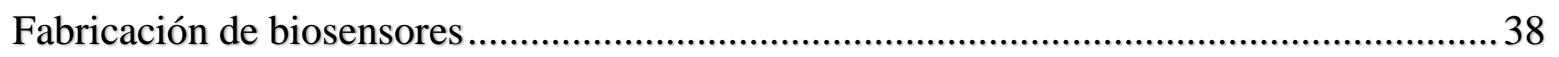

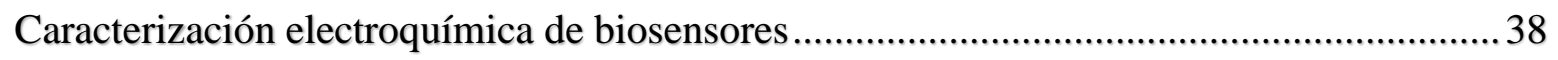

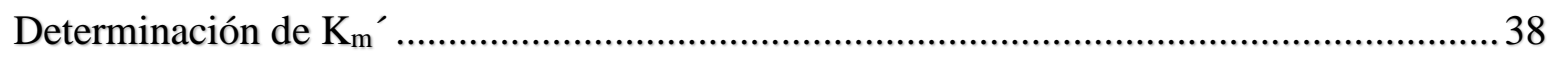

Preparación de muestras y determinación de la capacidad antioxidante..............................39

Capítulo 2. Biosensores con laccasa de Trametes versicolor. ..............................................40

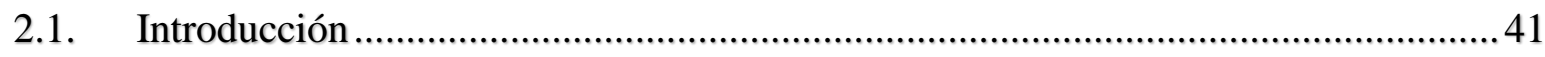

2.2. Caracterización espectrofotométrica UV-vis del sistema laccasa de Trametes

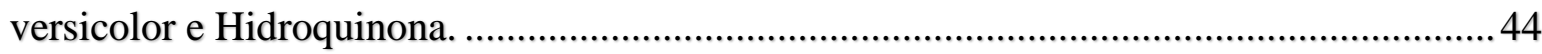

2.3. Cálculo de la constante de Michaelis-Menten para la laccasa de Trametes versicolor 46

2.4. Caracterización electroquímica de hidroquinona ………......................................50

2.4.1. Determinación del potencial de pseudoreferencia...........................................53

2.5. Caracterización electroquímica del sistema laccasa-hidroquinona …………...........54

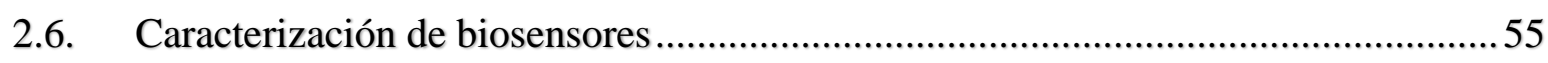

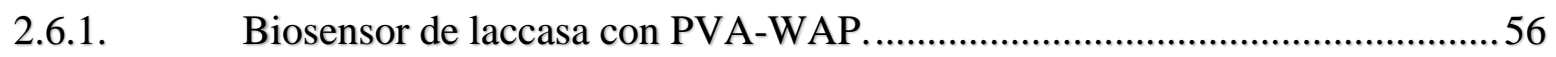

2.6.2. Biosensor de laccasa con glutaraldehído y albúmina de suero humano..........60 
2.6.3. Biosensor de laccasa con glutaraldehído termocurado a $40^{\circ} \mathrm{C}$ 66

2.6.4. Biosensor de laccasa con EDC, y sulfo-NHS ...............................................72

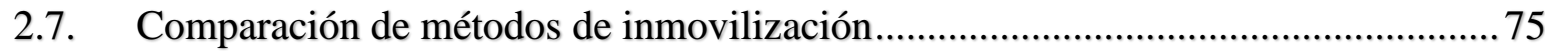

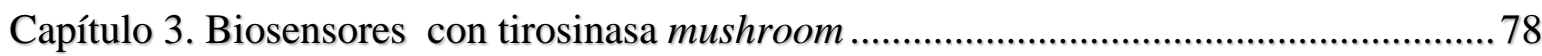

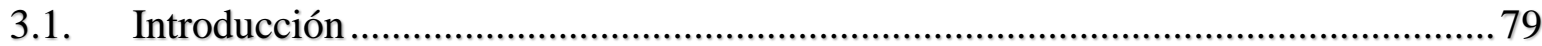

3.2. Caracterización espectrofotométrica de tirosinasa mushroom. .................................. 80

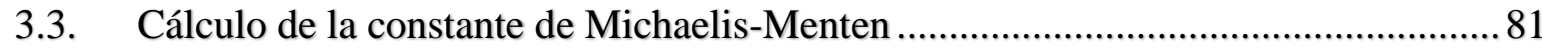

3.4. Caracterización electroquímica del sistema tirosinasa-catecol...................................82

3.5. Caracterización amperométrica de los diferentes biosensores. .................................... 83

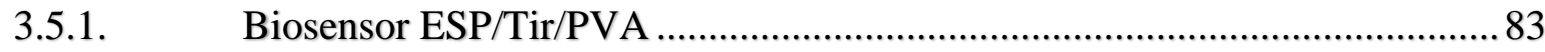

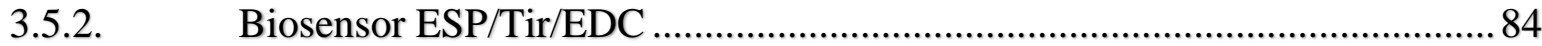

3.5.3. Biosensores ESP/Tir/ASH/GA 2.5\% y ESP/Tir/ASH/GA $1.0 \% \ldots \ldots \ldots \ldots \ldots \ldots . . .85$

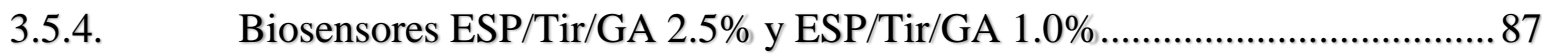

3.6. Estudio mediante Espectroscopia de Impedancia Electroquímica para los diferentes

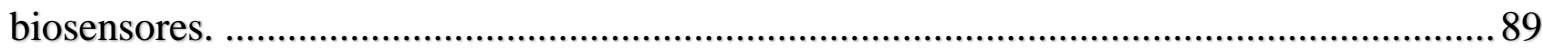

3.7. Comparación de métodos de inmovilización...............................................................93

Capítulo 4. Caracterización de la reducción electroquímica sobre el soporte de ESP.......96

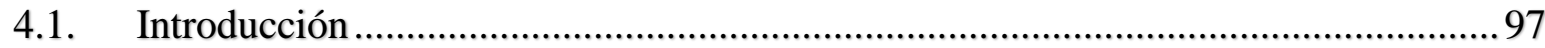

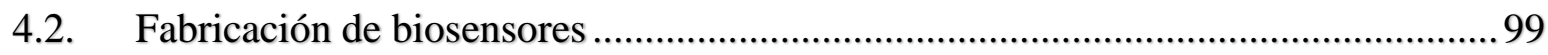

4.3. Caracterización amperométrica de los diferentes biosensores con laccasa .............100

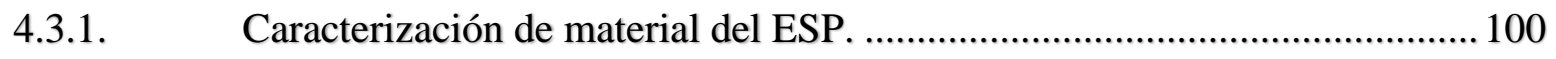

4.3.2. Caracterización electroquímica del sistema laccasa-HQ en solución............103 
4.4. Optimización de parámetros cinéticos y electroquímicos para la fabricación de biosensores.

4.1. Caracterización del biosensor con un área de $100 \%$ cubierto del electrodo de trabajo. 105

4.2. Caracterización de biosensor con el $70 \%$ del área cubierta en el electrodo de trabajo 108

4.3. Caracterización de biosensor con el 30\% del área cubierta en el electrodo de trabajo 110

4.4. Caracterización de biosensores de laccasa inmovilizada mediante atrapamiento a diferentes areaas del electrodo de trabajo.

Capítulo 5. Uso del radical DPPH para determinar TEAC en plantas medicinales de la zona de "tierra caliente" en el estado de Guerrero.

5.1. Introducción

5.2. Obtención de la capacidad antioxidante equivalente a Trolox mediante el método espectrofotométrico de DPPH.

5.3. Medición de la capacidad antioxidante de plantas medicinales del estado de

Guerrero, utilizando un biosensor de laccasa de Trametes versicolor.

5.4. Medición de la capacidad antioxidante de plantas medicinales del estado de

Guerrero. Usando el biosensor ESP/Tir/GA 2.5\%.

Conclusiones.

Perspectivas

Artículo publicado.

Anexo 1. Métodos de inmovilización 


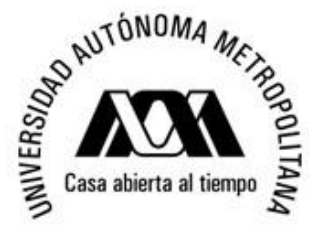

Universidad Autónoma Metropolitana Unidad Iztapalapa

División Ciencias Básicas e Ingeniería

Departamento de Química

Área de Química Analítica

Tesis de Doctorado

Q. Erika Rodríguez Sevilla

Anexo 2. Modelos matemáticos para estudiar la cinética enzimática.

161

Anexo 3. Fabricación de biosensores. .......................................................................... 168

Biosensores con laccasa de Trametes versicolor........................................................ 168

Biosensores con tirosinasa mushroom ...................................................................... 169

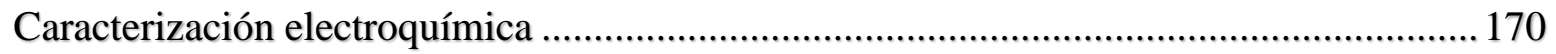

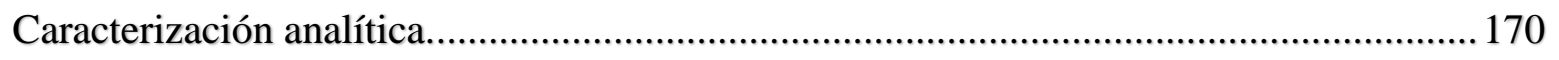

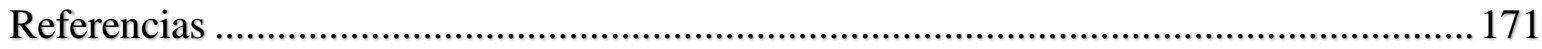




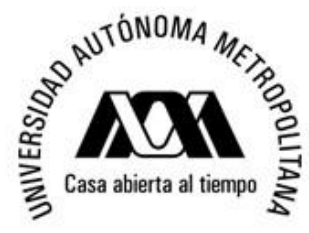

Universidad Autónoma Metropolitana Unidad Iztapalapa

División Ciencias Básicas e Ingeniería

Departamento de Química

Área de Química Analítica

Tesis de Doctorado

Q. Erika Rodríguez Sevilla

Agradezco a Dios por la oportunidad que me da de terminar un ciclo más en mi vida profesional, gracias por todas sus bendiciones derramadas día a día, por su protección y su dirección divina.

A mi esposo y a mi hijo por su invaluable amor y apoyo a cada momento, gracias por ser la fuerza que me motiva a seguir adelante, les amo.

A mis padres por su amor, su apoyo y por inculcarme que "la mejor herencia en este mundo son los estudios", gracias por ayudarme a cumplir un gran sueño, cada uno de mis logros siempre serán suyos también.

A mis hermanos gracias por su apoyo y cariño, y a cada miembro de la familia, gracias por todo. 


\section{Agradecimientos}

A CONACyT por la beca 229045 otorgada para la realización de estudios de posgrado.

A la Universidad Autónoma Metropolitana-Iztapalapa, por prestar sus instalaciones para la realización de esta investigación, por permitirme crecer profesionalmente.

A la Dra. Tere por la instrucción y la dirección en este proyecto, gracias por los conocimientos compartidos y el apoyo brindado para poder llegar hasta este momento.

Al Dr. Manuel Palomar Pardavé, gracias por los conocimientos compartidos y por el ánimo brindado durante la publicación del primer artículo.

A mis amigos en la UAM-I, y fuera de ella, a cada uno de los integrantes del Área de Química Analítica y del Departamento de Química, gracias por compartir conmigo este logro y por cada uno de los momentos vividos.

A cada uno de mis profesores en el Posgrado en Química, gracias por enseñarme la "magia de la química", gracias por ayudarme y dirigirme en mi vida profesional. 


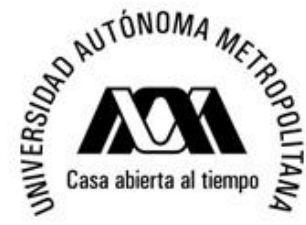

\section{Abreviaturas}

Universidad Autónoma Metropolitana Unidad Iztapalapa

División Ciencias Básicas e Ingeniería

Departamento de Química

Área de Química Analítica

Tesis de Doctorado

Q. Erika Rodríguez Sevilla

$\mathrm{Ag} \quad$ plata

$\mathrm{AgCl} \quad$ cloruro de plata

ASH Albumina de Suero Humano

$b \quad$ ordenada al origen

c concentración

DPPH 2,2-difenil-1-picrilhidrazil (DPPH)

E $\quad$ Enzima

[E] concentración de enzima

E potencial

EDC clorhidrato de N-etil-N'-(3dimetilaminopropil) carbodimida

ES Complejo enzima sustrato

ESP Electrodo screen-printed

GA glutaraldehído

HQ Hidroquinona

HSA Human Serum Albumin

I corriente

$K_{m}^{\prime}$, libre constante de Michaelis-Menten aparente para la enzima en solucion

$K_{m}{ }^{\prime} \quad$ constante de Michaelis-Menten aparente

$l \quad$ longotid de paso óptico

LDD Límite de detección

LDQ Límite de Cuantificación

LTV Laccasa de Trametes versicolor

M Molar

$m \quad$ pendiente 
MES ácido 2-(N-morfolino)- etano sulfónico

mTyr mushroom Tyrosinase

$\mu \mathrm{A} \quad$ Microamper

$\mu \mathrm{M} \quad$ Micromolar

$o-Q \quad$ orto-Quinona

$P \quad$ Producto

$\mathrm{p}-\mathrm{Q} \quad 1.4$, dibenzoquinona

$p-Q \quad$ para-Quinona

PVA Alcohol polivinílico

PVA-WAP Alcohol polivinílico soluble en agua

$\mathrm{R}_{\mathrm{tc}} \quad$ resistencia a la transferencia de carga

$S \quad$ Sustrato

$[S] \quad$ concentración de sustrato

SEM Microscopia Electronica de Barrido, por sus siglas en ingles

SPE screen-printed electrode

sulfo-NHS sal sulfónica ácida de sodio

tir Tirosinsa mushroom

TROLOX ácido 6-hidroxi-2,5,7,8-tetrametilcroman-2-carboxílico

TvL Trametes versicolor Laccase

$v \quad$ velocidad

V volts

VC voltamperometria ciclica

$v_{\text {máx }} \quad$ velocidad máxima

$V_{T} \quad$ volumen total 


\section{Resumen}

En esta investigación se describe la caracterización cinética y analítica de biosensores, elaborados sobre electrodos de tipo screen-printed (ESP) utilizando laccasa de Trametes versicolor, o tirosinasa mushroom como elementos de reconocimiento ambas son el atrapamiento, el reticulado y el enlace covalente en seis condiciones experimentales diferentes (ver Tabla I). Cada uno de ellos se caracteriza mediante Voltamperometría Cíclica, Espectroscopia Ultravioleta Visible, Amperometría y Microscopia Electrónica de Barrido (SEM). La caracterización electroquímica y espectrofotométrica se realiza a $(30.0 \pm 0.5){ }^{\circ} \mathrm{C}$ y $\mathrm{pH}=4.70 \pm 0.01$ impuesto con amortiguador de acetatos $0.1 \mathrm{M}$, la constante de MichaelisMenten aparente $\left(K_{m}{ }^{\prime}\right)$, para la oxidación enzimática de hidroquinona (HQ) a p-quinona, (pQ), es usada como parámetro de comparación, ya que provee información tanto de los parámetros de la cinética enzimática como de los parámetros analíticos ligados directamente con el biosensor.

Tabla I. Componentes de cada biosensor fabricado con laccasa sobre electrodos de tipo screen-printed.

\begin{tabular}{|c|c|c|c|c|c|}
\hline $\begin{array}{l}\text { Elemento de } \\
\text { reconocimiento }\end{array}$ & \multicolumn{5}{|c|}{ laccasa de Trametes versicolor (LTv) $5 \mathrm{mg} / \mathrm{mL}$} \\
\hline $\begin{array}{l}\text { Método de } \\
\text { inmovilización }\end{array}$ & Atrapamiento & \multicolumn{3}{|c|}{ Reticulado } & Enlace covalente \\
\hline \multirow{5}{*}{ Reticulante } & \multirow{5}{*}{$\begin{array}{l}\text { Alcohol } \\
\text { polivinílico } \\
\text { soluble en } \\
\text { agua (PVA) }\end{array}$} & Puro & \multicolumn{2}{|c|}{ Co-reticulado } & \multirow{5}{*}{$\begin{array}{l}\text { clorhidrato de N- } \\
\text { etil-N'-(3-dimetil- } \\
\text { aminopropil) } \\
\text { carbodimida } \\
\text { (EDC) }\end{array}$} \\
\hline & & $\begin{array}{c}\text { Sin albúmina de } \\
\text { suero humano (ASH) }\end{array}$ & $\begin{array}{r}\text { Con albún } \\
\text { hu } \\
(\mathrm{A}\end{array}$ & $\begin{array}{l}\text { a de suero } \\
\text { no } \\
\text { H) }\end{array}$ & \\
\hline & & \multicolumn{3}{|c|}{ glutaraldehído } & \\
\hline & & $1.0 \%$ & \multirow{2}{*}{$2.5 \%$} & \multirow{2}{*}{$1.0 \%$} & \\
\hline & & Termocurado a $40^{\circ} \mathrm{C}$ & & & \\
\hline Biosensor & ESP/LTv/PVA & $\begin{array}{cc}\text { ESP/LTv } & \text { ESP/LTv } \\
\text { /GA } & / \mathrm{GA} \\
2.5 \% & 1.0 \% \\
\end{array}$ & $\begin{array}{l}\text { ESP/LTv/ } \\
\text { ASH/GA } \\
2.5 \%\end{array}$ & $\begin{array}{l}\text { ESP/LTv/ } \\
\text { ASH/GA } \\
1.0 \%\end{array}$ & ESP/LTv/EDC \\
\hline
\end{tabular}

Después de comparar los distintos métodos de inmovilización, se encuentra que el mejor método de inmovilización es el reticulado utilizando glutaraldehído al $2.5 \%$ a $40{ }^{\circ} \mathrm{C}$, 


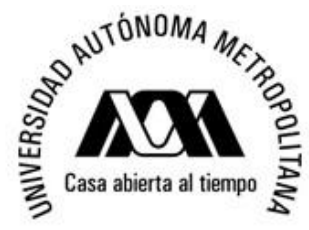
Universidad Autónoma Metropolitana Unidad Iztapalapa
División Ciencias Básicas e Ingeniería
Departamento de Química
Área de Química Analítica
Tesis de Doctorado
Q. Erika Rodríguez Sevilla

obteniendo una $K_{m}{ }^{\prime}$ de $170 \pm 3 \mu \mathrm{M}$, y un límite de detección de HQ de $17 \pm 6 \mu \mathrm{M}$, su tiempo de fabricación es de 1.5 horas y tiene un tiempo de vida > 5 meses almacenado a temperatura ambiente.

Para analizar el efecto de la enzima sobre el método de inmovilización se fabricaron biosensores con las mismas condiciones experimentales mencionadas anteriormente utilizando ahora tirosinasa mushroom (Tm) como elemento de reconocimiento (Tabla II). Cada uno de estos biosensores fue caracterizado mediante Voltamperometría Cíclica, Espectroscopia Ultravioleta Visible, Amperometría, Espectroscopia de Impedancia Electroquímica (EIS) y Microscopía Electrónica de Barrido (SEM).

\begin{tabular}{cccccc}
\multicolumn{2}{c}{ Tabla II. Componentes de cada biosensor fabricado con tirosinasa sobre electrodos de tipo } \\
screen-printed.
\end{tabular}

De la caracterización amperométrica se obtiene la constante de Michaelis-Menten aparente, $K_{m}^{\prime}$, de cada biosensor, mientras que de las mediciones de la impedancia se obtiene la resistencia a la transferencia de carga, $\mathrm{R}_{\mathrm{tc}}$, de los biosensores caracterizados. Se encontró que el biosensor ESP/Tm/GA $2.5 \%$ tiene la $K_{m}^{\prime}=(57 \pm 7) \mu \mathrm{M}$ y los valores de $\mathrm{R}_{\mathrm{tc}}$, más bajos, 

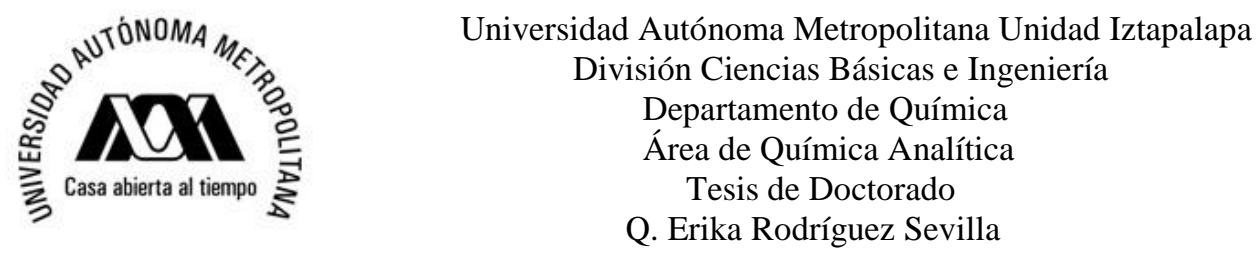

así como los límites de detección y cuantificación más bajo para la cuantificación de catecol; no obstante, la sensibilidad más alta corresponde al biosensor ESP/Tm/PVA.

Con el fin de mejorar la transferencia electrónica, se diseñaron biosensores de tipo screenprinted con electrodos de trabajo de $0.7 \mathrm{~cm}^{2}$ de área, sin embargo la membrana polimérica al inmovilizar mediante atrapamiento y reticulado solo cubre el 30\%, 70\% y 100\% del área del electrodo de trabajo. Utilizado LTv como elemento de reconocimiento se encuentra que los biosensores que tienen el $70 \%$ del área cubierta por la membrana polimérica, mejoran los parámetros cinéticos $\left(K_{m}^{\prime}\right.$ y $\left.I_{\max }\right)$ y los parámetros analíticos del biosensor (límite de detección, límite de cuantificación, sensibilidad, intervalo lineal, etc.)

Usando los biosensores ESP/LTv/GA 2.5\% y ESP/Tm/GA 2.5\%, se determina la capacidad antioxidante equivalente a Trolox (TEAC) para las infusiones preparadas con Mirto (Salvia microphylla), Hierba San Cayetano (Solanum rudepannum), Muicle (Justicia spicigera), Hierba dulce (Lippia dulcis) y Salve Real (Lippia alba); plantas medicinales de uso común en México. En este trabajo se obtiene que Mirto es una planta rica en compuestos fenólicos para-sustituidos pues se obtiene un mayor TEAC al utilizar el biosensor de LTv, mientras que el resto de las infusiones estudiadas muestran una composición de compuestos orto- y meta-sustituidos mayor al obtener un TEAC mayor con el biosensor de Tm. 


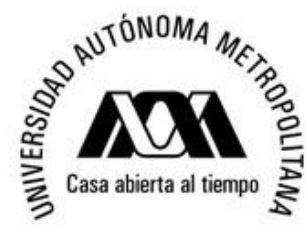

Abstract
Universidad Autónoma Metropolitana Unidad Iztapalapa

División Ciencias Básicas e Ingeniería

Departamento de Química

Área de Química Analítica

Tesis de Doctorado

Q. Erika Rodríguez Sevilla

A biosensor's detection principle is based on the specific interaction between the compound of interest and the recognition agent. As result of such bond, one or more physicochemical properties varies ( $\mathrm{pH}$, transport of electrons, heat, potential difference, mass, optical properties variation, etc.) that is detected through the transductor. This system transforms the recognition agent's response into an electronic signal thus indicating the analytes' concentration in the sample. With the passage of time, the sensors required have become inexpensive, practical and easy to use; presently, the most common biosensor is the glucose biosensor, used by diabetics. Among the latest developments, the devices that are now constructed use the technology called "thick film". These biosensors are formed with ink or paste layers sequentially deposited on a support or substrate. A key factor that distinguishes this technology is the screen-printing method responsible of depositing the film.

The present research project describes the fabrication and characterization of biosensors made with screen-printed type-electrodes (SPE) using Trametes versicolor Laccase (TvL) and mushroom Tyrosinase ( $m$ Tyr), immobilized through entrapment, cross-linking and co-crosslinking covalent bond methods, and its implementation for the determination of the antioxidant capacity of medicinal plants in the state of Guerrero, Mexico.

The Laccase immobilization from Trametes versicolor $(\mathrm{TvL})$ by means of entrapment, cross-linking and covalent bonding methods is analyzed through the development and characterization of amperometric screen-printed sensors for phenolic compounds. In order to perform the immobilization with each of the methods stated, polyvinyl alcohol (PVA), glutaraldehyde (GA) and N-ethyl-N'-(3dimethylaminopropyl) carbodiimide clorhydrate (EDC), were used respectively; the electrochemical characterization was carried out at $(30.0 \pm 0.5){ }^{\circ} \mathrm{C}$ and $\mathrm{pH}=4.70 \pm 0.01$. The apparent MichaelisMenten constant, $K_{m}{ }^{\prime}$, for the enzymatic oxidation of hydroquinone, HQ, to p-quinone, p-Q, was used 


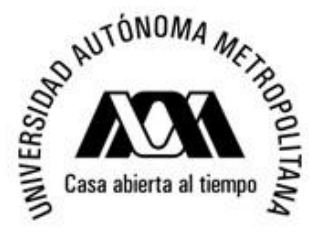
Universidad Autónoma Metropolitana Unidad Iztapalapa
División Ciencias Básicas e Ingeniería
Departamento de Química
Área de Química Analítica
Tesis de Doctorado
Q. Erika Rodríguez Sevilla

as comparison parameter, to provide information on the enzymatic kinetic parameters, as well as the analytic parameter linked directly to the biosensor. After comparing the different immobilization methods, it became apparent that the best one was cross-linking at $40{ }^{\circ} \mathrm{C}$, that gave the lowest $K_{m}{ }^{\prime}$ $((170.1 \pm 3.2) \mu \mathrm{M})$, and HQ limit of detection $((17.0 \pm 6.6) \mu \mathrm{M})$ values. The antioxidant capacity of real samples from infusions of medicinal plants, was evaluated using this biosensor.

The working area of a screen-printed electrode, SPE, was modified with the Tyrosinase enzyme (Tyr) using different immobilization methods, namely: entrapment, with water soluble polyvinyl alcohol, PVA, cross-linking using glutaraldehyde, GA, and cross-linking using GA and Human Serum Albumin, HSA; the resulting electrodes were termed SPE/Tyr/PVA, SPE/Tyr/GA and SPE/Tyr/HSA/GA, respectively. These biosensors were characterized by means of amperometry and EIS techniques. From amperometric evaluations, the apparent Michaelis-Menten constant, $K_{m}^{\prime}$, of each biosensor was evaluated while the respective charge transfer resistance, $R_{c t}$, was assessed from impedance measurements. It was found that the SPE/Tyr/GA had the smallest $K_{m}{ }^{\prime}(57 \pm 7) \mu \mathrm{M}$ and $R_{c t}$ values. This electrode also displayed both the lowest detection and quantification limits for catechol quantification. Using the SPE/Tyr/GA, the Trolox Equivalent Antioxidant Capacity (TEAC) was determined from infusions prepared with "Mirto" (Salvia microphylla), "Hierba dulce" (Lippia dulcis) and "Salve Real" (Lippia alba); medicinal plants commonly used in Mexico.

The determination of the antioxidant capacity give qualitative information about the chemical composition of the samples analyzed, obtaining that Mirto is a plant rich in phenolic compounds parasubstituted, while the rest of the infusions studied show a high composition of ortho and meta substituted compounds. 


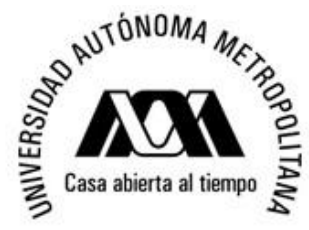

Universidad Autónoma Metropolitana Unidad Iztapalapa

División Ciencias Básicas e Ingeniería

Departamento de Química

Área de Química Analítica

Tesis de Doctorado

Q. Erika Rodríguez Sevilla

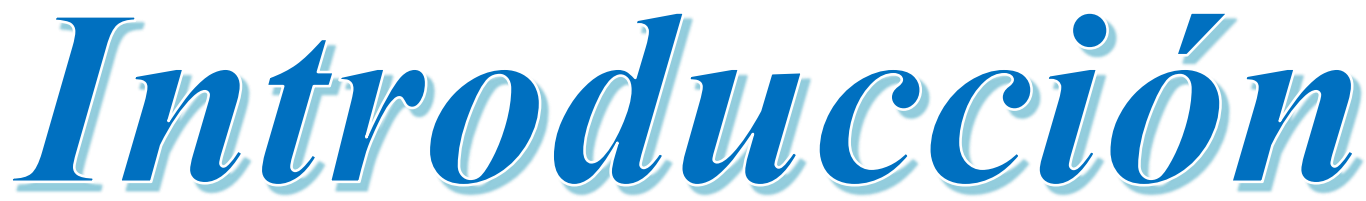




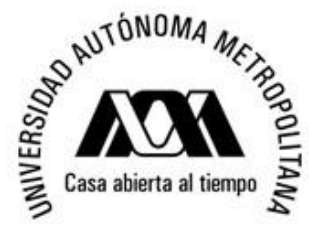
Universidad Autónoma Metropolitana Unidad Iztapalapa
División Ciencias Básicas e Ingeniería
Departamento de Química
Área de Química Analítica
Tesis de Doctorado
Q. Erika Rodríguez Sevilla

Un biosensor es un dispositivo formado por un elemento de reconocimiento biológico inmovilizado a un soporte y un transductor. Para fabricar un biosensor robusto es necesario utilizar un buen método de inmovilización, mantener una velocidad de reacción enzimática adecuada y no afectar la transferencia de carga entre la enzima y el sustrato además deben ser dispositivos de bajo costo y fácil fabricación que puedan ser aplicables en algún campo de la ciencia.

A lo largo de esta investigación se presentan los resultados obtenidos para biosensores elaborados con laccasa de Trametes versicolor o tirosinasa mushroom inmovilizada mediante los métodos de atrapamiento, reticulado, co-reticulado y enlace covalente en sensores de tipo screen-printed, cada uno de ellos es caracterizado mediante Espectroscopia de UV-Vis, voltamperometría cíclica y amperometría cuantificando la oxidación de Hidroquinona y Catecol respectivamente.

Para evaluar el efecto del método de inmovilización en la transferencia de carga de la reacción enzimática se utiliza Espectroscopia de Impedancia Electroquímica, estos resultados son comparados con el efecto de la inmovilización en la constante aparente de MichaelisMenten en donde se obtiene que el mejor método de inmovilización para el desarrollo de biosensores es el reticulado sin albumina a $40^{\circ} \mathrm{C}$ ya que mantiene un equilibrio entre la constante cinética $\left(K_{m}\right)$ y la constante de velocidad heterogénea $\left(k^{0}\right)$. 


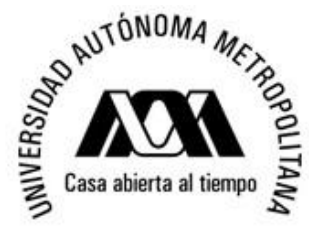
Universidad Autónoma Metropolitana Unidad Iztapalapa
División Ciencias Básicas e Ingeniería
Departamento de Química
Área de Química Analítica
Tesis de Doctorado
Q. Erika Rodríguez Sevilla

Mediante la Microscopía Electrónica de barrido se analiza la conformación de la membrana polimérica del biosensor y se observa que la superficie del biosensor pierde rugosidad lo que complica la transferencia de electrones en la reacción redox de hidroquinona, por lo tanto se propone un nuevo diseño en la fabricación de biosensores cubriendo solo un porcentaje del área del electrodo, los mejores resultados se obtienen al cubrir el 70\% del área del electrodo de trabajo en el biosensor y dejar el resto descubierto; esto mejora la transferencia electrónica en el sistema, la sensibilidad, el límite de detección y cuantificación, la intensidad en la respuesta electroquímica se incrementa y los parámetros cinéticos del biosensor mejoran.

Una de las aplicaciones de estos biosensores es la determinación de la capacidad antioxidante equivalente a Trolox, en infusiones preparadas con plantas medicinales pertenecientes a la herbolaria mexicana. Estas infusiones son utilizadas por la población para combatir malestares como el dolor de cabeza, malestar estomacal, incluso enfermedades como la hipertensión, alteraciones del sistema nervioso o la migraña. Mediante un estudio amperométrico se determina la capacidad antioxidante de dichas infusiones y se discute la razón por la cual estas infusiones son eficaces al combatir dichas enfermedades.

Es por ello que esta investigación constituye una base para el desarrollo de biosensores que mantienen una cinética enzimática y una cinética electroquímica adecuada y pueden ser aplicables en distintos campos de la ciencia, economizando tiempo, recursos y materiales en el desarrollo de futuras investigaciones. 


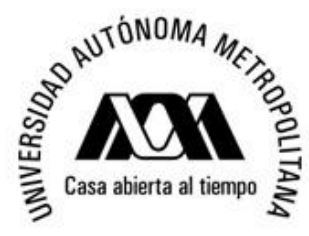

Universidad Autónoma Metropolitana Unidad Iztapalapa

División Ciencias Básicas e Ingeniería

Departamento de Química

Área de Química Analítica

Tesis de Doctorado

Q. Erika Rodríguez Sevilla
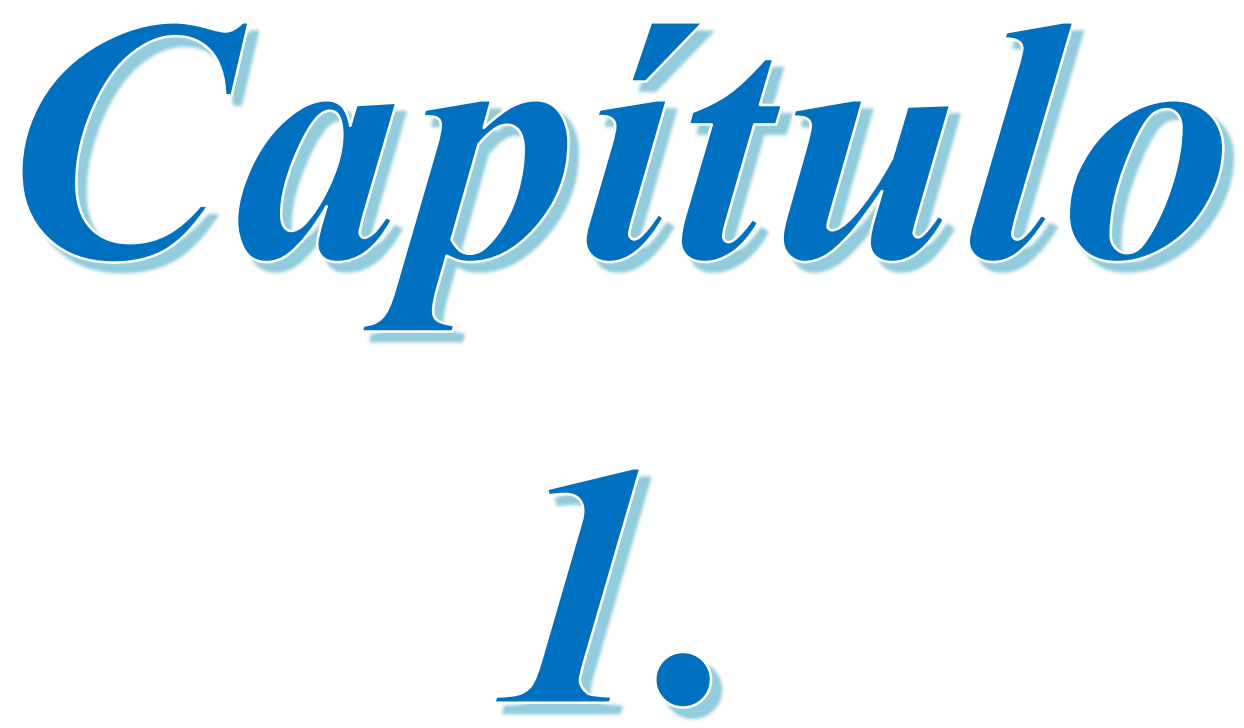

Antecedentes 


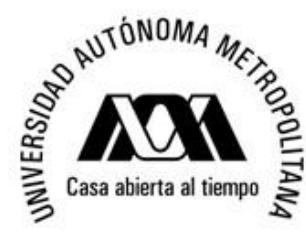

\subsection{Enzimas}

La necesidad del ser humano por conocer cuál es su procedencia se ha convertido en una prioridad, algunos dicen que el ser humano desciende del mono, y defienden la cultura evolucionista planteada por Darwin[1], otros se apegan a lo que la biblia comenta y defienden que un Dios extraordinario fue quien creó todo lo que hoy podemos ver. Pero con el paso del tiempo el ser humano ha intentado comprender un poco la naturaleza y todo lo que en el universo existe teniendo éxito en algunas de sus investigaciones. Una de esas incógnitas implica el funcionamiento del cuerpo humano; ¿cómo es que una serie de reacciones químicas ocurren en el momento y en las condiciones adecuadas, es decir en pequeños intervalos de temperatura, $\mathrm{pH}$, presión, etc? [2].

En el año de 1878 el fisiólogo Wilhelm Kühne (1837 - 1900) acuñó el término enzima, que viene del griego $\varepsilon v \zeta v \mu$ ov "en levadura", para describir la fermentación del azúcar. Louis Pasteur llegó a la conclusión de que esta fermentación era catalizada por células de la levadura, llamadas fermentos, e inicialmente se pensó que solo funcionaba con organismos vivos [3]. En 1897 Eduard Buchner comenzó a estudiar la capacidad de los extractos de levadura para fermentar azúcar en ausencia de células vivientes de levadura, y encontró que el azúcar era fermentado inclusive cuando no había elementos vivos en los cultivos de células de levadura. Llamó a la enzima que causa la fermentación de la sacarosa, "zimasa”. En 1907 recibió el Premio Nobel de Química "por sus investigaciones bioquímicas y por haber descubierto la fermentación libre de células".

La Unión Internacional de Bioquímica y Biología Molecular ha desarrollado una nomenclatura para identificar a las enzimas basada en los denominados Números EC [4]. De este modo, cada enzima queda registrada por una secuencia de cuatro números precedidos por las letras "EC". El primer número clasifica a la enzima en base a su mecanismo de acción mientras que el resto de ellos indican la especie química que participa en la reacción enzimática. 


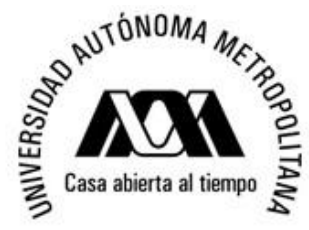

$$
\begin{gathered}
\text { Universidad Autónoma Metropolitana Unidad Iztapalapa } \\
\text { División Ciencias Básicas e Ingeniería } \\
\text { Departamento de Química } \\
\text { Área de Química Analítica } \\
\text { Tesis de Doctorado } \\
\text { Q. Erika Rodríguez Sevilla }
\end{gathered}
$$

A continuación se indican las seis grandes clases de enzimas que se conocen hasta ahora [5]:

- EC1 Oxidorreductasas: catalizan reacciones de óxido-reducción o redox. Precisan la colaboración de las coenzimas de óxido-reducción (NAD+, NADP+, FAD) que aceptan o ceden los electrones correspondientes. Ejemplos: deshidrogenasas, peroxidasas.

- EC2 Transferasas: transfieren grupos activos (obtenidos de la ruptura de ciertas moléculas) a otras sustancias receptoras. Suelen actuar en procesos de interconversión de monosacáridos, aminoácidos, etc. Ejemplos: transaminasas, quinasas.

- EC3 Hidrolasas: catalizan reacciones de hidrólisis con la consiguiente obtención de monómeros a partir de polímeros. Actúan en la digestión de los alimentos, previamente a otras fases de su degradación. Ejemplos: glucosidasas, lipasas, esterasas.

- EC4 Liasas: catalizan reacciones en las que se eliminan grupos $\mathrm{H}_{2} \mathrm{O}, \mathrm{CO}_{2}$ y NH 3 para formar un doble enlace o añadirse a un doble enlace. Ejemplos: descarboxilasas, liasas.

- EC5 Isomerasas: actúan sobre determinadas moléculas obteniendo de ellas sus isómeros funcionales o de posición, es decir, catalizan la racemización y cambios de posición de un grupo en determinada molécula obteniendo formas isoméricas. Suelen actuar en procesos de interconversión. Ejemplo: epimerasas (mutasa).

- EC6 Ligasas: catalizan la degradación o síntesis de los enlaces denominados "fuertes" mediante al acoplamiento a moléculas de alto valor energético como el ATP. Ejemplos: sintetasas, carboxilasas.

La investigación sobre las enzimas ha sido muy intensa desde la última parte del siglo XX. Esto ha conducido a la purificación de millares de enzimas, a la elucidación de la estructura y mecanismo químico de muchas de ellas [6] y a un conocimiento general sobre su método de acción. 
Con excepción de un pequeño grupo de moléculas de RNA catalítico, todas las enzimas son proteínas. Estas proteínas son catalizadores extraordinarios, además de ser muy específicos discriminando muy fácilmente entre dos sustratos con estructuras similares [7]. Su actividad catalítica depende de la integridad de su conformación proteica nativa. Si se desnaturaliza o se disocia una enzima en sus subunidades, puede perderse la actividad catalítica. Si se descompone una enzima en sus aminoácidos constituyentes, siempre se destruye su actividad catalítica. Sin embargo, aunque la estructura determina su función, predecir una nueva actividad enzimática basándose únicamente en la estructura de una proteína es muy difícil, y un problema aún no resuelto.

Existen dos condiciones fundamentales para la vida, la entidad viva debe ser capaz de autorreplicarse y de catalizar reacciones químicas eficiente y selectivamente. Como se sabe, los sistemas vivos utilizan la energía de su entorno. Muchos de nosotros, por ejemplo, consumimos cantidades sustanciales de sacarosa (azúcar de mesa común) como un tipo de combustible, ya sea en forma de alimentos y bebidas dulces o como azúcar propiamente dicho. La conversión de sacarosa en $\mathrm{CO}_{2}$ y $\mathrm{H}_{2} \mathrm{O}$ en presencia de oxígeno es un proceso altamente exergónico, que genera energía libre la cual podemos utilizar para pensar, movernos, saborear y ver. Sin embargo, se puede almacenar una bolsa de azúcar durante años sin que sufra ninguna transformación obvia a $\mathrm{CO}_{2}$ y $\mathrm{H}_{2} \mathrm{O}$. Siendo este proceso químico termodinámicamente favorable, es sin embargo ¡muy lento! Aun así, cuando el ser humano consume sacarosa, la energía química se libera en segundos [8].

La diferencia está en la catálisis, sin catálisis las reacciones químicas que son necesarias para mantener la vida, como la oxidación de la sacarosa, no podrían darse en una escala de tiempo conveniente. Los mejores catalizadores para los sistemas biológicos son las enzimas, ya que poseen un elevado grado de especificidad respecto a sus sustratos, aceleran espectacularmente las reacciones químicas específicas y funcionan en soluciones acuosas en condiciones muy suaves de temperatura y pH. Es por ello que las enzimas están en el centro 


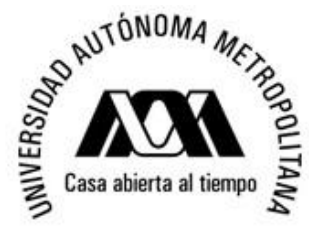

$$
\begin{gathered}
\text { Universidad Autónoma Metropolitana Unidad Iztapalapa } \\
\text { División Ciencias Básicas e Ingeniería } \\
\text { Departamento de Química } \\
\text { Área de Química Analítica } \\
\text { Tesis de Doctorado } \\
\text { Q. Erika Rodríguez Sevilla }
\end{gathered}
$$

de todos los procesos bioquímicos, y su estudio también tiene una importancia práctica inmensa [9].

\subsection{Métodos de inmovilización}

La inmovilización de enzimas mediante la unión a un soporte, es un campo de alto interés para los científicos. Los beneficios de llevar a cabo una reacción química con una enzima inmovilizada son variados, es decir hay beneficios tanto en el costo de la investigación como en la actividad enzimática, la estabilidad o bien en el tiempo [10]. Las enzimas inmovilizadas son a menudo más estables que las enzimas purificadas en solución acuosa, diluida y también pueden ser más resistentes al calor, a intervalos más amplios de $\mathrm{pH}$ y al almacenamiento. Es por ello que la inmovilización de enzimas es un tema actual con aplicaciones en varios campos de la ciencia; es importante hacer una buena elección de un método de inmovilización de enzimas para no afectar las propiedades de las mismas.

Al momento de inmovilizar se confina o localiza a la enzima en una región definida del espacio, para dar lugar a formas insolubles que retienen su actividad catalítica y que pueden ser reutilizadas repetidamente [11] y con el paso del tiempo se ha ampliado a aquel proceso por el cual se restringen, completa o parcialmente, los grados de libertad de movimiento de enzimas, organelos, células, etcétera por su unión a un soporte [12]. La Figura 1.1 muestra un esquema de los métodos de inmovilización y su clasificación de acuerdo a sus propiedades químicas y/o físicas.

Los métodos más utilizados son la adsorción física, el atrapamiento, el reticulado (crosslinking) y la formación de enlaces covalentes. En Anexo 1 se describe cada uno de los métodos de inmovilización así como sus ventajas y desventajas. 


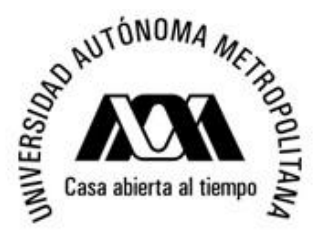

Universidad Autónoma Metropolitana Unidad Iztapalapa

División Ciencias Básicas e Ingeniería

Departamento de Química

Área de Química Analítica

Tesis de Doctorado

Q. Erika Rodríguez Sevilla

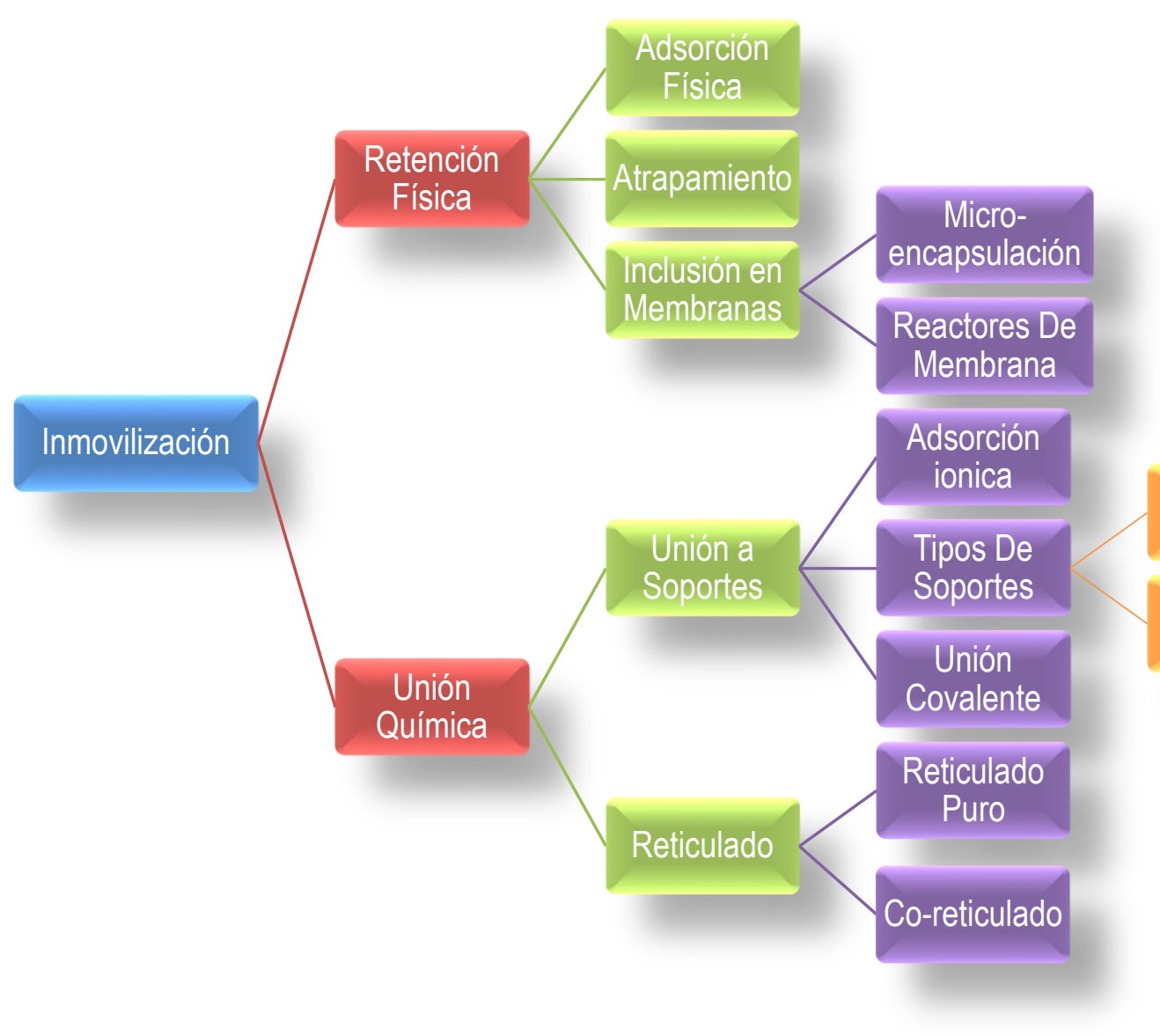

Orgánicos

Inorgánicos

Figura 1.1 Mapa conceptual sobre algunos métodos de inmovilización de enzimas, conocidos actualmente.

\subsection{Cinética enzimática}

Un estudio de la velocidad (v), o cinética, de una reacción catalizada por una enzima es útil para determinar los pasos que suceden en la reacción total, es decir puede determinarse el mecanismo de reacción. Muchas enzimas comparten algunas propiedades cinéticas. Cuando se añade sustrato a una enzima, la reacción enseguida llega a un estado estacionario en el que la velocidad a la que se forma el complejo ES (enzima-sustrato) se equilibra con la velocidad a la que reacciona. 


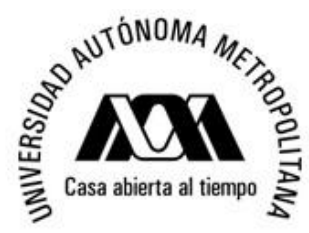
Universidad Autónoma Metropolitana Unidad Iztapalapa
División Ciencias Básicas e Ingeniería
Departamento de Química
Área de Química Analítica
Tesis de Doctorado
Q. Erika Rodríguez Sevilla

La cinética enzimática muestra que las velocidades de reacción de las enzimas dependen de las condiciones de la solución y de la concentración de sustrato [13]. Aquellas condiciones que desnaturalizan una proteína, como temperaturas elevadas, valores extremos de $\mathrm{pH}$ o altas concentraciones de sal, dificultan o impiden la actividad enzimática, mientras que elevadas concentraciones de sustrato tienden a incrementar la actividad [14].

Se sabe que $v$ aumenta a medida que aumenta la concentración de sustrato, hasta que la enzima $(E)$ se satura. En la Figura 1.2 se observa que la saturación ocurre porque, cuando la concentración de sustrato aumenta, disminuye la concentración de enzima libre, que se convierte en la forma $E S$ y propicia la formación del producto $(P)$.

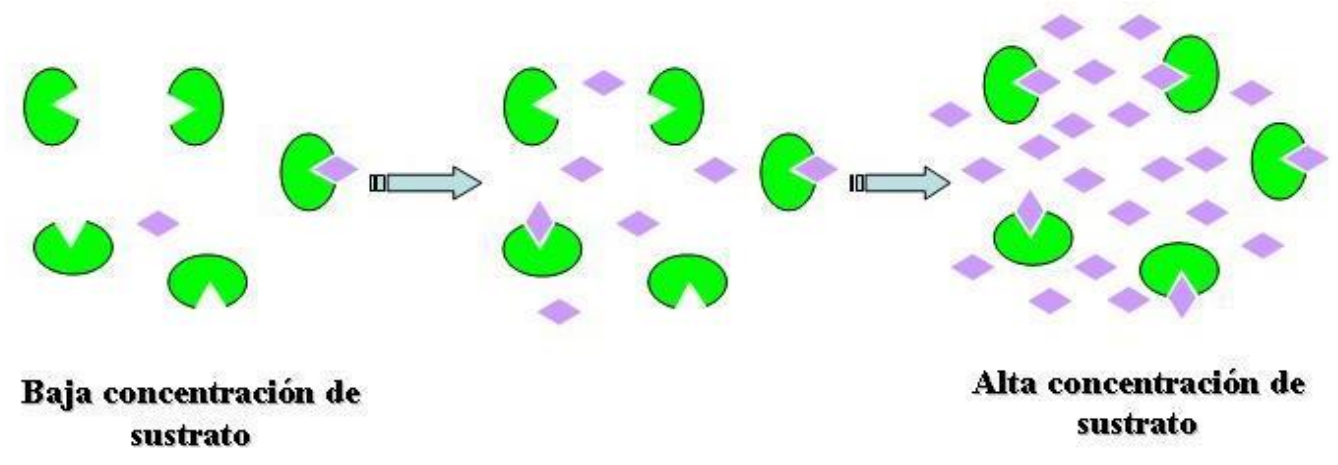

Figura 1.2 Esquema de saturación de la enzima debido al aumento en la concentración de sustrato.

Cuando se alcanza la velocidad máxima $\left(v_{\max x}\right)$ de la reacción enzimática, todos los sitios activos de la enzima tienen sustrato unido, y la cantidad de complejos ES, es igual a la cantidad total de enzima, esta es una de los parámetros considerado en la definición de la ecuación de Michaelis-Menten (ecuación 1.1) donde se considera que la velocidad de reacción está dada en términos de la concentración de sustrato ([S]), la velocidad máxima y la constante de Michaelis-Menten es decir la concentración media de saturación.

$$
v_{0}=\frac{v_{\text {máx }}[S]}{K_{m}+[S]}
$$


En la Figura 1.3 es posible observar de manera gráfica como al aumentar la concentración de sustrato y llegar a la saturación de la solución, la velocidad alcanza un valor máximo.

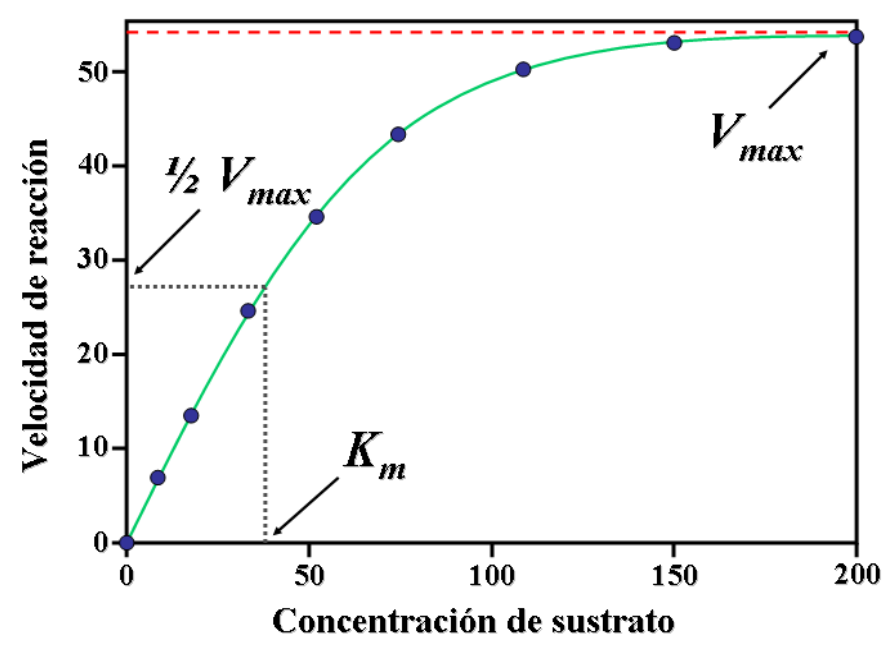

Figura 1.3 Representación gráfica de la velocidad de una reacción enzimática donde se puede observar los parámetros básicos de la ecuación de Michaelis-Menten.

\subsubsection{Factores que afectan la velocidad de la reacción enzimática.}

La velocidad de una reacción es sensible a numerosas condiciones experimentales por ejemplo: temperatura, $\mathrm{pH}$, fuerza iónica, concentración aniónica y catiónica, etcétera. Una falta de control de estos parámetros puede generar resultados erróneos en las mediciones, por el contrario si estas condiciones experimentales son controladas de manera adecuada se obtiene información valiosa del mecanismo de reacción y de la cinética enzimática. Algunos de los factores que afectan la reacción enzimática son:

\subsubsection{Concentración del sustrato.}

Conforme cambia la concentración de sustrato, se produce un aumento rápido de la velocidad de reacción, pero si la concentración de sustrato crece, la velocidad de reacción se estabiliza 


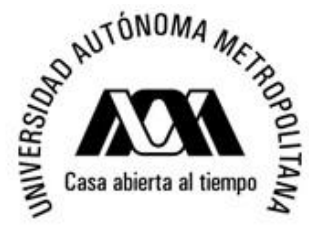
Universidad Autónoma Metropolitana Unidad Iztapalapa
División Ciencias Básicas e Ingeniería
Departamento de Química
Área de Química Analítica
Tesis de Doctorado
Q. Erika Rodríguez Sevilla

hasta alcanzar la velocidad máxima y a concentraciones de sustrato relativamente altas, se observa que no cambia la velocidad de reacción, es en esta etapa que los centros activos de la enzima se encuentran saturados (Figura 1.3). La $K_{m}{ }^{\prime}$ es la concentración a la cual se obtiene un medio de la vmáx.

\subsubsection{Concentración de la enzima.}

Si se trabaja con la condición de que la concentración del sustrato sature a la enzima, variando entonces la concentración de enzima a pH y temperatura constantes, se observa que aumenta la cantidad de sustrato transformado y por lo tanto aumenta la velocidad de reacción (Figura $1.4)$,

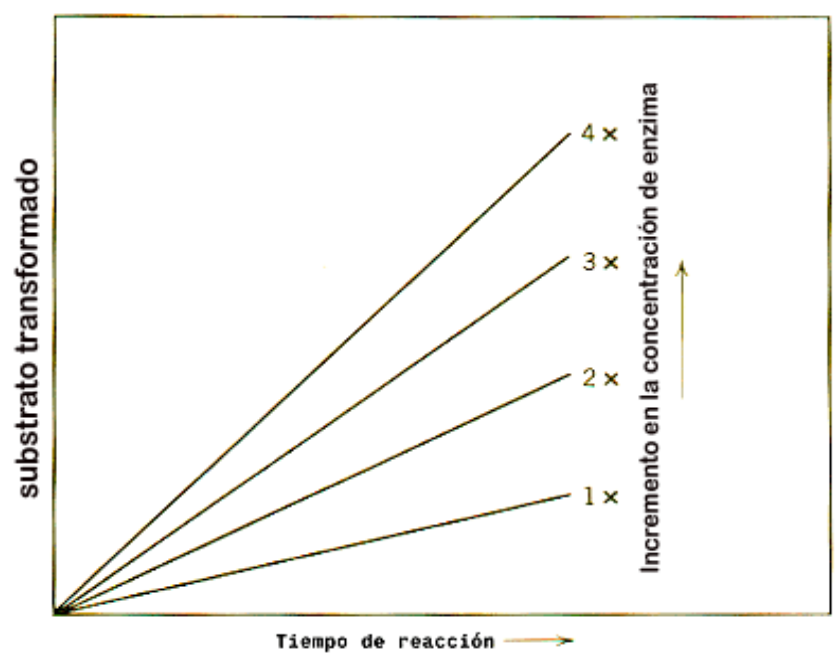

Figura 1.4 Representación gráfica del efecto de la concentración de enzima sobre la velocidad de reacción [].

\subsubsection{Efecto de la temperatura.}

Cuando la temperatura sube, la velocidad de reacción aumenta; la formación del complejo enzima-sustrato se lleva a cabo de forma más rápida ya que la barrera del complejo de activación es menor. Existe una temperatura máxima a la cual la proteína se desnaturaliza 


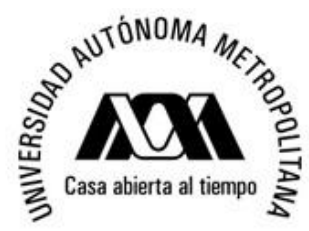
Universidad Autónoma Metropolitana Unidad Iztapalapa
División Ciencias Básicas e Ingeniería
Departamento de Química
Área de Química Analítica
Tesis de Doctorado
Q. Erika Rodríguez Sevilla

dejando de ser funcional. La mayor parte de las enzimas se desnaturalizan a temperaturas mayores de $50{ }^{\circ} \mathrm{C}[15]$.

\subsubsection{Efecto del pH}

El efecto del pH [16] en la cinética enzimática se ve reflejado en:

$\checkmark$ La desnaturalización de la enzima,

$\checkmark$ La ionización de las especies del sistema, por ejemplo la forma iónica del sustrato

$\checkmark$ La formación de complejo $E S$ y por lo tanto en $K_{m}$

$\checkmark$ La velocidad de descomposición del complejo ES hacia los productos $\left(k_{2}\right)$.

\subsection{Constante de Michaelis-Menten en solución}

En espectroscopia para determinar los parámetros cinéticos de la enzima es necesario analizar el efecto de la concentración de sustrato $[S]$ en la velocidad de la reacción catalizada; esto se hace siguiendo la banda de absorción del producto $(\mathrm{P})$ a una longitud de onda donde el resto de los componentes no interfiera con la banda a seguir, es decir donde la absorbancia del resto de los componentes sea prácticamente nula a esa longitud de onda o permanezca constante durante la medición. La preparación de las muestras se hace variando la concentración de sustrato $[S]$ y manteniendo constante la concentración de la enzima ([E]) y el volumen total de la celda $\left(V_{T}\right)$. Lo siguiente es calcular la velocidad $(v)$ en cada muestra, para ello es necesario conocer el coeficiente de extinción molar de la especie de interés.

Mediante la ley de Lambert-Beer,

$$
A=\varepsilon l c
$$

Donde $A$ es la absorbancia, $\varepsilon$ es el coeficiente de absorción molar, $l$ es la longitud de paso óptico (igual a $1 \mathrm{~cm}$ ) y $c$ es la concentración; puede obtenerse el valor de $v$ que será 


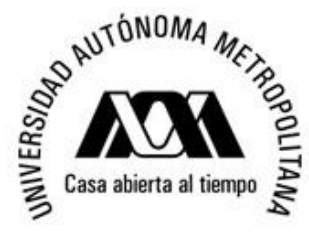

Universidad Autónoma Metropolitana Unidad Iztapalapa
División Ciencias Básicas e Ingeniería
Departamento de Química
Área de Química Analítica
Tesis de Doctorado
Q. Erika Rodríguez Sevilla

$$
v=\Delta c=\frac{\Delta A}{\varepsilon l} ;\left[\frac{\frac{1}{\min }}{\frac{1}{M c m} c m}\right]=\left[\frac{M}{\min }\right]
$$

Los parámetros cinéticos característicos de la enzima pueden determinarse mediante el uso de algún modelo matemático para analizar la cinética enzimática (ver anexo 2) puede ser gráfico o algebráico.

\subsection{Constante de Michaelis-Menten aparente}

Al utilizar algún método de inmovilización de enzimas, la cinética de ésta suele ser distinta, ya que los sitios activos de la enzima son bloqueados o expuestos al sustrato. La constante de Michaelis-Menten, recibe el término de constante de Michaelis-Menten aparente $\left(K_{m}\right)$ cuando la enzima ha sufrido algún cambio [17]. En esta investigación, ese nombre se le otorga debido a que la enzima no se encuentra en solución, y la metodología para su obtención no es la establecida por el modelo de Michaelis-Menten original, a pesar de que las ecuaciones que se utilizan para definir la $K_{m}$ se conservan [18].

De acuerdo con Thévenot [19] $K_{m}{ }^{\prime}$ representa la concentración de analito que produce una respuesta igual a la mitad de su valor máximo para una concentración de analito infinita; por lo tanto cuando la enzima es inmovilizada en un dispositivo de respuesta electroquímica, la constante de Michaelis-Menten aparente $\left(K_{m}\right)$ se determina haciendo una regresión no lineal a los datos experimentales (I vs $[S]$ ) dependiendo del electrodo utilizado por ejemplo: electrodos porosos [20], electrodos de pasta de carbono [21], electrodo de membrana enzimática [22], entre otros [23]. 


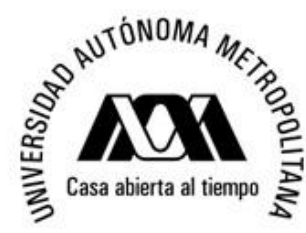

\subsection{Biosensores}

A través de la historia los químicos han encontrado maneras y métodos generales sistemáticos, razonados y reproducibles para analizar los fenómenos químicos, para sintetizar nuevas moléculas, o bien para diseñar procesos químicos. En este sentido, la tecnología de biosensores ha experimentado un notable avance en los últimos años, y ahora constituyen un campo extenso de estudio de los dispositivos de análisis para la detección de analitos y otros parámetros de diversidad biológica de interés.

Para diseñar un biosensor suele combinarse un componente biológico (ácido nucléico, enzima, anticuerpo, tejido, célula) o biomimético (polímeros de impresión molecular o PIMs, aptámeros) con un transductor físico-químico [24] que permite procesar la señal producida por la interacción entre el elemento de reconocimiento y el analito (Figura 1.5). Las características más destacables de estos dispositivos son su especificidad, su alta sensibilidad, su corto tiempo de análisis, su capacidad de inclusión en sistemas integrados, su facilidad de automatización, la determinación "in situ” del analito, su versatilidad y su bajo costo, entre otras [25], razón por la cual los biosensores se están convirtiendo en una herramienta imprescindible en muchas áreas de la ciencia y la industria.

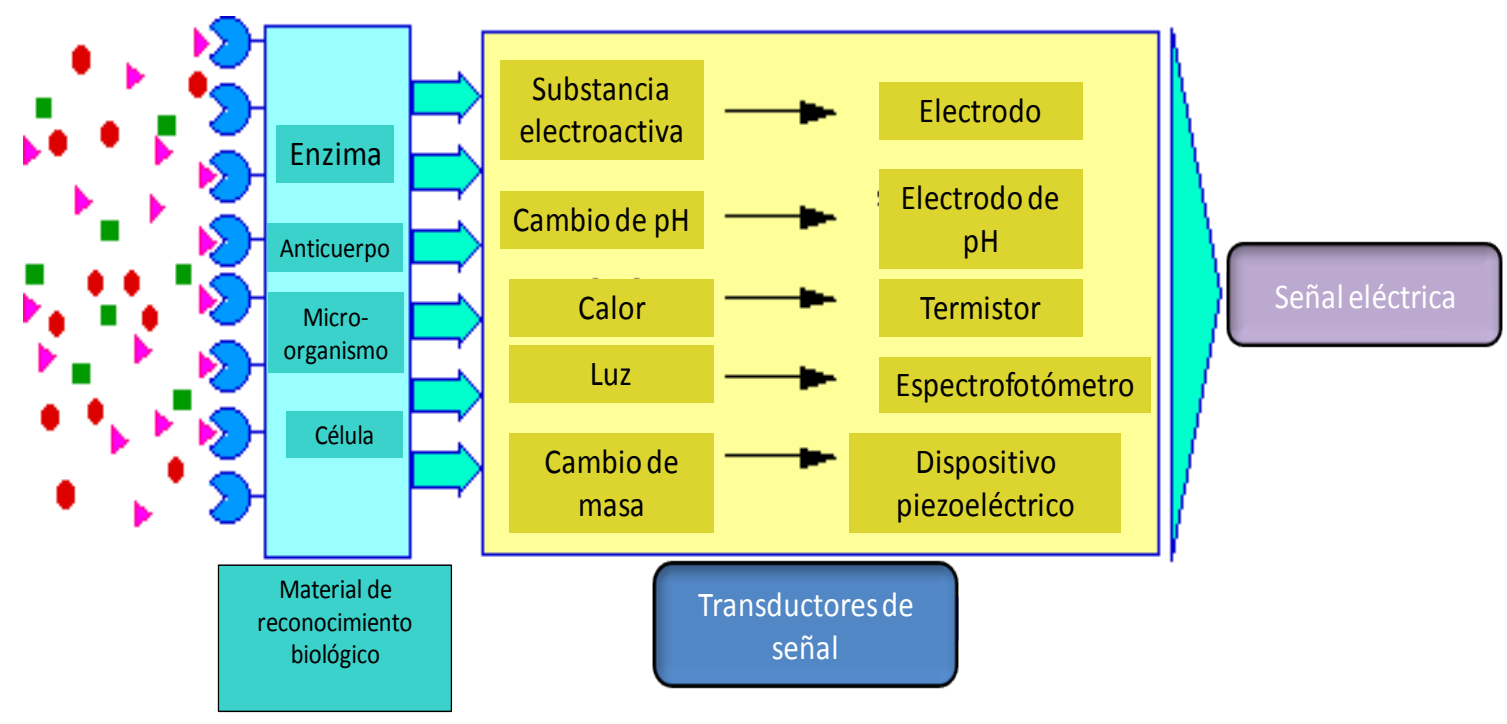

Figura 1. 5 Esquema del diseño y principio de detección de un biosensor. 
El principio de detección de un biosensor se basa en la interacción específica entre el compuesto de interés y el elemento de reconocimiento. Como resultado de esta unión se produce la variación de una o más propiedades fisicoquímicas $(\mathrm{pH}$, transferencia de electrones, de calor, diferencia de potencial, de masa, variación de las propiedades ópticas, etc.) que detecta el transductor. Este sistema transforma la respuesta del elemento de reconocimiento en una señal electrónica indicativa de la presencia del analito (Figura 1.5) o proporcional a su concentración en la muestra [26].

En general un biosensor es un dispositivo que recibe y responde a una señal o estímulo, por ejemplo; un biosensor electroquímico es un dispositivo químico que responde a cambios específicos en el potencial o en la corriente eléctrica como consecuencia de la presencia de una especie química que interactúa con él [27], de esta forma proporcionará información analítica cuantitativa o semicuantitativa especifica [28]. Los biosensores de transducción amperométrica [29] presentan una respuesta en la corriente (I) con respecto a la concentración (C) de forma lineal (I vs C). Mientras que los biosensores de transducción potenciométrica presenta un comportamiento con respecto a la concentración que se conoce como comportamiento de Nikolsky ( $\Delta \mathrm{E}$ vs $\log \mathrm{C}$ ) [30].

La posibilidad de poder incorporar en el electrodo otros componentes (biomoléculas), confiere a este tipo de biosensores una gran diversidad de uso. La mayor parte de los biosensores amperométricos utilizan enzimas del grupo óxido-reductasas, pues los productos consumidos o producidos durante el proceso de óxido-reducción, suelen ser fácilmente leídos por el transductor amperométrico [31].

Con el paso del tiempo se han requerido biosensores, que sean de bajo costo, prácticos y fáciles de utilizar, el biosensor más común es el "medidor" de glucosa, el cual es utilizado por las personas con diabetes. 


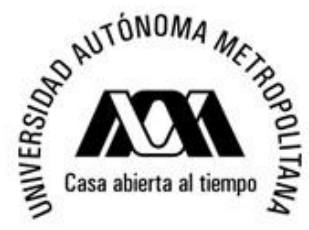
Universidad Autónoma Metropolitana Unidad Iztapalapa
División Ciencias Básicas e Ingeniería
Departamento de Química
Área de Química Analítica
Tesis de Doctorado
Q. Erika Rodríguez Sevilla

Actualmente se utilizan biosensores minuaturizados, que pueden estar hechos de pasta de carbono, nanotubos de carbono [32], o bien se pueden hacer mediante tecnología electrónica o por serigrafía [33, 34]. Esta última técnica permite, utilizar la mínima cantidad de reactivos, y hacer el análisis en el lugar de interés.

Por lo general se busca diseñar biosensores robustos es decir biosensores que tengan las siguientes características:

Alta selectividad. El elemento de reconocimiento debe interaccionar exclusivamente con el analito y no con otros componentes de propiedades similares.

Bajo costo. En general estos sistemas pueden fabricarse a escala industrial lo cual reduce considerablemente su costo. Sin embargo, existen fases críticas en su construcción que dificultan el proceso (por ejemplo procesos de inmovilización).

Especificidad. Permite el análisis de compuestos en concentraciones de partes por billón $(\mu \mathrm{g} / \mathrm{L})$

Manejo sencillo. Esta tecnología no requiere personal calificado. Sus diseños portátiles permiten su aplicación "in situ". Prescindir del control manual facilita su integración dentro de los sistemas automatizados.

Multi-análisis. Ciertos biosensores llevan a cabo la determinación de diferentes analitos de forma simultánea. La combinación de varios de ellos podría darles ventaja frente a las técnicas de análisis convencionales (cromatografía, espectrometría, etc.)

Tamaño. Los desarrollos en microelectrónica y nanotecnología han permitido reducir las dimensiones de estos dispositivos. Así pueden ensamblarse varios de ellos en un mismo sistema que realiza varias tareas a la vez y son aplicables a ensayos donde el tamaño físico del dispositivo o el volumen de la muestra son factores limitantes.

Tiempo de respuesta. Muchos biosensores emplean algunos minutos en cuantificar el compuesto de interés. 


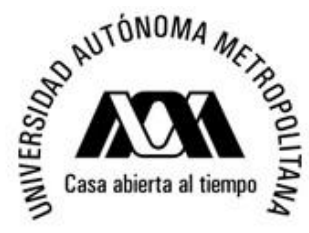

Universidad Autónoma Metropolitana Unidad Iztapalapa

División Ciencias Básicas e Ingeniería

Departamento de Química

Área de Química Analítica

Tesis de Doctorado

Q. Erika Rodríguez Sevilla

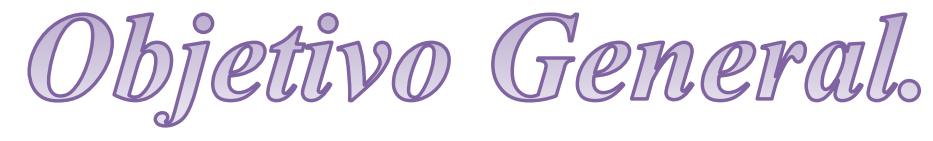

Estudiar el desempeño cinético y analítico de biosensores fabricados sobre electrodos de tipo screen-printed, utilizando dos enzimas del grupo de las oxidasas: laccasa de Trametes versicolor y tirosinasa mushroom, inmovilizadas mediante cuatro métodos de inmovilización (atrapamiento, reticulado, co-reticulado y enlace covalente) en seis condiciones experimentales distintas. Y analizar cada biosensor mediante técnicas espectrofotométricas (Espectrofotometría Ultravioleta Visible), electroquímicas (Voltamperometría Cíclica, Amperometría, Espectroscopia de Impedancia Electroquímica) y ópticas tales como la Microscopía Electrónica de Barrido. 


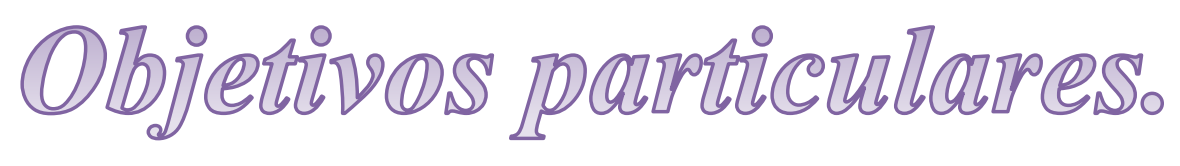

1. Caracterizar electroquímica y espectrofotométricamente los sustratos afines a las enzimas a utilizar.

2. Caracterizar mediante técnicas electroquímicas el electrodo screen-printed.

3. Construir un biosensor con laccasa de Trametes versicolor inmovilizada mediante atrapamiento, reticulado, co-reticulado y enlace covalente.

4. Evaluar el efecto de la inmovilización sobre la constante de Michaelis-Menten aparente.

5. Determinar los parámetros analíticos de cada biosensor y elegir el mejor método de inmovilización

6. Construir un biosensor con tirosinasa mushroom inmovilizada mediante atrapamiento, reticulado, co-reticulado y enlace covalente.

7. Evaluar el efecto de la inmovilización sobre la constante de Michaelis-Menten aparente.

8. Determinar los parámetros analíticos de cada biosensor y elegir el mejor método de inmovilización

9. Evaluar el efecto de la enzima en el diseño del biosensor para un método de inmovilización específico.

10. Evaluar el efecto en la constante de velocidad heterogénea en el desempeño analítico del biosensor.

11. Evaluar la capacidad antioxidante de plantas medicinales utilizando el mejor biosensor. 
A menor valor de la constante de Michaelis-Menten y mayor valor de la constante de velocidad heterogénea se obtiene como resultado un mejor desempeño del biosensor y por lo tanto mejor respuesta analítica. 


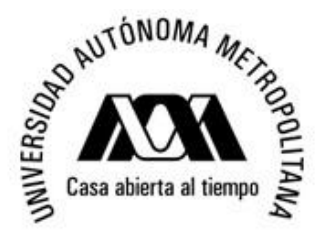

Universidad Autónoma Metropolitana Unidad Iztapalapa División Ciencias Básicas e Ingeniería

Departamento de Química Área de Química Analítica

Tesis de Doctorado

Q. Erika Rodríguez Sevilla

\section{Materi̊les}

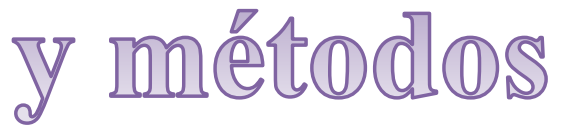

\section{Reactivos}

Laccasa de Trametes versicolor $\geq 10 \mathrm{U} \mathrm{mg}^{-1}$ obtenida de Sigma, Tirosinasa mushroom $34 \mathrm{U}$ $\mathrm{mg}^{-1}$, obtenida de FLUKA, el polímero PVA-AWP fue adquirido de Toyo Gosei Co., Japón, glutaraldehído al 25\% obtenido de Aldrich; Albumina de Suero Humano (ASH) obtenidad de Sigma, fosfato de potasio dibásico $\left(\mathrm{K}_{2} \mathrm{HPO}_{4}\right)$ (3252) con una pureza del $99.6 \%$, y fosfato de potasio monobásico $\left(\mathrm{KH}_{2} \mathrm{PO}_{4}\right)$ (3246) con una pureza del 99.36\%, cloruro de sodio $(\mathrm{NaCl})$ obtenidos de Baker Analyzed; 2-(N-morfolino)-acido etano sulfónico (MES), clorhidrato de N-etil-N'-(3dimetilaminopropil) carbodimida (EDC), hidroxi-2,5-dioxopirrolidina-3- sal sulfónica ácida de sodio (Sulfo-NHS), obtenidos de Aldrich, Hidroquinona (Hq) obtenida de Merk, con una pureza de 99\%, Pirocatecol obtenido de Fluka, con una pureza de 99\%, tanto el cloruro de potasio $(\mathrm{KCl})$, ácido acético glacial $\left(\mathrm{CH}_{3} \mathrm{COOH}\right)$, acetato de sodio $\left(\mathrm{NaCH}_{3} \mathrm{COO}\right)$ con una pureza del 99\%, 2,2-difenil-1-picrilhidrazil (•Dpph), ácido 6-hidroxi2,5,7,8-tetrametilcroman-2-carboxílico (Trolox), como el Etanol (grado HPLC) fueron obtenidos de Aldrich. Todas la soluciones se prepararon con agua desionizada de tipo I.

\section{Equipos}

Para analizar el pH de cada solución se utiliza un pH-metro Mettler Toledo modelo MP230, con un electrodo de vidrio. Los resultados electroquímicos se comparar con estudios realizados al utilizar un electrodo de referencia $\Omega$ Metrohm 6.0736.110 $\mathrm{Ag}, \mathrm{AgCl} / 0 \ldots 80^{\circ} \mathrm{C}$. Los estudios espectrofotométricos se realizaran en un espectrofotómetro Perkin Elmer Lamba 20. 


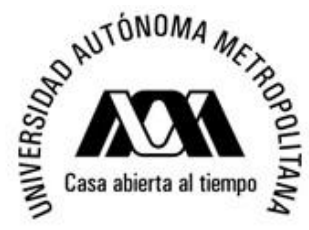
Universidad Autónoma Metropolitana Unidad Iztapalapa
División Ciencias Básicas e Ingeniería
Departamento de Química
Área de Química Analítica
Tesis de Doctorado
Q. Erika Rodríguez Sevilla

Los biosensores son caracterizados mediante voltamperometría cíclica, en un potenciostato Epsilon BASi EW-8111.

Para los análisis por amperometría, se utiliza el programa de computo DAISYLab y un detector amperométrico LC-4C.

\section{Caracterización espectrofotométrica por UV-vis del sistema laccasa de Trametes versicolor e Hidroquinona (sección 2.2).}

Los estudios espectrofotométricos se realizan colocando laccasa de Trametes versicolor 170 $\mathrm{U} \mathrm{mg}^{-1} \mathrm{~mL}^{-1}$ con/sin hidroquinona $100 \mu \mathrm{M}$ en amortiguador de acetatos $0.1 \mathrm{M}$ у pH $4.70 \pm$ 0.01 a $(30.0 \pm 0.5){ }^{\circ} \mathrm{C}$. Se mide el espectro de absorción para cada componente y para el sistema reaccionante. Posteriormente cambiando la concentración de hidroquinona en la celda se mide el cambio de absorbancia en función del tiempo a $289 \mathrm{~nm}$.

\section{Caracterización espectrofotométrica de tirosinasa mushroom.}

Los estudios espectrofotométricos se realizan colocando tirosinasa mushroom $170 \mu \mathrm{g} / \mathrm{mL}$ y/o catecol $100 \mu \mathrm{M}$ en amortiguador de acetatos $0.1 \mathrm{M}$ y pH $4.50 \pm 0.01$ a $(30.0 \pm 0.5){ }^{\circ} \mathrm{C}$. Se mide el espectro de absorción para cada componente y para el sistema reaccionante. Posteriormente cambiando la concentración de catecol en la celda se mide el cambio de absorbancia en función del tiempo a $388 \mathrm{~nm}$. 


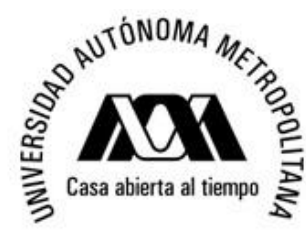

Fabricación de biosensores
Universidad Autónoma Metropolitana Unidad Iztapalapa

División Ciencias Básicas e Ingeniería

Departamento de Química

Área de Química Analítica

Tesis de Doctorado

Q. Erika Rodríguez Sevilla

Los biosensores se fabricaron utilizando electrodos de tipo screen-printed, impresos en un sistema de tres electrodos, el electrodo de trabajo y el contraelectrodo están impresos en tinta de carbono, mientras que el electrodo de pseudoreferencia esta impresos con tinta de plata cloruro de plata $(\mathrm{Ag} / \mathrm{AgCl})$. La enzima es inmovilizada sobre el electrodo de trabajo mediante los métodos de atrapamiento, reticulado, co-reticulado y enlace covalente (ver Anexo 3).

\section{Caracterización electroquímica de biosensores}

En una celda termostatada a $30^{\circ} \mathrm{C}$, se colocan $10 \mathrm{~mL}$ de amortiguador de acetatos $0.1 \mathrm{M}$ a $\mathrm{pH}=4.70 \pm 0.01$, se impone un potencial de $-0.300 \mathrm{~V}$, con agitación constante se hacen alícuotas de hidroquinona (sensores de laccasa) o catecol (sensores de tirosinasa) a diferentes concentraciones, obteniendo de esta forma el comportamiento cinético de cada biosensor. La caracterización de los biosensores mediante EIS se realiza utilizando $\mathrm{KCl} 0.1 \mathrm{M}$ y $\mathrm{Fe}(\mathrm{CN})_{6}^{3-/ 4-} 1 \mathrm{mM}$.

\section{Determinación de $K_{m}{ }^{\prime}$}

La constante de Michaelis-Menten es obtenida mediante el ajuste de una regresión no lineal utilizando el software OriginLab 9, con el modelo de Hill y Michaelis-Menten. La constante de Michaelis-Menten aparente $\left(K_{m}\right)$ es evaluada siguiendo la reducción potenciostática de benzoquinona, formada enzimáticamente por laccasa de Trametes versicolor y tirosinasa mushroom para diferentes concentraciones de hidroquinona y catecol respectivamente. 


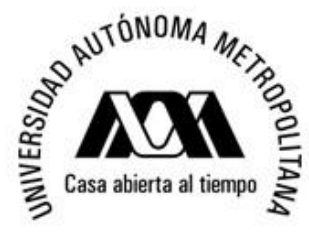
Universidad Autónoma Metropolitana Unidad Iztapalapa
División Ciencias Básicas e Ingeniería
Departamento de Química
Área de Química Analítica
Tesis de Doctorado
Q. Erika Rodríguez Sevilla

\section{Preparación de muestras y determinación de la capacidad antioxidante.}

Las plantas medicinales son obtenidas de la zona de "Tierra caliente" en el Estado de Guerrero, México. Las infusiones se preparan colocando $4.8637 \mathrm{~g}$ de Mirto (Salvia microphylla) incluyendo tallo y hojas en $50 \mathrm{~mL}$ de agua, $2.4685 \mathrm{~g}$ de Hierba dulce (Lippia dulcis) incluyendo tallo, hojas y flor en $50 \mathrm{~mL}$ de agua y $7.8930 \mathrm{~g}$ de Salve Real (Lippia $a l b a$ ) incluyendo raíz, tallo, hoja y flor en $50 \mathrm{~mL}$ de agua, $23.406 \mathrm{~g}$ de Hierba San Cayetano (Solanum rudepannum) incluyendo tallo, hoja, flor y fruto en $100 \mathrm{~mL}$ de agua y $11.7571 \mathrm{~g}$ de Muicle (Justicia spicigera) incluyendo tallo, hoja y flor en $50 \mathrm{~mL}$ de agua por 5 minutos respectivamente. Las soluciones son decantadas y colectadas a temperatura ambiente.

La capacidad antioxidante es determinada usando el método espectrofotométrico de $\cdot$ Dpph y Trolox como estándar, para $\cdot$ Dpph se mide la absorbancia a $514 \mathrm{~nm}$ con respecto a la variación de la concentración de Trolox en el sistema. Para la determinación de la capacidad antioxidante equivalente a Trolox (TEAC), se construye la curva de calibración para las muestras reales y los resultados son reportados en $\mu \mathrm{g}$ de Trolox por $\mathrm{g}$ de muestra. 


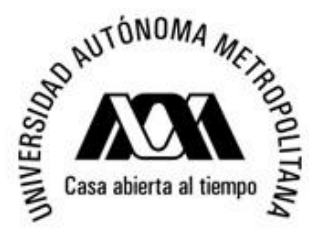

Universidad Autónoma Metropolitana Unidad Iztapalapa

División Ciencias Básicas e Ingeniería

Departamento de Química

Área de Química Analítica

Tesis de Doctorado

Q. Erika Rodríguez Sevilla
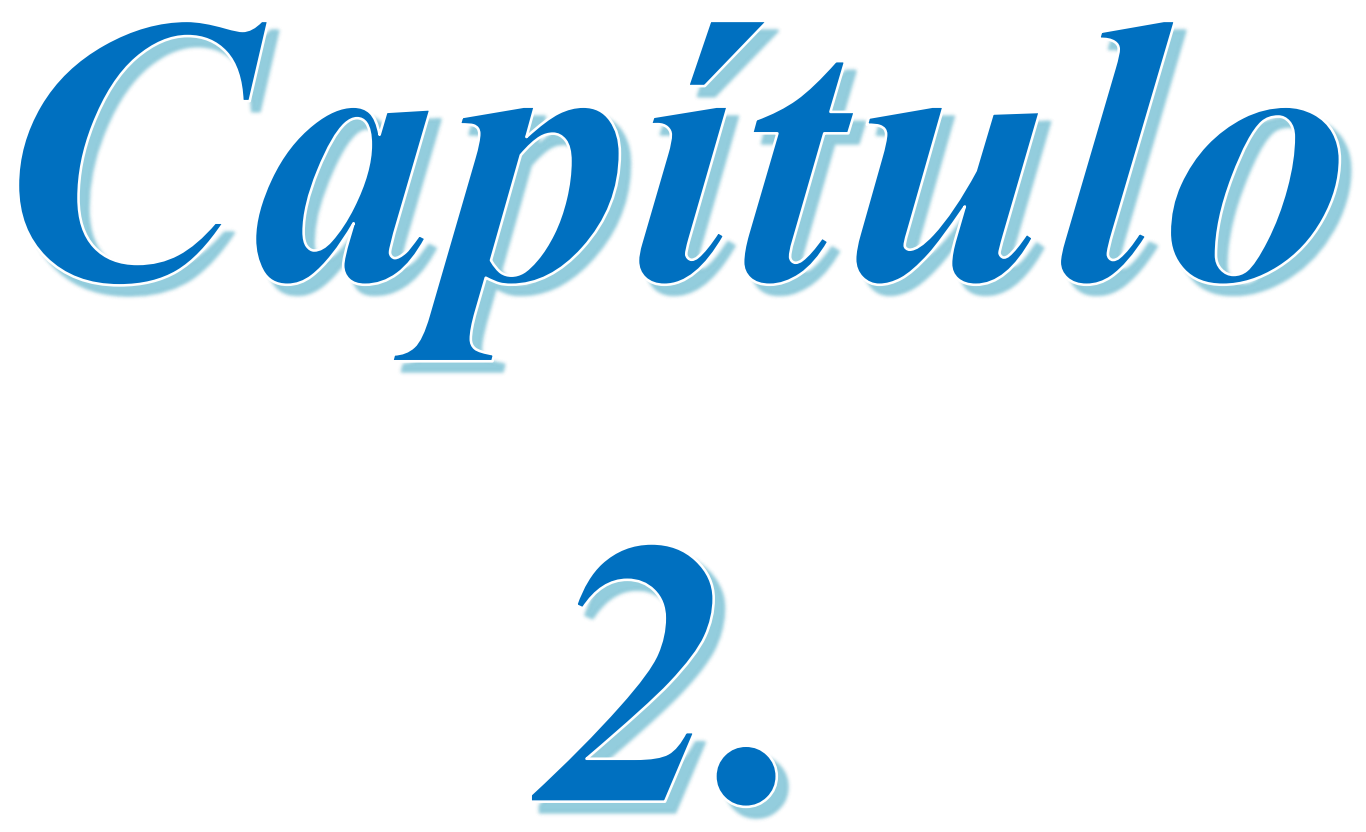

\title{
Biosensores con
}

\section{laccasa de Trametes}

\author{
versicolor.
}




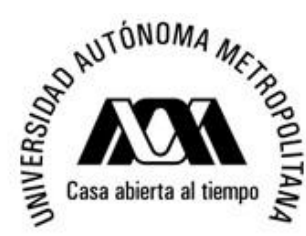

\subsection{Introducción}

Las laccasas son enzimas pertenecientes al grupo de las oxidasas (EC1) ya que catalizan reacciones de óxido-reducción, y están presentes en hongos, en plantas y algunas bacterias [35]. Gracias al conocimiento de sus propiedades catalíticas estas enzimas han sido incluidas en otros campos de la ciencia por ejemplo tratamiento de desechos [36, 37], producción de etanol [38], clarificación de vinos [39], fabricación de detergente [40], degradación de herbicidas [41], así como en biotecnología [42] y biosensores entre otros.

Algunas laccasas procedentes de hongos son proteínas monoméricas, diméricas o tetraméricas y pertenece al grupo de las oxidasas azul multicobre. En 2002 Piontek y colaboradores [43] caracterizaron la especie Trametes versicolor, cuya estructura es un monómero organizado en tres dominios secuenciales (Figura 2.1) con dimensiones cerca de 65 X 55 X $45 \AA^{3}$. Contiene cuatro átomos de cobre en sus sitios activos el cobre de tipo 1 es coordinado con dos histidinas y dos sulfuros, uno de metionina y otro de cisteína (Figura 2.2), el cobre de tipo 2 es tri-coordinado con dos histidinas y agua como ligando, el cobre de tipo 3 es tetra-coordinado, tiene tres ligandos de histidina y un grupo hidroxilo [44].

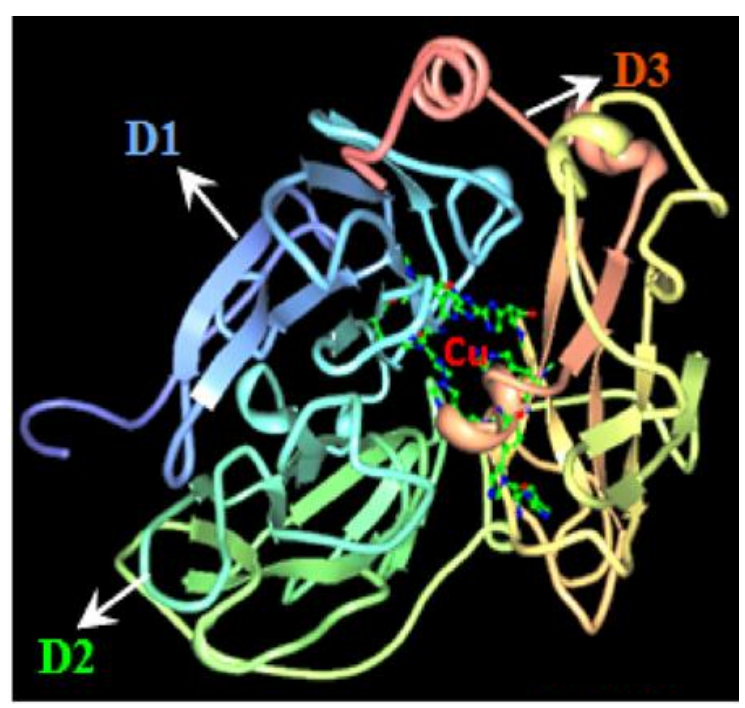

Figura 2.1. Estructura tridimensional de laccasa de Trametes versicolor [45] 


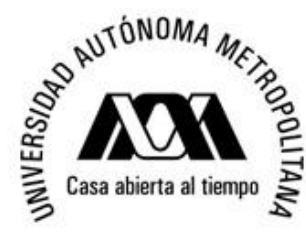

Universidad Autónoma Metropolitana Unidad Iztapalapa

División Ciencias Básicas e Ingeniería

Departamento de Química

Área de Química Analítica

Tesis de Doctorado

Q. Erika Rodríguez Sevilla

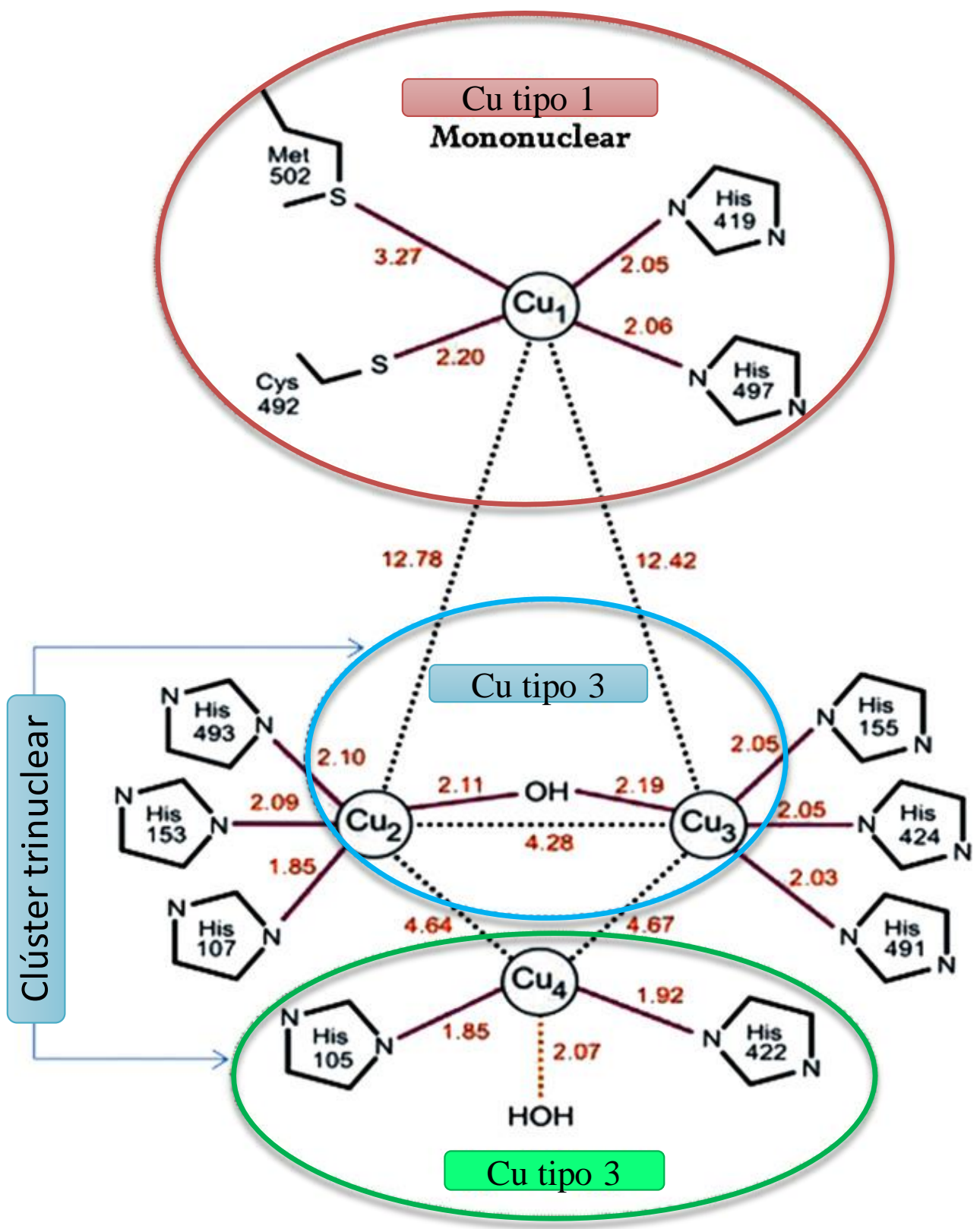

Figura 2.1. Representación esquemática de los átomos de cobre presentes en los sitios activos de laccasa de Trametes versicolor incluyendo las distancias interatómicas del átomo central a los ligandos principales [45].

El uso de laccasa como elemento de reconocimiento en el desarrollo de biosensores ha permitido obtener mejoras en las propiedades fisicoquímicas de la enzima, pues comparado con la enzima libre la inmovilización de la misma suele dar como resultado una mejor 


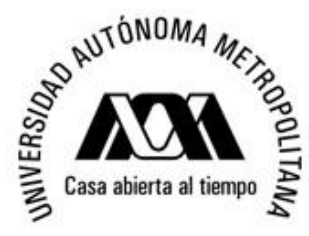

Universidad Autónoma Metropolitana Unidad Iztapalapa
División Ciencias Básicas e Ingeniería
Departamento de Química
Área de Química Analítica
Tesis de Doctorado
Q. Erika Rodríguez Sevilla

actividad y un decremento en la constante de Michaelis-Menten lo que implica una buena inmovilización en la elaboración de biosensores [46], como consecuencia esto permite realizar estudios con un amplio intervalo de sustratos así como el desarrollo de nuevos sistemas de detección de procesos químicos "in situ".

Para la elaboración de biosensores suelen utilizarse distintos métodos de inmovilización [10, 15, 47, 48]; los más utilizados son el método de atrapamiento en los que suele utilizarse alcohol polivinílico [49], poliamida [50], entre otros; el método de reticulado en el que se utiliza quitosan [51], glutaraldehído [52], $\beta$-ciclodextrina [53]; el método de enlace covalente en el que suelen usarse materiales mesoestructurados [54], clorhidrato de N-etil- $\mathrm{N}^{\prime}$ (3dimetilaminopropil) carbodimida [55] entre otros. Cada uno de estos métodos presenta ventajas y desventajas del sistema, por lo tanto es recomendable hacer una buena elección el método de inmovilización dependiendo lo que se requiera, para economizar, tiempo, recursos y sobre todo para obtener buenos resultados. En general, los métodos de difícil preparación y de mayor costo proporcionan biocatalizadores más estables y duraderos; en cambio, aquellos métodos más sencillos como el atrapamiento o la adsorción, donde la unión de la enzima con el soporte es débil, originan derivados inmovilizados que presentan pérdidas de actividad y que deben ser repuestos continuamente. La Tabla 2.1 nos muestra algunas de las características de cada método para llevar a cabo una buena elección del método de inmovilización.

¿Cómo saber cuál es el mejor método de inmovilización para laccasa de Trametes versicolor? En este capítulo se muestra la evaluación de cuatro diferentes métodos de inmovilización para laccasa de Trametes versicolor, bajo seis condiciones experimentales distintas y su caracterización electroquímica por medio de voltamperometría cíclica y amperometría, así como la evaluación del método de inmovilización y algunos parámetros analíticos del sensor a través de la constante de Michaelis-Menten aparente $K_{m}$ '. 


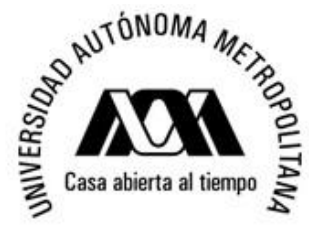

Universidad Autónoma Metropolitana Unidad Iztapalapa

División Ciencias Básicas e Ingeniería

Departamento de Química

Área de Química Analítica

Tesis de Doctorado

Q. Erika Rodríguez Sevilla

Tabla 2.1. Elección del método de inmovilización

\begin{tabular}{|c|c|c|c|c|c|}
\hline Método & $\begin{array}{l}\text { Inclusión en } \\
\text { Membranas }\end{array}$ & Atrapamiento & Reticulado & $\begin{array}{l}\text { Adsorción } \\
\text { química }\end{array}$ & $\begin{array}{c}\text { Unión } \\
\text { covalente }\end{array}$ \\
\hline Preparación & Intermedia & Difícil & Intermedia & Sencilla & Difícil \\
\hline Fuerza de unión & Débil & Media & Débil-Media & Media & Fuerte \\
\hline $\begin{array}{c}\text { Actividad } \\
\text { enzimática }\end{array}$ & Media-Alta & Baja & Baja & Media & Alta \\
\hline $\begin{array}{l}\text { Regeneración del } \\
\text { soporte }\end{array}$ & Posible & Imposible & Imposible & Posible & Difícil \\
\hline Costo del proceso & Medio-Alto & Medio & Medio & Bajo & Alto \\
\hline Estabilidad & Media & Alta & Alta & Baja & Alta \\
\hline Validez & General & General & Limitada & General & Limitada \\
\hline $\begin{array}{l}\text { Resistencia } \\
\text { microbiana }\end{array}$ & Sí & Sí & Sí & No & No \\
\hline
\end{tabular}

\subsection{Caracterización espectrofotométrica UV-vis del sistema laccasa de Trametes versicolor e Hidroquinona.}

El estudio realizado para laccasa de Trametes versicolor (fuente y pureza), muestra tres bandas de absorción a una longitud de onda de 245 nm, 255 nm y 289 nm, (Figura 2.3 línea continua), la hidroquinona (Figura 2.3 línea ***) muestra dos bandas de absorción una en $221 \mathrm{~nm}$ y la segunda en $289 \mathrm{~nm}$, en el caso de la p-quinona pueden observarse dos bandas de absorción (Figura 2.3 línea ---); una a $245 \mathrm{~nm}$ y la segunda a $289 \mathrm{~nm}$, dichas bandas se asocian a transiciones electrónicas de tipo $\sigma$ y $\sigma^{*}$ así como transiciones de tipo $\pi$ y $\pi^{*}$.

En la Tabla 2.2 se muestra la longitud de onda para cada banda de absorcion de los componentes del sistema LTv-HQ, a $289 \mathrm{~nm}$ tanto HQ como p-Q y LTv sin embargo es 


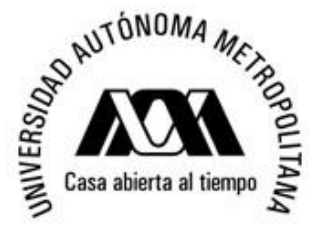

Universidad Autónoma Metropolitana Unidad Iztapalapa

División Ciencias Básicas e Ingeniería

Departamento de Química

Área de Química Analítica

Tesis de Doctorado

Q. Erika Rodríguez Sevilla

necesario eliminar las contribuciones de la enzima y del producto a esa longitud de onda para determinar la velocidad de reacción de la cinética enzimática.

Tabla 2.2 Longitudes de onda a las cuales aparecen bandas de absorción para el sistema laccasa - HQ

\begin{tabular}{cccc}
\hline $\begin{array}{c}\text { Longitud de onda }(\lambda) \\
(\mathbf{n m})\end{array}$ & laccasa & Hidroquinona & p-Quinona \\
\hline $\mathbf{2 2 1}$ & & SI & \\
\hline $\mathbf{2 4 5}$ & SI & & SI \\
\hline $\mathbf{2 5 5}$ & SI & & SI \\
\hline $\mathbf{2 8 9}$ & SI & SI & SI \\
\hline
\end{tabular}

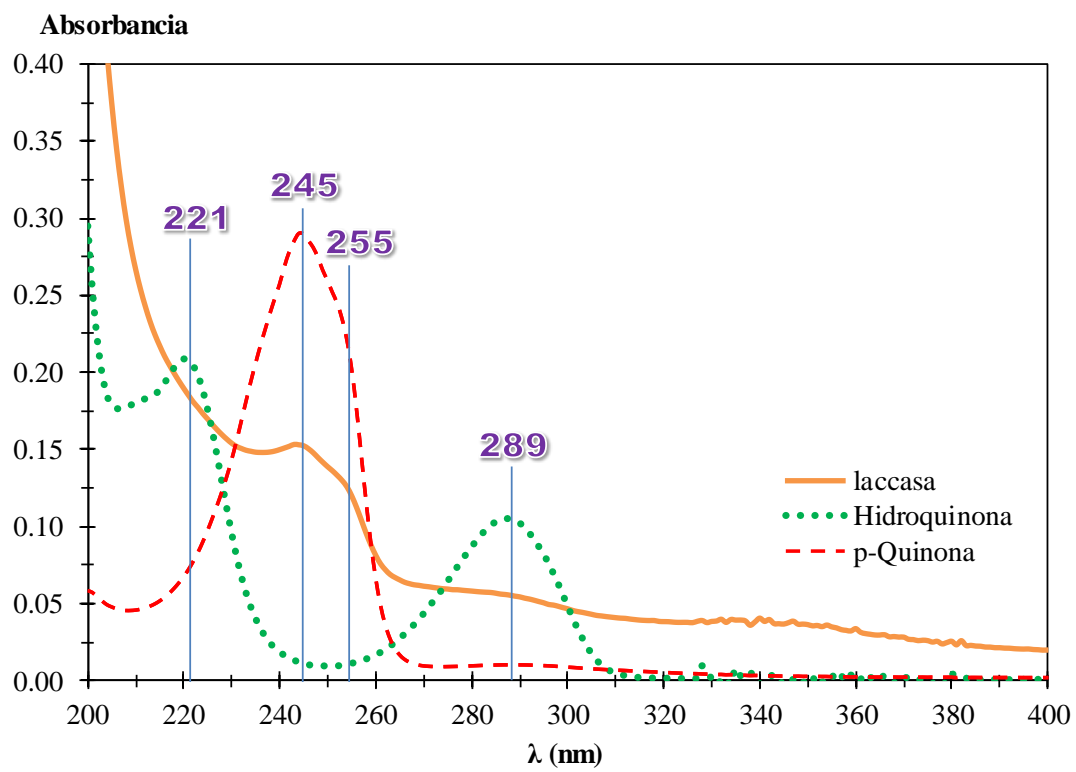

Figura 2.3. Espectros de absorción para el sistema laccasa-Hidroquinona en amortiguador de acetatos $0.1 \mathrm{M}$ $\mathrm{pH} 4.70 \pm 0.01 \mathrm{a}(30.0 \pm 0.5){ }^{\circ} \mathrm{C}$ 


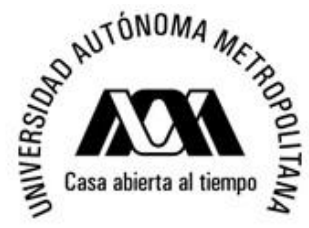

Universidad Autónoma Metropolitana Unidad Iztapalapa

División Ciencias Básicas e Ingeniería

Departamento de Química

Área de Química Analítica

Tesis de Doctorado

Q. Erika Rodríguez Sevilla

\subsection{Cálculo de la constante de Michaelis-Menten para la laccasa de Trametes versicolor (LTv)}

El sistema se basa en una ecuación química del tipo:

$\operatorname{laccasa}(L)_{a q}+$ Hidroquinona $(H Q)_{a q} \stackrel{k_{1}}{\longleftarrow} L(H Q)_{a q} \stackrel{k_{2}}{\longrightarrow}$ Laccasa $_{a q}+p-$ Quinona $_{a q}$

(R.

La constante de Michaelis-Menten aparente $\left(K_{m}\right)($ anexo 2$)$ para este sistema se define como:

$$
K_{m}^{\prime}=\frac{k_{-1}+k_{2}}{k_{1}}
$$

En el sistema conformado por laccasa (LTv) e hidroquinona (HQ), la formación del producto de reacción (p-quinona, Q), muestra bandas de absorción a la misma longitud de onda que el reactivo, por lo que basados en la ley de Lambert-Beer (ecuación 2.2) se genera un sistema de ecuaciones (Eq. 2.3-2.7) para observar el cambio en la absorbancia con respecto a la concentración de Q en el sistema. La absorbancia de la enzima se mantiene constante y es restada a las mediciones para obtener el comportamiento cinético del sistema, la longitud de paso óptico $(l)$ es de $1 \mathrm{~cm}$.

$$
\begin{gathered}
A=\varepsilon l C \\
A_{\mathrm{T}}=A_{T}^{245 n m}+A_{T}^{287 n m} \\
A_{\mathrm{T}}^{245 n m}=\varepsilon_{H Q}^{245 n m}[H Q]+\varepsilon_{Q}^{245 n m}[Q] \\
A_{\mathrm{T}}^{289 n m}=\varepsilon_{H Q}^{289 n m}[H Q]+\varepsilon_{Q}^{289 n m}[Q] \\
{[H Q]=\frac{A_{\mathrm{T}}^{245 n m}-\varepsilon_{Q}^{245 n m}[Q]}{\varepsilon_{H Q}^{245 n}}}
\end{gathered}
$$




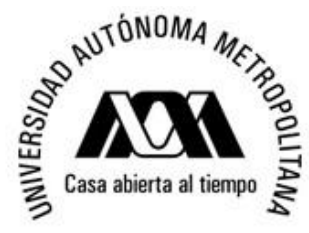
Universidad Autónoma Metropolitana Unidad Iztapalapa
División Ciencias Básicas e Ingeniería
Departamento de Química
Área de Química Analítica
Tesis de Doctorado
Q. Erika Rodríguez Sevilla

$$
[Q]=\frac{\varepsilon_{H Q}^{245 n m} A_{\mathrm{T}}^{289 n m}-\varepsilon_{H Q}^{289 n m} A_{\mathrm{T}}^{245 n m}}{\varepsilon_{H Q}^{245 n m} \varepsilon_{Q}^{289 n m}-\varepsilon_{H Q}^{289 n m} \varepsilon_{Q}^{245 n m}}
$$

De esta forma es posible obtener el coeficiente de absortividad molar para los reactivos y productos, así como la concentración de hidroquinona [HQ] y p-quinona [Q] real en el sistema y su contribución a la absorbancia.

La Figura 2.4 muestra la dependencia de la absorbancia con respecto a la [HQ]; de acuerdo con la ecuación 2.3 la pendiente de la recta proporciona el coeficiente de absortividad molar para HQ a una longitud de onda $(\lambda)$ de $245 \mathrm{~nm}$ y $289 \mathrm{~nm}$ respectivamente, obteniendo así un $\varepsilon_{H Q}^{245 n m}=(0.00064 \pm 0.00001) \mu \mathrm{M}^{-1}, \mathrm{y}{ }^{289 n m}=(0.00128 \pm 0.00001) \mu \mathrm{M}^{-1}$

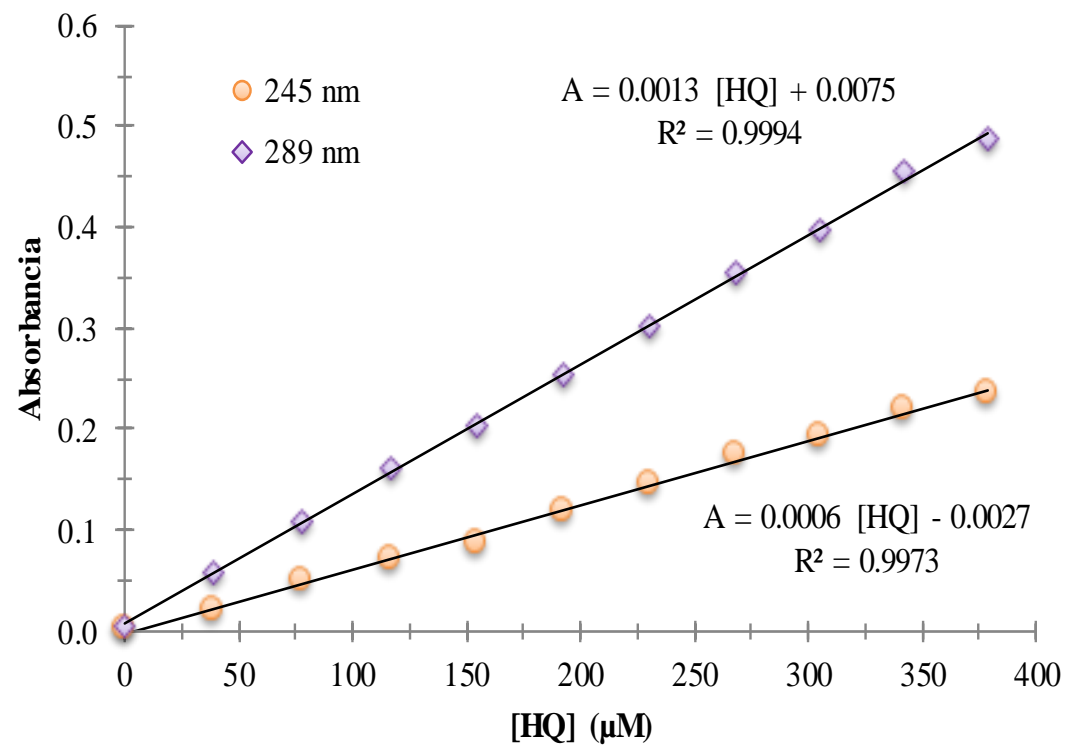

Figura 2.4. Dependencia de la Absorbancia con respecto a la concentración de HQ en ausencia de LTv, en amortiguador de acetatos $0.1 \mathrm{M}$ a pH $4.70 \pm 0.01$ y $(30.0 \pm 0.5){ }^{\circ} \mathrm{C}$ 


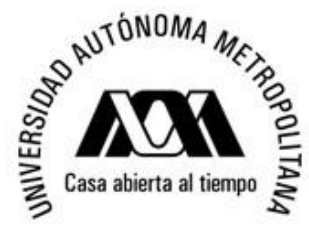

Universidad Autónoma Metropolitana Unidad Iztapalapa

División Ciencias Básicas e Ingeniería

Departamento de Química

Área de Química Analítica

Tesis de Doctorado

Q. Erika Rodríguez Sevilla

Los coeficientes de absortividad molar de $\mathrm{Q}$ son $\varepsilon_{Q}^{245 n m}=(0.0224 \pm 0.0005) \mu \mathrm{M}^{-1}$, y $\varepsilon_{Q}^{289 n m}$ $=(0.0003 \pm 0.0001) \mu \mathrm{M}^{-1}$ respectivamente, los cuales se obtiene al determinar la dependencia de la Absorbancia en función de [Q] (Figura 2.5).

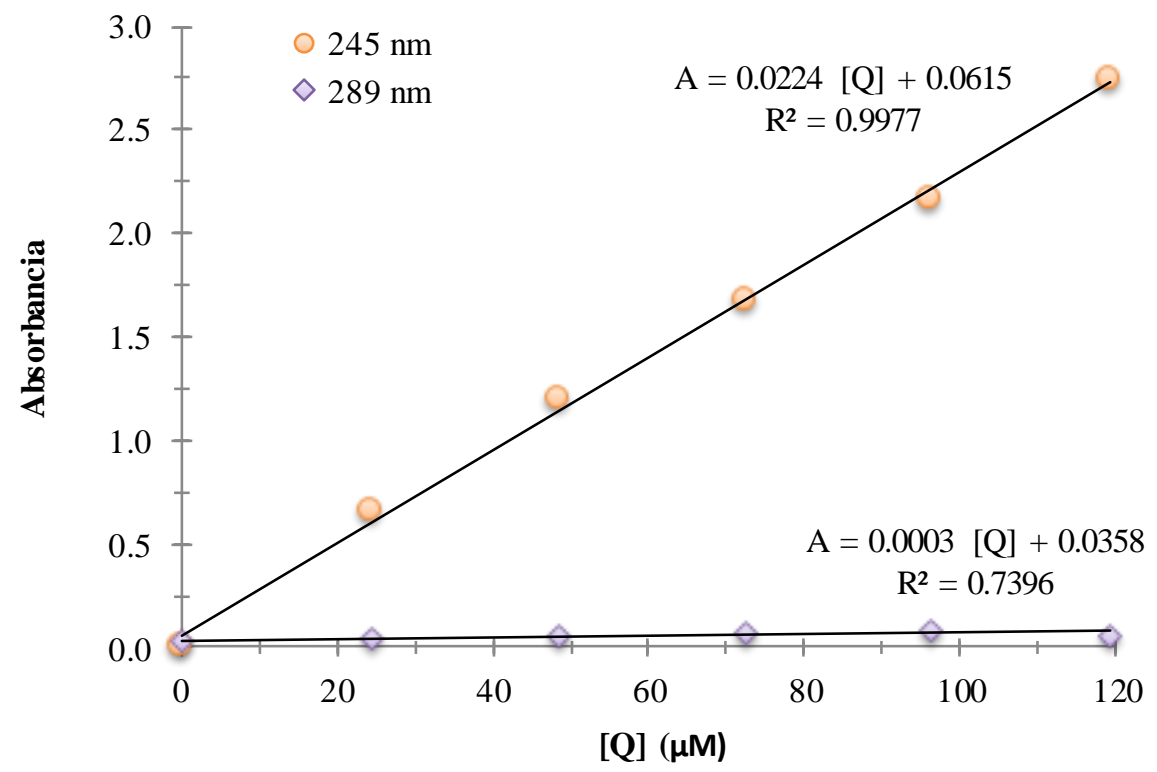

Figura 2.5. Dependencia de la Absorbancia con respecto a la concentración de Q en ausencia de LTv, en amortiguador de acetatos $0.1 \mathrm{M}$ a pH $4.70 \pm 0.01$ y $(30.0 \pm 0.5){ }^{\circ} \mathrm{C}$

La figura 2.6 muestra las curvas de absorbancia en función del tiempo para diferentes [HQ], la velocidad de la reacción está dada por la pendiente de cada curva, ya que esta representa el cambio de absorbancia en función del tiempo (ver Anexo 2) a una longitud de onda de 289 $\mathrm{nm}$.

Haciendo uso de las ecuaciones 2.3-2.7, se describe el comportamiento cinético del sistema formado por LTv y HQ a una temperatura de $(30.0 \pm 0.5){ }^{\circ} \mathrm{C}$ y un $\mathrm{pH}$ de $4.70 \pm 0.01$, que es el $\mathrm{pH}$ donde la enzima muestra mayor actividad catalítica, siguiendo la respuesta dada únicamente por el producto (Q) a diferentes concentraciones de sustrato (HQ) (Figura 2.7). 

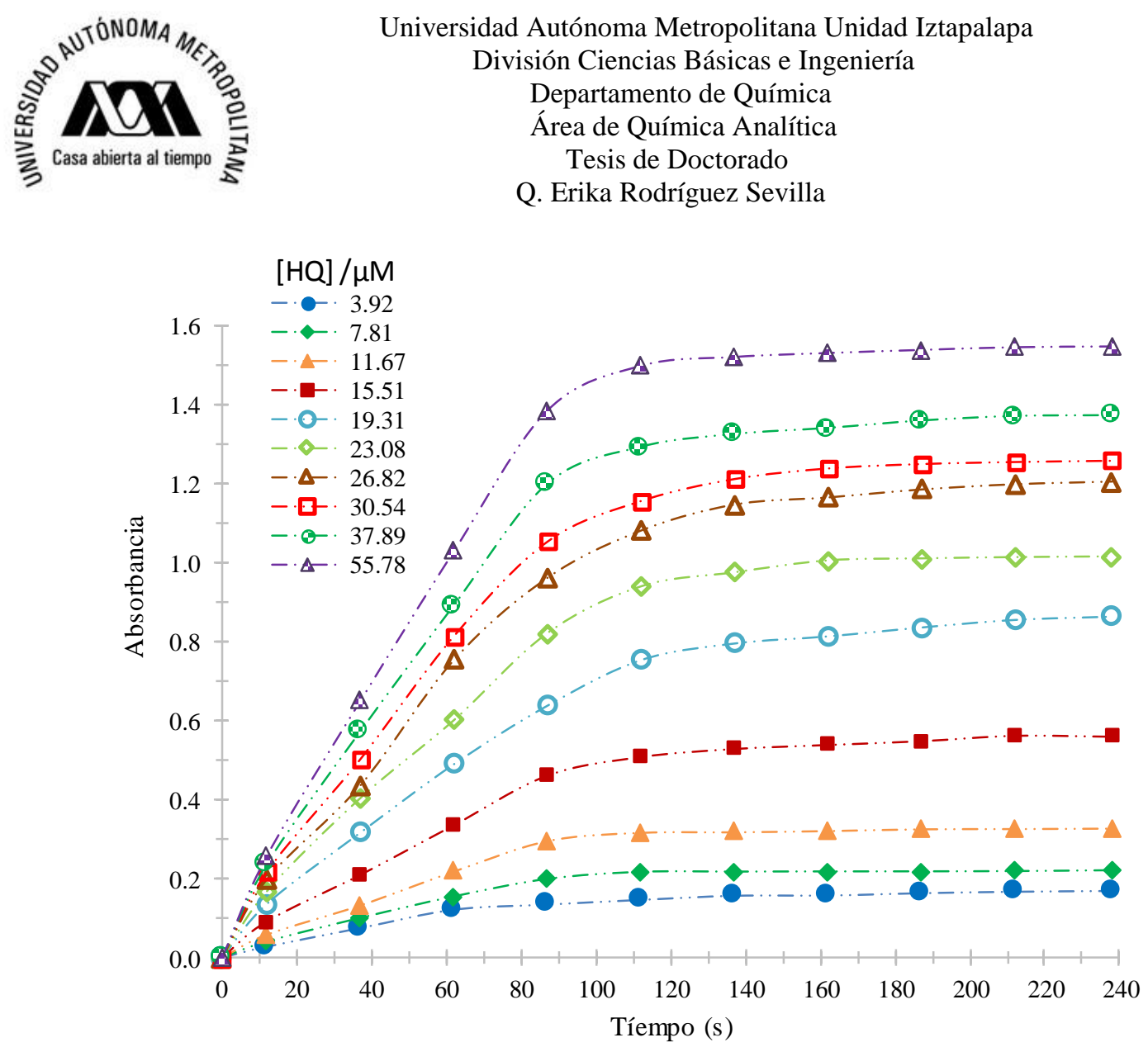

Figura 2.6. Determinación de la velocidad de reacción para el sistema laccasa e hidroquinona en amortiguador de acetatos $0.1 \mathrm{M}$ a pH $4.70 \pm 0.01$ a $(30.0 \pm 0.5){ }^{\circ} \mathrm{C}$, seguido mediante UV-Vis

Mediante la regresión de Lineweare-Burk se obtienen los parámetros cinéticos característicos del sistema mediante la pendiente $(m)$ y la ordenada al origen $(b)$; de la recta generada descritos por $v_{\text {máx }}=1 / b$, y $K_{m}=m^{*} v_{\operatorname{máx}}=m / b$, el valor de ambos parámetros es determinado también al realizar una regresión no lineal de los datos experimentales utilizando el software OriginLab. Para LTv en solución la constante de Michaelis-Menten es de $(9.4 \pm 0.2) \mu \mathrm{M}$ con una $v_{\max }$ de $(0.169 \pm 0.002) \mu \mathrm{Ms}^{-1}$. 


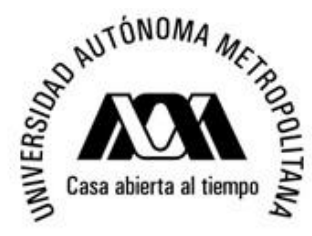

Universidad Autónoma Metropolitana Unidad Iztapalapa

División Ciencias Básicas e Ingeniería

Departamento de Química

Área de Química Analítica

Tesis de Doctorado

Q. Erika Rodríguez Sevilla

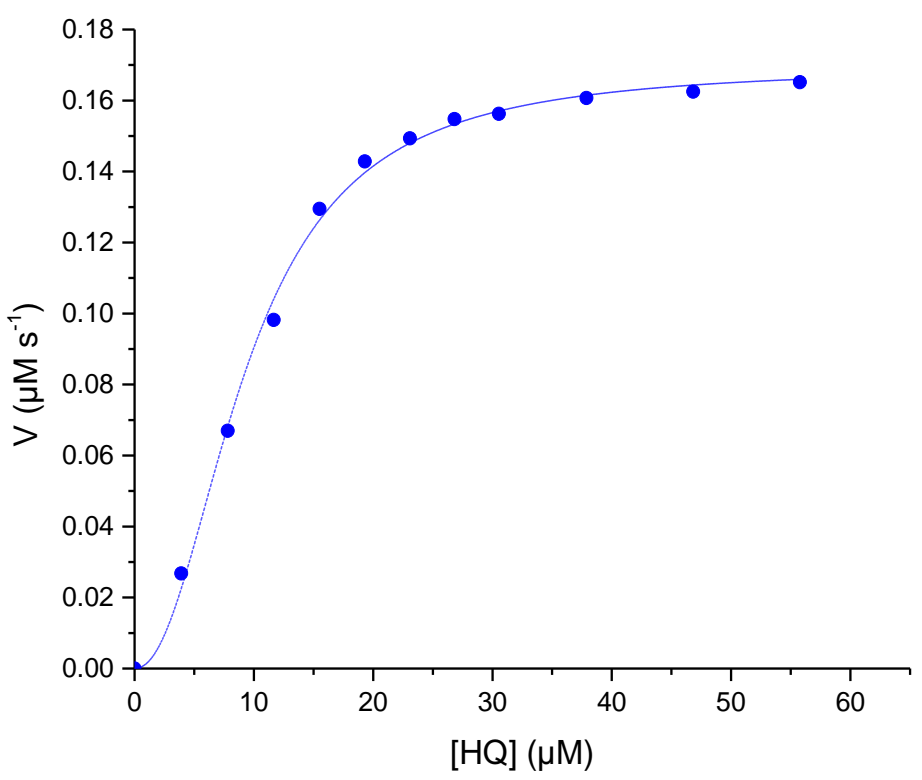

Figura 2.7. Cinética enzimática para la reacción de laccasa e hidroquinona en amortiguador de acetatos $0.1 \mathrm{M}$ a pH $4.70 \pm 0.01$ a $(30.0 \pm 0.5){ }^{\circ} \mathrm{C}$, seguido mediante UV-Vis

\subsection{Caracterización electroquímica de hidroquinona}

Para llevar a cabo la caracterización electroquímica se utiliza un electrodo de tipo screenprinted (ESP) el cual es impreso con tinta de carbono, y está diseñado en un esquema de tres electrodos (Figura 2.8); electrodo de trabajo, electrodo de referencia y electrodo de pseudoreferencia impreso en tinta de $\mathrm{Ag} / \mathrm{AgCl}$. El electrodo de trabajo tiene un diámetro de $3 \mathrm{~mm}$, y por lo tanto un área superficial de $7 \mathrm{~mm}^{2}$. 


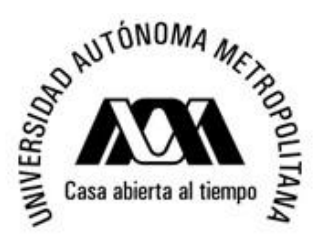

Contraelectrodo
Universidad Autónoma Metropolitana Unidad Iztapalapa

División Ciencias Básicas e Ingeniería

Departamento de Química

Área de Química Analítica

Tesis de Doctorado

Q. Erika Rodríguez Sevilla

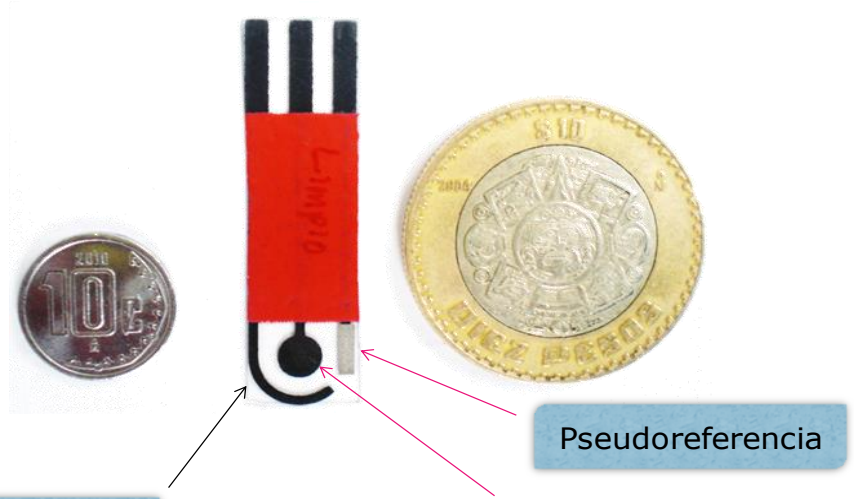

Electrodo de trabajo

Figura 2.8. Electrodo de tipo screen-printed (ESP), formado por un electrodo de trabajo de $7 \mathrm{~mm}^{2}$ de área, un contraelectrodo, ambos impresos con tinta de carbono y un electrodo de pseudoreferencia impreso con tinta de $\mathrm{Ag} / \mathrm{AgCl}$.

En la Figura 2.9 se observa el voltamperograma cíclico de una solución de hidroquinona 500 $\mathrm{mM}$ en amortiguador de acetatos $0.1 \mathrm{M}$ a pH $4.70 \pm 0.01 \mathrm{a}(30.0 \pm 0.5){ }^{\circ} \mathrm{C}$, sin atmósfera de $\mathrm{N}_{2}$, a una velocidad de barrido de $0.1 \mathrm{Vs}^{-1}$ utilizando un ESP sin modificar. El voltamperograma de referencia (línea sólida) se obtiene en una solución amortiguadora de acetatos sin hidroquinona, iniciando en el potencial a corriente nula de $\mathrm{E}_{\mathrm{i}=0}=0.000 \mathrm{~V}$ y hacia potenciales negativos hasta un valor de $-1.200 \mathrm{~V}$, en este intervalo no se observa ningún proceso electroquímico, al llegar a $-1.200 \mathrm{~V}$, se invierte el barrido de potencial en dirección a potenciales positivos hasta $1.200 \mathrm{~V}$, como se puede observar, en este intervalo de potencial no hay ningún proceso electroquímico, que interfiera con la medición.

Al colocar una alícuota de $50 \mu \mathrm{L}$ de hidroquinona $500 \mathrm{mM}$, (Figura 2.9 línea - - ) el voltamperograma inicia en un potencial $\mathrm{E}_{\mathrm{i}=0}=0.000 \mathrm{~V}$ hacia potenciales negativos, hasta 1.200 V, utilizando como electrodo de referencia, un electrodo comercial de $\mathrm{Ag} / \mathrm{AgCl}$, en este intervalo no hay ningún proceso de reducción, considerando que la HQ se encuentra reducida, este resultado indica que el reactivo se encuentra puro (no se ha descompuesto, 


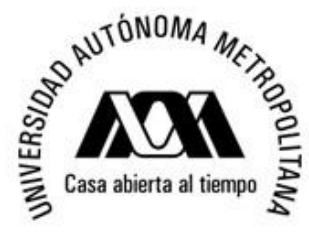

Universidad Autónoma Metropolitana Unidad Iztapalapa

División Ciencias Básicas e Ingeniería

Departamento de Química

Área de Química Analítica

Tesis de Doctorado

Q. Erika Rodríguez Sevilla

oxidado), al invertir el barrido de potencial hacia valores positivos, se observa un pico de oxidación en un potencial de $0.903 \mathrm{~V}$ y con una corriente de pico anódico de $12.2 \mu \mathrm{A}$, el proceso observado es la oxidación de la hidroquinona a p-quinona.

El tercer voltamperograma observado en la Figura 2.9 muestra la respuesta obtenida con el electrodo de pseudoreferencia (línea $\cdots$ ) al iniciar en $\mathrm{E}_{\mathrm{i}=0}=0.000 \mathrm{~V}$ hacia potenciales negativos, no se observa ningún proceso de reducción, al llegar a un valor de $-1.200 \mathrm{~V}$ el barrido de potencial es invertido hasta un valor de $1.200 \mathrm{~V}$, en este intervalo, se observa un pico de oxidación en un potencial de $0.673 \mathrm{~V}$ con una corriente de pico de $12.4 \mu \mathrm{A}$. Por último se invierte una vez más el potencial hasta llegar al potencial de corriente nula.

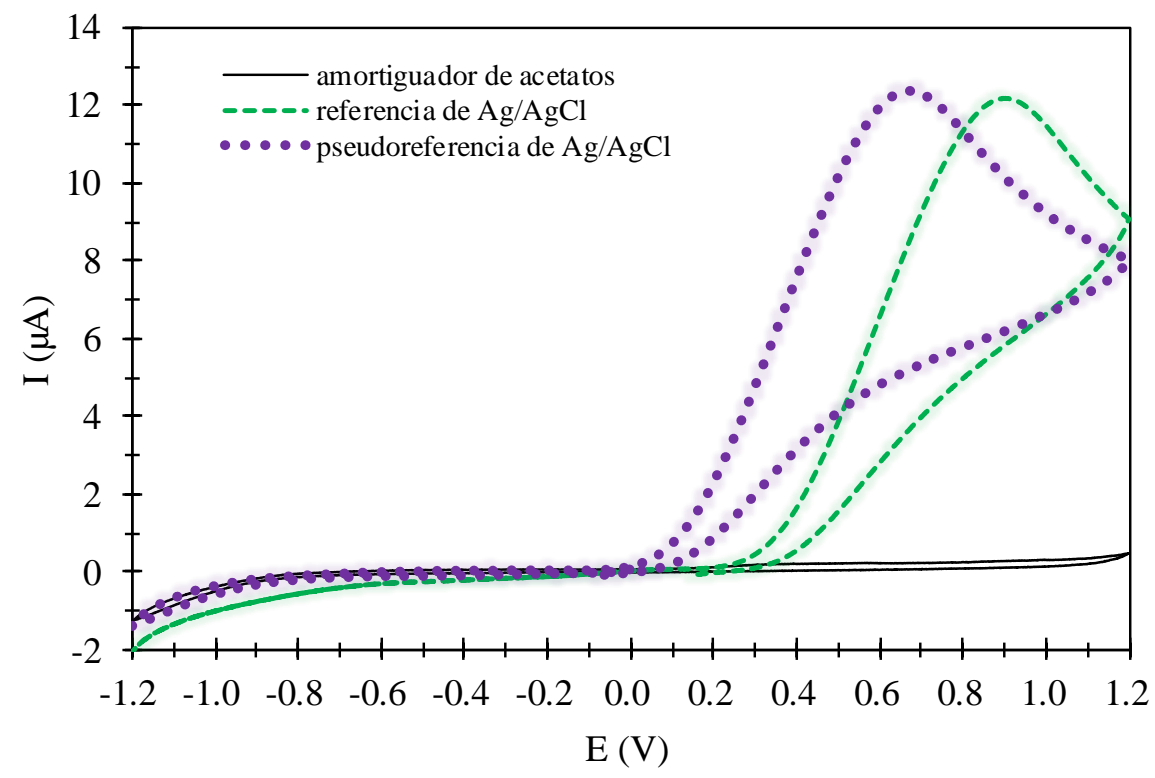

Figura 2.9. VC de hidroquinona $500 \mathrm{mM}$, utilizando como referencia un electrodo comercial de $\mathrm{Ag} / \mathrm{AgCl}$, la pseudoreferencia es el electrodo impreso con tinta de $\mathrm{Ag} / \mathrm{AgCl}$ en el $\mathrm{ESP}$, el voltamperograma es obtenido a una velocidad de barrido de $100 \mathrm{mVs}^{-1}$ partiendo de un potencial de $0 \mathrm{~V}$ hacia reducción, en amortiguador de acetatos $0.1 \mathrm{M} \mathrm{a} \mathrm{pH} 4.70 \pm 0.01 \mathrm{a}(30.0 \pm 0.5){ }^{\circ} \mathrm{C}$. 


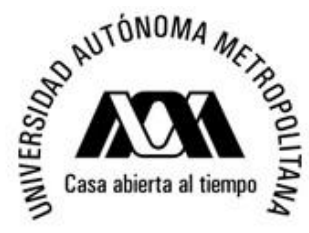

Universidad Autónoma Metropolitana Unidad Iztapalapa

División Ciencias Básicas e Ingeniería

Departamento de Química

Área de Química Analítica

Tesis de Doctorado

Q. Erika Rodríguez Sevilla

\subsubsection{Determinación del potencial de pseudoreferencia.}

Para determinar el potencial que se impone en amperometría, se obtuvieron los voltamperogramas mostrados en la Figura 2.10, iniciando en un potencial de corriente nula de $0.000 \mathrm{~V}$, con un barrido hacia potenciales positivos, hasta un valor de $1.200 \mathrm{~V}$, en este caso es posible observar un pico de oxidación de hidroquinona a p-quinona en $0.722 \mathrm{~V}$ para la pseudoreferencia y de $0.893 \mathrm{~V}$ para la referencia de $\mathrm{Ag} / \mathrm{AgCl}$ con una corriente de pico anódico de $12.16 \mu \mathrm{A}$ y $12.71 \mu \mathrm{A}$ respectivamente. Al invertir el barrido de potencial hacia valores negativos hasta $-1.200 \mathrm{~V}$, se observan los picos de la reducción de p-quinona a hidroquinona en un potencial de - $0.466 \mathrm{~V}$ con una corriente de pico catódico de $-6.93 \mu \mathrm{A}$ para la pseudoreferencia y una corriente de pico catódico de $-7.19 \mu \mathrm{A}$ a un potencial de $-0.294 \mathrm{~V}$ para la referencia de $\mathrm{Ag} / \mathrm{AgCl}$. Con las referencias utilizadas se obtiene una diferencia de $0.172 \mathrm{~V}$ entre el electrodo de referencia y el de pseudoreferencia, esto se debe a que en el biosensor, no se tiene una concentración de $\mathrm{AgCl}$ constante. Debido a esta razón en la caracterización de los biosensores fabricados con LTv se impondrá un potencial de reducción de - $0.300 \mathrm{~V}$ para el estudio amperométrico utilizando la pseudoreferencia que correspondería a imponer un potencial de $-0.100 \mathrm{~V}$ con un electrodo comercial.

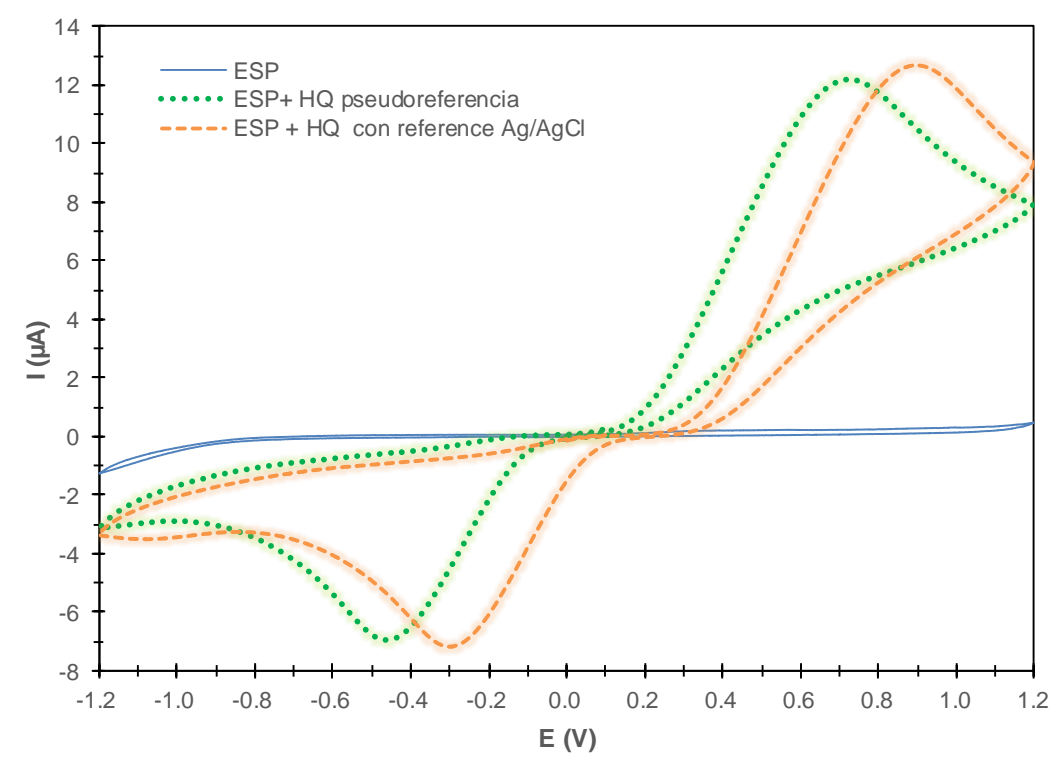

Figura 2.10. VC de hidroquinona $500 \mathrm{mM}$, utilizando como referencia un electrodo comercial de $\mathrm{Ag} / \mathrm{AgCl}$, la pseudoreferencia es el electrodo impreso con tinta de $\mathrm{Ag} / \mathrm{AgCl}$ en el ESP, a $v=100 \mathrm{mVs}^{-1}$ partiendo de un potencial de $0 \mathrm{~V}$ hacia oxidación, en amortiguador de acetatos $0.1 \mathrm{M}$ a pH $4.70 \pm 0.01$ a $(30.0 \pm 0.5){ }^{\circ} \mathrm{C}$. 


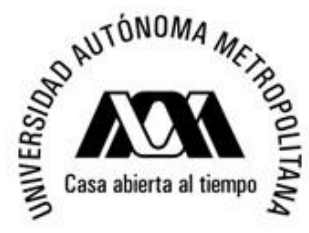

Universidad Autónoma Metropolitana Unidad Iztapalapa

División Ciencias Básicas e Ingeniería

Departamento de Química

Área de Química Analítica

Tesis de Doctorado

Q. Erika Rodríguez Sevilla

\subsection{Caracterización electroquímica del sistema laccasa-hidroquinona}

En el sistema analizado, se estudia principalmente la reacción de óxido-reducción de la hidroquinona, catalizada por la laccasa, la serie de reacciones que se llevan a cabo se muestran en la Figura 2.11, en ella se observa que para llevar a cabo la reacción enzimática es necesaria la presencia de oxígeno.

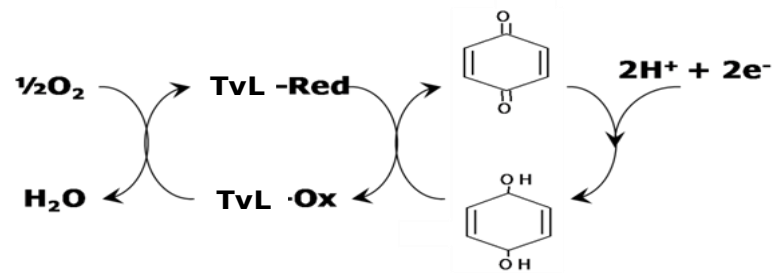

Figura 2.11. Secuencia para la reacción de laccasa con hidroquinona, la cual se lleva a cabo sobre la superficie del electrodo.

La determinación amperométrica de HQ se lleva a cabo utilizando laccasa en solución usando un electrodo screen-printed sin modificar, ESP, y un detector de BAS LC-4C amperométrica. Para estas determinaciones, se aplica un potencial constante de $-300 \mathrm{mV}$, La determinación se realiza colocando $10 \mathrm{~mL}$ de amortiguador de acetatos $0.1 \mathrm{M}$ a pH $=4.70 \pm 0.01$ en una celda termostatada a $(30.0 \pm 0.5){ }^{\circ} \mathrm{C}$ con agitación constante.

De acuerdo con Kurganov y colaboradores [56], la corriente generada por el biosensor está dada como función de la concentración de hidroquinona, por lo tanto se caracteriza amperométricamente el sistema LTv-HQ, en solución y se analiza con los modelos de Hill [57] y Michaelis-Menten (ver anexo 2).

Para estudiar la cinética enzimática de LTv se colocaron $5 \mu \mathrm{L}$ de una solución de laccasa $5 \mathrm{mg} / \mathrm{mL}$ en $10 \mathrm{~mL}$ de solución amortiguador de acetatos $0.1 \mathrm{M}$ a pH $=4.70 \pm 0.01$ y (30.0 $\pm 0.5)^{\circ} \mathrm{C}$ usando un ESP sin modificar se mide la respuesta en la corriente al cambiar la concentración de HQ en el sistema. 


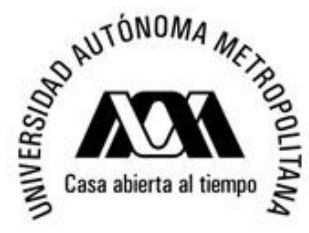
Universidad Autónoma Metropolitana Unidad Iztapalapa
División Ciencias Básicas e Ingeniería
Departamento de Química
Área de Química Analítica
Tesis de Doctorado
Q. Erika Rodríguez Sevilla

Para LTv la cinética enzimática muestra un comportamiento sigmoidal (Figura 2.12), con un intervalo lineal de $(26 \leq[\mathrm{HQ}] \leq 280) \mu \mathrm{M}$, un coeficiente de regresión lineal $\left(\mathrm{R}^{2}\right)$ de 0.9913. Los parámetros cinéticos enzimáticos obtenidos para la enzima libre son: $K_{m}^{\prime}$, libre $=$ $(199 \pm 5) \mu \mathrm{M}, I_{\operatorname{máx}}=(6.95 \pm 0.12) \mu \mathrm{A}$ y un coeficiente de Hill $(h)$ de $1.733 \pm 0.049$ lo cual indica que la cooperatividad del sistema es positiva. Es importante mencionar que la constante de Michaelis-Menten aparente para la enzima libre $\left(K_{m}^{\prime}, l i b r e\right)$ es independiente del valor de $K_{m}$ de la enzima libre [58] calculado por el método de espectroscopia UV-Vis, ver sección 2.2.

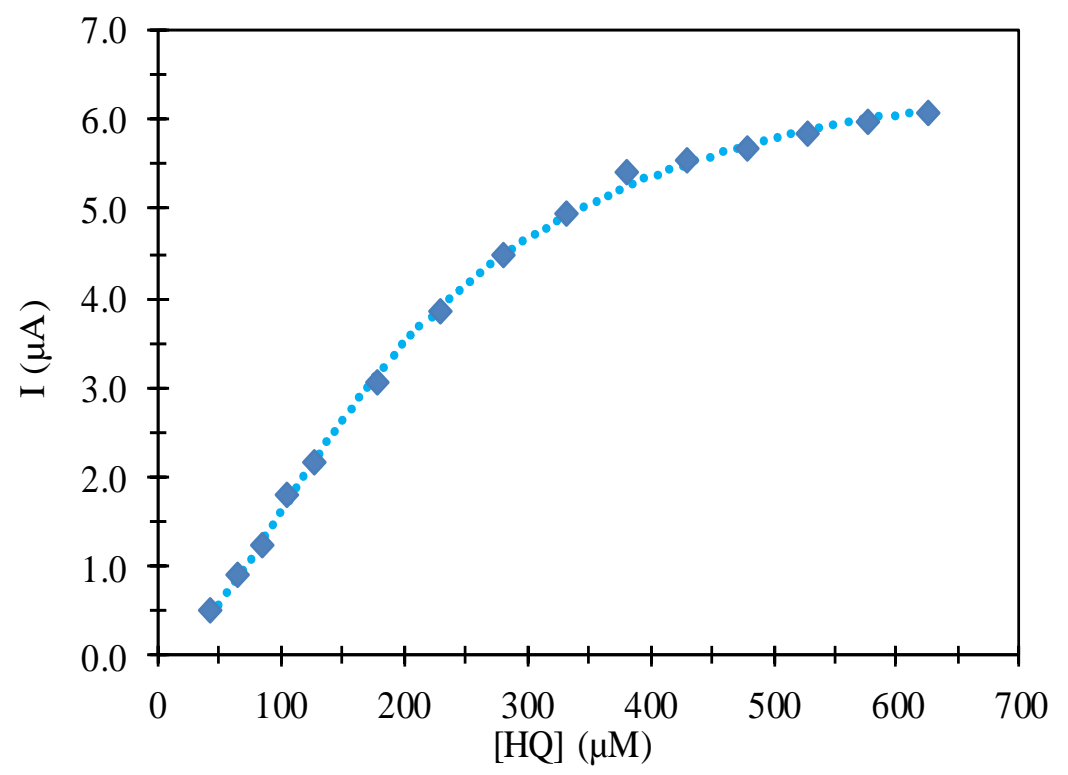

Figura 2.12. Estudio de la cinética enzimática para la reacción de laccasa e hidroquinona en amortiguador de acetatos $0.1 \mathrm{M}$ a pH $4.70 \pm 0.01$ a $(30.0 \pm 0.5){ }^{\circ} \mathrm{C}$, seguido mediante amperometría.

\subsection{Caracterización de biosensores}

Para evaluar el efecto de la inmovilización de la enzima sobre los parámetros cinéticos se utilizaron cuatro distintos métodos de inmovilización en seis condiciones experimentales 


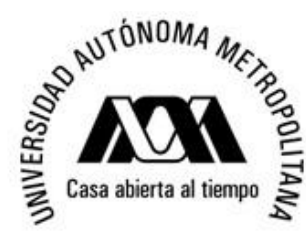

distintas, elaborando así seis biosensores que utilizan LTv como elemento de reconocimiento.

\subsubsection{Biosensor de laccasa con PVA-WAP (ESP/LTv/PVA).}

La caracterización mediante voltamperometría cíclica del biosensor construido con el método de atrapamiento (ver Anexo 3) se muestra en la Figura 2.13, los voltamperogramas se obtienen partiendo de un potencial de equilibrio de $-0.199 \mathrm{~V}$ hacia potenciales negativos, hasta un valor de $-0.600 \mathrm{~V}$, en este intervalo de potencial se observa la reducción de Q a HQ la cual ha sido previamente oxidada por la enzima, a potenciales mayores de $-0.450 \mathrm{~V}$ se observa una corriente prácticamente constante, este comportamiento se debe al efecto catalítico de la enzima presente en el sistema; esto es un indicativo de que la HQ producida potenciométricamente es nuevamente oxida por la enzima lo que mantiene la corriente prácticamente constante a potenciales entre -0.450 y $-0.600 \mathrm{~V}$.

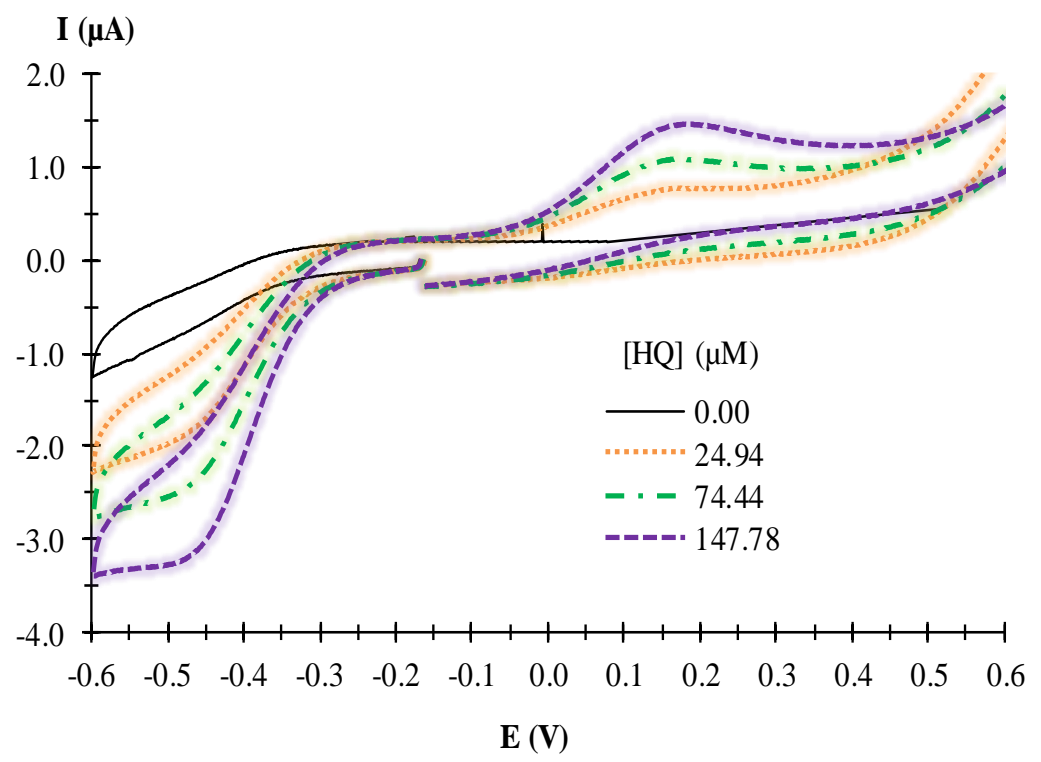

Figura 2.13. Voltamperometría cíclica de ESP/LTv/PVA, a diferentes concentraciones de hidroquinona (HQ), partiendo del potencial de equilibrio hacia reducción, a una velocidad de barrido de $100 \mathrm{mVs}^{-1}$, en amortiguador de acetatos $0.1 \mathrm{M}$ a pH $4.70 \pm 0.01$ y $(30.0 \pm 0.5){ }^{\circ} \mathrm{C}$. 
Al caracterizar dicho sensor mediante amperometría e imponiendo un potencial de reducción de $-0.300 \mathrm{~V}$ (Figura 2.14), puede observarse que bastan 10 minutos para humectar la membrana polimérica y obtener mediciones estables en la corriente. Al biosensor le toma en promedio 45 segundos en estabilizar la respuesta en la corriente al cambiar la concentración de HQ en el sistema, este tiempo de respuesta se conserva incluso en la etapa de saturación de la enzima.

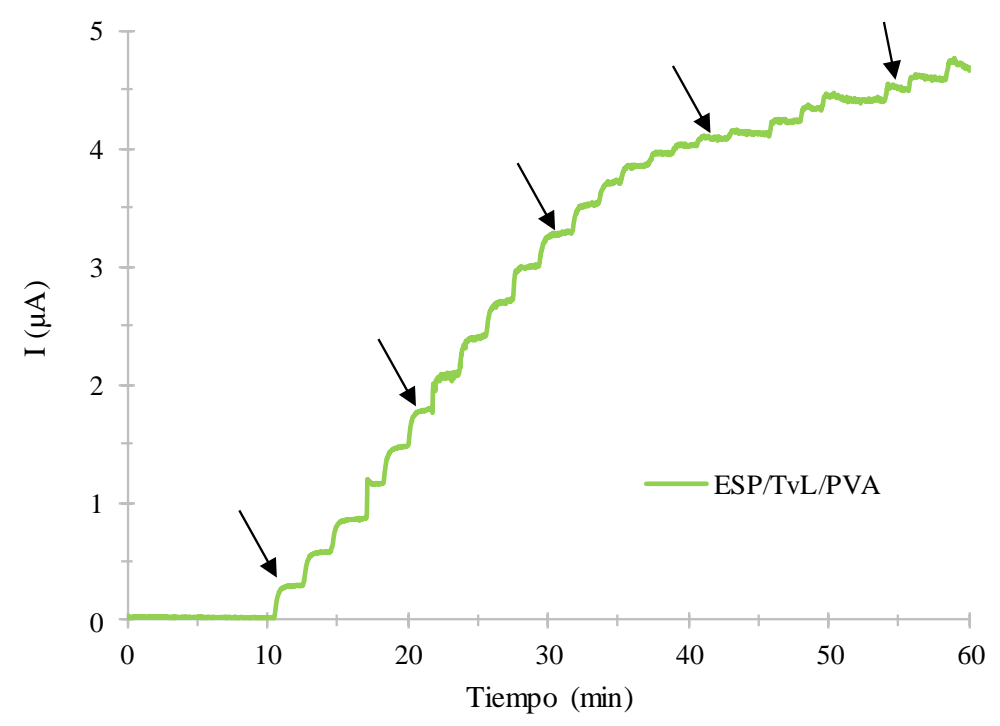

Figura 2.14. Amperometría de ESP/LTv/PVA, a diferentes concentraciones de hidroquinona (HQ), en amortiguador de acetatos $0.1 \mathrm{M}$ a pH $4.70 \pm 0.01$, a $(30.0 \pm 0.5){ }^{\circ} \mathrm{C}$, con un potencial impuesto de $-0.300 \mathrm{~V}$.

El biosensor elaborado con LTv inmovilizada mediante atrapamiento con PVA (ESP/LTv/PVA) muestra un comportamiento cinético de tipo Michaeliano (Figura 2.15) con una $K_{m}{ }^{\prime}$ de $(188 \pm 5) \mu \mathrm{M}$, una $I_{\max }$ de $(4.7 \pm 0.1) \mu \mathrm{A}$, y un coeficiente de Hill de $1.9 \pm 0.1$. La $K_{m}^{\prime}$ obtenida al inmovilizar de esta manera es menor comparada con la $K_{m}^{\prime}$, libre esto implica que la actividad enzimática mejora (ver secciones 1.3-1.5). Los parámetros analíticos del sistema muestran que los sitios activos de la enzima han sido expuestos de manera adecuada para la interacción con $\mathrm{HQ}$, pues se obtiene una alta sensibilidad (11.6 \pm 0.7$)$ 


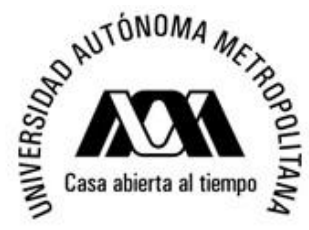

Universidad Autónoma Metropolitana Unidad Iztapalapa

División Ciencias Básicas e Ingeniería

Departamento de Química

Área de Química Analítica

Tesis de Doctorado

Q. Erika Rodríguez Sevilla

$\mathrm{nA} \mu \mathrm{M}^{-1}$, un intervalo lineal de $(26 \leq[\mathrm{HQ}] \leq 348) \mu \mathrm{M}$ con $\mathrm{R}^{2}=0.9955$, así como bajos límites de detección, $\mathrm{LOD}=(20 \pm 7) \mu \mathrm{M}$, y cuantificación, $\mathrm{LOQ}=(67 \pm 23) \mu \mathrm{M}$.

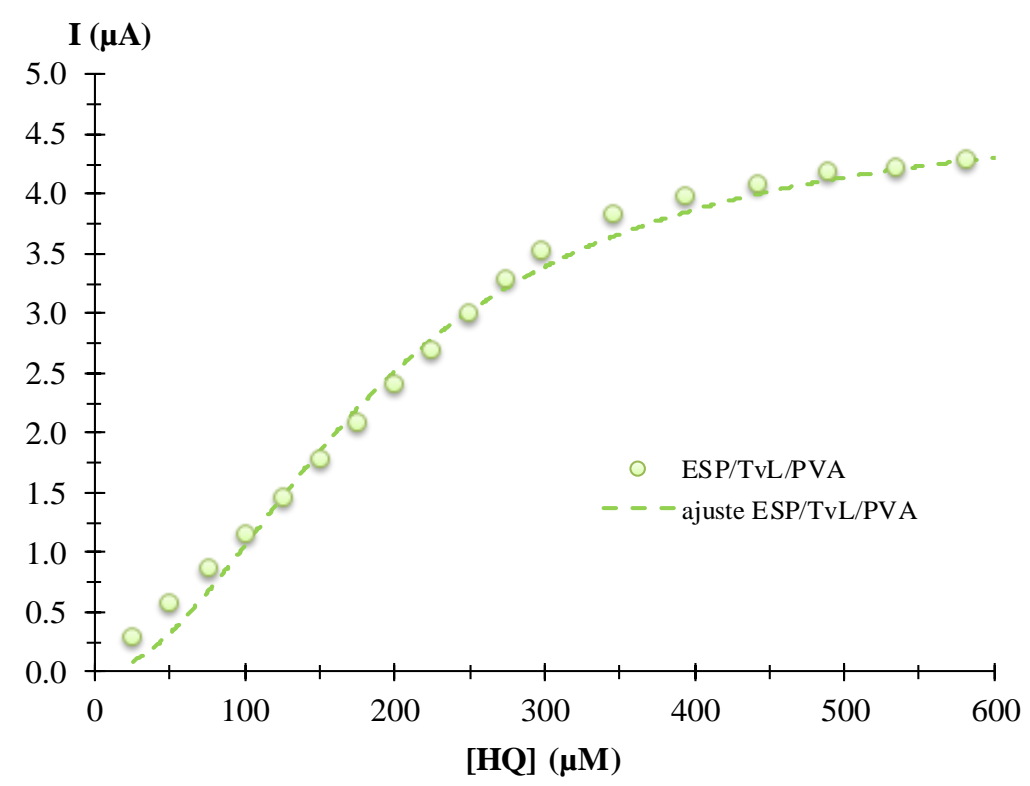

Figura 2.15. Cinética enzimática (puntos) obtenida para el sistema laccasa de Trametes versicolor inmovilizada mediante atrapamiento (biosensor ESP/LTv/PVA), en amortiguador de acetatos $0.1 \mathrm{M}$ a pH 4.70 $\pm 0.01 \mathrm{a}(30.0 \pm 0.5){ }^{\circ} \mathrm{C}$ a $-300 \mathrm{mV}$ de potencial impuesto, la línea es el ajuste obtenido mediante el modelo de Hill usando los valores de $K_{m}^{\prime}, I_{\max }$ y $h$ reportados en la Tabla 2.1.

La superficie del electrodo sin modificar es prácticamente uniforme y posee poca rugosidad (Figura 2.16) sin embargo cuando se deposita la mezcla de LTv con alcohol polivinílico se forma una red polimérica que impide la deslocalización de la enzima en el seno de la solución. La red muestra intersticios uniformes (Figura 2.17) lo cual facilita la interacción de LTV con HQ.

A partir de estos resultados, se puede concluir que la red polimérica formada por el alcohol polivinílico (Figura 2.17) mejora la actividad enzimática durante el proceso de inmovilización. Una de las ventajas que ofrece este tipo de inmovilización es el largo tiempo 


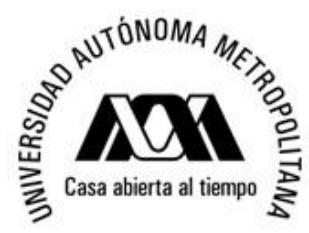

Universidad Autónoma Metropolitana Unidad Iztapalapa

División Ciencias Básicas e Ingeniería

Departamento de Química

Área de Química Analítica

Tesis de Doctorado

Q. Erika Rodríguez Sevilla

de vida del biosensor, pues puede ser utilizado durante 12 meses (Figura 2.18), obteniendo resultados confiables mientras que el biosensor solo es almacenado a temperatura ambiente.

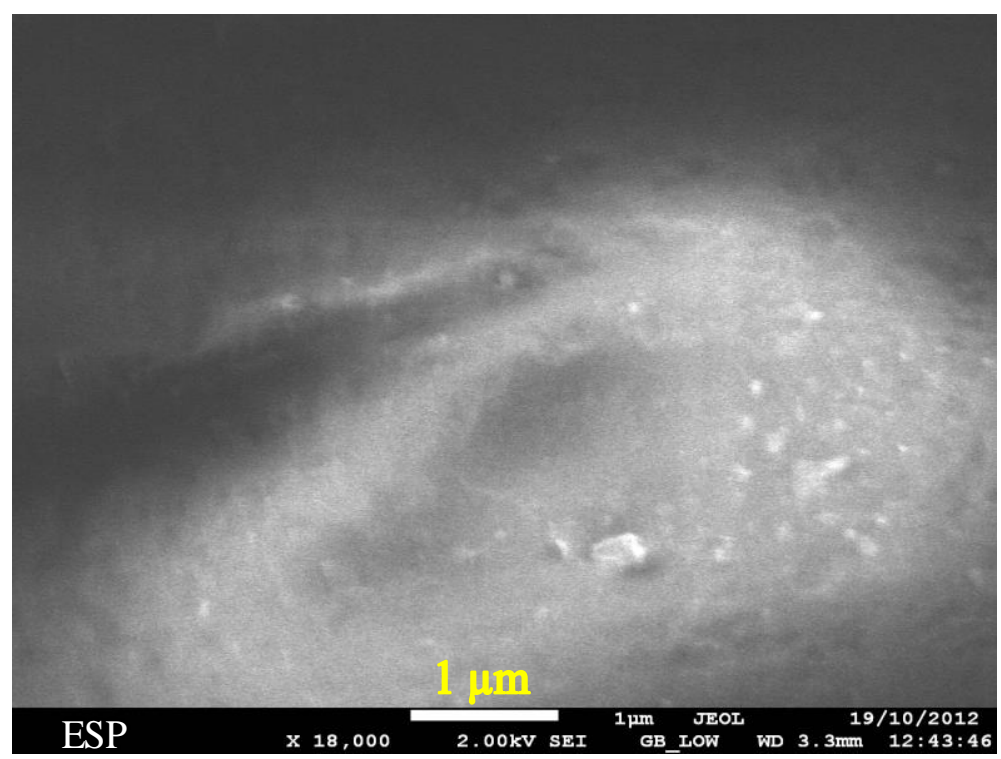

Figura 2.16. Microscopía electrónica de barrido (SEM) del ESP sin modificar

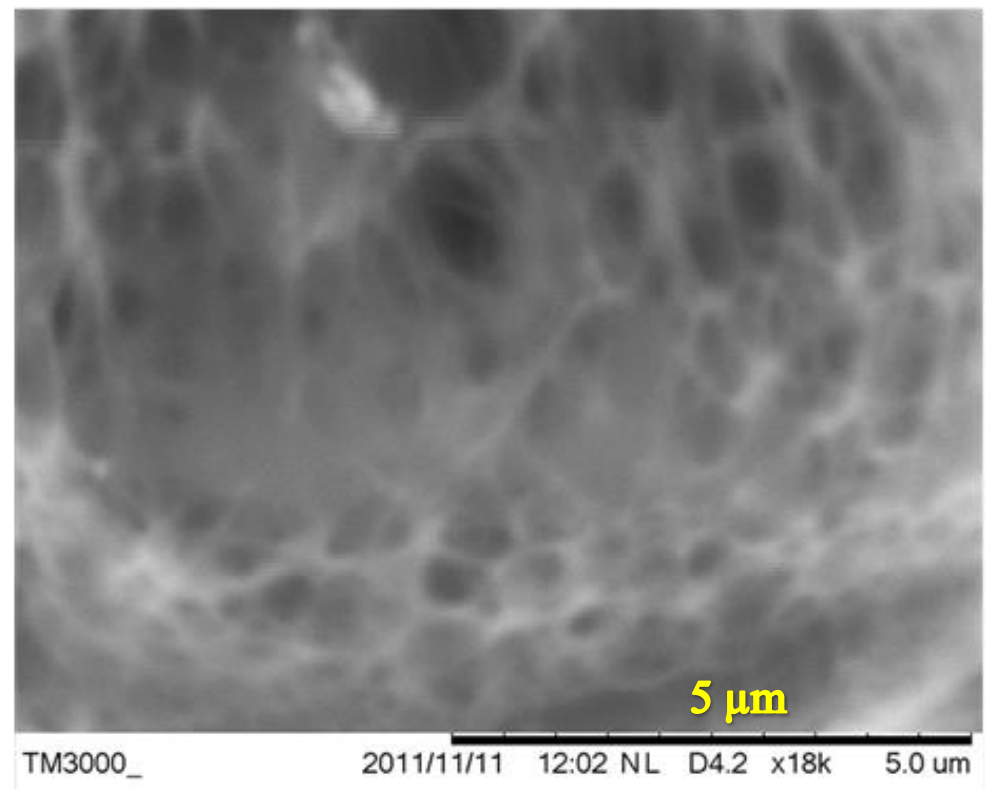

Figura 2.17. Microscopía electrónica de barrido (SEM) del ESP modificado con laccasa mediante atrapamiento (ESP/LTv/PVA), 
División Ciencias Básicas e Ingeniería

Departamento de Química

Área de Química Analítica

Tesis de Doctorado

Q. Erika Rodríguez Sevilla

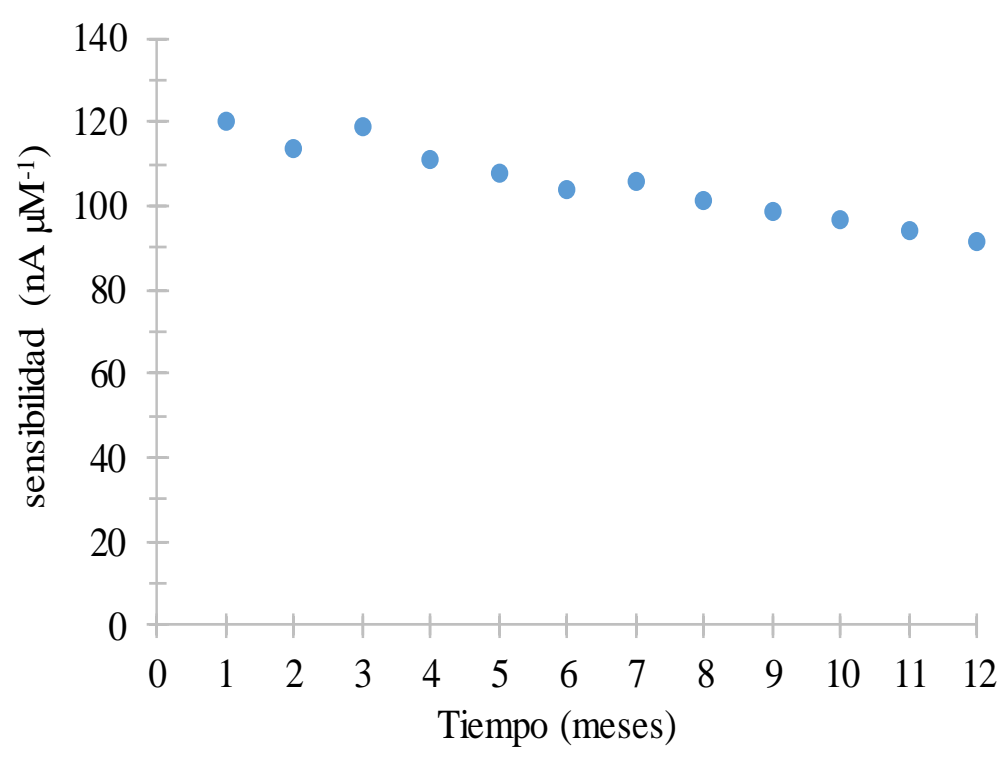

Figura 2.18. Estabilidad del biosensor ESP/LTV/PVA, midiendo el cambio en la sensibilidad con respecto al tiempo, el biosensor es almacenado a temperatura ambiente.

\subsubsection{Biosensor de laccasa con glutaraldehído (GA) y albúmina de suero humano (ASH)}

El uso de Albúmina de Suero Humano (ASH) en el desarrollo de biosensores se ha implementado en los últimos años debido a que funcionaliza los sitios activos de la enzima y se espera que genere biosensores con un amplio intervalo de linealidad así como con buenos parámetros tanto cinéticos como analíticos [59]. Por otra parte es común utilizar glutaraldehído para la inmovilización de enzimas, es decir como agente reticulante [60], pues brinda a la enzima estabilidad y resistencia a distintas condiciones experimentales.

Al caracterizar el biosensor utilizando voltamperometría cíclica se observa que hay un cambio en el potencial de reducción de Q (Figura 2.19), pues ahora el pico de reducción se observa en un potencial de $-0.400 \mathrm{~V}$ este desplazamiento de potencial es atribuido a la 


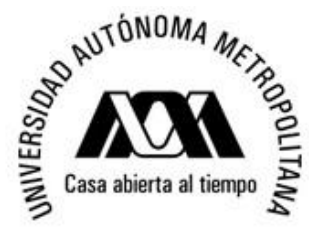

Universidad Autónoma Metropolitana Unidad Iztapalapa

División Ciencias Básicas e Ingeniería

Departamento de Química

Área de Química Analítica

Tesis de Doctorado

Q. Erika Rodríguez Sevilla

presencia de la albúmina en el sistema, pues al colocarla sobre el sensor forma un "capa" (Figura 2.20) que dificulta la interacción de la enzima con el sustrato como consecuencia no se observa un efecto catalítico por parte de la enzima. Tomando esto en consideración, la membrana se deja humectar durante 10 minutos, posteriormente se realiza la caracterización amperométrica imponiendo un potencial de $-0.300 \mathrm{~V}$ cambiando la concentración de HQ en el sistema cada 2 minutos (Figura 2.21).

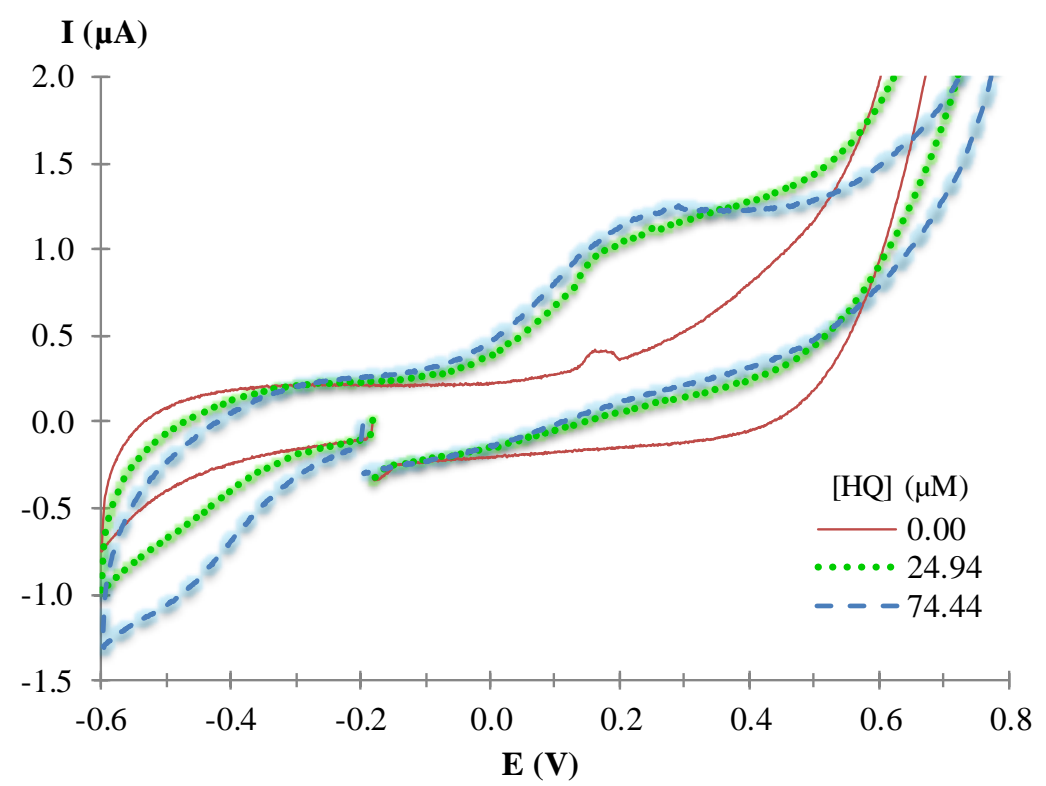

Figura 2.19. Voltamperometría cíclica de ESP/LTv/ASH/GA 2.5\%, a diferentes concentraciones de hidroquinona (HQ), partiendo del potencial de equilibrio hacia reducción, a una velocidad de barrido de 100 $\mathrm{mVs}^{-1}$, en amortiguador de acetatos $0.1 \mathrm{M}$ a pH $4.70 \pm 0.01$ y $(30.0 \pm 0.5)^{\circ} \mathrm{C}$.

$\mathrm{Al}$ inmovilizar LTv mediante el método de reticulado utilizando albúmina de suero humano, ASH, y glutaraldehído al 2.5\% como reticulante (biosensor ESP/LTv/ASH/GA 2.5\%) la cinética enzimática muestra un comportamiento sigmoidal (Figura 2.22), con una constante de Michaelis-Menten aparente de $(367 \pm 6) \mu \mathrm{M}$, una corriente máxima de $(7.9 \pm 0.1) \mu \mathrm{A}$ y un coeficiente de Hill de $1.8 \pm 0.5$, esto muestra que la cooperatividad del sistema es positiva sin embargo para este biosensor el intervalo lineal abarca concentraciones de $(26 \leq[\mathrm{HQ}] \leq$ 527) $\mu \mathrm{M}$ con un $\mathrm{R}^{2}=0.9960$ la sensibilidad es de $(11.1 \pm 0.7) n A \mu M^{-1}$, un $\mathrm{LOD}=(30 \pm 11)$ $\mu \mathrm{M}$ y un $L O Q=(101 \pm 35) \mu \mathrm{M}$, a pesar de tener una buena sensibilidad, los límites de 


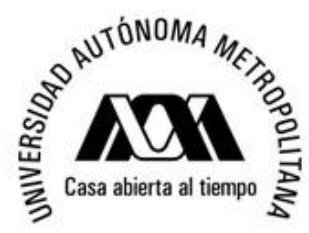

Universidad Autónoma Metropolitana Unidad Iztapalapa

División Ciencias Básicas e Ingeniería

Departamento de Química

Área de Química Analítica

Tesis de Doctorado

Q. Erika Rodríguez Sevilla

detección y cuantificación son altos debido a la interferencia de la albúmina sobre todo a bajas concentraciones de HQ (Figura 2.20, [HQ] < $200 \mu \mathrm{M}$ ).
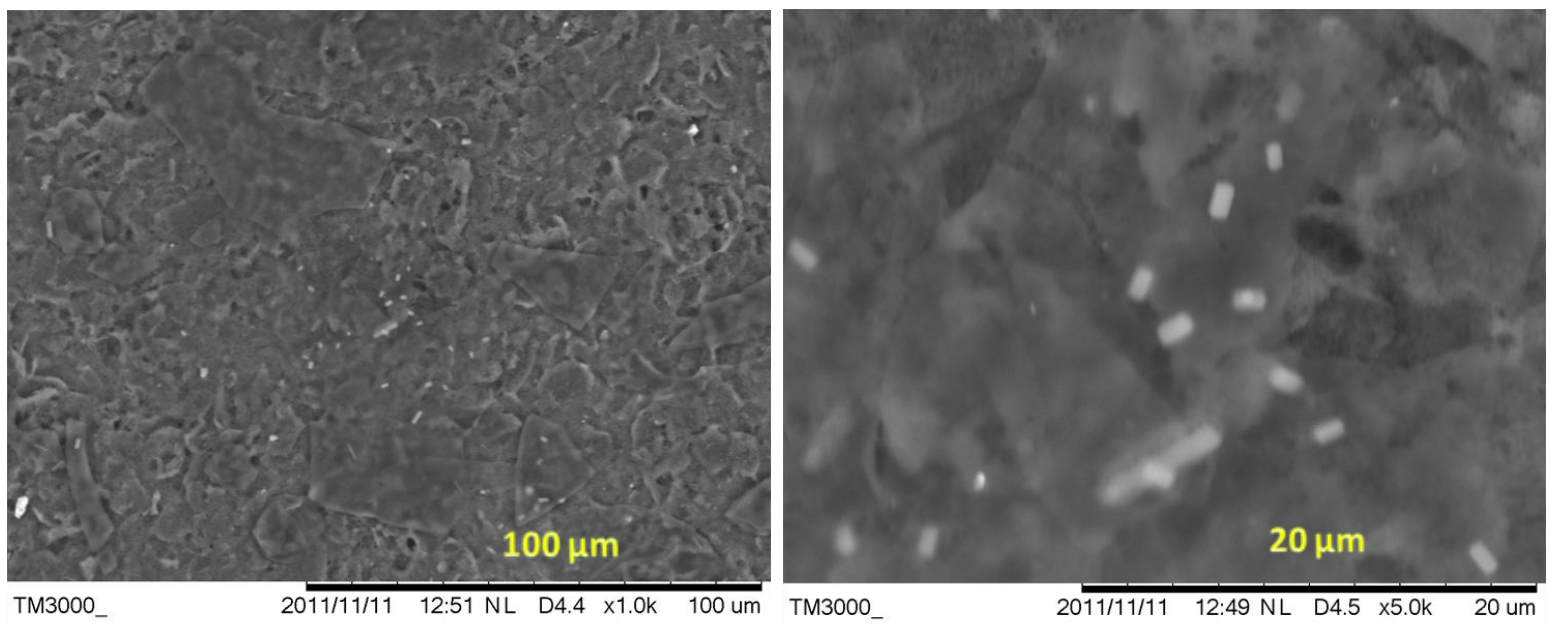

Figura 2.20. Microscopía electrónica de barrido del screen-printed modificado con laccasa mediante reticulado (ESP/LTv/ASH/GA),

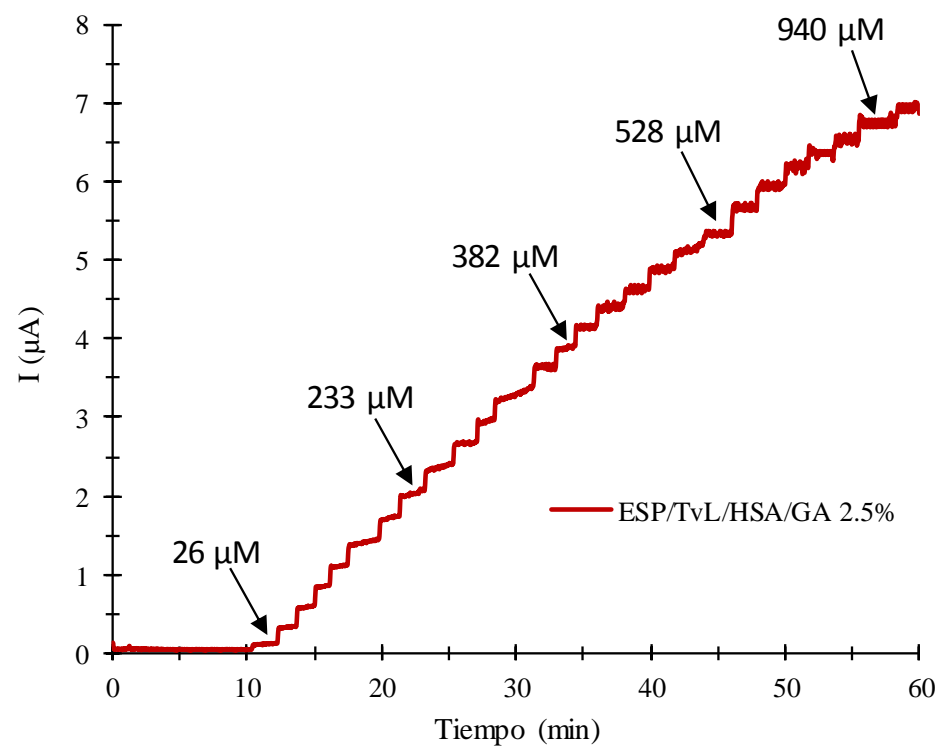

Figura 2.21. Amperometría de ESP/LTv/ASH/GA 2.5\%, a diferentes concentraciones de hidroquinona (HQ), en amortiguador de acetatos $0.1 \mathrm{M}$ a pH $4.70 \pm 0.01$, a $(30.0 \pm 0.5){ }^{\circ} \mathrm{C}$, con un potencial impuesto de $-0.3 \mathrm{~V}$. 


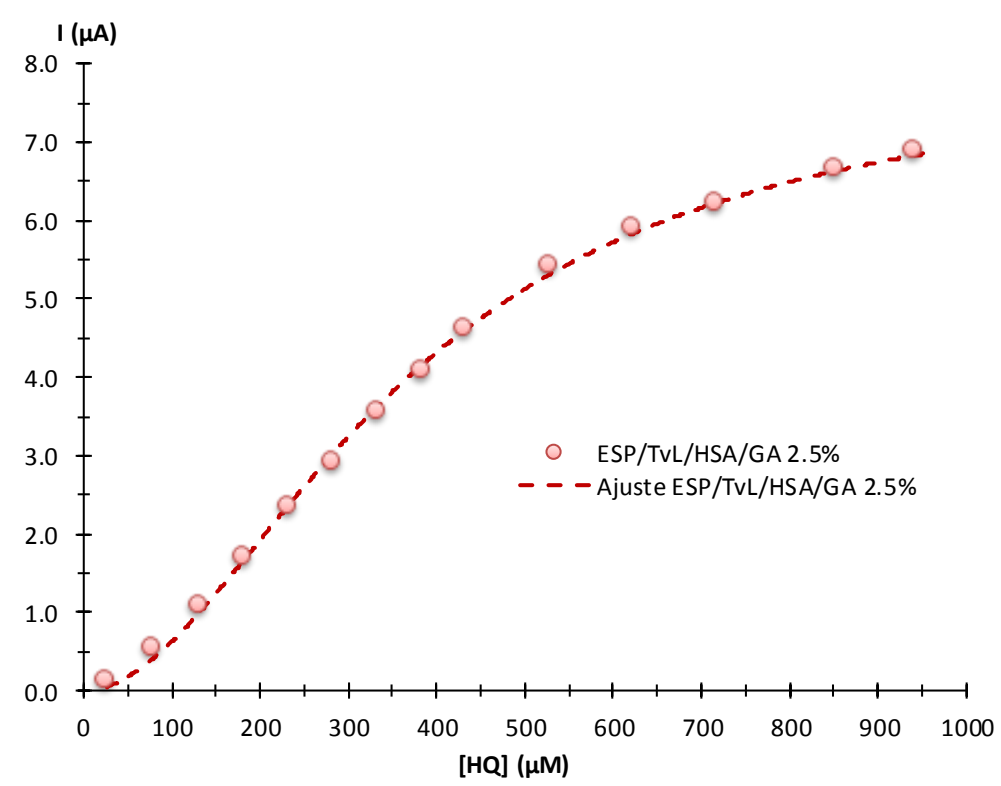

Figura 2.22. Comparación experimental (marcadores) registrados en el sistema laccasa de Trametes versicolor inmovilizada mediante reticulado (biosensor ESP/ LTv/ASH/GA 2.5\% en amortiguador de acetatos $0.1 \mathrm{M} \mathrm{a}$ $\mathrm{pH} 4.70 \pm 0.01 \mathrm{a}(30.0 \pm 0.5)^{\circ} \mathrm{C}$. Seguida por la corriente medida a $-300 \mathrm{mV}$ de potencial impuesto como función de la concentración de HQ, la línea es el ajuste obtenido mediante el modelo de Hill usando los valores de $K_{m}^{\prime}, I_{\max }$ y $h$ reportados en la Tabla 2.1.

El incremento en el valor de la constante de Michaelis-Menten indica que hay una pérdida en la actividad enzimática de LTv, esto debido a que los sitios activos de la enzima no se encuentran expuestos de manera adecuada, en la Figura 2.20 se observa que parte de la membrana cristaliza lo cual puede deberse a la presencia de la albúmina lo cual afecta la transferencia de carga.

Para mejorar la interacción de LTv con HQ, se fabrica un nuevo biosensor disminuyendo la concentración de glutaraldehído, colocando una concentración de GA al 1.0\% se construye el biosensor ESP/LTv/ASH/GA 1.0\%, al caracterizar mediante voltamperometría cíclica se observa que el potencial de equilibrio sufre un desplazamiento hacia potenciales negativos, la reducción de Q a HQ se observa ahora a $-0.450 \mathrm{~V}$ (Figura 2.23), no es posible observar el 


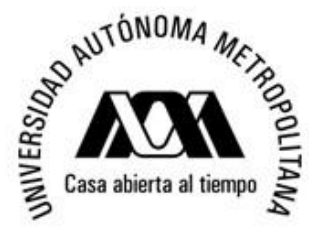

Universidad Autónoma Metropolitana Unidad Iztapalapa

División Ciencias Básicas e Ingeniería

Departamento de Química

Área de Química Analítica

Tesis de Doctorado

Q. Erika Rodríguez Sevilla

efecto catalítico de la enzima, ni tampoco la reducción de Q como un pico definido, al invertir el barrido de potencial hacia valores positivos se observa la oxidación de HQ a Q en un potencial de $0.350 \mathrm{~V}$. para este sistema no se observan picos de reducción y oxidación definidos lo cual es un indicativo de que el sistema ha perdido reversibilidad.

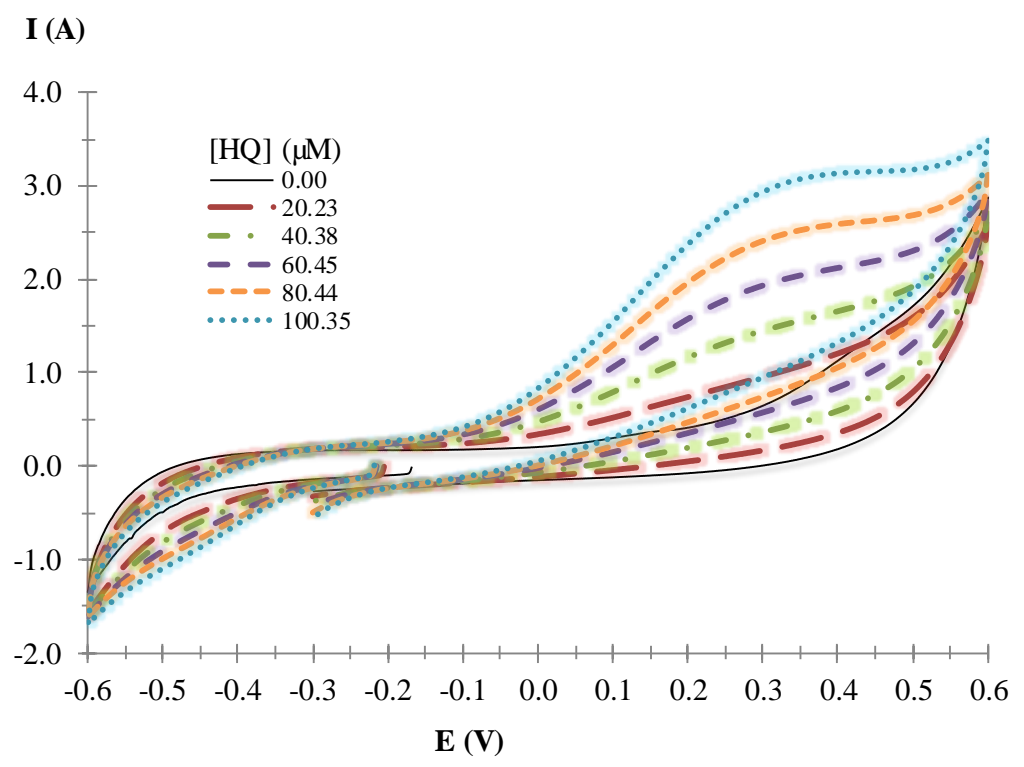

Figura 2.23. Voltamperometría cíclica de ESP/LTv/ASH/GA 1.0\%, a diferentes concentraciones de hidroquinona (HQ), partiendo del potencial de equilibrio hacia reducción, a una velocidad de barrido de 100 $\mathrm{mVs}^{-1}$, en amortiguador de acetatos $0.1 \mathrm{M}$ a pH $4.70 \pm 0.01$ y $(30.0 \pm 0.5)^{\circ} \mathrm{C}$.

El tiempo de respuesta del biosensor es de 50 segundos y le toma solo un minuto llegar al equilibrio (Figura 2.24), si se impone un potencial mayor de $-0.400 \mathrm{~V}$ la membrana los sitios activos de la enzima son reducidos y por lo tanto la membrana polimérica sufre daños irreversibles, por esta razón se impone un potencial de $-0.300 \mathrm{~V}$ para la caracterización amperométrica, en ella se observa una cinética enzimática de tipo sigmoidal (Figura 2.25) con un comportamiento similar a la cinética de tipo Michaeliano con una cooperatividad positiva $(h=1.5 \pm 0.3)$. La $K_{m}$ ' es de $(439 \pm 6) \mu \mathrm{M}$, es mayor que al colocar GA al $2.5 \%$, esto se debe a que la red formada por el polímero puede ser demasiado abierta y se pierden unidades de LTv al contacto con la solución, la $K_{m}$, y la $I_{\max }=(4.9 \pm 0.4) \mu \mathrm{A}$, son un 


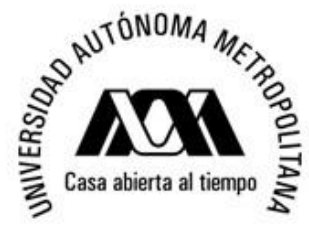

Universidad Autónoma Metropolitana Unidad Iztapalapa

División Ciencias Básicas e Ingeniería

Departamento de Química

Área de Química Analítica

Tesis de Doctorado

Q. Erika Rodríguez Sevilla

indicativo de que la concentración de la enzima ha cambiado al momento de la caracterización (ver sección 1.3.1.2.)

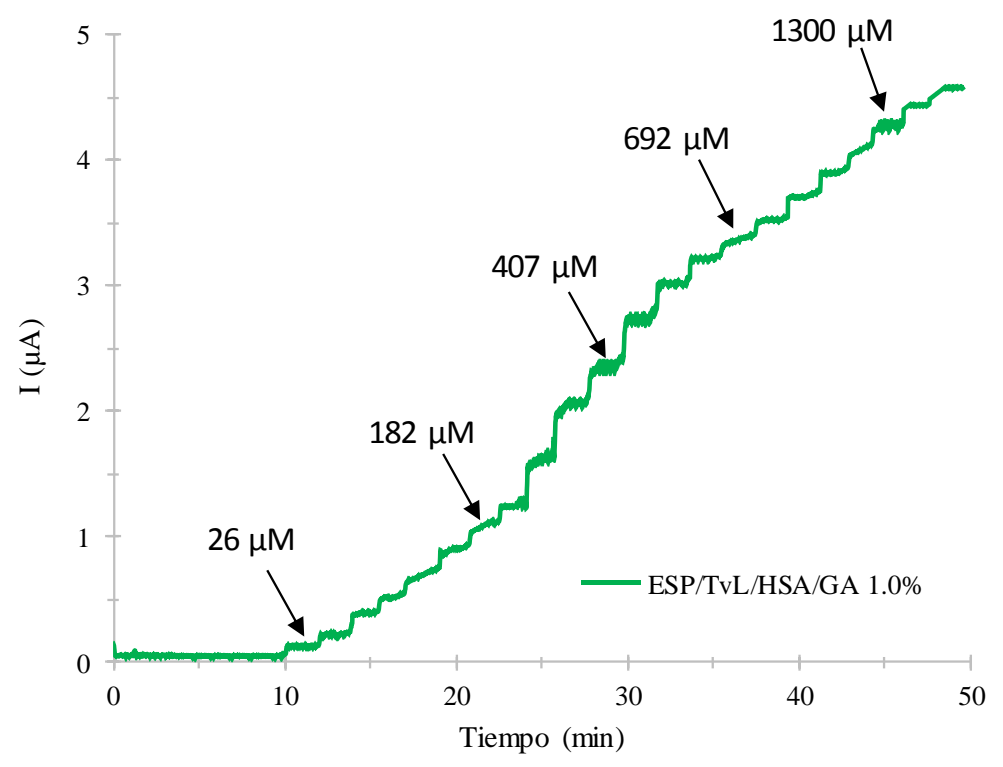

Figura 2.24. Amperometría de ESP/LTv/ASH/GA $1.0 \%$, a diferentes concentraciones de hidroquinona (HQ), en amortiguador de acetatos $0.1 \mathrm{M}$ a pH $4.70 \pm 0.01$, a $(30.0 \pm 0.5){ }^{\circ} \mathrm{C}$, con un potencial impuesto de $-0.3 \mathrm{~V}$.

Los parámetros analíticos obtenidos para el biosensor ESP/LTV/ASH/GA 1.0\% tampoco mejoran pues se obtiene una sensibilidad baja $\left((5.7 \pm 0.5) \mathrm{nA \mu M}^{-1}\right)$, un intervalo lineal de $(26 \leq[\mathrm{HQ}] \leq 504) \mu \mathrm{M}$, con un $\mathrm{R}^{2}=0.9952$, los límites de detección y cuantificación son (34 $\pm 13) \mu \mathrm{M}$ у $(113 \pm 39) \mu \mathrm{M}$ respectivamente; utilizando este método de inmovilización se obtienen parámetros cinéticos y analíticos mayores comparados con la inmovilización de LTv en los métodos anteriores. De acuerdo con Migneault y colaboradores [61] la pérdida en la actividad enzimática de LTv inmovilizada con GA se debe a la distorsión de la conformación de las enzimas y sus alteraciones durante el proceso de inmovilización debido a la presencia de albúmina [62] (ver Figura 2.18), a -0.300 V la corriente obtenida es pequeña pues a estas condiciones se ha reducido muy poco sustrato. 


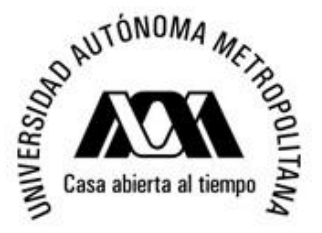

Universidad Autónoma Metropolitana Unidad Iztapalapa

División Ciencias Básicas e Ingeniería

Departamento de Química

Área de Química Analítica

Tesis de Doctorado

Q. Erika Rodríguez Sevilla

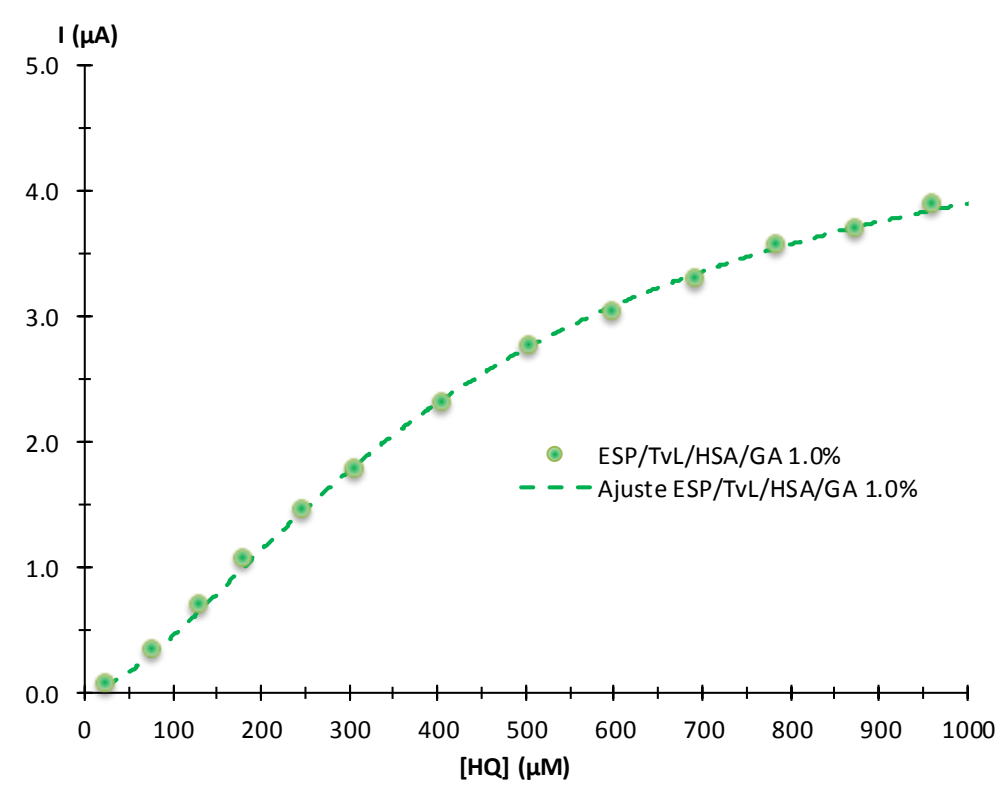

Figura 2.25. Comparación experimental (marcadores) registrados en el sistema laccasa de Trametes versicolor inmovilizada mediante reticulado (biosensor ESP/LTv/ASH/GA $1.0 \%$ en amortiguador de acetatos $0.1 \mathrm{M} \mathrm{a} \mathrm{pH}$ $4.70 \pm 0.01$ a $(30.0 \pm 0.5){ }^{\circ} \mathrm{C}$. Seguida por la corriente medida a $-300 \mathrm{mV}$ de potencial impuesto como función de la concentración de HQ, la línea es el ajuste obtenido mediante el modelo de Hill usando los valores de $K_{m}^{\prime}, I_{\max }$ y $h$ reportados en la Tabla 2.1.

\subsubsection{Biosensor de laccasa con glutaraldehído termocurado a $40^{\circ} \mathrm{C}$}

El biosensor ESP/LTv/GA 2.5\% se caracteriza mediante voltamperometría cíclica partiendo de un potencial de $0.0 \mathrm{~V}$ hacia reducción (Figura 2.26), en este primer segmento se observa la reducción de Q a HQ a un potencial de $-0.300 \mathrm{~V}$ el efecto catalítico de la enzima se observa desde este potencial hasta $-0.500 \mathrm{~V}$, a partir de $-0.500 \mathrm{~V}$ la membrana del biosensor se reduce dañando de esta forma la membrana polimérica. Como se mencionó anteriormente cuando la enzima se inmoviliza utilizando glutaraldehído, se pierde parte de su conformación por lo que ahora sufre también procesos de reducción a partir de $-0.500 \mathrm{~V}$. Al invertir el barrido de potencial hacia oxidación hasta un valor de $0.800 \mathrm{~V}$ se observa la oxidación de HQ a un potencial de $0.250 \mathrm{~V}$. 
División Ciencias Básicas e Ingeniería

Departamento de Química

Área de Química Analítica

Tesis de Doctorado

Q. Erika Rodríguez Sevilla

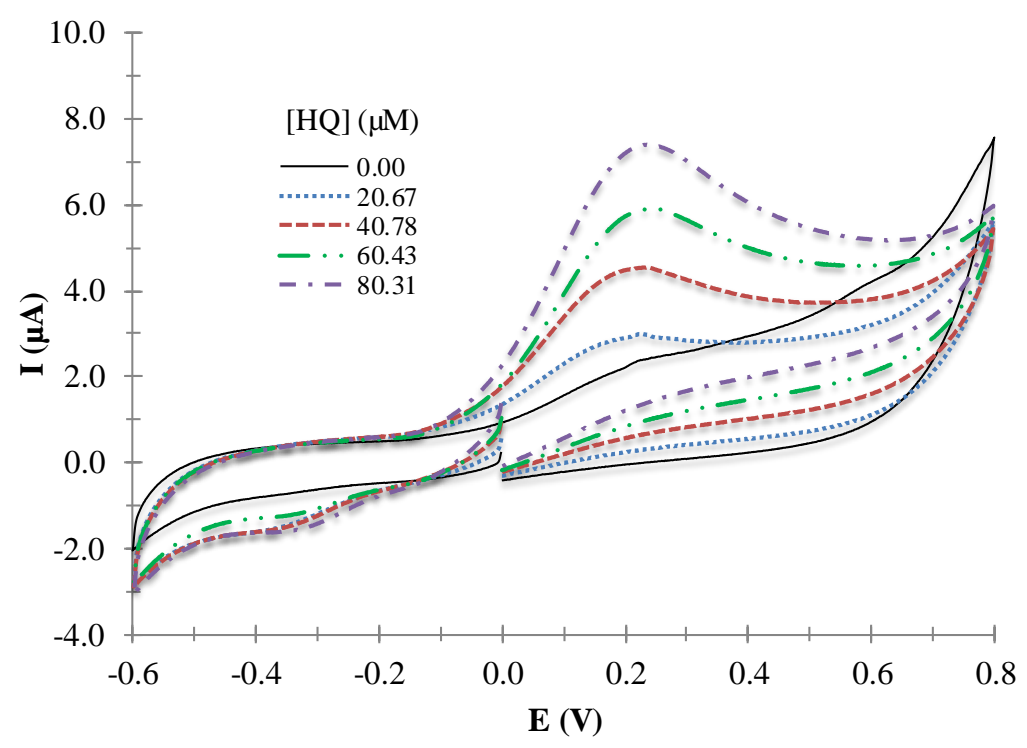

Figura 2.26. Voltamperometría cíclica de ESP/LTv/GA 2.5\%, a diferentes concentraciones de hidroquinona (HQ), partiendo del potencial de corriente nula hacia reducción, a una velocidad de barrido de $100 \mathrm{mVs}^{-1}$, en amortiguador de acetatos $0.1 \mathrm{M}$ a pH $4.70 \pm 0.01$ y $(30.0 \pm 0.5){ }^{\circ} \mathrm{C}$.

Partiendo de los resultados anteriores se impone un potencial de $-0.300 \mathrm{~V}$ y se lleva a cabo la caracterización amperométrica sumergiendo el biosensor ESP/LTv/GA 2.5\% en $10 \mathrm{~mL}$ de amortiguador de acetatos $0.1 \mathrm{M} \mathrm{a} \mathrm{pH} 4.7 \pm 0.1$ a $(30.0 \pm 0.5){ }^{\circ} \mathrm{C}$ (Figura 2.27), a bajas concentraciones de $\mathrm{HQ}$, le toma más tiempo al sensor llegar a el equilibrio, cuando la concentración sobrepasa los $250 \mu \mathrm{M}$, el biosensor responde en un tiempo de 30 segundos y llega al equilibrio en 1 minuto.

El hecho de prescindir de la albúmina y elaborar el biosensor mediante el termocurado de GA, provee a la enzima una mejor eficiencia catalítica; al utilizar una concentración de GA de $2.5 \%$, la red polimérica formada es similar a la que se obtiene al inmovilizar mediante el método de reticulado (Figura 2.28). Las propiedades obtenidas también son similares a las del biosensor elaborado con PVA pues expone de manera adecuada los sitios de la enzima generando de esta forma un biosensor con buenos parámetros cinéticos y analíticos para la 


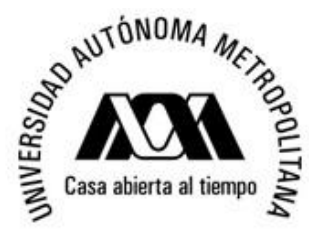

Universidad Autónoma Metropolitana Unidad Iztapalapa

División Ciencias Básicas e Ingeniería

Departamento de Química

Área de Química Analítica

Tesis de Doctorado

Q. Erika Rodríguez Sevilla

determinación de HQ. $\left(K_{m}{ }^{\prime}=(170 \pm 3) \mu \mathrm{M}, \mathrm{LDD}=(14 \pm 5) \mu \mathrm{M}, \mathrm{LDQ}=(48 \pm 17) \mu \mathrm{M}\right)$. La cinética enzimática obtenida es de tipo Michaeliano con una cooperatividad positiva (Figura 2.29) al fabricar el biosensor con este nuevo método de inmovilización se observa que los sitios activos de la enzima interactúan de manera directa con el sustrato, y por lo tanto no se daña la conformación de la enzima al inmovilizar de esta forma.

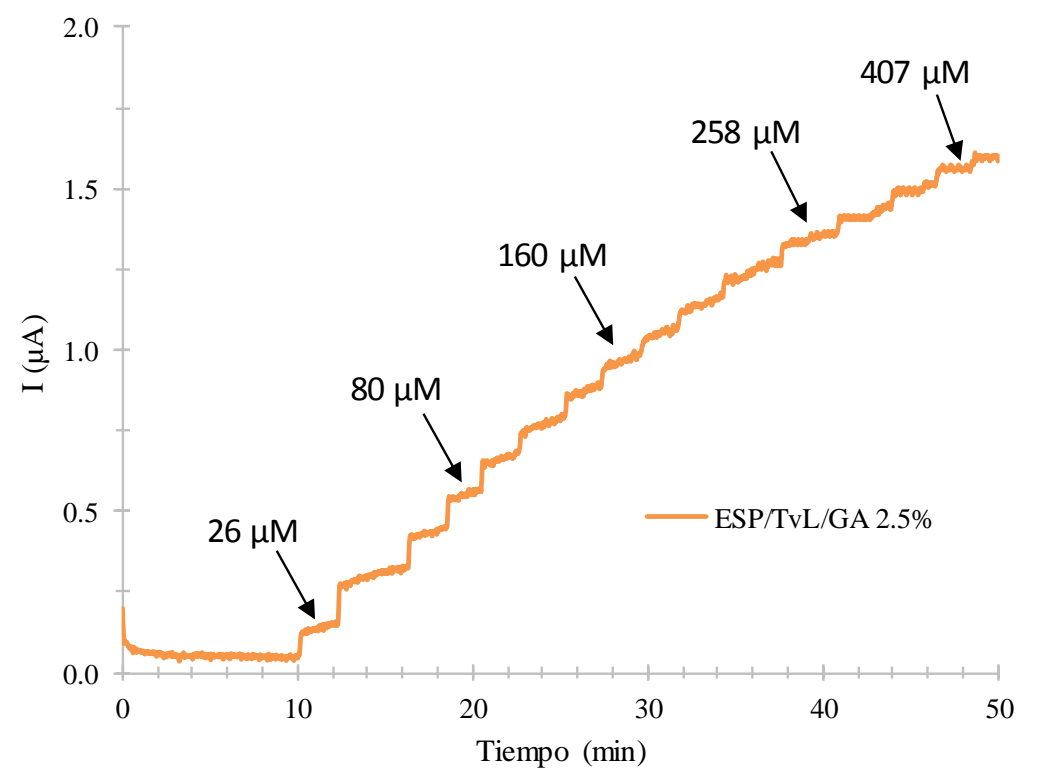

Figura 2.27. Amperometría de ESP/LTv/GA $2.5 \%$, a diferentes concentraciones de hidroquinona (HQ), en amortiguador de acetatos $0.1 \mathrm{M}$ a pH $4.70 \pm 0.01$, a $(30.0 \pm 0.5){ }^{\circ} \mathrm{C}$, con un potencial impuesto de $-0.3 \mathrm{~V}$.

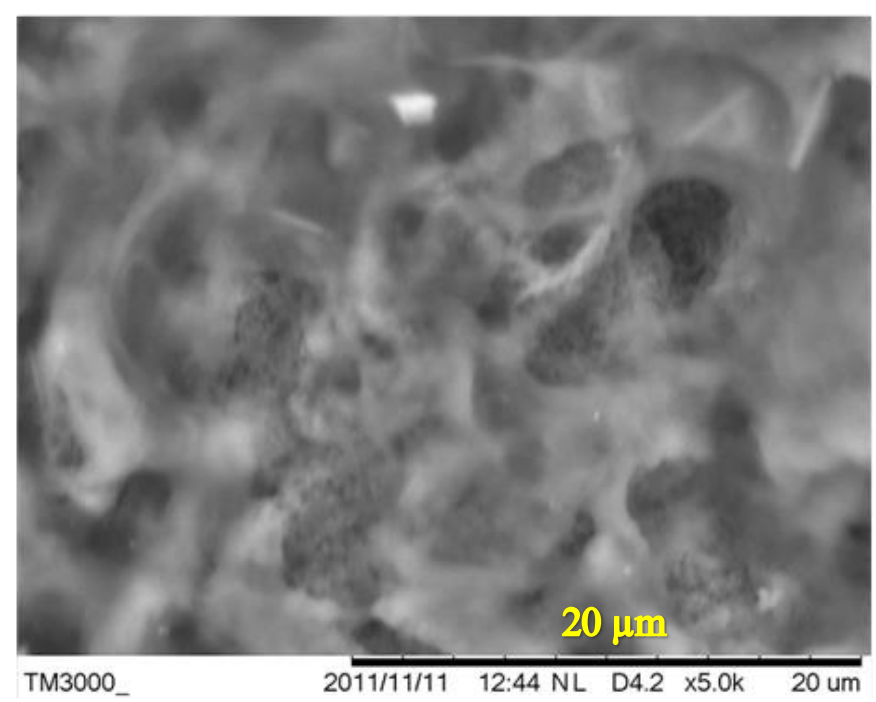

Figura 2.28. Microscopía electrónica de barrido del electrodo screen-printed modificado con laccasa mediante reticulado (ESP/LTv/GA 2.5\%), 


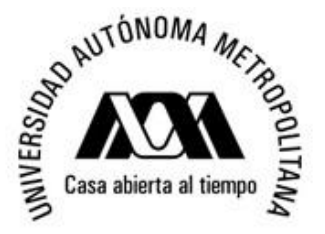

Universidad Autónoma Metropolitana Unidad Iztapalapa

División Ciencias Básicas e Ingeniería

Departamento de Química

Área de Química Analítica

Tesis de Doctorado

Q. Erika Rodríguez Sevilla

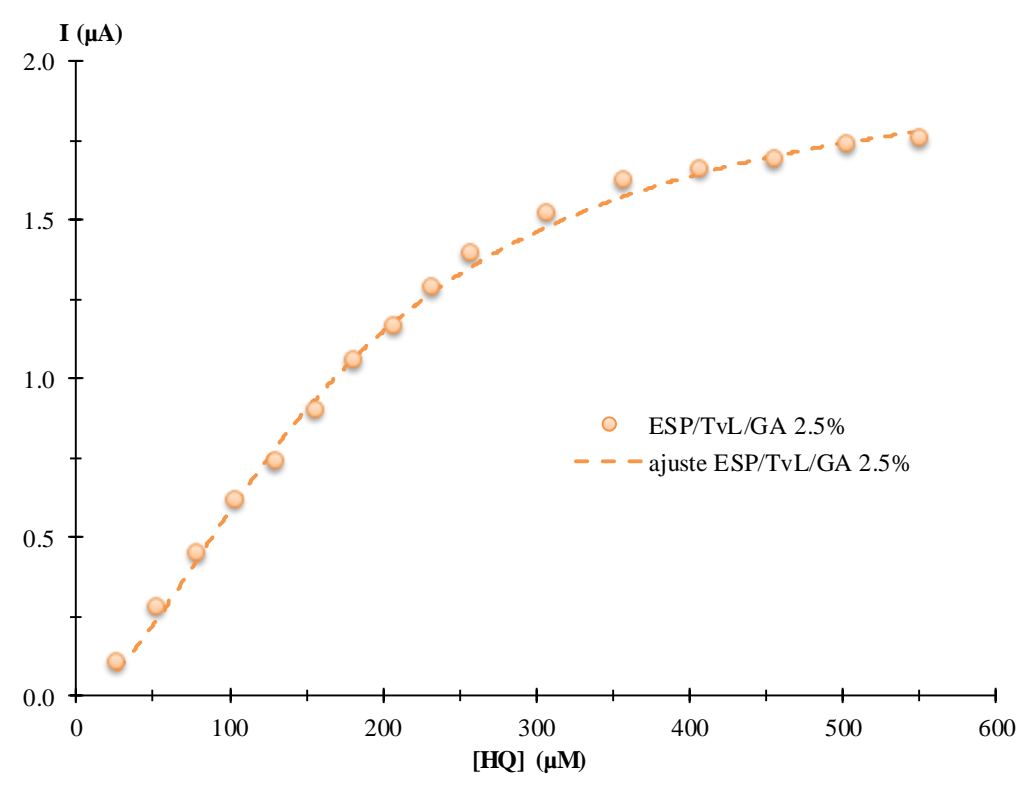

Figura 2.29. Cinética enzimática descrita por el biosensor ESP/ LTv/GA 2.5\%, en amortiguador de acetatos $0.1 \mathrm{M}$ a pH $4.70 \pm 0.01 \mathrm{a}(30.0 \pm 0.5){ }^{\circ} \mathrm{C}$. a $-300 \mathrm{mV}$ de potencial impuesto, la línea es el ajuste obtenido mediante el modelo de Hill usando los valores de $K_{m}{ }^{\prime}, I_{\max }$ y $h$ reportados en la Tabla 2.1.

Cuando se cambia la concentración de GA en el proceso de fabricación del biosensor, el potencial de equilibrio del sistema se encuentra ahora en $-0.230 \mathrm{~V}$, la reducción de $\mathrm{Q}$ se observa a cantidades elevadas de sustrato, el efecto catalítico de la enzima en el sistema no se observa (Figura 2.30) esto es un indicativo de que la velocidad de la reacción electroquímica es afectada durante el proceso de inmovilización.

Imponiendo un potencial de $-0.300 \mathrm{~V}$ se evalúa el cambio en la corriente en el biosensor para diferentes concentraciones de HQ, se toman 10 minutos para estabilizar la corriente inicial del electrodo (Figura 2.31), a concentraciones bajas de HQ el tiempo de respuesta del biosensor es de 12 segundos, pero le toma más de dos minutos llegar al equilibrio, a concentraciones medias y altas de HQ el biosensor responde en un tiempo de 28 segundos y le toma 55 segundos llegar al equilibrio. 
División Ciencias Básicas e Ingeniería

Departamento de Química

Área de Química Analítica

Tesis de Doctorado

Q. Erika Rodríguez Sevilla

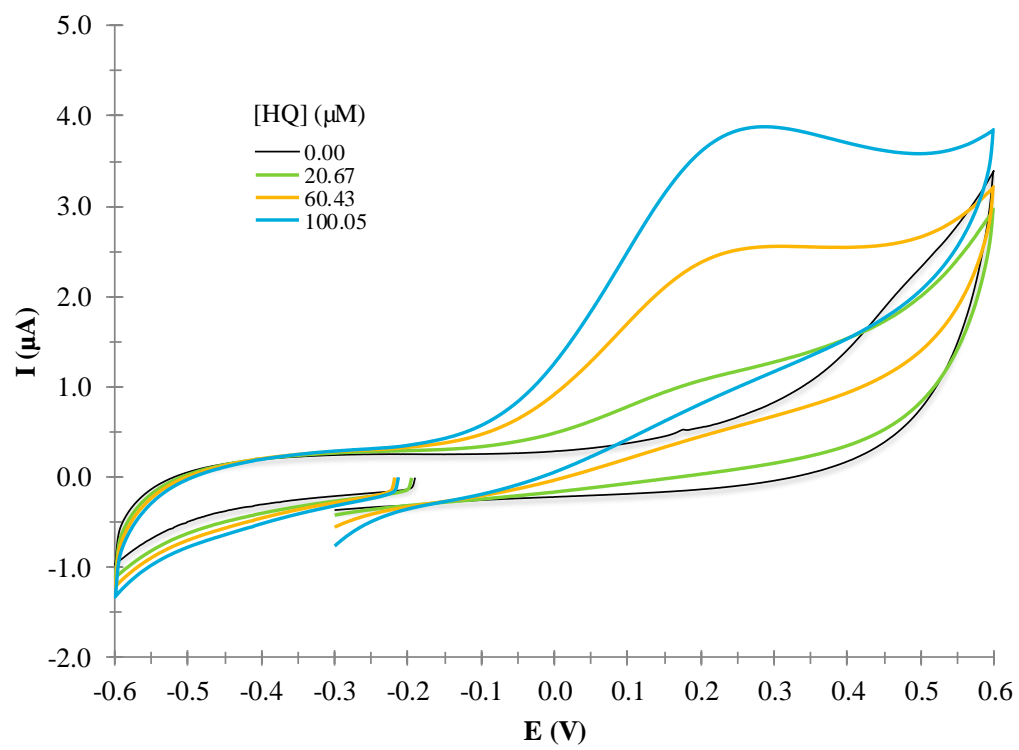

Figura 2.30. Voltamperometría cíclica de ESP/LTv/GA 1.0\%, a diferentes concentraciones de hidroquinona, partiendo del potencial de equilibrio hacia reducción, a una velocidad de barrido de $100 \mathrm{mVs}^{-1}$, en amortiguador de acetatos $0.1 \mathrm{M}$ a pH $4.70 \pm 0.01 \mathrm{y}(30.0 \pm 0.5){ }^{\circ} \mathrm{C}$.

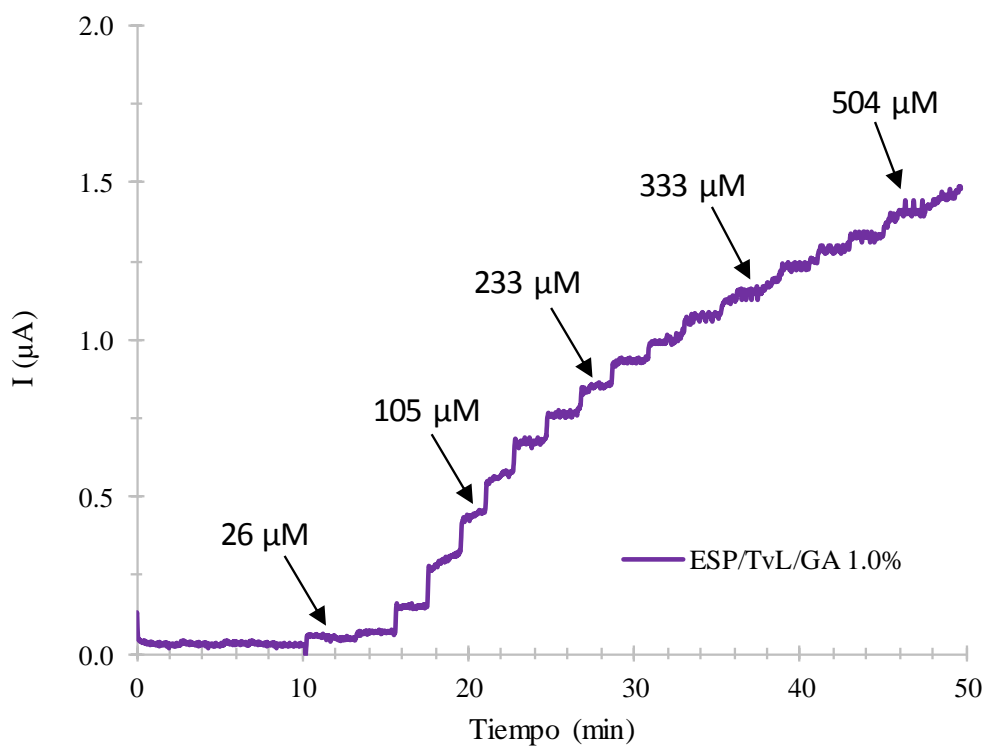

Figura 2.31. Amperometría de ESP/LTv/GA $1.0 \%$, a diferentes concentraciones de hidroquinona (HQ), en amortiguador de acetatos $0.1 \mathrm{M}$ a pH $4.70 \pm 0.01$, a $(30.0 \pm 0.5){ }^{\circ} \mathrm{C}$, con un potencial impuesto de $-0.3 \mathrm{~V}$. 


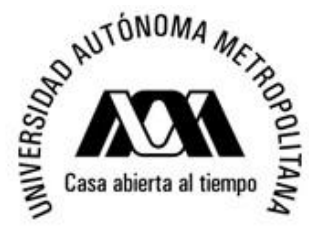

Universidad Autónoma Metropolitana Unidad Iztapalapa

División Ciencias Básicas e Ingeniería

Departamento de Química

Área de Química Analítica

Tesis de Doctorado

Q. Erika Rodríguez Sevilla

La dependencia de la corriente con respecto a la concentración de HQ permite evaluar el comportamiento cinético de la enzima en el biosensor (Figura 2.31), al disminuir la concentración de GA al 1.0\%, hay una pérdida en la eficiencia catalítica por parte de LTv, con respecto a ESP/LTv/GA 2.5\%, esta pérdida se refleja en la baja sensibilidad (4.5 \pm 0.4$)$ $\mathrm{nA} \mu \mathrm{M}^{-1} \mathrm{y}$ los altos límites de detección y cuantificación $(\mathrm{LDD}=(17 \pm 6) \mu \mathrm{M}, \mathrm{LDQ}=(56 \pm$ 20) $\mu \mathrm{M})$, sin embargo es mejor aún que la inmovilización mediante atrapamiento y reticulado con albúmina (ver secciones 2.6.1. y 2.6.2.).

La corriente presenta un decremento conforme aumenta la concentración de HQ, esto es atribuido a la conformación de la red la cual puede quedar con intersticios relativamente grandes (Figura 2.32), por lo tanto al disminuir la $[E]$ en el sensor disminuye la corriente de respuesta para el biosensor, esto repercute en los parámetros analíticos del biosensor.

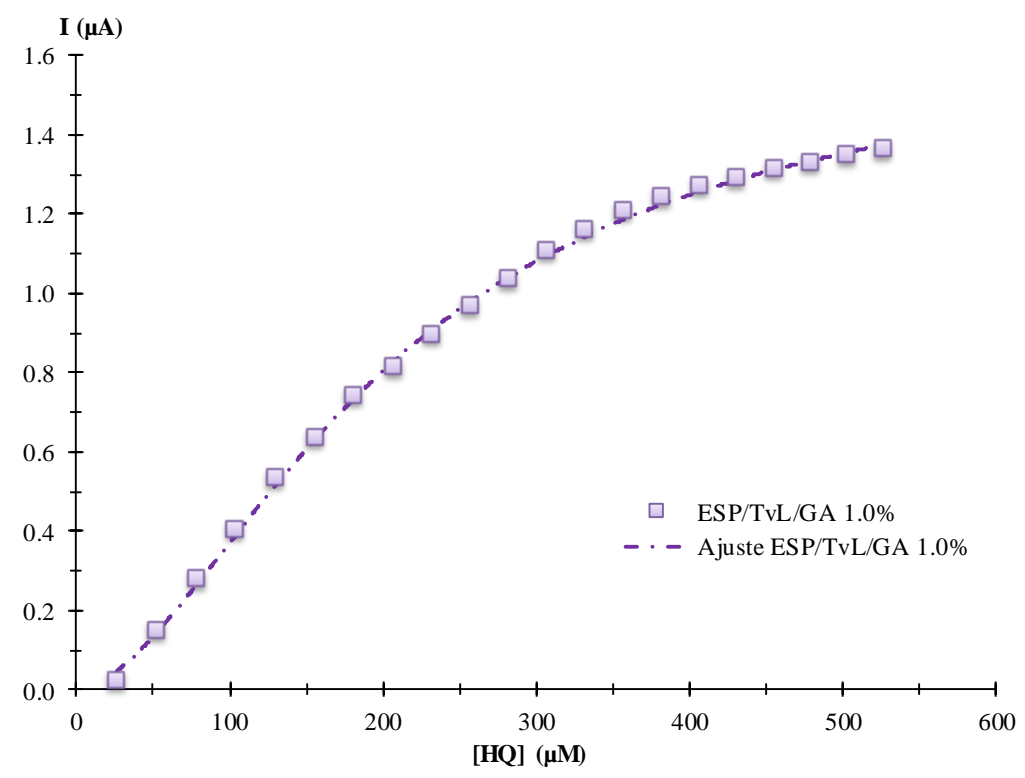

Figura 2.31. Comportamiento cinético del biosensor ESP/ LTv/GA 1.0\%, caracterizado en amortiguador de acetatos $0.1 \mathrm{M}$ a pH $4.70 \pm 0.01$ a $(30.0 \pm 0.5){ }^{\circ} \mathrm{C}$. Seguida por la corriente medida a $-300 \mathrm{mV}$ de potencial impuesto como función de la concentración de $\mathrm{HQ}$, la línea es el ajuste obtenido mediante el modelo de Hill usando los valores de $K_{m}{ }^{\prime}, I_{\max }$ y $h$ reportados en la Tabla 2.1. 


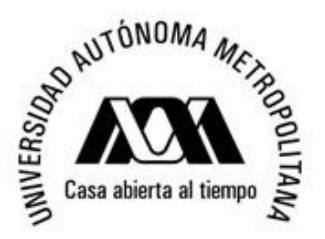

Universidad Autónoma Metropolitana Unidad Iztapalapa

División Ciencias Básicas e Ingeniería

Departamento de Química

Área de Química Analítica

Tesis de Doctorado

Q. Erika Rodríguez Sevilla

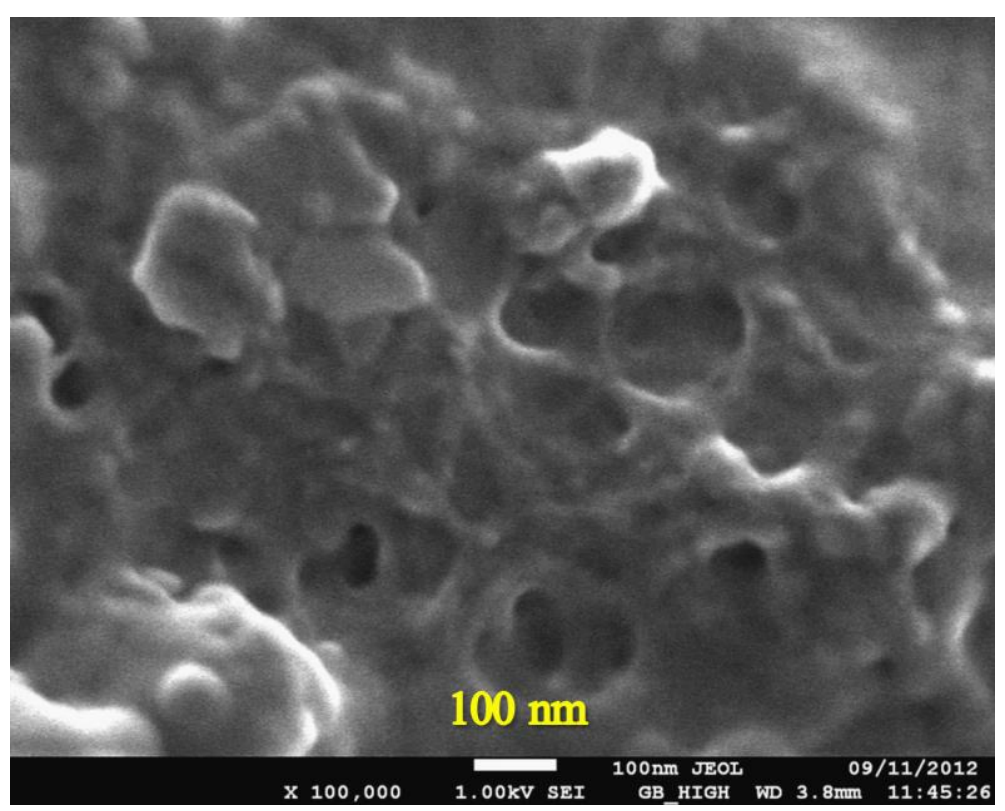

Figura 2.32. Microscopía electrónica de barrido del electrodo screen-printed modificado con laccasa mediante reticulado (ESP/LTv/GA 2.5\%),

\subsubsection{Biosensor de laccasa con EDC, y sulfo-NHS}

Mediante voltamperometría cíclica se evalúa el efecto de la membrana polimérica en el potencial de reducción de $\mathrm{Q}$ así como el potencial de oxidación de $\mathrm{HQ}$, partiendo de un potencial de corriente nula hacia reducción, en este intervalo se observa la reducción de Q a HQ a un potencial de $-0.300 \mathrm{~V}$, en este caso el efecto catalítico de la enzima no puede observarse en esta caracterización a potenciales menores de $-0.450 \mathrm{~V}$, se observa un nuevo proceso de reducción atribuido a algunos grupos enzimáticos (Figura 2.33) . Al invertir el barrido de potencial hacia valores positivos se observa a un potencial de $0.200 \mathrm{~V}$ el sistema sufre un desplazamiento tanto en el potencial de reducción como de oxidación hacia valores mayores al incrementar la concentración de HQ en el sistema. 
División Ciencias Básicas e Ingeniería

Departamento de Química

Área de Química Analítica

Tesis de Doctorado

Q. Erika Rodríguez Sevilla

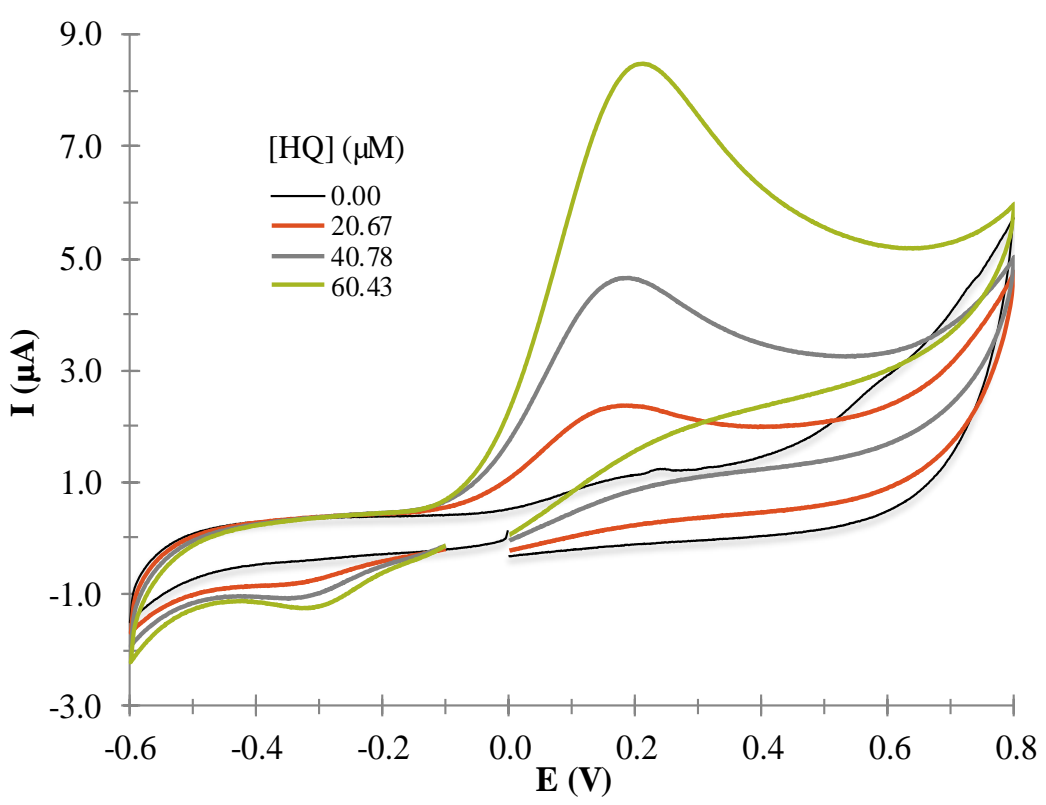

Figura 2.33. Voltamperometría cíclica de ESP/LTv/EDC, a diferentes [HQ], partiendo del potencial de corriente nula hacia reducción, a una $v=100 \mathrm{mVs}^{-1}$, en amortiguador de acetatos $0.1 \mathrm{M} \mathrm{a} \mathrm{pH} 4.70 \pm 0.01 \mathrm{y}$ $(30.0 \pm 0.5){ }^{\circ} \mathrm{C}$.

Imponiendo un valor de $-0.300 \mathrm{~V}$ se evalúa la respuesta amperométrica del biosensor (Figura 2.34), la membrana se acondiciona durante 10 minutos, posteriormente se cambia la concentración de HQ en el sistema cada dos minutos. El tiempo de respuesta para el biosensor es de 12 segundos, y le toma 70 segundos en promedio en llegar al equilibrio, a concentraciones de HQ mayores de $260 \mu \mathrm{M}$ se observa la presencia de interferentes en la respuesta del biosensor, pues la corriente medida es inestable, esto se debe a que al reaccionar la enzima con el sustrato se obtiene un precipitado (Figura 2.35) el cual se queda depositado sobre la superficie del electrodo de trabajo y afecta la reacción enzimática. 

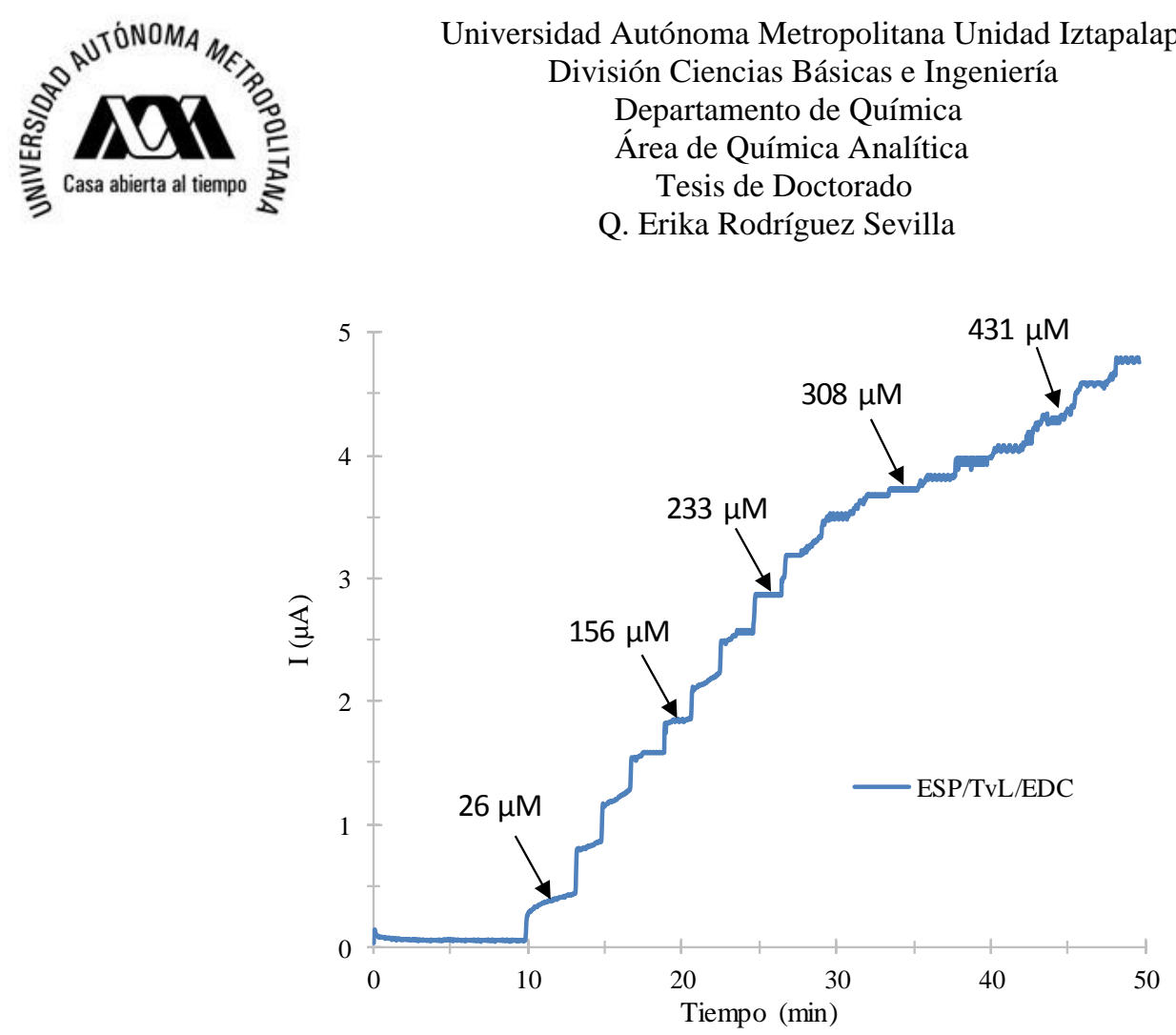

Figura 2.34. Amperometría de ESP/LTv/EDC, a diferentes concentraciones de HQ, en amortiguador de acetatos $0.1 \mathrm{M}$ a pH $4.70 \pm 0.01$, a $(30.0 \pm 0.5)^{\circ} \mathrm{C}$, con un potencial impuesto de $-0.3 \mathrm{~V}$.
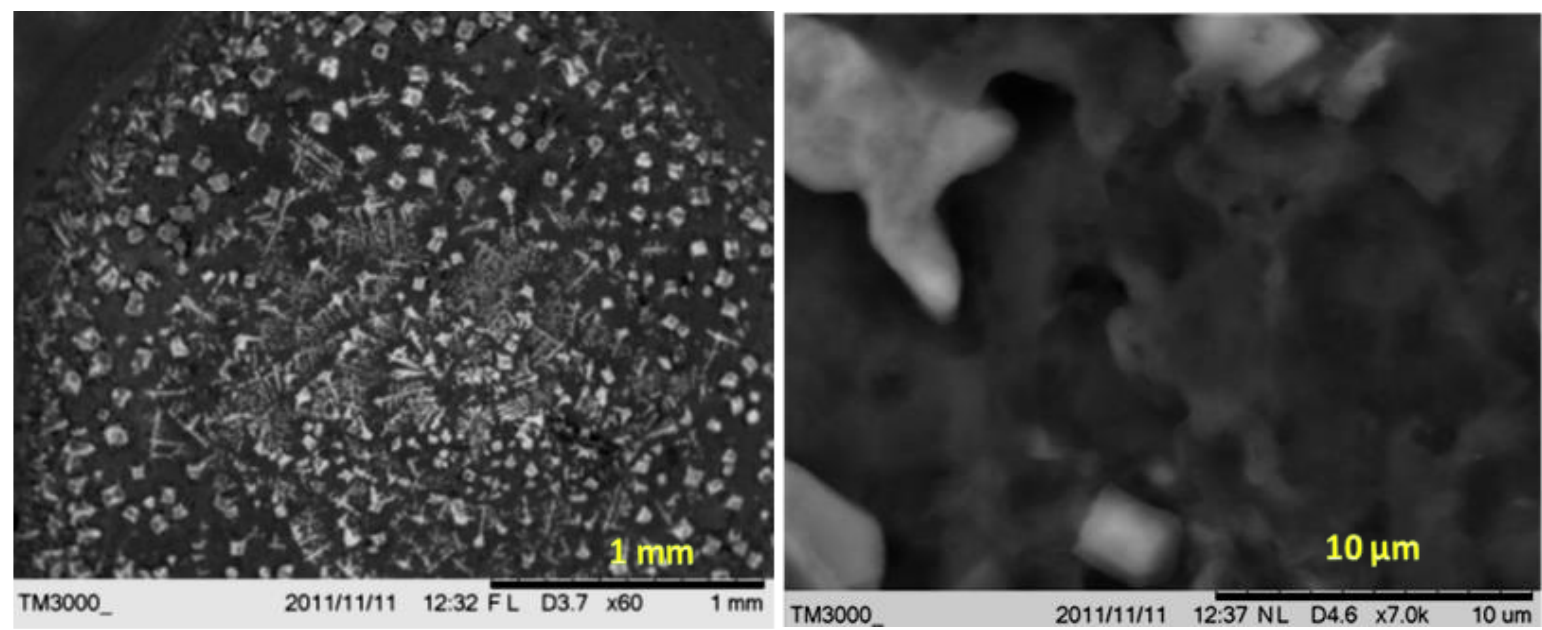

Figura 2.35. Microscopía electrónica de barrido del ESP modificado con laccasa mediante enlace covalente (ESP/LTv/EDC).

Cuando LTv se inmoviliza mediante unión covalente se genera una actividad enzimática mejorada, con $K_{m}^{\prime}=(192 \pm 6) \mathrm{M}$, la cinética descrita se ajusta a los modelos de Michaelis- 


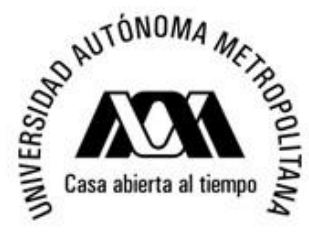
Universidad Autónoma Metropolitana Unidad Iztapalapa
División Ciencias Básicas e Ingeniería
Departamento de Química
Área de Química Analítica
Tesis de Doctorado
Q. Erika Rodríguez Sevilla

Menten y Hill y muestra una cooperatividad positiva [3] entre la enzima y su sustrato (Figura 2.33). Una de las desventajas del método de unión covalente es la solubilidad del sistema una vez que la enzima y el sustrato han interactuado, a pesar de ello se obtiene un límite de detección de $(23 \pm 8) \mu \mathrm{M}$, límite de cuantificación de $(78 \pm 27) \mu \mathrm{M}$, un intervalo lineal de $(26 \leq[\mathrm{HQ}] \leq 333) \mu \mathrm{M}\left(\mathrm{R}^{2}=0.9938\right)$ y una sensibilidad de $(12.2 \pm 0.8) \mathrm{nA}_{\mu} \mathrm{M}^{-1}$, de acuerdo con estos resultados la inmovilización de enzimas mediante el método de enlace covalente genera buenos biosensores sin embargo no son reutilizables.

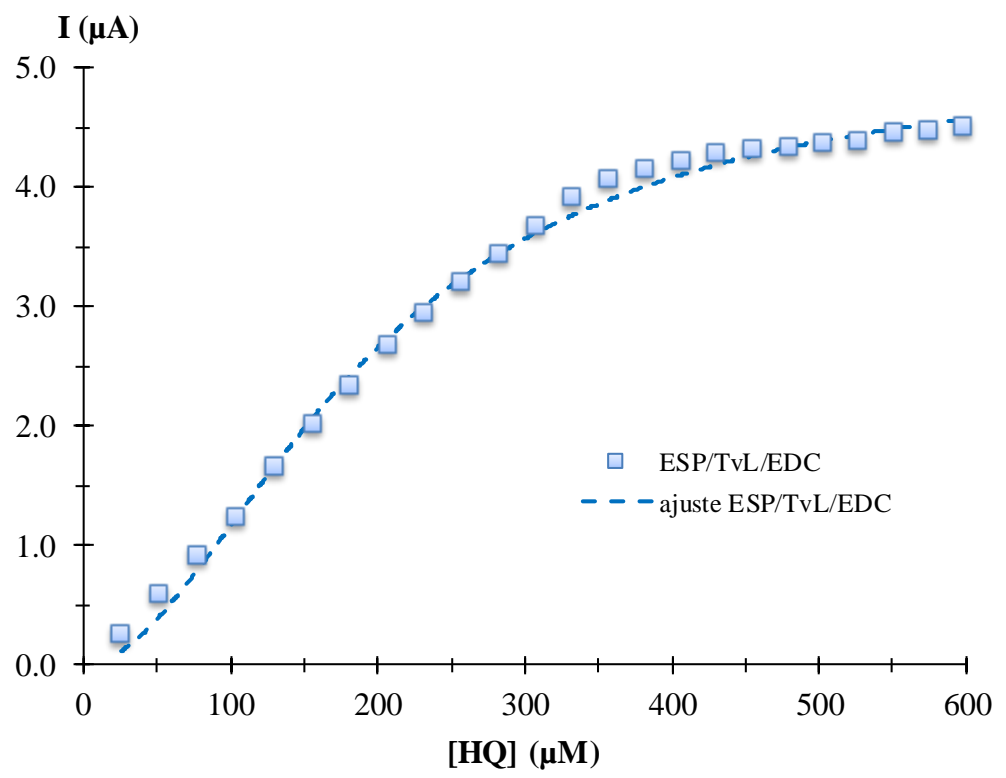

Figura 2.33. Cinética enzimática para el biosensor ESP/ LTv/EDC), caracterizado en amortiguador de acetatos $0.1 \mathrm{M}$ a pH $4.50 \pm 0.01 \mathrm{a}(30.0 \pm 0.5){ }^{\circ} \mathrm{C}$. Seguida por la corriente medida a $-300 \mathrm{mV}$ de potencial impuesto como función de la concentración de $\mathrm{HQ}$, la línea es el ajuste obtenido mediante el modelo de Hill usando los valores de $K_{m}{ }^{\prime}, I_{\max }$ y $h$ reportados en la Tabla 2.1.

\subsection{Comparación de métodos de inmovilización}

Todos los biosensores con caracterizados amperométricamente imponiendo un potencial de $-0.300 \mathrm{~V}$; si se impusiera un potencial menor podrían tenerse falsos positivos como resultados 


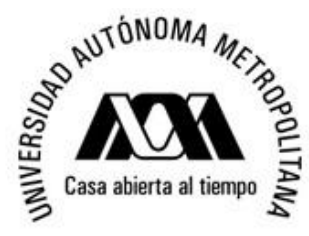

Universidad Autónoma Metropolitana Unidad Iztapalapa
División Ciencias Básicas e Ingeniería
Departamento de Química
Área de Química Analítica
Tesis de Doctorado
Q. Erika Rodríguez Sevilla

en la determinación de muestras reales debido a que a este valor de potencial se reduce una gran cantidad de especies electroquímicas.

La Tabla 2.1 muestra la comparación de los parámetros cinéticos y analíticos de cada uno de los biosensores fabricados utilizando laccasa de Trametes versicolor (LTv), los menores límites de detección y cuantificación, la menor $K_{m}$ ' así como el menor coeficiente de Hill se obtienen para el biosensor ESP/LTv/GA 2.5\%, la inmovilización mediante atrapamiento es considerado el segundo mejor método de inmovilización para LTv, seguida por la inmovilización mediante enlace covalente, el cual es un buen método de inmovilización si se utiliza en condiciones a las cuales aún no ha cristalizado la membrana.

Como se planteó al inicio de este capítulo, la inmovilización de la enzima afecta la $K_{m}$ 'así como los límites de cuantificación y detección, así como el tiempo de vida del sensor, de esta forma es posible concluir que para laccasa de Trametes versicolor, el mejor método de inmovilización es el co-reticulado, atrapamiento, enlace covalente y finalmente reticulado, generando biosensores con una alta actividad enzimática, bajo costo y fácil fabricación. La Tabla 2.2 muestra el valor de las constantes de velocidad de formación del producto $k_{2} \mathrm{o}$ también conocida como $k_{\text {catalítica }}\left(k_{c a t}\right)$, la cual se obtiene mediante la velocidad máxima y la concentración total de la enzima (ver anexo 2) y es un indicativo de la efectividad de transformación del complejo enzima-sustrato en el producto de la reacción. La eficiencia catalítica de la enzima cambia con cada método de inmovilización, con esto queda demostrada que la inmovilización de la enzima tiene un impacto directo en la constante de Michaelis-Menten aparente y como consecuencia en los parámetros analíticos del biosensor.

En la actualidad existen diversos métodos y técnicas de inmovilización de laccasa de Trametes versicolor [63], para diversas aplicaciones [64], y se han evaluado diversos métodos de inmovilización de esta enzima sobre diferentes superficies [65, 66, 67, 68], es por ello que esta investigación aporta una base para la inmovilización de laccasa en electrodos de tipo screen-printed, desarrollando dispositivos con buenos parámetros analíticos y de bajo costo comparado con otros biosensores [69, 70, 71]. 
Tabla 2.1. Parámetros analíticos de la laccasa de Trametes versicolor inmovilizada mediante los métodos de atrapamiento y reticulado, sobre sensores de tipo screen-printed.

\begin{tabular}{|c|c|c|c|c|c|c|}
\hline Biosensor & $\begin{array}{c}K_{m}^{\prime} \\
(\mu \mathrm{M})\end{array}$ & $\begin{array}{c}\text { Sensibilidad } \\
\left(\text { nA } \mu M^{-1}\right)\end{array}$ & $\begin{array}{c}\text { Límite de } \\
\text { detección } \\
\text { (LDD)/ } \\
\mu \mathrm{M}\end{array}$ & $\begin{array}{c}\text { Límite de } \\
\text { cuantificación } \\
(\mathrm{LDQ}) / \mu \mathrm{M}\end{array}$ & $\begin{array}{c}\text { Intervalo lineal } \\
\qquad(\mu \mathrm{M})\end{array}$ & $\begin{array}{c}\text { Tiempo } \\
\text { de vida* } \\
\text { (días) }\end{array}$ \\
\hline ESP/LTv/PVA & $188 \pm 5$ & $11.6 \pm 0.7$ & $20 \pm 7$ & $67 \pm 23$ & $26 \leq[\mathrm{HQ}] \leq 348$ & $>360$ \\
\hline ESP/LTv/EDC & $192 \pm 6$ & $12.2 \pm 0.8$ & $23 \pm 8$ & $78 \pm 27$ & $26 \leq[\mathrm{HQ}] \leq 333$ & $<1$ \\
\hline $\begin{array}{c}\text { ESP/LTv/ASH/ } \\
\text { GA } 2.5 \%\end{array}$ & $367 \pm 9$ & $11.1 \pm 0.7$ & $30 \pm 11$ & $101 \pm 35$ & $26 \leq[\mathrm{HQ}] \leq 527$ & $<3$ \\
\hline $\begin{array}{c}\text { ESP/LTv/ASH/ } \\
\text { GA } 1.0 \%\end{array}$ & $439 \pm 6$ & $5.7 \pm 0.5$ & $34 \pm 13$ & $113 \pm 39$ & $26 \leq[\mathrm{HQ}] \leq 504$ & $<3$ \\
\hline $\begin{array}{c}\text { ESP/LTv/GA } \\
2.5 \%\end{array}$ & $170 \pm 3$ & $5.6 \pm 0.4$ & $14 \pm 5$ & $48 \pm 17$ & $26 \leq[\mathrm{HQ}] \leq 258$ & $>165$ \\
\hline $\begin{array}{c}\text { ESP/LTv/ GA } \\
1.0 \%\end{array}$ & $206 \pm 5$ & $4.5 \pm 0.4$ & $17 \pm 6$ & $56 \pm 20$ & $26 \leq[\mathrm{HQ}] \leq 208$ & $>165$ \\
\hline
\end{tabular}

* los biosensores son almacenados a temperatura ambiente evitando el contacto con la luz.

Tabla 2.2. Parámetros cinéticos de biosensores con laccasa de Trametes versicolor inmovilizada mediante los métodos de atrapamiento y reticulado, sobre sensores de tipo screen-printed.

\begin{tabular}{|c|c|c|c|c|c|}
\hline Biosensor & $K_{m}^{\prime}(\mu \mathrm{M})$ & $\begin{array}{l}I_{\text {máx }} \\
(\mu \mathrm{A})\end{array}$ & $\boldsymbol{h}$ & 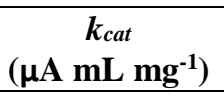 & $\begin{array}{c}k_{\text {cat }} / K_{m} \\
\left(\mu \mathrm{A} \mathbf{m L ~}^{-1} \mu \mathbf{M}^{-1}\right)\end{array}$ \\
\hline ESP/LTv/PVA & $188 \pm 5$ & $4.7 \pm 0.1$ & $1.9 \pm 0.1$ & 0.944 & 0.0050 \\
\hline ESP/LTv/EDC & $192 \pm 6$ & $5.1 \pm 0.1$ & $1.8 \pm 0.1$ & 0.953 & 0.0050 \\
\hline ESP/LTv/ASH/GA $2.5 \%$ & $367 \pm 9$ & $7.9 \pm 0.1$ & $1.8 \pm 0.5$ & 1.487 & 0.0041 \\
\hline ESP/LTv/ASH/GA $1.0 \%$ & $439 \pm 6$ & $4.9 \pm 0.4$ & $1.5 \pm 0.3$ & 0.931 & 0.0021 \\
\hline ESP/LTv/GA $2.5 \%$ & $170 \pm 3$ & $2.0 \pm 0.2$ & $1.7 \pm 0.2$ & 0.403 & 0.0024 \\
\hline ESP/LTv/ GA $1.0 \%$ & $206 \pm 5$ & $1.6 \pm 0.3$ & $1.7 \pm 0.1$ & 0.329 & 0.0016 \\
\hline
\end{tabular}




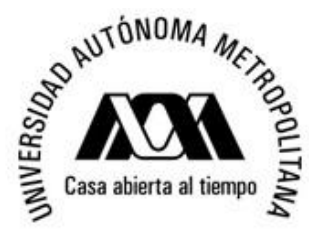

Universidad Autónoma Metropolitana Unidad Iztapalapa

División Ciencias Básicas e Ingeniería

Departamento de Química

Área de Química Analítica

Tesis de Doctorado

Q. Erika Rodríguez Sevilla
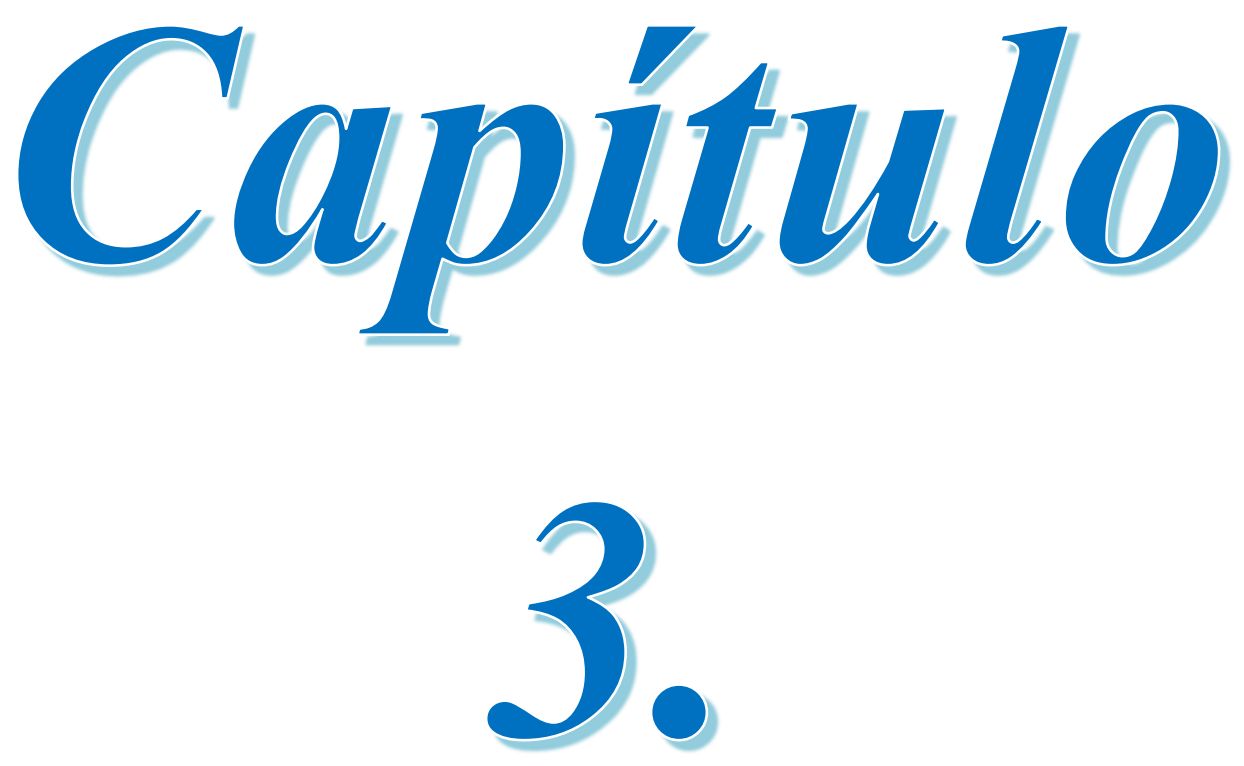

Biosensores con tirosinasa mushroom. 


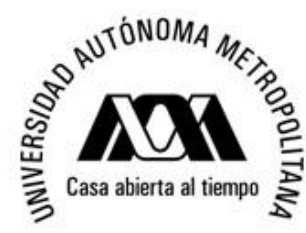

\subsection{Introducción}

La tirosinasa (Tir), una enzima del grupo de las oxidasas, contiene dos átomos de cobre en estados "meta" "oxi” y "desoxi" en sus sitios activos; la función de éstos es catalizar la ortohidroxilación de monofenoles [72] y la oxidación de o-difenoles a o-quinonas [73,74] y puede ser inmovilizada mediante distintos métodos con el propósito de mejorar sus propiedades catalíticas en el biosensor. Actualmente la tirosinasa es utilizada en diversas áreas de la ciencia, una de ellas es el desarrollo de biosensores [75] con diversas aplicaciones por ejemplo determinar el contenido fenólico en tés [76] o en cervezas [77], biosensores para la determinación de fluoruro [78], etcétera.

En este caso se utiliza catecol como sustrato para Tir [79]. A través de la constante de Michaelis-Menten aparente se puede obtener información descriptiva del sistema, y por ende puede ser utilizada como un parámetro descriptivo de la robustez del sensor, sin embargo hasta ahora solo ha sido utilizada como una característica más del sensor sin ajustar el modelo matemático a los resultados experimentales, o bien sin mencionar el tipo de cinética descrita en la reacción [80, 81, 82, 83].

Por ello en el presente trabajo se muestra la inmovilización de tirosinasa mushroom mediante los métodos de atrapamiento, reticulado y enlace covalente, en seis condiciones experimentales distintas, en todos ellos la constante de Michaelis-Menten aparente es utilizada como un parámetro descriptivo del comportamiento cinético del sistema para conocer el efecto en los sitios activos de la enzima al ser inmovilizada, la velocidad de formación del producto de reacción entre otros parámetros cinéticos, fisicoquímicos y analíticos. Estos resultados son reforzados al caracterizar cada biosensor mediante Voltamperometría Cíclica, Espectroscopia de Ultravioleta Visible, Espectroscopia de Impedancia Electroquímica (EIS) y Microscopía Electrónica de Barrido (SEM). 


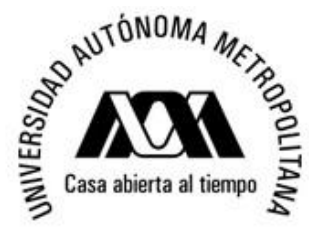

Universidad Autónoma Metropolitana Unidad Iztapalapa

División Ciencias Básicas e Ingeniería

Departamento de Química

Área de Química Analítica

Tesis de Doctorado

Q. Erika Rodríguez Sevilla

\subsection{Caracterización espectrofotométrica de tirosinasa mushroom.}

El sistema formado por tirosinasa (tir) y Catecol (Cat) que produce o-quinona (o-Q), se describe mediante una reacción enzimática como la siguiente:

$$
\operatorname{tir}_{(a q)}+\operatorname{Cat}_{(a q)} \Leftrightarrow \operatorname{tirCat}_{(a q)} \rightarrow \operatorname{tir}_{(a q)}+o-Q_{(a q)}
$$

En la caracterización espectrofotométrica de Tir se obtienen los espectros de la enzima y de catecol, que es usado como sustrato afín a la enzima, en amortiguador de acetatos $0.1 \mathrm{M}$ y $\mathrm{pH} 4.70 \pm 0.01$ a $(30.0 \pm 0.5){ }^{\circ} \mathrm{C}$, la tirosinasa (Figura 3.1, línea) muestra una banda de absorción en 289 nm., así como un hombro en 380 nm., por su parte el catecol (Figura 3.1, - -) muestra una banda de absorción en $275 \mathrm{~nm}$.

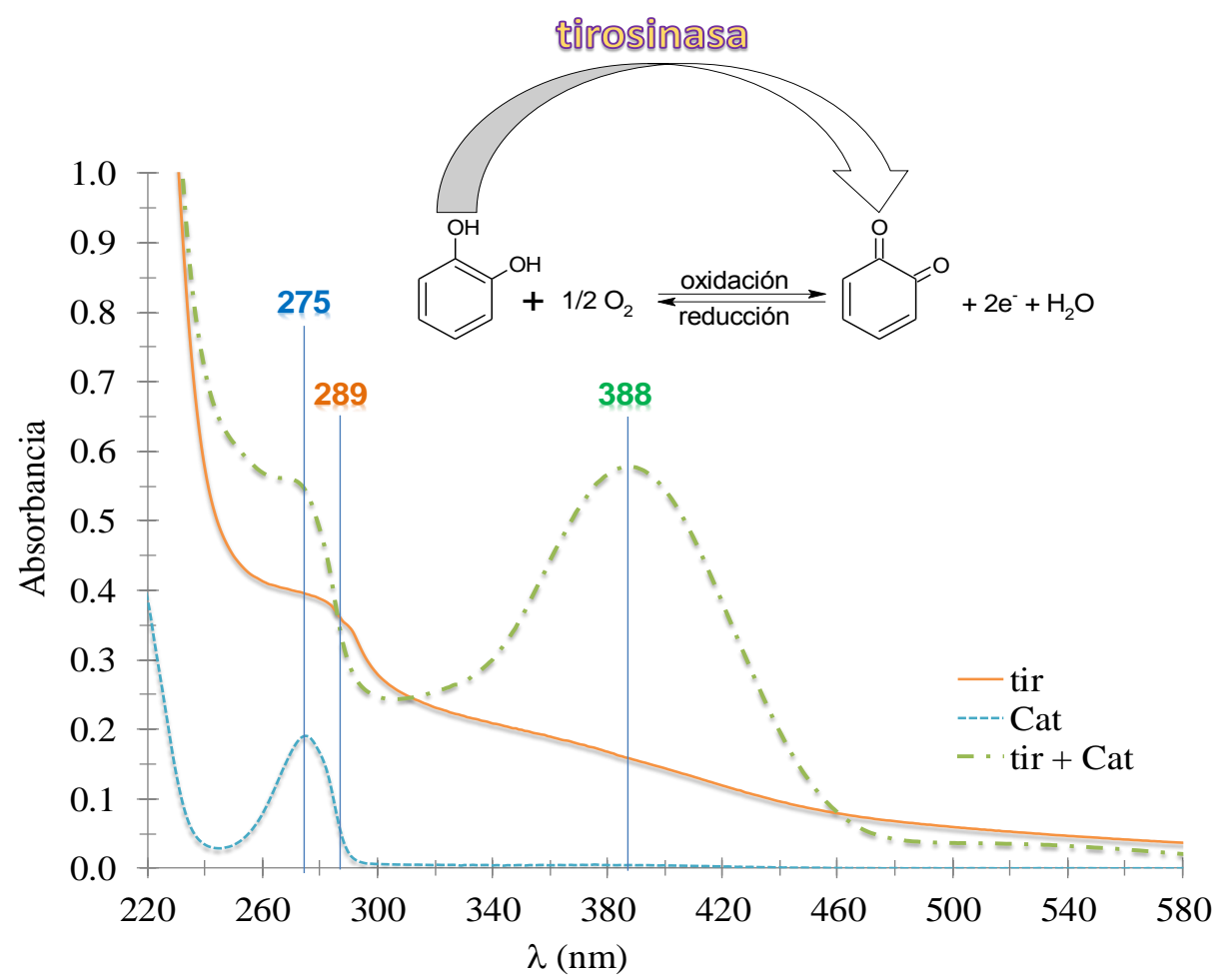

Figura 3.1. Espectro de absorción de tirosinasa mushroom (tir) $145 \mu \mathrm{g} / \mathrm{mL}$ (línea solida), Catecol (Cat) 118 $\mu \mathrm{M}$ (línea punteada) y el sistema reaccionante tir + Cat, cada espectro fue obtenido en amortiguador de acetatos $0.1 \mathrm{M} \mathrm{a}(30.0 \pm 0.5)^{\circ} \mathrm{C}$ y pH $4.70 \pm 0.01$. El inserto muestra el esquema de reacción entre tir y Cat. 


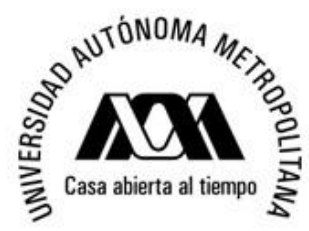

Universidad Autónoma Metropolitana Unidad Iztapalapa

División Ciencias Básicas e Ingeniería

Departamento de Química

Área de Química Analítica

Tesis de Doctorado

Q. Erika Rodríguez Sevilla

Al obtener el espectro del sistema reaccionante (Figura 3.1, - - -) de tirosinasa (Tir) con Catecol (Cat), en donde se forma el complejo enzima-sustrato, en este caso tirosinasa-Catecol (TCat), que posteriormente se disocia para obtener la enzima y el producto; que en este caso es benzoquinona $(o-Q)$ se observan dos bandas de absorción una en 275, que es atribuida al catecol que no reaccionó en el sistema y una más a 388 nm, atribuida a la formación de benzoquinona.

\subsection{Cálculo de la constante de Michaelis-Menten}

Para la obtención de los parámetros cinéticos de la enzima se sigue la absorbancia a $388 \mathrm{~nm}$, para diferentes concentraciones de catecol, la velocidad de reacción del sistema formado por tirosinasa y catecol a $(30.0 \pm 0.5){ }^{\circ} \mathrm{C}$ en amortiguador de acetatos $0.1 \mathrm{M}$ y pH $4.70 \pm 0.01$ como función de la concentración de Catecol, ([Catecol]) se muestra en la Figura 3.2.

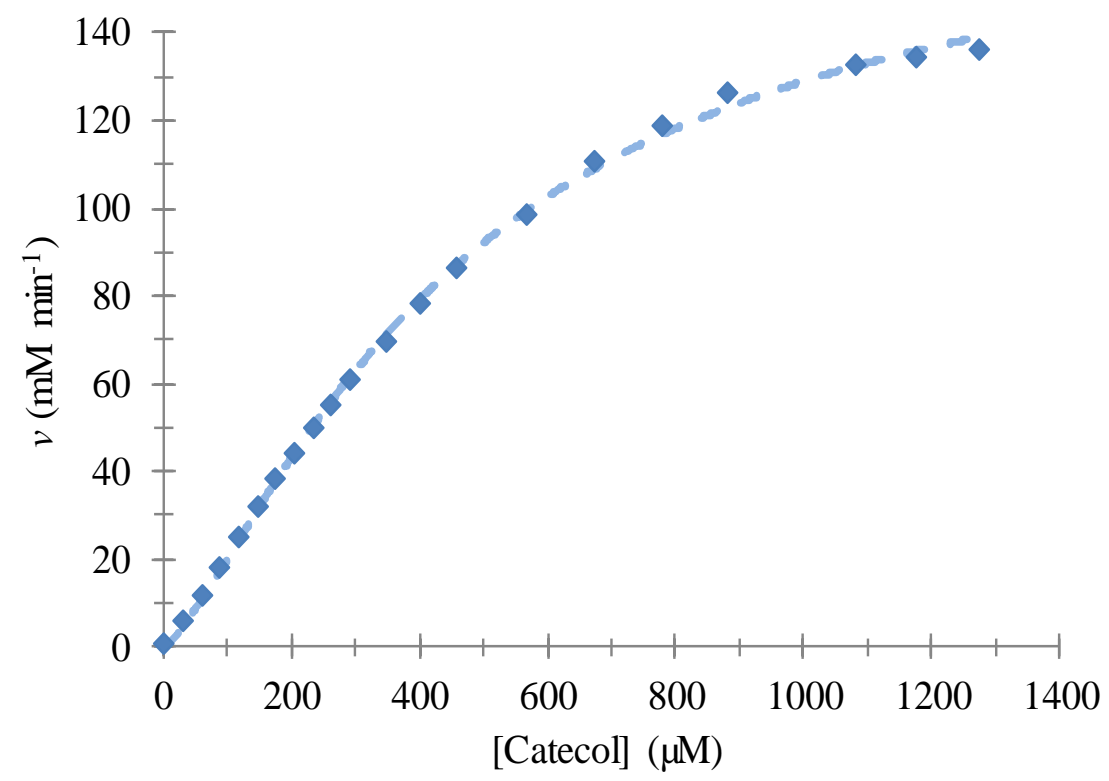

Figura 3.2. Cinética enzimática para catecol usando tirosinasa mushroom en amortiguador de acetatos $0.1 \mathrm{M}$ a $\mathrm{pH} 4.70 \pm 0.01 \mathrm{a}(30.0 \pm 0.5){ }^{\circ} \mathrm{C}$. Los puntos son los datos experimentales y la línea es obtenida mediante el modelo de Hill, usando los valores de $\mathrm{K}_{\mathrm{m}}, v_{\max } \mathrm{y} h$ reportados en esta seccion. 
En este caso se observa un intervalo lineal que abarca concentraciones de $(29 \leq$ [Catecol] $\leq$ 289) $\mu \mathrm{M}$ con un coeficiente de regresión lineal de 0.9988 , mediante la regresión no lineal de los datos experimentales se obtienen los parámetros cinéticos correspondientes a la enzima en solución $K_{m}=(460 \pm 2) \mu \mathrm{M}, v_{\max }=(174 \pm 4) \mu \mathrm{Mmin}^{-1}$ y $h=1.33 \pm 0.04$, es importante mencionar que el valor obtenido en el coeficiente de Hill $(h)$ es un indicativo de la cooperatividad del sistema, de acuerdo con Coperland [3] la tirosinasa muestra una cooperatividad positiva con el sustrato, y por lo tanto el coeficiente de Hill es mayor que 1.

\subsection{Caracterización electroquímica del sistema tirosinasa-catecol}

Para la determinación amperométrica de tirosinasa y catecol en solución, se utiliza un sensor screen-printed sin modificar y se lleva a cabo a determinación de la corriente en función de la concentración de catecol para tirosinasa mushroom $5 \mu \mathrm{g} / \mathrm{mL}$. Para la caracterización de catecol se utilizan los biosensores de tirosinasa inmovilizada mediante seis metodologías distintas, para ambas caracterizaciones se utiliza un detector BAS LC-4C, se impone un potencial constante de $-0.300 \mathrm{~V}$ usando un electrodo de pseudoreferencia de $\mathrm{Ag} / \mathrm{AgCl}$, en amortiguador de acetatos $0.1 \mathrm{M} \mathrm{y} \mathrm{pH} 4.70 \pm 0.01 \mathrm{a}(30.0 \pm 0.5){ }^{\circ} \mathrm{C}$, con agitación constante.

Cuando tirosinasa en solución es evaluada amperométricamente se observa un comportamiento cinético de tipo Michaeliano, (Figura 3.3), en donde se mide la corriente dada por la reducción de benzoquinona a catecol (inserto de la Figura 3.3) en amortiguador de acetatos $0.1 \mathrm{M}$ a pH $4.70 \pm 0.01$ a $(30.0 \pm 0.5){ }^{\circ} \mathrm{C}$ utilizando un electrodo screen-printed (ESP) sin modificar; en este caso la $K_{m}{ }^{\prime}=(404 \pm 11) \mu \mathrm{M}$, que es similar a la obtenida mediante la espectroscopia de UV-Vis y a la reportada por Rivas y Solis [84], lo que nos permite descartar algún efecto negativo por parte del material del biosensor o de la pseudoreferencia utilizada, sin embargo la constante de Michaelis-Menten se denota como una constante aparente $\left(K_{m}\right)$ debido a que no es obtenida mediante el modelo original; $I_{\text {máx }}$ 


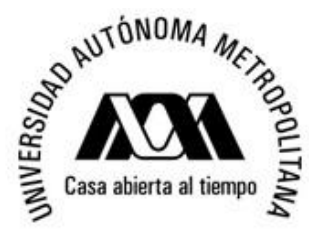

Universidad Autónoma Metropolitana Unidad Iztapalapa

División Ciencias Básicas e Ingeniería

Departamento de Química

Área de Química Analítica

Tesis de Doctorado

Q. Erika Rodríguez Sevilla

$=(27.5 \pm 0.4) \mu \mathrm{A}$ y $h=1.35 \pm 0.03$ lo que nos indica que la cooperatividad del sistema tampoco se ve afectada por la técnica electroquímica empleada. El intervalo lineal abarca concentraciones de $(29 \leq[\mathrm{Catecol}] \leq 318) \mu \mathrm{M}$ con un coeficiente de regresión lineal de 0.9992.

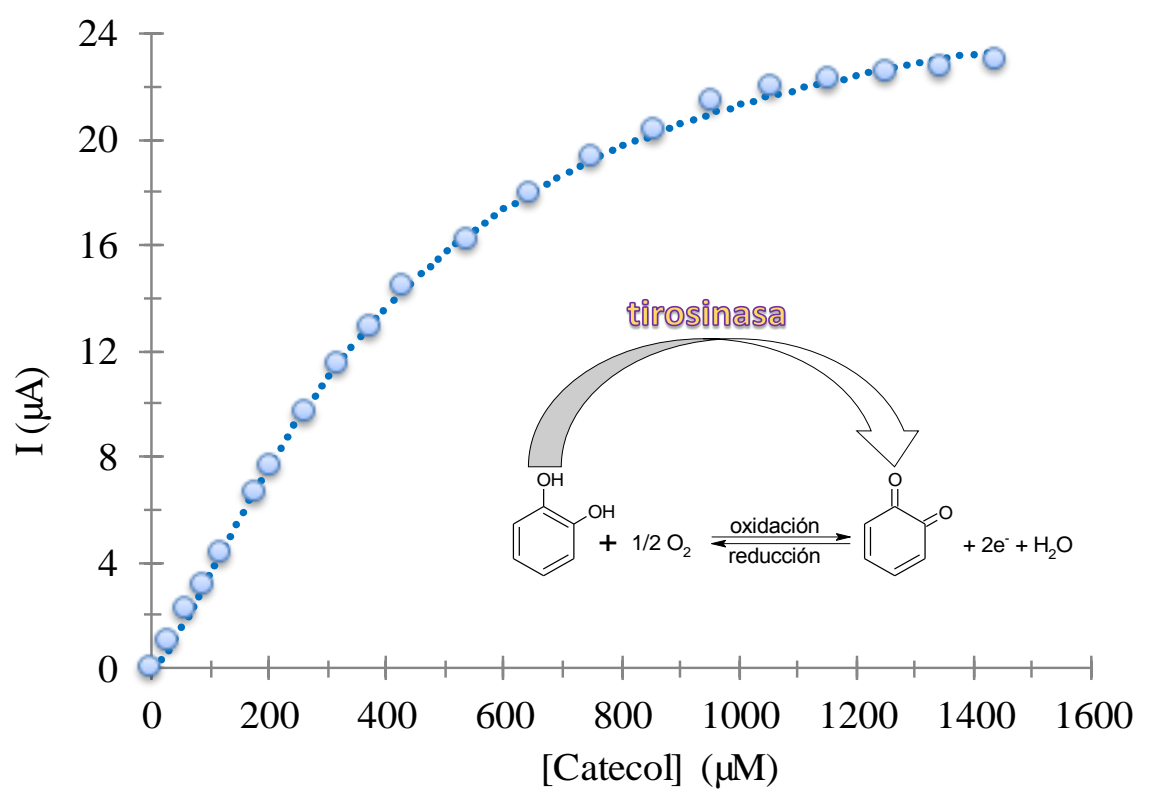

Figura 3.3. Cinética enzimática para catecol usando tirosinasa mushroom en solución, contenida en amortiguador de acetatos $0.1 \mathrm{M}$ a pH $4.50 \pm 0.01$ a $(30.0 \pm 0.5){ }^{\circ} \mathrm{C}$. Seguida por la corriente medida a $-300 \mathrm{mV}$ de potencial impuesto, los puntos son los datos experimentales y la línea es el ajuste obtenido mediante el modelo de Hill [anexo 2] usando los valores de $\mathrm{K}_{\mathrm{m}}=(406 \pm 11) \mu \mathrm{M}, \mathrm{I}_{\max }=(27.5 \pm 0.4) \mu \mathrm{A} \mathrm{y} \mathrm{h}=1.35 \pm 0.03$.

El inserto muestra el esquema de reacción de catecol y benzoquinona catalizada por tirosinasa.

\subsection{Caracterización amperométrica de los diferentes biosensores.}

\subsubsection{Biosensor ESP/Tir/PVA}

En la Figura 3.4 (puntos) se muestra el comportamiento cinético de la tirosinasa inmovilizada por atrapamiento; al variar la concentración de catecol en el sistema a pH de $4.70 \pm 0.01$ impuesto con amortiguador de acetatos en concentración $0.1 \mathrm{M} \mathrm{a}(30.0 \pm 0.5){ }^{\circ} \mathrm{C}$, en este caso es posible observar un intervalo lineal de $(10 \leq[$ Catecol $] \leq 82) \mu \mathrm{M}$ con un $\mathrm{R}^{2}=0.9995$, con una sensibilidad de $(120 \pm 20) \mathrm{nA \mu M}^{-1}$, un límite de detección (LOD) de $(9.5 \pm 3.5) \mu \mathrm{M}$ 


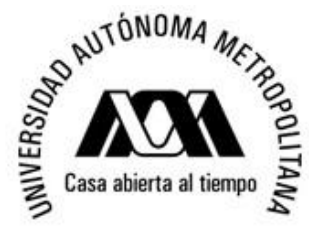

Universidad Autónoma Metropolitana Unidad Iztapalapa

División Ciencias Básicas e Ingeniería

Departamento de Química

Área de Química Analítica

Tesis de Doctorado

Q. Erika Rodríguez Sevilla

y un límite de cuantificación (LOQ) de $(31 \pm 10) \mu \mathrm{M}$. Para conocer los parámetros cinéticos de la enzima inmovilizada se utiliza el modelo de Hill (ver sección 1.3), el tipo de cinética descrita por la enzima y su sustrato sigue siendo una cinética cooperativa $(h=1.35 \pm 0.23)$. Los parámetros cinéticos $I_{\operatorname{máx}}=(16.8 \pm 0.2) \mu \mathrm{A}$ y la $K_{m}=(65 \pm 2) \mu \mathrm{M}$ indican que la actividad catalítica de la enzima ha sido mejorada con respecto a la enzima en solución.

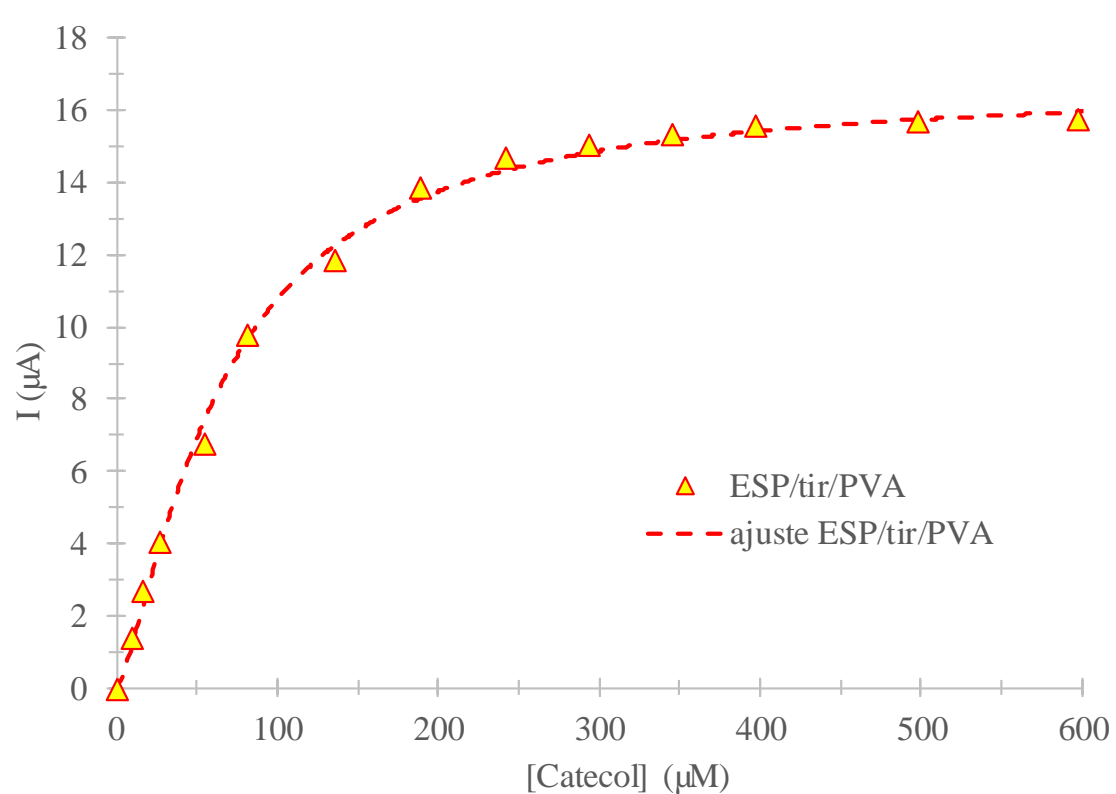

Figura 3.4. Cinética enzimática registrada en el sistema tirosinasa inmovilizada mediante atrapamiento (ESP/Tir/PVA) en amortiguador de acetatos $0.1 \mathrm{M}$ a pH $4.70 \pm 0.01$ a $(30.0 \pm 0.5){ }^{\circ} \mathrm{C}$, la línea es obtenida usando el modelo de Hill [anexo 2] usando los valores correspondientes de $K_{m}{ }^{\prime}, I_{\max }$ y $h$ mostrados en la Tabla 3.2 .

\subsubsection{Biosensor ESP/Tir/EDC}

Cuando la enzima es inmovilizada mediante enlace covalente utilizando EDC (Figura 3.5), hay una pérdida de la actividad enzimática $\left(K_{m}{ }^{\prime}=(75 \pm 18) \mu \mathrm{M}\right)$ con respecto al método de atrapamiento; esto es atribuido a la cristalización de la membrana una vez usado el biosensor, esto afecta directamente los parámetros analíticos del mismo, tanto el límite de detección $(\mathrm{LOD}=(15 \pm 6) \mu \mathrm{M})$ como el límite de cuantificación $(\mathrm{LOQ}=(51 \pm 17) \mu \mathrm{M})$ tiene un valor mayor, el intervalo lineal comprende valores desde $27 \mu \mathrm{M} \leq[$ Catecol $] \leq 109 \mu \mathrm{M}$ con una 


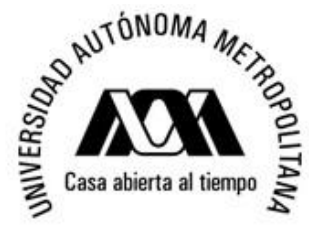

Universidad Autónoma Metropolitana Unidad Iztapalapa

División Ciencias Básicas e Ingeniería

Departamento de Química

Área de Química Analítica

Tesis de Doctorado

Q. Erika Rodríguez Sevilla

sensibilidad de $(11 \pm 2) \mathrm{nA}_{\mu} \mathrm{M}^{-1}$, con un coeficiente de regresión lineal de 0.9958 . La cooperatividad del sistema enzima-sustrato también se ve afectada, $(h=1.55 \pm 0.06)$ ya que se necesita una cantidad de sustrato mayor para lograr una cooperatividad positiva.

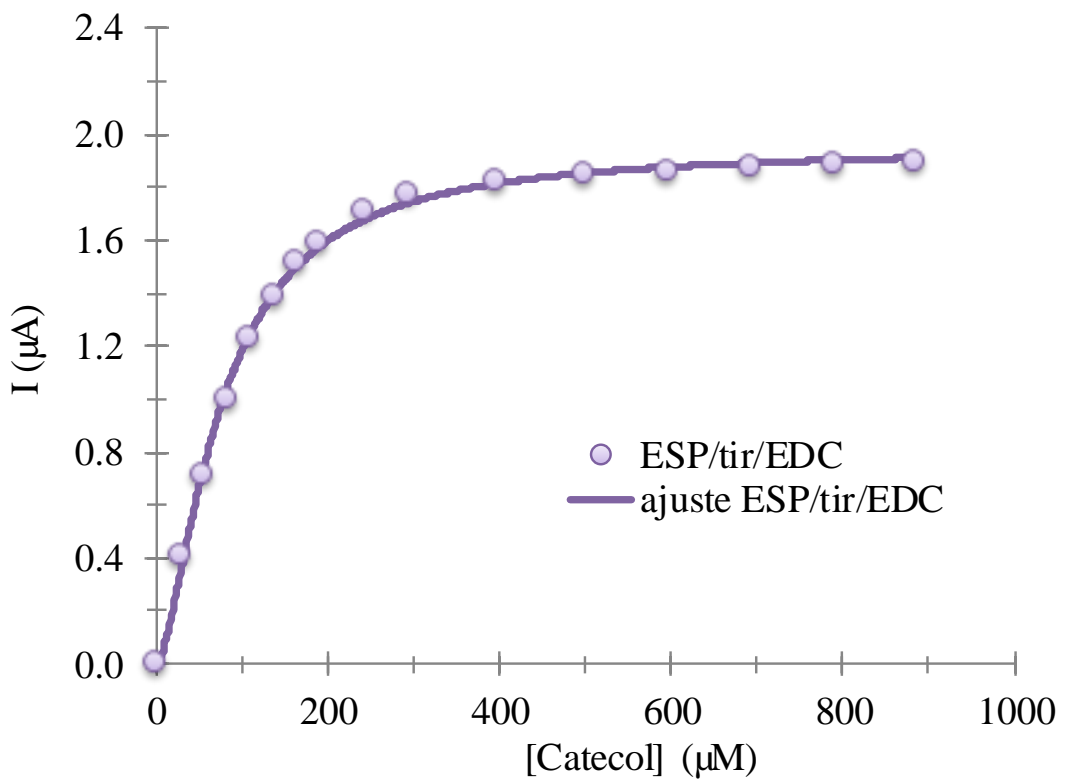

Figura 3.5. Cinética enzimática registrada en el sistema tirosinasa inmovilizada mediante enlace covalente (ESP/tir/EDC) en amortiguador de acetatos $0.1 \mathrm{M} \mathrm{a} \mathrm{pH} 4.70 \pm 0.01 \mathrm{a}(30.0 \pm 0.5){ }^{\circ} \mathrm{C}$. la línea es obtenida usando el modelo de Hill [anexo 2] usando los valores correspondientes de $K_{m}^{\prime}, I_{\max }$ y $h$ mostrados en la Tabla 3.2.

\subsubsection{Biosensores ESP/Tir/ASH/GA $2.5 \%$ y ESP/Tir/ASH/GA $1.0 \%$}

La Figura 3.6 muestra el comportamiento cinético de la tirosinasa al ser inmovilizada con glutaraldehído (GA) al 2.5\% como agente reticulante, el uso de la albúmina de suero de humano (ASH) ayuda a la funcionalización de los sitios activos de la enzima con el fin de hacerlos aún más reactivos (biosensor ESP/Tir/ASH/GA 2.5\%). En este caso el intervalo lineal es de $(27 \leq[$ Catecol $] \leq 109) \mu \mathrm{M}$ con un $\mathrm{R}^{2}=0.9950$, La constante de Michaelis-Menten aparente para dicho sensor que es de $(98 \pm 6) \mu \mathrm{M}$ lo que indica que algunos de los sitios activos de la enzima no están expuestos de manera adecuada o bien han sido bloqueados por el reticulante. Los parámetros analíticos del sensor son mayores, (límite de detección (26 \pm 


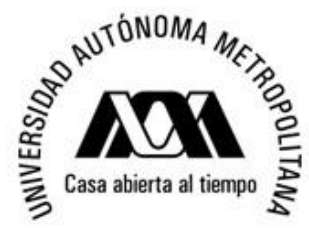

Universidad Autónoma Metropolitana Unidad Iztapalapa

División Ciencias Básicas e Ingeniería

Departamento de Química

Área de Química Analítica

Tesis de Doctorado

Q. Erika Rodríguez Sevilla

10) $\mu \mathrm{M}$ y cuantificación $(88 \pm 32) \mu \mathrm{M}$ y sensibilidad $\left.(32 \pm 1) n A \mu \mathrm{M}^{-1}\right)$, comparado con la inmovilización por atrapamiento como para la inmovilización por enlace covalente.

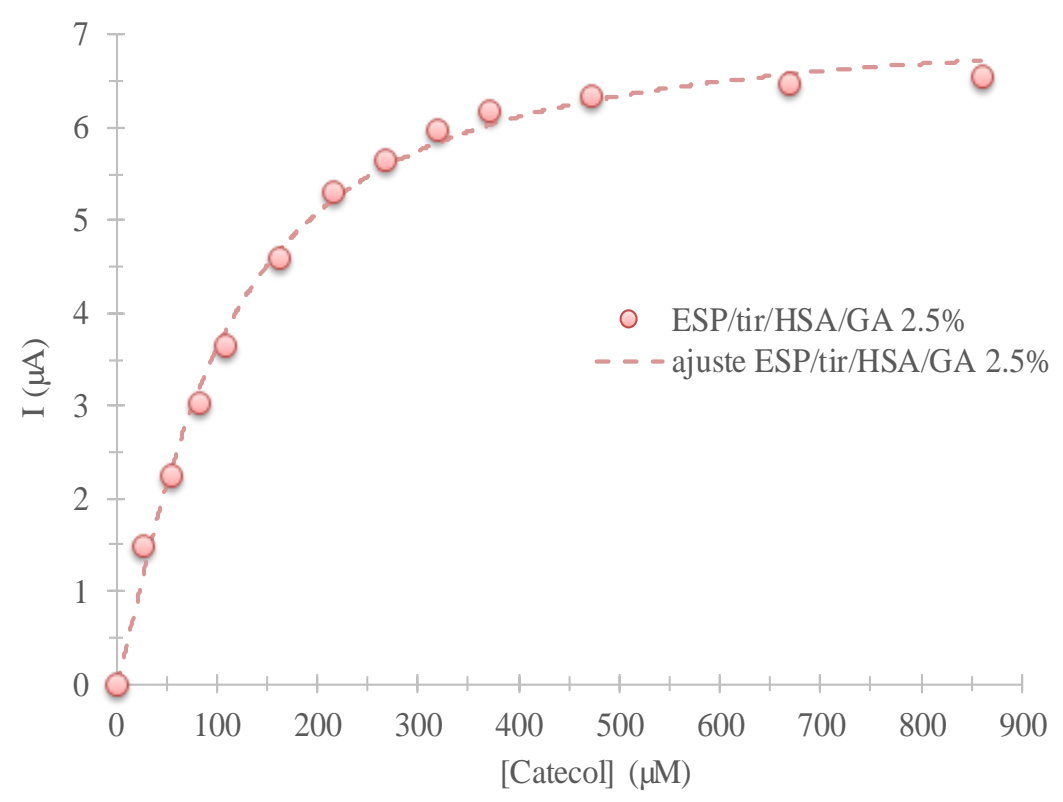

Figura 3.6. Cinética enzimática registrada en el sistema tirosinasa inmovilizada mediante reticulado (ESP/Tir/ASH/GA 2.5\%) en amortiguador de acetatos $0.1 \mathrm{M} \mathrm{a} \mathrm{pH} 4.70 \pm 0.01$ a $(30.0 \pm 0.5){ }^{\circ} \mathrm{C}$, la línea es obtenida usando el modelo de Hill [anexo 2] usando los valores correspondientes de $K_{m}^{\prime}, I_{\max }$ y $h$ mostrados en la Tabla 3.2.

Al disminuir la concentración de glutaraldehído en el sensor, la cinética enzimática (Figura 3.7) muestra una mejora con respecto a la interacción del sustrato con la enzima, obteniendo una $K_{m}^{\prime}$ de $(141 \pm 4) \mu \mathrm{M}$ así como un límite de detección $(10 \pm 3) \mu \mathrm{M}$, límite de cuantificación $(33 \pm 11) \mu \mathrm{M}$ menores con respecto a la inmovilización con glutaraldehído al $2.5 \%$ y una sensibilidad de $(58 \pm 5) \mathrm{nA}_{\mu} \mathrm{M}^{-1}$, debido a la baja concentración de glutaraldehído la enzima es retenida de manera correcta en la red polimérica sin embargo debido al método de inmovilización hay una pérdida de la actividad enzimática, a pesar de que la cooperatividad del sistema es positiva $(h=1.25 \pm 0.09)$. 


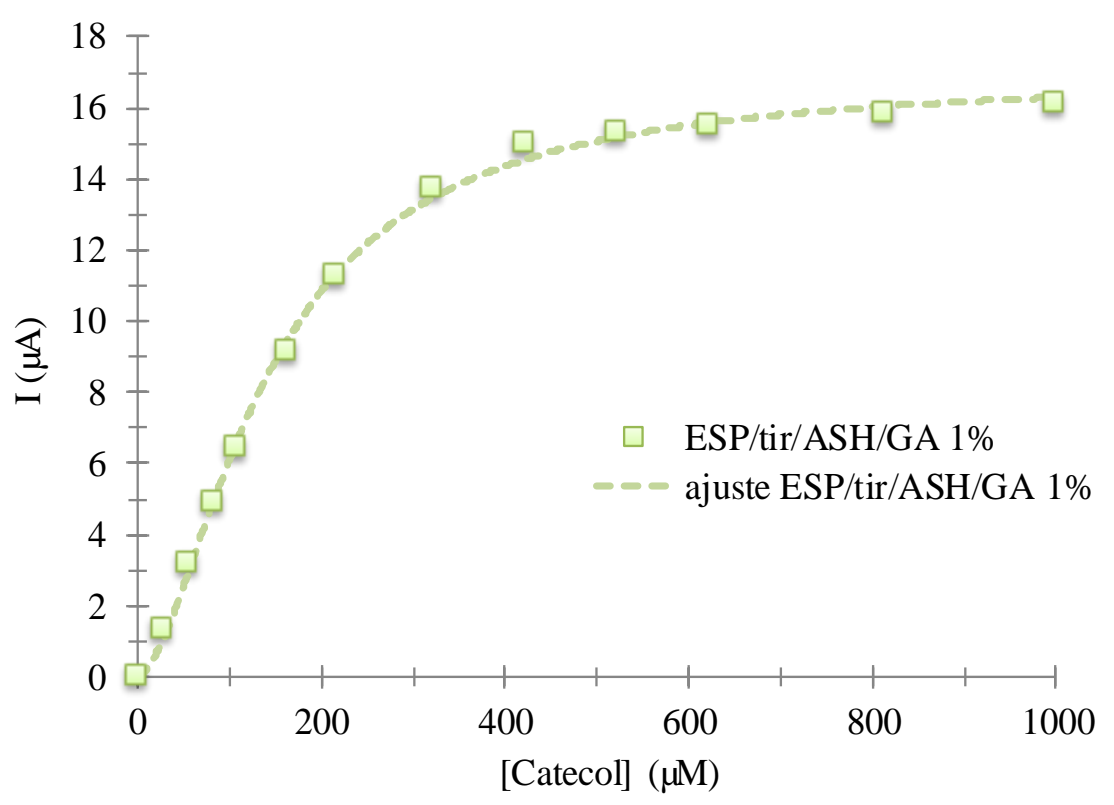

Figura 3.7. Cinética enzimática registrada en el sistema tirosinasa inmovilizada mediante reticulado (ESP/Tir/ASH/GA $1.0 \%$ ) en amortiguador de acetatos $0.1 \mathrm{M}$ a pH $4.70 \pm 0.01$ a $(30.0 \pm 0.5){ }^{\circ} \mathrm{C}$, la línea es obtenida usando el modelo de Hill [anexo 2] usando los valores correspondientes de $K_{m}{ }^{\prime}, I_{\max } \mathrm{y} h$ mostrados en la Tabla 3.2.

\subsubsection{Biosensores ESP/Tir/GA $2.5 \%$ y ESP/Tir/GA $1.0 \%$}

El hecho de prescindir de la ASH y someter el sensor a un proceso de termocurado (anexo 3) en la fabricación del sensor ESP/Tir/GA 2.5\%, mejora significativamente la interacción de la enzima con el sustrato (Figura 3.8) debido a la membrana formada por el glutaraldehído en el proceso de inmovilización, confiriendo al sensor propiedades asociadas con la inmovilización por atrapamiento, incrementando la actividad enzimática del sensor $\left(K_{m}{ }^{\prime}=\right.$ $57 \pm 7 \mu \mathrm{M})$, con un intervalo lineal de $(27 \leq[$ Catecol $] \leq 136) \mu \mathrm{M}$, un coeficiente de regresión lineal de 0.9998, en este caso la cinética enzimática es de tipo cooperativo $(h=1.56 \pm 0.03)$, sin embargo al utilizar una concentración menor de glutaraldehído (biosensor ESP/Tir/GA $1.0 \%$ ) la cinética enzimática sufre cambios considerables (Figura 3.9) debido a la pérdida de actividad enzimática, $\left(K_{m}{ }^{\prime}=244 \pm 10 \mu \mathrm{M}\right)$ este hecho se ve reflejado en los parámetros analíticos del sensor $(\mathrm{LOD}=(15 \pm 6) \mu \mathrm{M}),(\mathrm{LOQ}=(51 \pm 17) \mu \mathrm{M})$, el intervalo lineal 


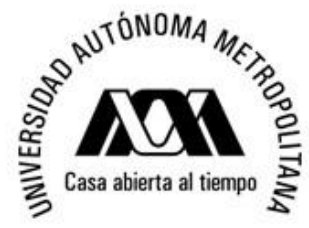

Universidad Autónoma Metropolitana Unidad Iztapalapa

División Ciencias Básicas e Ingeniería

Departamento de Química

Área de Química Analítica

Tesis de Doctorado

Q. Erika Rodríguez Sevilla

comprende valores desde $(27 \mu \mathrm{M} \leq[\mathrm{Catecol}] \leq 109) \mu \mathrm{M}$ con una sensibilidad de $(6.6 \pm 0.4)$ $\left.\mathrm{nA} \mu \mathrm{M}^{-1}\right)$, mientras que la cooperatividad del sistema mejora $(h=1.45 \pm 0.06)$.

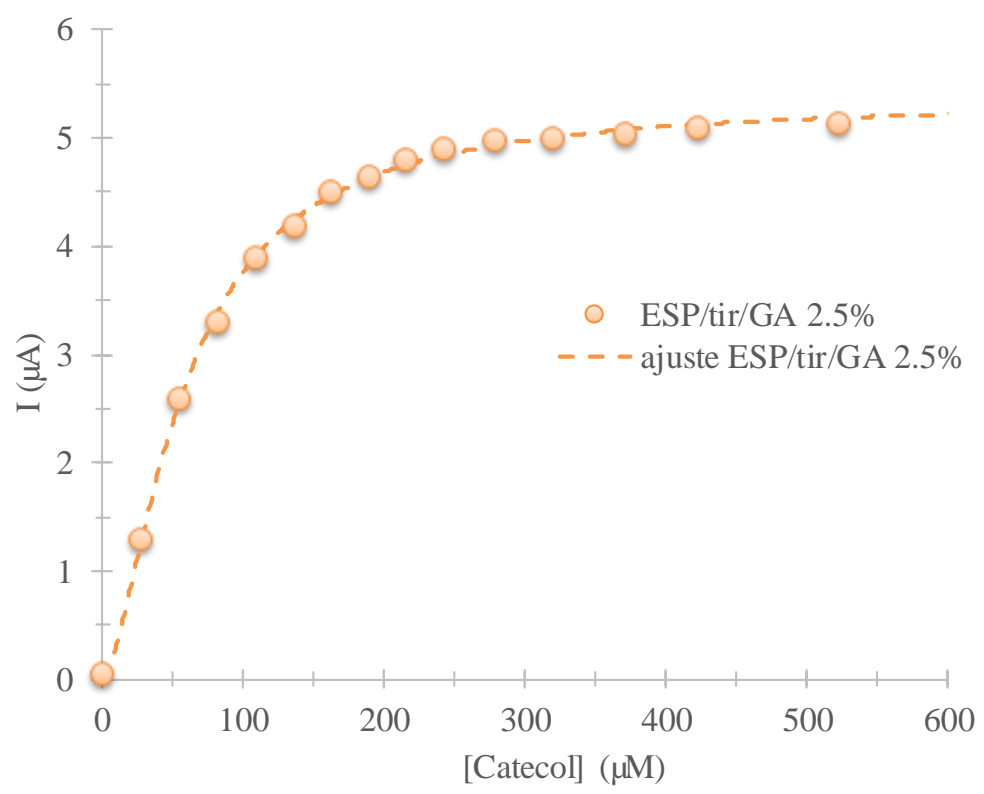

Figura 3.8. Cinética enzimática registrada en el sistema tirosinasa inmovilizada mediante reticulado (ESP/Tir/GA $2.5 \%)$ en amortiguador de acetatos $0.1 \mathrm{M}$ a pH $4.70 \pm 0.01$ a $(30.0 \pm 0.5){ }^{\circ} \mathrm{C}$, la línea es obtenida usando el modelo de Hill (anexo 2) usando los valores correspondientes de $K_{m}^{\prime}, I_{\max }$ y $h$ mostrados en la Tabla 3.2.

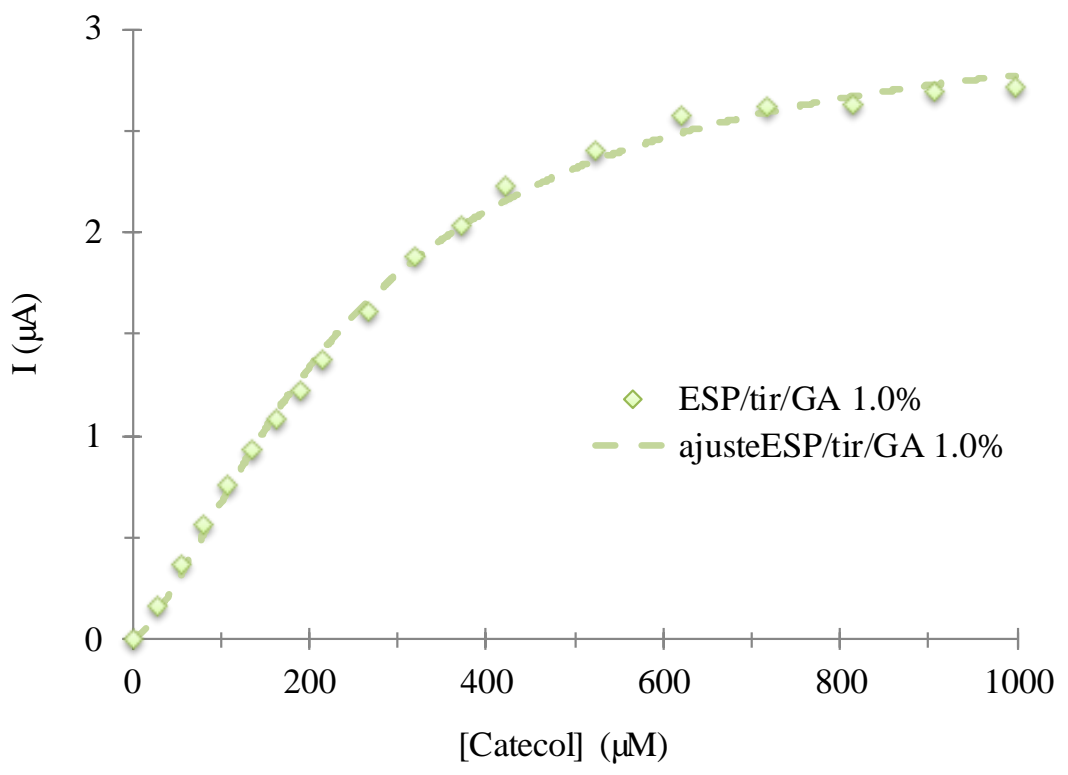

Figura 3.9. Cinética enzimática del biosensor ESP/Tir/GA $1.0 \%$ en amortiguador de acetatos $0.1 \mathrm{M}$ a pH $4.70 \pm 0.01$ a $(30.0 \pm 0.5)^{\circ} \mathrm{C}$, la línea es obtenida usando el modelo de Hill (anexo 2) usando los valores correspondientes de $K_{m}^{\prime}, I_{\max } \mathrm{y} h$ mostrados en la Tabla 3.2. 


\subsection{Estudio mediante Espectroscopia de Impedancia Electroquímica para los diferentes biosensores.}

La espectroscopia de impedancia electroquímica es una técnica no invasiva de respuesta lineal en donde se aplica una perturbación al sistema en estudio a través de una señal sinusoidal de corriente o potencial con frecuencia variable donde la función de transferencia obtenida de la relación entre la perturbación y la respuesta es conocida como impedancia. Hoy en dia esta técnica ha sido utilizada como una herramienta en diversos campos de estudio como baterías, caldas de combustible, procesos bilógicos, biosensores, entre otros [85, 86, 87].

Mediante la Espectroscopia de Impedancia Electroquímica (EIS) es posible evaluar la porosidad del electrodo, el efecto de la membrana en el trasporte de carga así como la formación de la doble capa electroquímica y con ello evaluar los limitantes en cuanto a la transferencia de carga y la difusión del sistema en cada biosensor. La Figura 3.10 (puntos) muestra el diagrama de Nyquist para los diferentes biosensores construidos sobre electrodos screen-printed (ESP), así como el ajuste (línea) realizado mediante el software Zview, utilizando el circuito de Randels como modelo (inserto Figura 3.10), donde $R_{t c}$ es la resistencia a la transferencia de carga, $R_{s}$ es la resistencia de la solución, $C(\mu \mathrm{F})$ es la capacitancia de la doble capa electroquímica en el diagrama de Nyquist se observa como al agregar cada componente al momento de la fabricación del biosensor, la capacitancia se ve afectada de manera considerable.

En la Figura 3.11, se observa que la superficie del ESP es prácticamente lisa (Figura 3.11, ESP) sin embargo al modificar la superficie del ESP con Tir esta se vuelve más rugosa (Figura 3.11, Tir) sin embargo al agregar PVA, la superficie pierde porosidad, lo que afecta directamente la interacción de la enzima con el sustrato, y por lo tanto la resistencia a la transferencia de carga es mayor (ver Figura 3.10) 


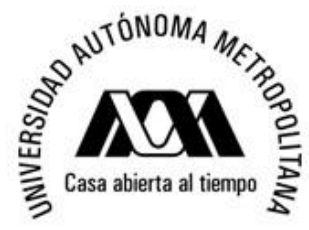

Universidad Autónoma Metropolitana Unidad Iztapalapa

División Ciencias Básicas e Ingeniería

Departamento de Química

Área de Química Analítica

Tesis de Doctorado

Q. Erika Rodríguez Sevilla

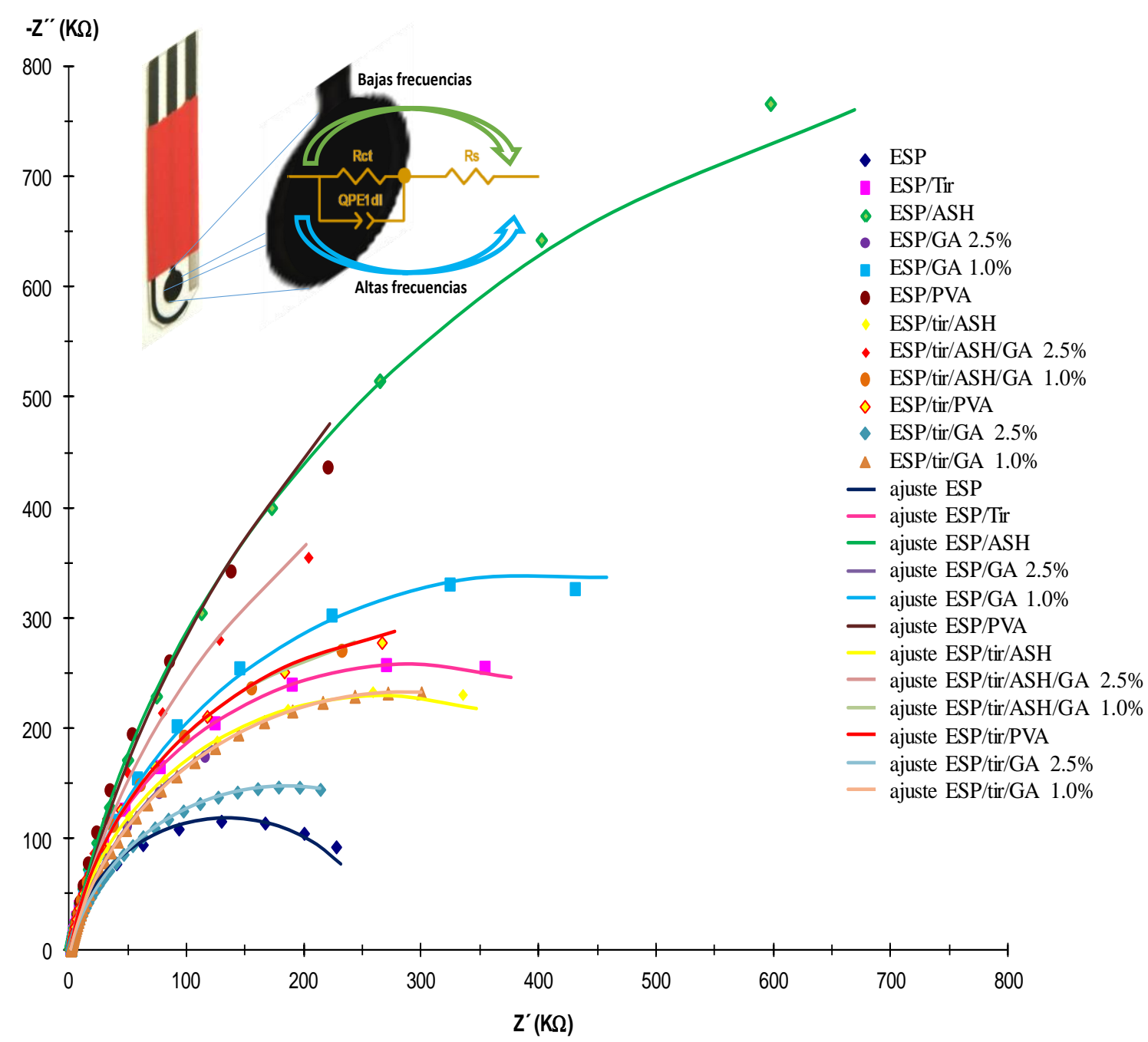

Figura 3.10. Diagrama de Nyquist que muestra la comparación experimental (puntos) de la impedancia de cada componente de los biosensores elaborados con tirosinasa mushroom, en amortiguador de fosfatos $0.1 \mathrm{M}$ a pH $7.00 \pm 0.01$ a $(30.0 \pm 0.5){ }^{\circ} \mathrm{C}$, con $\mathrm{KCl} 0.1 \mathrm{M} \mathrm{y} \mathrm{Fe}(\mathrm{CN})_{6}^{3-/ 4-} 1 \mathrm{mM}$. El inserto muestra el circuito de Randels utilizado para obtener el ajuste (línea) empleando el software Zview.

$\mathrm{Al}$ modificar la superficie del sensor con albúmina el sensor se vuelve más resistivo $\left(R_{t c}=\right.$ 1918.8 K $\Omega$ ) que al tener un ESP sin modificar, sin embargo al modificarlo con la mezcla de tirosinasa y albúmina, el sistema disminuye la resistencia a la transferencia de carga $\left(R_{t c}=\right.$ $533.5 \mathrm{~K} \Omega)$, pero al colocar el agente reticulante, este dificulta la transferencia de carga $\left(R_{t c}\right.$ $=1359 \mathrm{~K} \Omega$ ) a pesar de que la superficie porosa (Figura 3.11, ESP/Tir/ASH/GA); cuando la 

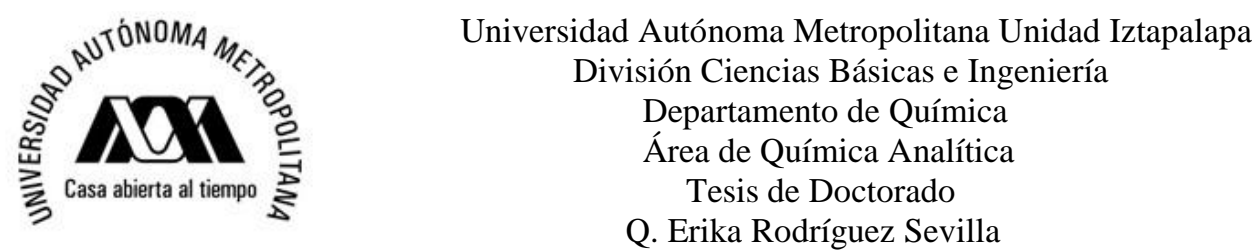

concentración de GA es disminuida al $1 \%, R_{t c}$ disminuye $(672.6 \mathrm{~K} \Omega)$, y esto tiene un impacto directo en los parámetros analíticos del biosensor por lo que se obtienen límites de detección, y cuantificación menores que en el caso anterior y la interacción entre la enzima y el sustrato se ve favorecida (ver sección 3.5).

Cuando la superficie del ESP es modificada con GA, polimerizado a $40^{\circ} \mathrm{C}$, la membrana pierde porosidad, sin embargo posee una porosidad uniforme (Figura 3.11, ESP/Tir/GA), una concentración de GA del $2.5 \%$ permite que la interacción de la enzima con el sustrato mejore generando biosensores con la más baja resistencia a la transferencia de carga $(367.6 \mathrm{~K} \Omega)$, obteniendo de esta forma sensores robustos.

La impedancia electroquímica es calculada por la ecuación

$$
Z=\frac{1}{C(j \omega)^{n}}
$$

donde $Z$ es el módulo de impedancia, $C$ es la capacitancia de la doble capa, $j=\sqrt{-1}$, $\omega$ es la frecuencia y de acuerdo con T. Pajkossy [88], $n$ es un indicativo de la rugosidad o porosidad del electrodo y tomo valores de 0 a 1 , donde cero indica un electrodo no poroso y 1 indica que se tiene un electrodo poroso. En la tabla 3.1 se muestra una comparación de la $R_{s}(\mathrm{~K} \Omega), R_{c t}(\mathrm{~K} \Omega)$, la C $(\mu \mathrm{F})$ y $n$ obtenida para cada biosensor.

Estos resultados coinciden con la información obtenida mediante Microscopia Electrónica de Barrido (Figura 3.11), en donde una vez más se muestra que al depositar la enzima sobre el ESP, la superficie es rugosa (Figura 6, Tir), los sensores elaborados con tirosinasa inmovilizada mediante atrapamiento (ESP/tir/PVA) muestra una superficie menos rugosa, el biosensor ESP/tir/EDC muestra cavidades más amplias, por su parte la inmovilización con albúmina y glutaraldehído muestra una membrana más cerrada, comparada con el resto de los biosensores. 


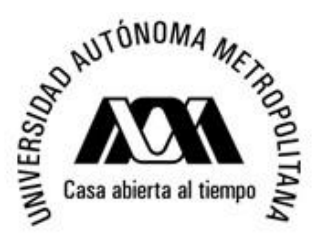

Universidad Autónoma Metropolitana Unidad Iztapalapa

División Ciencias Básicas e Ingeniería

Departamento de Química

Área de Química Analítica

Tesis de Doctorado

Q. Erika Rodríguez Sevilla
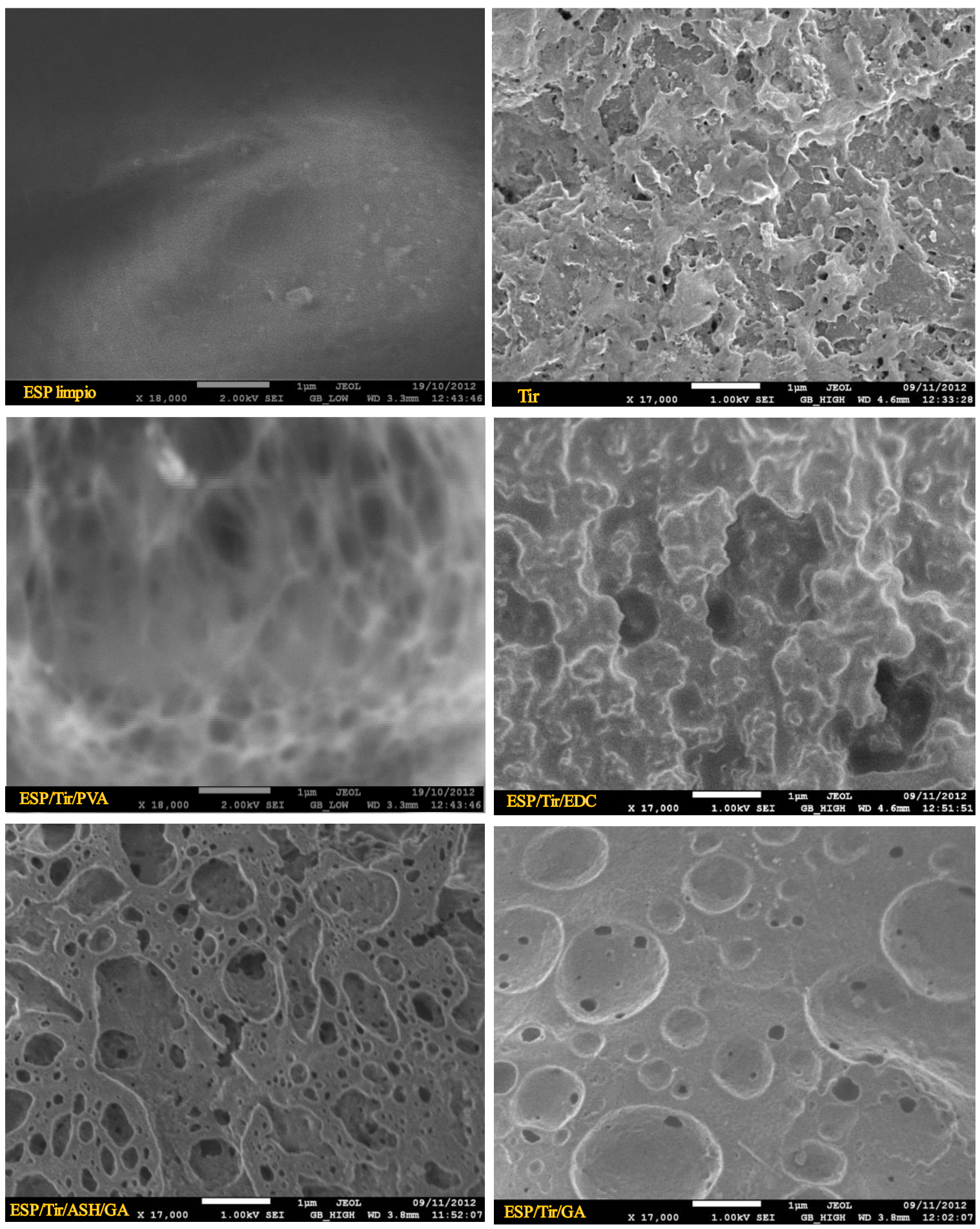

Figura 3.11. Microscopia electrónica de barrido (SEM) del electrodo de tipo screen-printed (ESP) y los ESP modificados con tirosinasa mushroom (Tir), tirosinasa inmovilizada mediante atrapamiento (ESP/Tir/PVA), enlace covalente (ESP/Tir/EDC), reticulado puro con albúmina de suero de humano (ESP/Tir/ASH/GA) y coreticulado a $(40.0 \pm 0.5){ }^{\circ} \mathrm{C}(\mathrm{ESP} / \mathrm{Tir} / \mathrm{GA})$. 
Tabla 3.1. Caracterización mediante espectroscopia de impedancia electroquímica para los electrodos screenprinted en las diferentes etapas de fabricación.

\begin{tabular}{ccccc}
\hline & $\boldsymbol{R}_{\boldsymbol{s}}$ & $\boldsymbol{R}_{\boldsymbol{t c}}$ & $\boldsymbol{C}$ & $\boldsymbol{n}$ \\
& $\mathrm{K} \Omega$ & $\mathrm{K} \Omega$ & $\mu \mathrm{F}$ & \\
\hline ESP & 1.67 & 265.3 & 0.007 & 0.91789 \\
tir & 1.60 & 582.1 & 0.659 & 0.92578 \\
ASH & 1.56 & 1918.8 & 0.206 & 0.88906 \\
GA 2.5\% & 1.85 & 580.5 & 0.963 & 0.87006 \\
GA 1\% & 1.88 & 804.2 & 0.338 & 0.89526 \\
PVA & 1.59 & 2248.6 & 0.389 & 0.87001 \\
ESP/tir/ASH & 1.54 & 533.5 & 0.520 & 0.90658 \\
ESP/tir/ASH/GA 2.5\% & 1.70 & 1359.0 & 0.552 & 0.87764 \\
ESP/tir/ASH/GA 1.0\% & 1.70 & 672.6 & 0.897 & 0.90977 \\
ESP/tir/GA 2.5\% & 1.62 & 367.6 & 0.430 & 0.86756 \\
ESP/tir/GA 1.0\% & 1.68 & 572.0 & 0.360 & 0.86982 \\
ESP/tir/PVA & 1.62 & 679.8 & 0.740 & 0.90614 \\
ESP/tir/EDC & --- & --- & & -- \\
\hline \hline
\end{tabular}

\subsection{Comparación de métodos de inmovilización}

La superficie del electrodo de trabajo sufre diversos cambios en cada método de inmovilización, al colocar la albumina se incrementa la resistencia a la solución debido a las cavidades formadas en la inmovilización, la inmovilización mediante enlace covalente conserva la estructura de la enzima solo evita la perdida de esta al momento de la inmovilización, y finalmente la red formada por glutaraldehído en el co-reticulado es similar a una membrana permeable lo cual facilita la interacción de la enzima con el sustrato mejorando la cinética enzimática. 


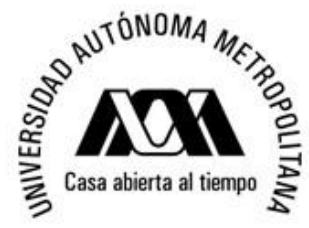

Universidad Autónoma Metropolitana Unidad Iztapalapa

División Ciencias Básicas e Ingeniería

Departamento de Química

Área de Química Analítica

Tesis de Doctorado

Q. Erika Rodríguez Sevilla

Cada uno de estos cambios afecta directamente los parámetros cinéticos y analíticos del biosensor, para tirosinasa mushroom el mejor método de inmovilización es el co-reticulado a $40^{\circ} \mathrm{C}$, pues presenta la menor resistencia a la transferencia de carga, menor $\mathrm{Km}^{\prime}$ y mejores límites de detección y cuantificación, seguido por la inmovilización por atrapamiento, enlace covalente y finalmente el reticulado puro. Los valores obtenidos para la constante de Michaelis-Menten, son menores que los reportados en la literatura para la inmovilización de tirosinasa inmovilizada por los mismos métodos e incluso con nanopartículas $[89,90]$

Tabla 3.2. Parámetros analíticos para tirosinasa inmovilizada mediante atrapamiento, reticulado y enlace covalente sobre sensores de tipo screen-printed.

\begin{tabular}{|c|c|c|c|c|c|c|}
\hline Método & $\begin{array}{c}K_{m}^{\prime} \\
(\mu \mathrm{M})\end{array}$ & $\begin{array}{c}\text { Sensibilidad } \\
\left(\mu \mathrm{A} \mu \mathbf{M}^{-1}\right)\end{array}$ & $\begin{array}{l}\text { Límite de } \\
\text { detección } \\
\text { (LD) } / \mu \mathrm{M}\end{array}$ & $\begin{array}{c}\text { Límite de } \\
\text { cuantificación } \\
(\mathrm{LQ}) / \mu \mathrm{M}\end{array}$ & $\begin{array}{l}\text { Intervalo lineal } \\
\qquad(\mu \mathrm{M})\end{array}$ & $\mathbf{R}^{2}$ \\
\hline $\begin{array}{c}\text { Atrapamiento } \\
\text { (ESP/Tir/PVA) }\end{array}$ & $65 \pm 2$ & $120 \pm 20$ & $9.5 \pm 3.5$ & $31 \pm 10$ & $10 \leq[$ Catecol $] \leq 82$ & 0.9995 \\
\hline $\begin{array}{c}\text { Enlace } \\
\text { covalente } \\
\text { (ESP/Tir/EDC) }\end{array}$ & $75 \pm 18$ & $11 \pm 2$ & $15 \pm 6$ & $51 \pm 17$ & $27 \leq[$ Catecol $] \leq 109$ & 0.9958 \\
\hline $\begin{array}{c}\text { Reticulado } \\
\text { (ESP/Tir/ASH/ } \\
\text { GA 2.5\%) }\end{array}$ & $98 \pm 6$ & $32 \pm 1$ & $26 \pm 10$ & $88 \pm 32$ & $27 \leq[$ Catecol $] \leq 109$ & 0.9950 \\
\hline $\begin{array}{c}\text { Reticulado } \\
\text { (ESP/Tir/ASH/ } \\
\text { GA 1.0\%) }\end{array}$ & $141 \pm 4$ & $58 \pm 5$ & $10 \pm 3$ & $33 \pm 11$ & $27 \leq[$ Catecol $] \leq 162$ & 0.9967 \\
\hline $\begin{array}{c}\text { Reticulado } \\
\text { (ESP/Tir/GA } \\
2.5 \%)\end{array}$ & $57 \pm 7$ & $26 \pm 4$ & $1.5 \pm 0.6$ & $5 \pm 1$ & $27 \leq[$ Catecol $] \leq 136$ & 0.9998 \\
\hline $\begin{array}{c}\text { Reticulado } \\
\text { (ESP/Tir/GA } \\
1.0 \%)\end{array}$ & $244 \pm 10$ & $6.6 \pm 0.4$ & $10 \pm 4$ & $35 \pm 12$ & $27 \leq[$ Catecol $] \leq 189$ & 0.9971 \\
\hline
\end{tabular}

La Tabla 3.3 muestra el valor de las constantes de velocidad de formación del producto $k_{2} \mathrm{o}$ también conocida como $k_{\text {catalitica }}\left(k_{c a t}\right)$, la cual se obtiene mediante la velocidad máxima y la concentración total de la enzima (ver anexo 2) cuando $k_{c a t}$ es pequeña indica que la afinidad de la enzima por el sustrato es elevada y por lo tanto $\mathrm{Km}$ debe ser pequeña. Cuando se obtienen una $k_{c a t}$ alta $K_{m}$ ' no puede ser alta y por lo tanto la afinidad de la enzima por el sustrato es limitada. Para tirosinasa mushroom la mayor eficiencia catalítica se obtiene al 


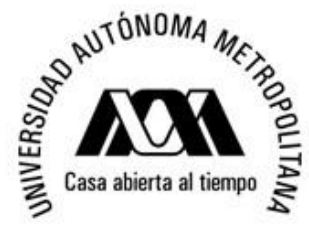

Universidad Autónoma Metropolitana Unidad Iztapalapa

División Ciencias Básicas e Ingeniería

Departamento de Química

Área de Química Analítica

Tesis de Doctorado

Q. Erika Rodríguez Sevilla

inmovilizar mediante el método de enlace covalente, seguido por el método de co-reticulado (biosensor ESP/Tir/GA 2.5\%), atrapamiento, y finalmente reticulado.

Tabla 3.3. Parámetros cinéticos de tirosinasa mushroom inmovilizada mediante los métodos de atrapamiento y reticulado, sobre sensores de tipo screen-printed.

\begin{tabular}{|c|c|c|c|c|c|}
\hline Biosensor & $K_{m}^{\prime}(\mu \mathrm{M})$ & $\begin{array}{l}I_{\operatorname{máx}} \\
(\mu \mathrm{A})\end{array}$ & $h$ & $\begin{array}{c}k_{\text {cat }} \\
\left(\mu \mathrm{A} \mathbf{m L} \mathrm{mg}^{-1}\right)\end{array}$ & $\begin{array}{c}k_{\text {cat }} / K_{m^{\prime}} \\
\left(\mu \mathrm{A} \mathrm{mL} \mathrm{mg}^{-1} \mu \mathrm{M}^{-1}\right)\end{array}$ \\
\hline ESP/Tir/PVA & $65 \pm 2$ & $16.8 \pm 0.2$ & $1.35 \pm 0.06$ & 3.32 & 0.0508 \\
\hline ESP/Tir/EDC & $75 \pm 18$ & $1.95 \pm 0.02$ & $1.55 \pm 0.06$ & 0.39 & 0.0051 \\
\hline ESP/Tir/ASH/GA $2.5 \%$ & $98 \pm 6$ & $7.2 \pm 0.2$ & $1.21 \pm 0.08$ & 1.43 & 0.0145 \\
\hline ESP/Tir/ASH/GA $1.0 \%$ & $141 \pm 4$ & $7.1 \pm 0.2$ & $1.25 \pm 0.09$ & 1.42 & 0.0100 \\
\hline ESP/Tir/GA $2.5 \%$ & $57 \pm 7$ & $5.35 \pm 0.02$ & $1.56 \pm 0.03$ & 0.62 & 0.0183 \\
\hline ESP/Tir/GA $1.0 \%$ & $244 \pm 10$ & $3.13 \pm 0.07$ & $1.45 \pm 0.06$ & 1.06 & 0.0025 \\
\hline
\end{tabular}

La eficiencia catalítica cambia con cada método de inmovilización, sin embargo también el sustrato afecta influye en la caracterización del biosensor. Se considera que el co-reticulado es el mejor método de inmovilización tanto para laccasa de Trametes versicolor como tirosinasa mushroom, sin embargo el enlace covalente es mejor método de inmovilización para Tir que para LTv, al igual que el reticulado puro, sin embargo el método de atrapamiento es considerado el segundo mejor método de inmovilización para ambas enzimas generando una mayor respuesta en la corriente, un tiempo de vida amplia y una buena trasferencia de carga en ambos casos. 


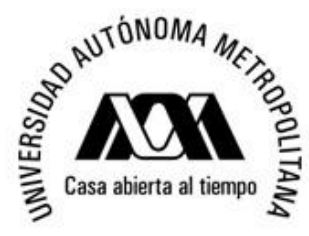

Universidad Autónoma Metropolitana Unidad Iztapalapa

División Ciencias Básicas e Ingeniería

Departamento de Química

Área de Química Analítica

Tesis de Doctorado

Q. Erika Rodríguez Sevilla
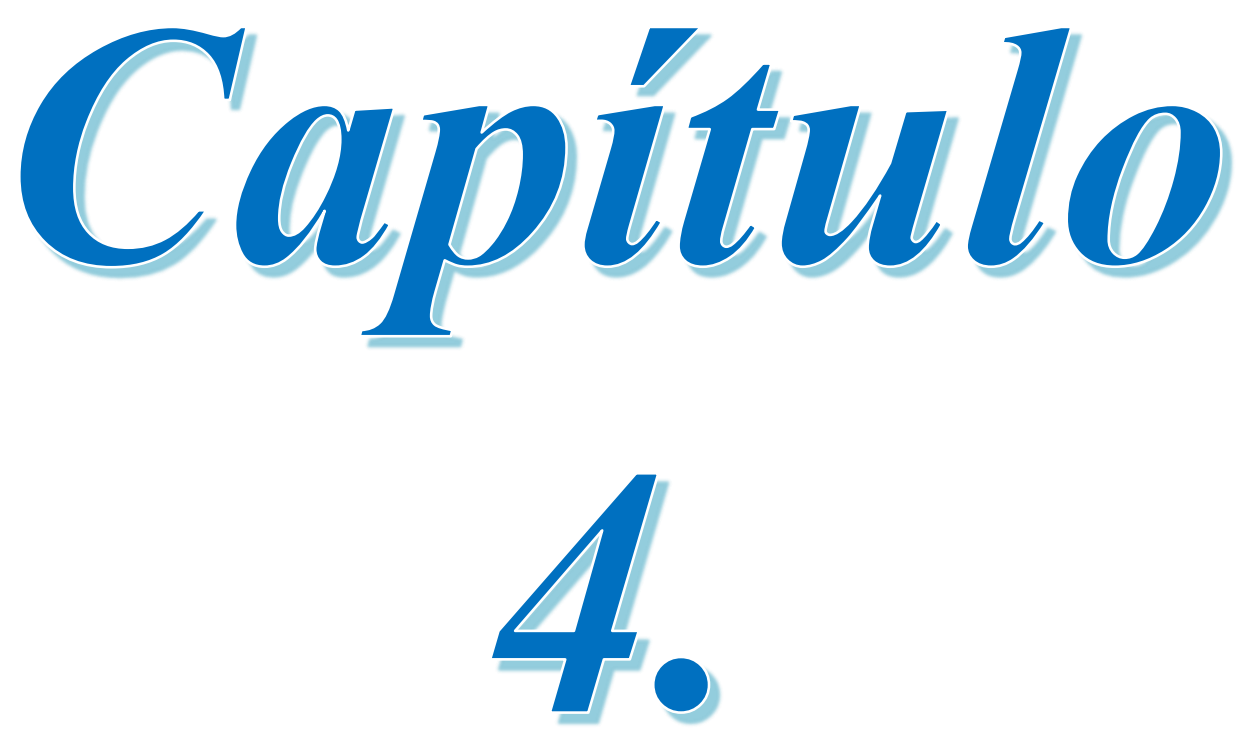

Caracterización de la reducción

\section{electroquímica sobre el soporte de ESP.}




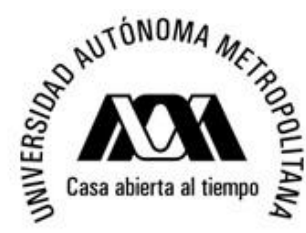

\subsection{Introducción}

Los parámetros relevantes para conocer la velocidad de reacción, en la cinética química son la concentración del reactivo y la constante de velocidad de formación del producto. Si la reacción química en estudio es una reacción enzimática de tipo:

$$
E+S \stackrel{k_{1}}{\stackrel{k_{-1}}{\longrightarrow}} E S \stackrel{k_{2}}{\longrightarrow} E+P
$$

donde $E$ es la enzima, $S$ es el sustrato, $E S$ es el complejo enzima-sustrato, $P$ es el producto de reacción, $k_{1}$ y $k_{-1}$ son las constantes de formación y disociación del complejo enzima sustrato y $k_{2}$ es la constante de formación del producto; las ecuaciones de velocidad estarán dadas en términos de la concentración de la enzima, la contracción del sustrato, o bien la concentración del complejo enzima sustrato así como de $k_{1}, k_{-1}$ y $k_{2}$ [6].

Si la reacción enzimática se lleva a cabo sobre un electrodo, ahora la distancia de los sitios activos de la enzima y la superficie del electrodo es otro parámetro relevante, es por ello que para la fabricación de biosensores debe tomarse en cuanta este hecho, pues la velocidad de transferencia de electrones entre una proteína grande redox y la superficie del electrodo es por lo general prohibitivamente lento, y se convierte en la principal barrera del sistema electroquímico [91].

El desarrollo de biosensores amperométricos ha ido avanzando en los últimos años [92, 93, 94, 95, 96, 97, 98] y con ello el interés por generar mejores dispositivos electroquímicos, de acuerdo con Lötzbeyer [99] un prerrequisito fundamental para el desarrollo de biosensores amperométricos es el control del proceso de transferencia de carga entre la enzima inmovilizada y la superficie del electrodo, razón por la cual la distancia entre el sitio activo de la enzima [100] y la superficie del electrodo de trabajo se convierte en un parámetro determinante que afecta directamente la robustez del biosensor.

Otra parte importante en el desarrollo de biosensores es la elección del elemento de reconocimiento, o bien de la enzima; para los biosensores basados en la transferencia de 


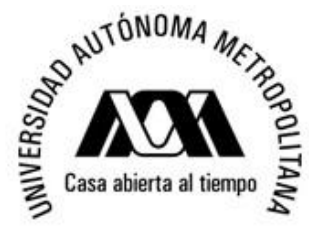
Universidad Autónoma Metropolitana Unidad Iztapalapa
División Ciencias Básicas e Ingeniería
Departamento de Química
Área de Química Analítica
Tesis de Doctorado
Q. Erika Rodríguez Sevilla

electrones directa de la proteína, la ausencia de mediador es la principal ventaja, proporcionándoles selectividad superior, debido a que deben operar en una ventana de potencial cercana al potencial redox de la enzima [91].

La laccasa (bencenodiol: oxígeno oxidorreductasas, EC 1.10.3.2) cataliza la oxidación de orto-y para-difenoles, amino-fenoles, polifenoles, poliaminas, ligninas, y diaminas de arilo, así como algunos iones inorgánicos acoplados a la reducción de dioxígeno molecular para agua $[101,102]$. Mediante un estudio teórico se ha determinado que los electrones se transfieren desde el electrodo al sitio activo de la proteína adsorbida con una distancia de 5 a $10 \AA$ de acuerdo con sus estructuras [103].

Se ha demostrado para algunas laccasas que $\mathrm{T} 1$ es el centro principal, en el que los electrones se aceptan a partir de la reducción de sustratos [104]. Debido a que el cobre T1 es el sitio primario aceptor de electrones y está conectado al clúster trinuclear T2/T3 por un tripéptido de His-Cys-His [105].

La eficiencia catalítica $\left(k_{c a t} / K_{m}\right)$ para algunos sustratos reductores puede afectarse al reducir u oxidar el cobre T1 en las laccasas [106] pues se ha demostrado que los sustratos se oxidan cerca del sitio T1, que luego transfiere el electrón al clúster T2/T3, donde se reduce el oxígeno molecular. De acuerdo con Ducros et al, [107] y Piontek et al, [43] la distancia entre el sitio de $\mathrm{T} 1$ y clúster T2/T3 es de 12 a $14 \AA$ A el sitio T1 todavía se puede reducir por un sustrato, pero la transferencia de electrones al clúster trinuclear es demasiado lento para ser catalíticamente relevante [108].

Las características de la electro-reducción de oxígeno en los electrodos de grafito o carbono modificados con laccasa dependen del origen y también de la cantidad de enzima sobre la superficie del electrodo $[109,110,111]$. Un mecanismo para la reducción bioelectro-catalítica 


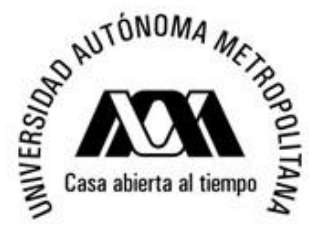

Universidad Autónoma Metropolitana Unidad Iztapalapa
División Ciencias Básicas e Ingeniería
Departamento de Química
Área de Química Analítica
Tesis de Doctorado
Q. Erika Rodríguez Sevilla

de oxígeno por laccasa adsorbida sobre electrodos de carbono ha sido propuesto por Tarasevich et al [112].

Todos los experimentos con electrodos de carbono modificados con laccasa confirman que el sitio $\mathrm{T} 1$ es el aceptor de electrones primaria de electrodos de carbono durante la reducción heterogénea tanto en condiciones aeróbicas y anaeróbicas.

De acuerdo con la teoría de Marcus y Sutin [113], la constante de velocidad para una reacción electroquímica enzimática se rige por la diferencia de potencial entre los centros redox involucrados, la energía de reorganización y más significativamente "la distancia entre el sitio activo de la enzima y la superficie del electrodo.

Para mejorar la transferencia electrónica de la enzima hacia el electrodo de trabajo, se han incorporado aceptores de electrones en algunos biosensores amperométricos que aceleren dicho proceso, y de esta forma obtener una mejor respuesta en la corriente.

Considerando todos estos parámetros en el presente trabajo se muestra el efecto del área cubierta por la membrana sobre el electrodo de trabajo de un biosensor de tipo screen-printed, utilizando laccasa de Trametes versicolor, como elemento de reconocimiento, inmovilizada mediante los métodos de atrapamiento y reticulado.

\subsection{Fabricación de biosensores}

Utilizando el procedimiento descrito en el anexo 3 para biosensores de LTV/PVA y LTv con GA al $2.5 \%$, se preparan biosensores con un diámetro de $1 \mathrm{~mm}, 2 \mathrm{~mm}$ y $3 \mathrm{~mm}$ cubiertos del área del electrodo de trabajo (Figura 4.1), los cuales son etiquetados como ESP/LTv/PVA30\%, ESP/LTv/PVA-60\%, ESP/LTv/PVA-100\% y ESP/LTv/GA-30\%, ESP/LTv/GA-60\%, ESP/LTV/GA-100\% respectivamente. 

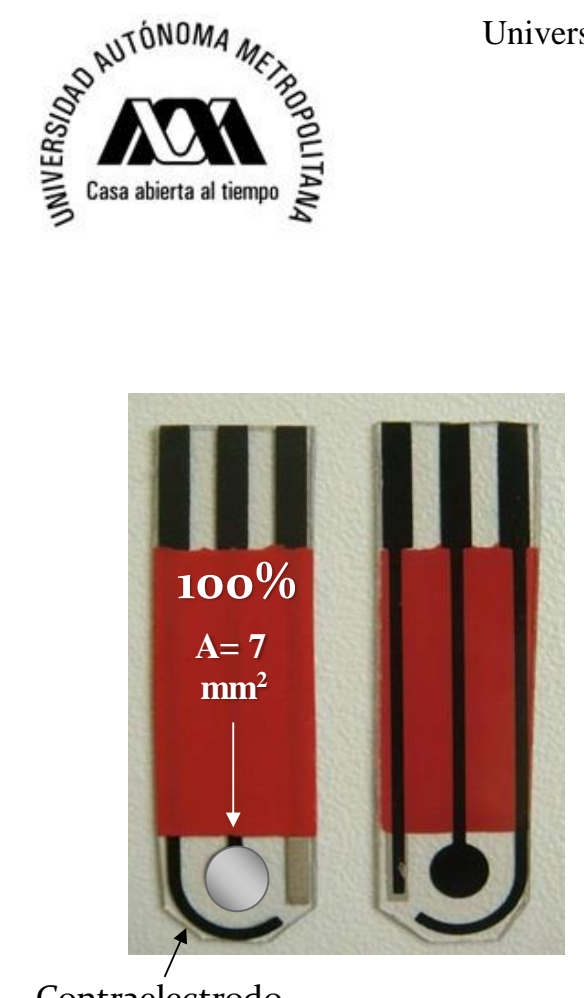

Contraelectrodo
Universidad Autónoma Metropolitana Unidad Iztapalapa

División Ciencias Básicas e Ingeniería

Departamento de Química

Área de Química Analítica

Tesis de Doctorado

Q. Erika Rodríguez Sevilla

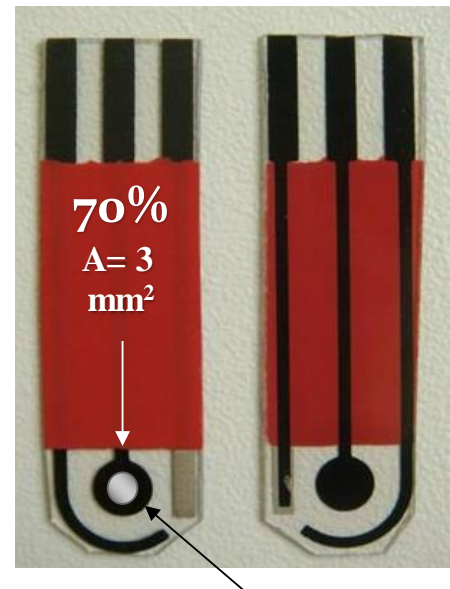

Electrodo de trabajo

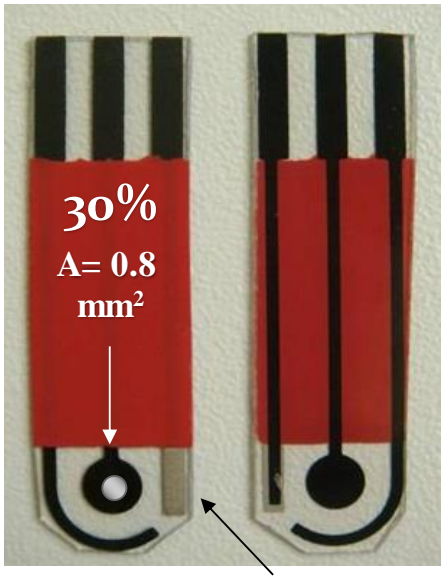

Pseudoreferencia $\mathrm{Ag} / \mathrm{AgCl}$

Figura 4.1. Esquema de la fabricación de los biosensores, con diferentes áreas cubiertas por la membrana en el electrodo de trabajo.

\subsection{Caracterización amperométrica de los diferentes biosensores con LTv}

\subsubsection{Caracterización de material del ESP.}

Para conocer si el sistema está controlado por difusión se lleva a cabo el estudio electroquímico de $Q$ mediante voltamperometría cíclica a diferentes velocidades de barrido. De acuerdo con la ecuación de Randles y Sevcik [114],

$$
i_{p}=\left(2.69 \times 10^{-5}\right) n^{3 / 2} A D^{1 / 2} v^{1 / 2} C^{*}
$$

donde $i_{p}$ es la corriente de pico expresada en amperios, $n$ es el número de electrones transferidos, $A$ es el área del electrodo en $\mathrm{cm}^{2}, D$ es el coeficiente de difusión de la especie que se oxida o se reduce en $\mathrm{cm}^{2} \mathrm{~s}^{-1}, v^{1 / 2}$ es la raíz cuadrada de la velocidad de barrido de potencial en $\mathrm{V} \mathrm{s}^{-1}, C^{*}$ es la concentración de la especie en el seno de la disolución en mol $\mathrm{cm}^{3}$.

La Figura 4.2 muestra los voltamperogramas cíclicos obtenidos para una $[Q]$ de $100 \mu \mathrm{M}$ utilizando un ESP sin modificar partiendo de un potencial de $0.1 \mathrm{~V}$ hacia valores negativos 


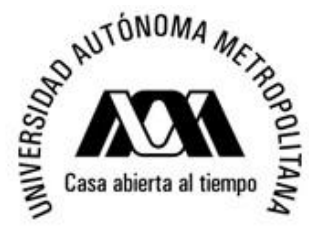
Universidad Autónoma Metropolitana Unidad Iztapalapa
División Ciencias Básicas e Ingeniería
Departamento de Química
Área de Química Analítica
Tesis de Doctorado
Q. Erika Rodríguez Sevilla

hasta un valor de $-0.6 \mathrm{~V}$, en este segmento se observa un pico de reducción correspondiente a la reducción de $Q$ a $H Q$, posteriormente al invertir el barrido de potencial hasta $0.6 \mathrm{~V}$ se observa la oxidación de $H Q$ a $Q$, el inserto muestra la dependencia de $-i_{p}$ con $v^{1 / 2}$, utilizando el valor de la pendiente de dicha recta se calcula el coeficiente de difusión $D=\left(2 \cdot 10^{-5}\right) \mathrm{cm}^{2} \mathrm{~s}^{-}$ ${ }^{1}$ el cual indica que el proceso de óxido-reducción de $H Q-Q$ está controlado por difusión.

Debido a que el sistema en estudio es un sistema cuasirreversible puede calcularse la constante velocidad heterogénea intrínseca $k^{0}$ para la reacción electroquímica a partir de la siguiente ecuación:

$$
i_{p}=0.227 n F A C^{*} k^{0} \exp \left[-\left(\frac{\alpha n_{\alpha} F}{R T}\right)\left(E_{p}-E^{0^{\prime}}\right)\right]
$$

donde $\alpha$ es el coeficiente de transferencia de carga y $n_{\alpha}$ es el número de electrones implicados en la etapa determinante de la velocidad del proceso electródico, $E_{p}$ es el potencial de pico, $E^{0^{\prime}}$ es el potencial del par redox, en este caso Q-HQ aplicando ln a la ecuación anterior se obtiene:

$$
\begin{gathered}
\ln i_{p}=\ln \left(0.227 n F A C^{*} k^{0} \exp \left[-\left(\frac{\alpha n_{\alpha} F}{R T}\right)\left(E_{p}-E^{0^{\prime}}\right)\right]\right) \\
\ln i_{p}=\ln 0.227 n F A C^{*} k^{0} \ln \left(\exp \left[-\left(\frac{\alpha n_{\alpha} F}{R T}\right)\left(E_{p}-E^{0^{\prime}}\right)\right]\right) \\
\ln i_{p}=\ln 0.227 n F A C^{*} k^{0}-\left(\frac{\alpha n_{\alpha} F}{R T}\right)\left(E_{p}-E^{0^{\prime}}\right)
\end{gathered}
$$

De acuerdo con la ecuación anterior a partir de la pendiente de la recta obtenida al graficar $\ln i_{p}$ vs $\left(E_{p}-E^{0^{\prime}}\right)$, es posible conocer $\alpha$, mientras que a partir de la ordenada al origen se obtiene $k^{0}$,

$$
m=-\left(\frac{\alpha n_{\alpha} F}{R T}\right) \Rightarrow \alpha=-\frac{m R T}{n_{\alpha} F}
$$




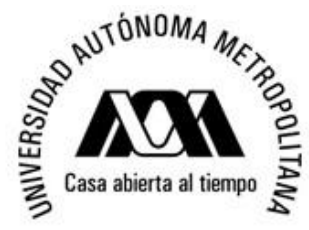

Universidad Autónoma Metropolitana Unidad Iztapalapa

División Ciencias Básicas e Ingeniería

Departamento de Química

Área de Química Analítica

Tesis de Doctorado

Q. Erika Rodríguez Sevilla

$$
b=0.227 n F A C^{*} k^{0} \Rightarrow k^{0}=\frac{\exp (b)}{0.227 n F A C^{*}}
$$

La Figura 4.3 muestra la dependencia de $\ln i_{p}$ con $\left(E_{p}-E^{0^{\prime}}\right)$, para este sistema se obtiene un valor de $\alpha$ de 0.22 así como una $k^{0}$ de $5.73 \times 10^{-5} \mathrm{~cm}^{2} \mathrm{~s}^{-1}$, lo que indica que la velocidad de transferencia electrónica es "lenta".

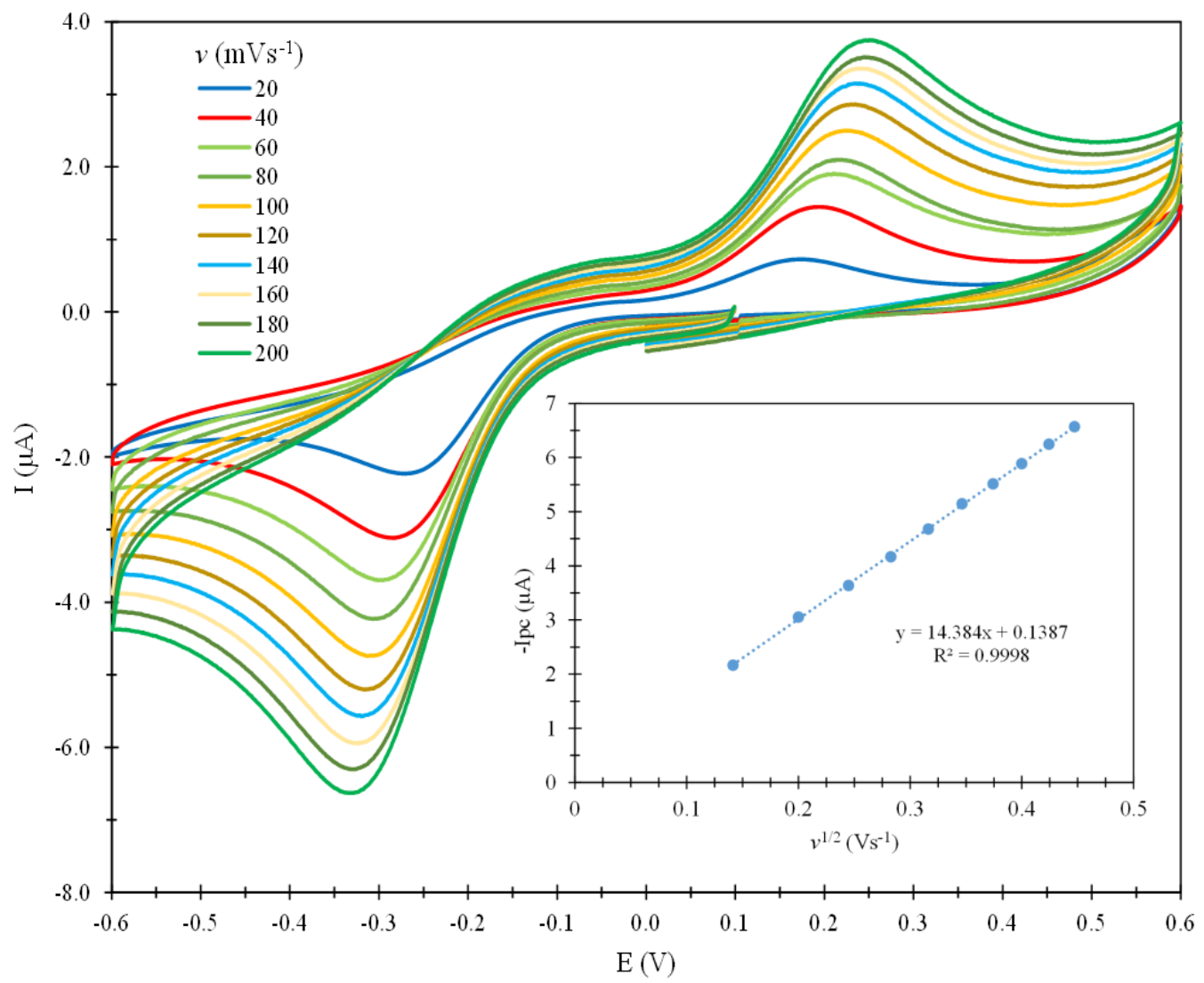

Figura 4.2. Estudio voltamperométrico de la velocidad de barrido en función del potencial para una [Q] 100 $\mu \mathrm{M}$, contenida en amortiguador de acetatos $0.1 \mathrm{M}$ a pH $4.70 \pm 0.01$ a $(30.0 \pm 0.5)^{\circ} \mathrm{C}$, utilizando un ESP sin modificar. 


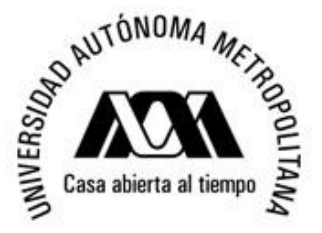

Universidad Autónoma Metropolitana Unidad Iztapalapa

División Ciencias Básicas e Ingeniería

Departamento de Química

Área de Química Analítica

Tesis de Doctorado

Q. Erika Rodríguez Sevilla

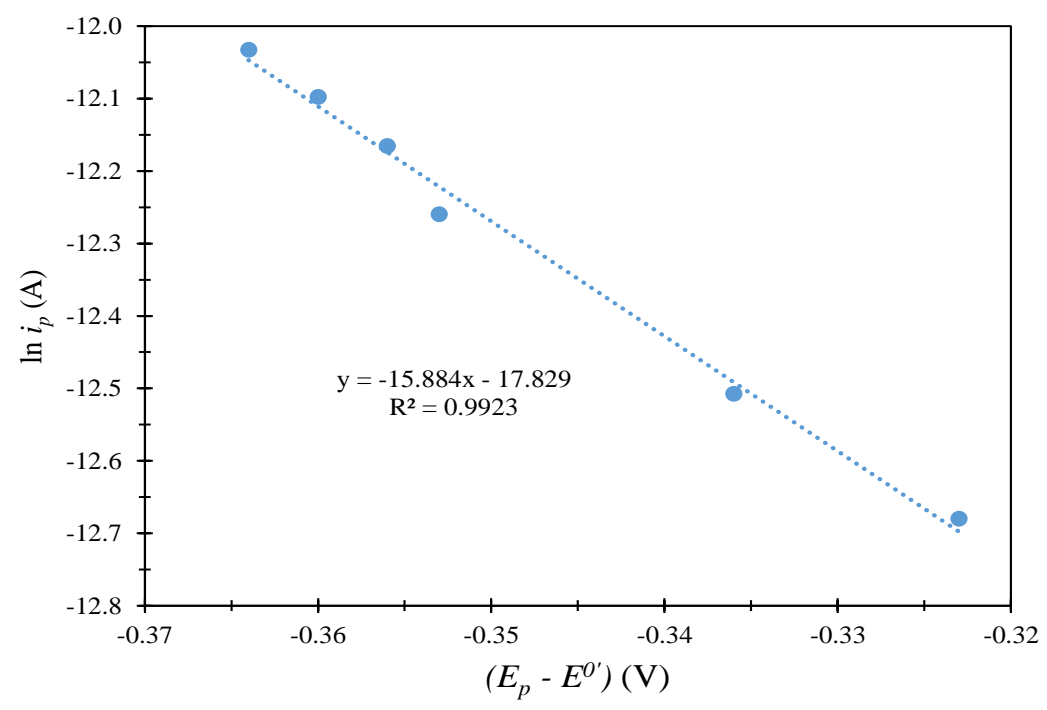

Figura 4.3. Dependencia de de $\ln \mathrm{i}_{\mathrm{p}}$ con $\left(\mathrm{E}_{\mathrm{p}}-\mathrm{E}^{0}\right)$, para una [Q] $100 \mu \mathrm{M}$, contenida en amortiguador de acetatos $0.1 \mathrm{M} \mathrm{a} \mathrm{pH} 4.70 \pm 0.01$ a $(30.0 \pm 0.5)^{\circ} \mathrm{C}$, utilizando un ESP sin modificar.

\subsubsection{Caracterización electroquímica del sistema $L T v-H Q$ en solución.}

A una velocidad de barrido de $100 \mathrm{mVs}^{-1}$, el pico de reducción de $Q$ a $H Q$ se encuentra a un potencial de $-0.313 \mathrm{~V}$, por lo tanto para la obtención de los parámetros cinéticos del sistema descrito en la ecuación (1), mediante amperometría se utiliza un ESP sin modificar y se sigue la reducción de quinona a un potencial impuesto de -0.300 V. En la Figura 4.4 se muestra el comportamiento cinético del sistema, al colocar $L T v$ de $11.34 \mu \mathrm{g} \mathrm{mL}{ }^{-1}$ con diferentes concentraciones de HQ en solución; el cual tiene una $K_{m}$ ' de (199 \pm 5$) \mu \mathrm{M}$, una $I_{\max }$ de (6.9 $\pm 0.1) \mu \mathrm{A}$ y sigue un comportamiento Michaeliano. Ambas técnicas describen de manera adecuada la cinética enzimática de laccasa, cuando se lleva a cabo la determinación mediante métodos espectrofotométricos, se observa un $99 \%$ de la quinona formada, mientras que al utilizar un ESP sin modificar se detecta el 97\% del producto. La Tabla 1 muestra una comparación de los parámetros cinéticos y analíticos de la enzima en solución obtenidos mediante las dos técnicas mencionadas anteriormente, los límites de detección y 
División Ciencias Básicas e Ingeniería

Departamento de Química

Área de Química Analítica

Tesis de Doctorado

Q. Erika Rodríguez Sevilla

cuantificación son estadísticamente iguales, este hecho valida el uso de un ESP para el estudio electroquímico de la enzima en el desarrollo de biosensores.

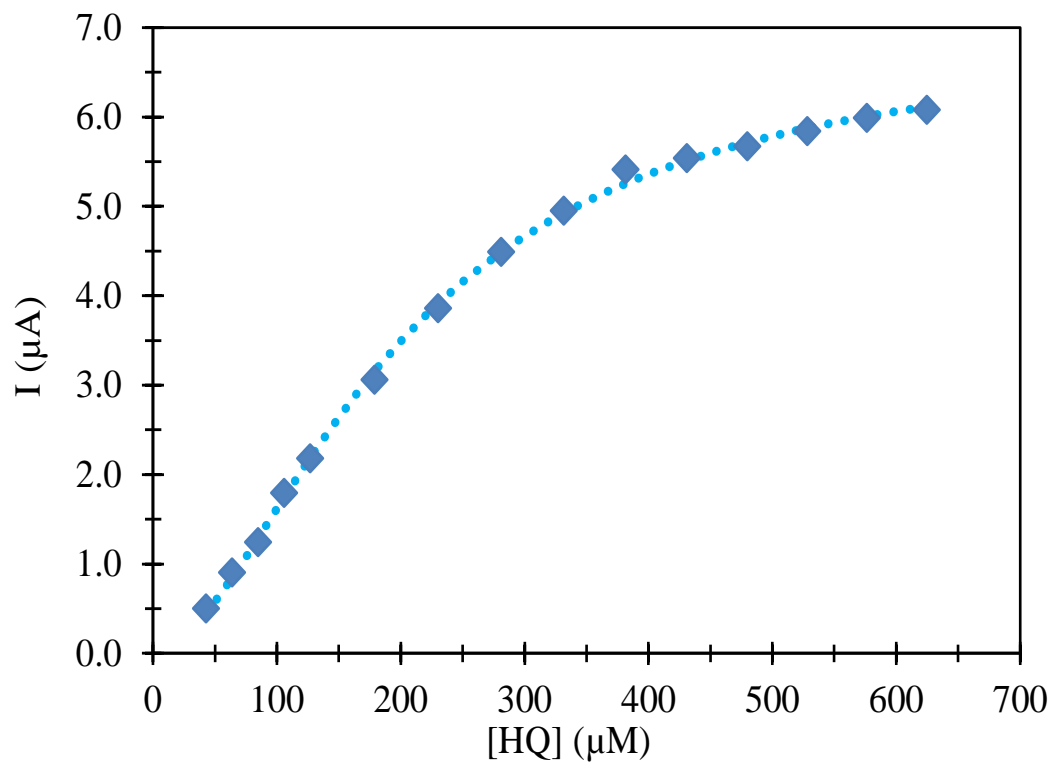

Figura 4.4. Cinética enzimática de laccasa de Trametes versicolor en amortiguador de acetatos $0.1 \mathrm{M} \mathrm{a} \mathrm{pH}=$ $4.70 \pm 0.01 \mathrm{a}(30.0 \pm 0.5)^{\circ} \mathrm{C}$ para diferentes concentraciones de Hidroquinona, la línea punteada es el ajuste obtenido mediante el modelo de Hill (anexo 2)

Tabla 4.1. Parámetros cinéticos y analíticos obtenidos para laccasa de Trametes versicolor en solución, caracterizada mediante espectrofotometría de UV-Vis y amperometría

LTv con HQ en solución mediante UV-Visible

\begin{tabular}{|c|c|c|c|c|c|c|c|}
\hline $\begin{array}{c}K_{m} \\
(\mu \mathbf{M})\end{array}$ & $\begin{array}{c}\text { Sensibilidad } \\
\left(\mathrm{s}^{-1}\right)\end{array}$ & $\begin{array}{l}\text { LDD } \\
(\mu \mathrm{M})\end{array}$ & $\begin{array}{l}\text { LDQ } \\
(\mu \mathrm{M})\end{array}$ & $\begin{array}{c}\text { Intervalo lineal } \\
(\mu \mathrm{M})\end{array}$ & $\begin{array}{c}V_{\text {máx. }} \\
\left(\mu \mathbf{M s}^{-1}\right)\end{array}$ & $\boldsymbol{h}$ & $\mathbf{R}^{2}$ \\
\hline $197 \pm 3$ & $0.20 \pm 0.06$ & $2.6 \pm 0.2$ & $8.7 \pm 0.5$ & $0 \leq[\mathrm{HQ}] \leq 268$ & $7.93 \pm 0.09$ & $2.17 \pm 0.08$ & 0.9913 \\
\hline \multicolumn{8}{|c|}{ ESP + LTv con HQ en solución mediante amperometría } \\
\hline $\begin{array}{c}K_{m}^{\prime} \\
(\mu \mathrm{M})\end{array}$ & $\begin{array}{l}\text { Sensibilidad } \\
\left(\mathbf{n A} \mu \mathbf{M}^{-1}\right)\end{array}$ & $\begin{array}{l}\text { LDD } \\
(\mu \mathrm{M})\end{array}$ & $\begin{array}{l}\text { LDQ } \\
(\mu \mathrm{M})\end{array}$ & $\begin{array}{c}\text { Intervalo lineal } \\
(\mu \mathrm{M})\end{array}$ & $\begin{array}{l}I_{\text {máx }} \\
(\mu \mathrm{A})\end{array}$ & $\boldsymbol{h}$ & $\mathbf{R}^{2}$ \\
\hline $199 \pm 5$ & $17 \pm 2$ & $2.4 \pm 0.1$ & $7.9 \pm 0.3$ & $0 \leq[\mathrm{HQ}] \leq 281$ & $6.9 \pm 0.1$ & $1.73 \pm 0.04$ & 0.9995 \\
\hline
\end{tabular}




\subsection{Optimización de parámetros cinéticos y electroquímicos para la fabricación de biosensores.}

Como se ha demostrado en los apartados anteriores, el sistema formado con laccasa de Trametes versicolor e Hidroquinona, es un sistema de tipo químico-electroquímico, es por esta razón que para la fabricación de biosensores debe cuidarse en no afectar la actividad enzimática (reflejada en $K_{m}$ ) ni la transferencia electrónica (reflejada en $k^{0^{0}}$ ). La Figura 4.5 muestra las reacciones químicas y electroquímicas acopladas que se llevan a cabo sobre el electrodo de trabajo del biosensor, entre LTv y HQ.

\subsection{Caracterización del biosensor con un área de $100 \%$ cubierto del electrodo de trabajo.}

$\mathrm{Al}$ inmovilizar LTv mediante el método de reticulado utilizando glutaraldehído al 2.5\%, la familia de voltamperogramas obtenidos (Figura 4.6) muestra que la transferencia electrónica se ve afectada, la separación de potencial entre el pico catódico y anódico indica que la velocidad en la reacción enzimática es mayor y la velocidad de la reacción electroquímica ha disminuido [115]. Por lo tanto se tiene una reacción química irreversible irreversible, imponiendo un potencial de $-0.300 \mathrm{~V}$, se obtienen el comportamiento cinético mediante amperometría (Figura 4.7 a), en este caso se observa un intervalo lineal de $(0 \leq[\mathrm{HQ}] \leq 249)$ $\mu \mathrm{M}$, una $K_{m}$ ' de $(163 \pm 5) \mu \mathrm{M}$ y una $I_{\text {máx }}$ de $(3.27 \pm 0.05) \mu \mathrm{A}$, ambos parámetros cinéticos son más bajos comparados con los de la enzima en solución. El valor de $K_{m}{ }^{\prime}$ nos indica que la interacción de los sitios activos de la enzima con HQ ha mejorado, es decir la actividad enzimática es mayor, sin embargo de acuerdo con el modelo de Hill (anexo 2), si la actividad enzimática mejora la respuesta obtenida por el biosensor debería de ser mayor, ( $I_{\max }$ en el biosensor $>I_{\max }$ para LTv en solución) lo que implica que la sensibilidad del sensor sea alta. 
División Ciencias Básicas e Ingeniería

Departamento de Química

Área de Química Analítica

Tesis de Doctorado

Q. Erika Rodríguez Sevilla

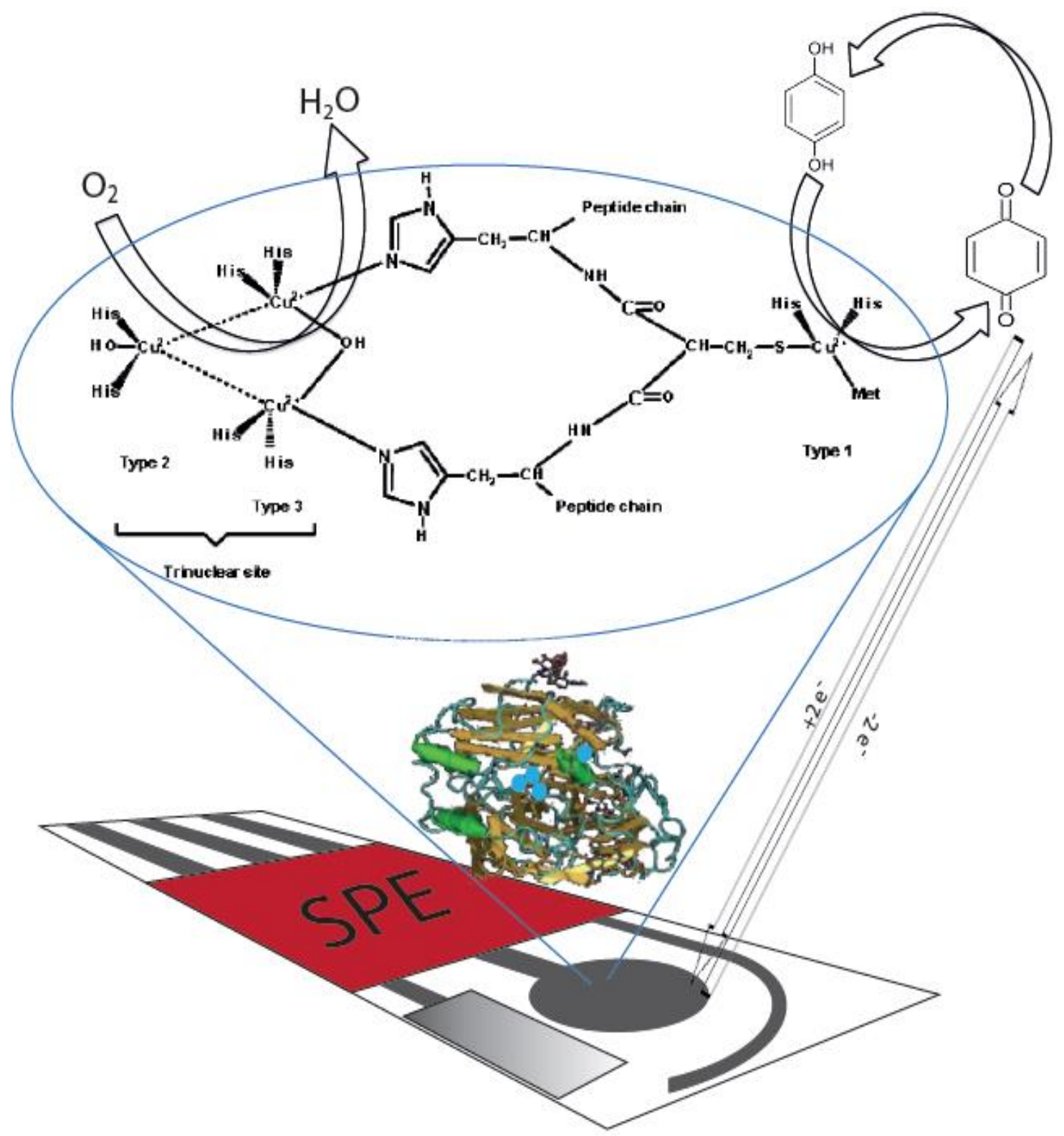

Figura 4.5. Esquema de la inmovilizacion de laccasa de Trametes versicolor sobre el electrodo de screenprinted (ESP), los puntos azules señalan los atomos de $\mathrm{Cu}$ involucrados en el sitio activo de la enzima, asi como las reacciones quimicas y electroquimas que se llevan a cabo al interactuar la enzima con el sustrato. 

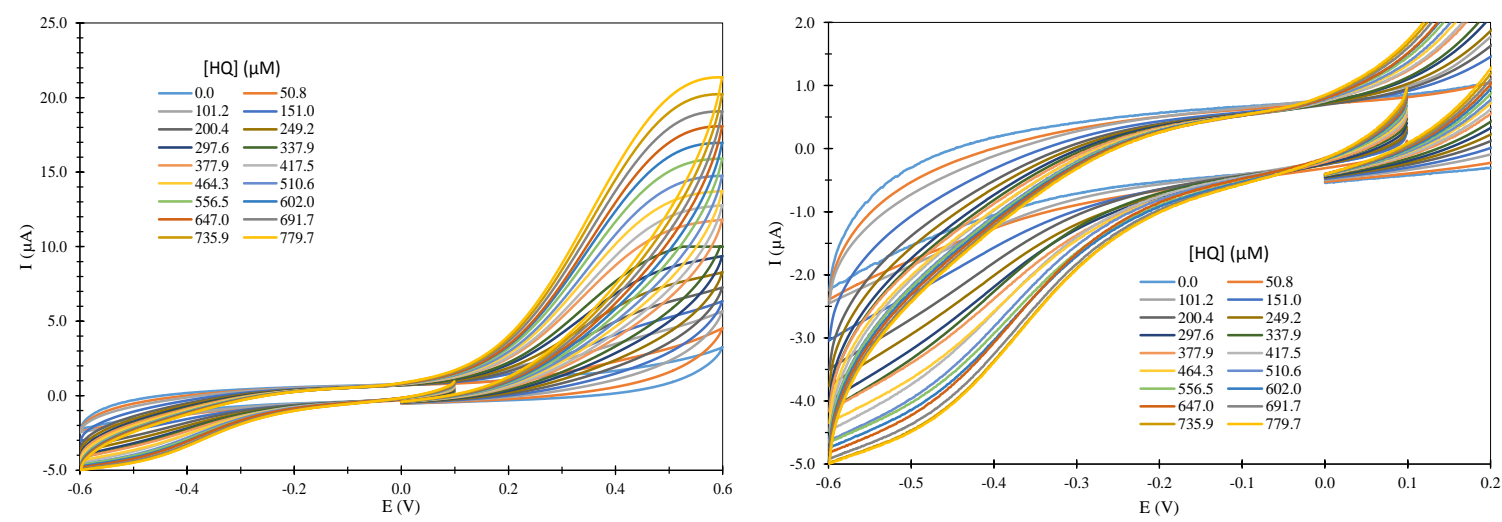

Figura 4.6. Voltamperogramas cíclicos obtenidos para el biosensor ESP/LTv/GA - 100\%, a diferentes concentraciones de HQ contenida en amortiguador de acetatos $0.1 \mathrm{M}$ a pH $4.70 \pm 0.01$ a $(30.0 \pm 0.5)^{\circ} \mathrm{C}$, partiendo de un potencial de $0.1 \mathrm{~V}$ hacia reducción, a una velocidad de barrido de $100 \mathrm{mVs}^{-1}$.

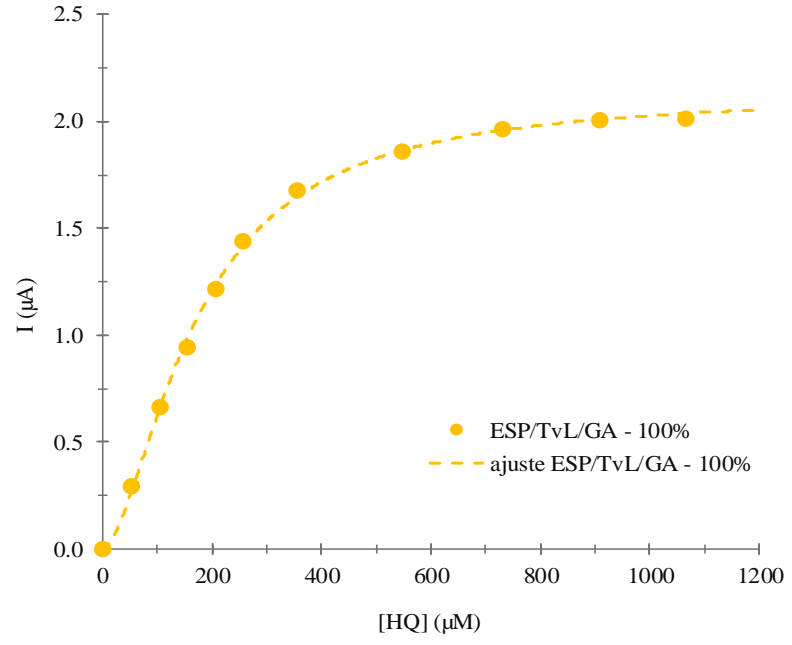

a)

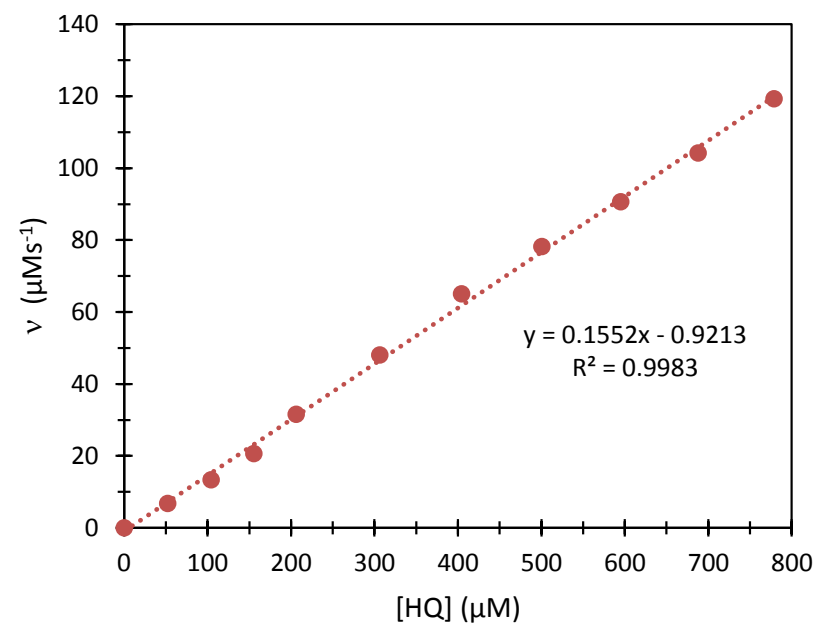

b)

Figura 4.7. Comportamiento cinético de LTv obtenido mediante a) voltamperometría cíclica, Ip obtenida para la reducción de Q a HQ, b) UV-Vis, utilizando el biosensor ESP/LTV/GA - 100\%, a diferentes concentraciones de HQ contenida en amortiguador de acetatos $0.1 \mathrm{M}$ a pH $4.70 \pm 0.01$ a $(30.0 \pm 0.5)^{\circ} \mathrm{C}$.

De manera simultánea se lleva a cabo la caracterización del sensor mediante espectrofotometría (Figura 4.7 b) en este caso se observa una velocidad de reacción mayor que para la enzima en solución (700\% mayor), sin embargo no es posible detectar el 

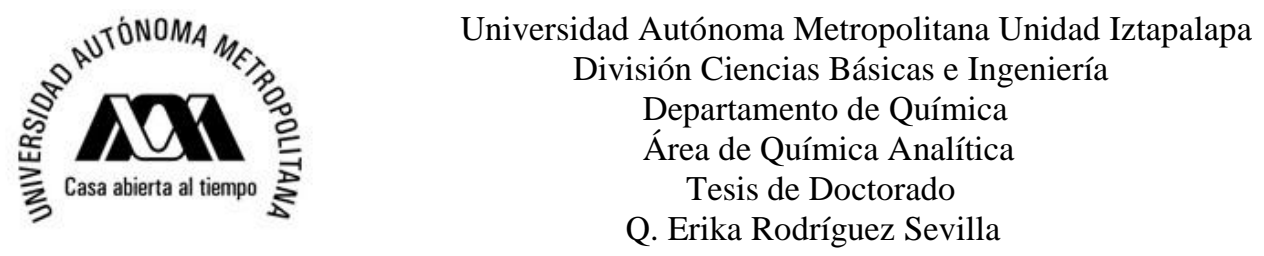

comportamiento cinético completo debido a la saturación en la señal del espectrofotómetro. Este comportamiento nos indica que la [Q] formada por la enzima es mayor que la [Q] detectada amperométricamente; en cuyo caso solo se observa el 30\% de la Q producida en la reacción enzimática, este problema en la detección de $\mathrm{Q}$ es atribuido a la red polimérica que es muy densa y por lo tanto no hay acceso del sustrato a la superficie del electrodo, lo que afecta directamente la velocidad de reacción electroquímica.

\subsection{Caracterización de biosensor con el $70 \%$ del área cubierta en el electrodo de trabajo}

De acuerdo a lo reportado en el literatura, cuando la enzima es inmovilizada, la actividad catalítica aumenta por lo tanto la $K_{m}{ }^{\prime}$ disminuye, como al cubrir el $100 \%$ del electrodo de trabajo en el biosensor, lo anterior no se observaba en la respuesta amperométrica, se propone descubrir el 30\% del área del electrodo de trabajo en el ESP, es decir cubrir solo el 70\% del área con la membrana polimérica, manteniendo la misma cantidad de enzima que en el caso anterior, al hacerlo la respuesta se incrementa un $36 \%$ de esta forma la [Q] detectada es el 95\% de la HQ oxidada enzimáticamente, el pico de reducción se observa en un potencial de $-0.541 \mathrm{~V}$ (Figura 4.8), y la forma del voltamperograma nos indica que se ha encontrado un equilibrio adecuado entre la cinética enzimática y la cinética electroquímica, ahora bien en efecto catalítico que se observa a bajas concentraciones es debido a la presencia de la enzima, pues la $\mathrm{Q}$ reducida potenciométricamente, es nuevamente oxidada enzimáticamente, al alcanzar concentraciones más altas de HQ este efecto se ve disminuido debido a la saturación de la enzima. 


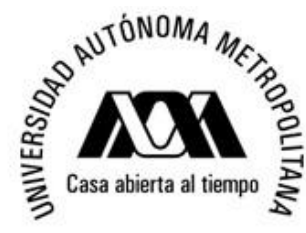

Universidad Autónoma Metropolitana Unidad Iztapalapa

División Ciencias Básicas e Ingeniería

Departamento de Química

Área de Química Analítica

Tesis de Doctorado

Q. Erika Rodríguez Sevilla

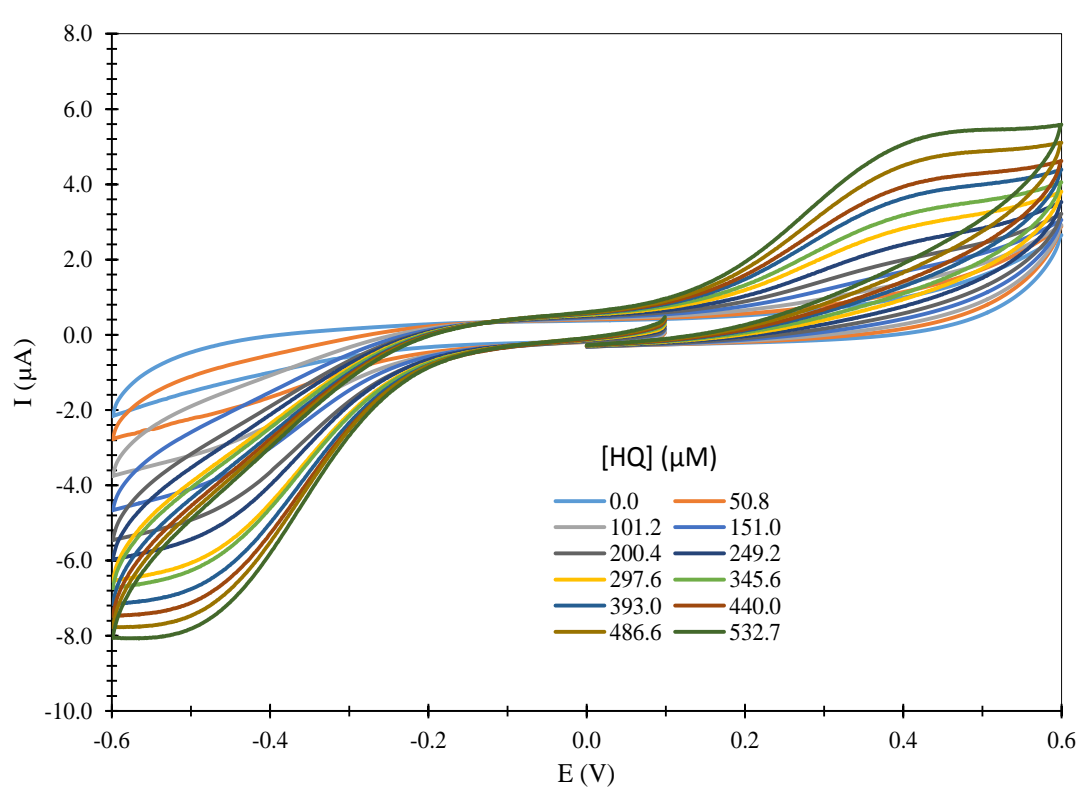

Figura 4.8. Voltamperogramas cíclicos obtenidos para el biosensor ESP/LTv/GA - 70\%, a diferentes concentraciones de $\mathrm{HQ}$ contenida en amortiguador de acetatos $0.1 \mathrm{M}$ a pH $4.70 \pm 0.01 \mathrm{a}(30.0 \pm 0.5)^{\circ} \mathrm{C}$, partiendo de un potencial de $0.1 \mathrm{~V}$ hacia reducción, a una velocidad de barrido de $100 \mathrm{mVs}^{-1}$.

El comportamiento cinético del biosensor se muestra en la Figura 4.9 a), es este caso se observa una $K_{m}{ }^{\prime}$ de $(143 \pm 3) \mu \mathrm{M}$, un intervalo lineal de $(0 \leq[\mathrm{HQ}] \leq 255) \mu \mathrm{M}$, con una sensibilidad $(26.7 \pm 0.4) \mathrm{nA} \mu \mathrm{M}^{-1}$; ambos parámetros analíticos son mejores que para el biosensor que tiene el 100\% del área del electrodo de trabajo cubierto por la membrana polimérica. De manera simultánea a la caracterización potenciométrica se realiza el análisis espectrofotométrico (Figura 4.9 b), en este caso se observa un incremento en la velocidad de reacción de $150 \%$ comparado con el electrodo cubierto totalmente, sin embargo el comportamiento cinético no puede ser determinado debido a la saturación en la respuesta del equipo. Estos resultados nos indican que cuando se tiene un 30\% libre de la superficie del electrodo de trabajo y un $70 \%$ cubierto por la enzima, tanto la cinética enzimática como la 


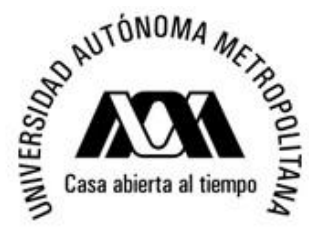

Universidad Autónoma Metropolitana Unidad Iztapalapa

División Ciencias Básicas e Ingeniería

Departamento de Química

Área de Química Analítica

Tesis de Doctorado

Q. Erika Rodríguez Sevilla

cinética electroquímica tienen un incremento la velocidad de reacción, por ello se obtienen mejores parámetros cinéticos y analíticos para el biosensor.

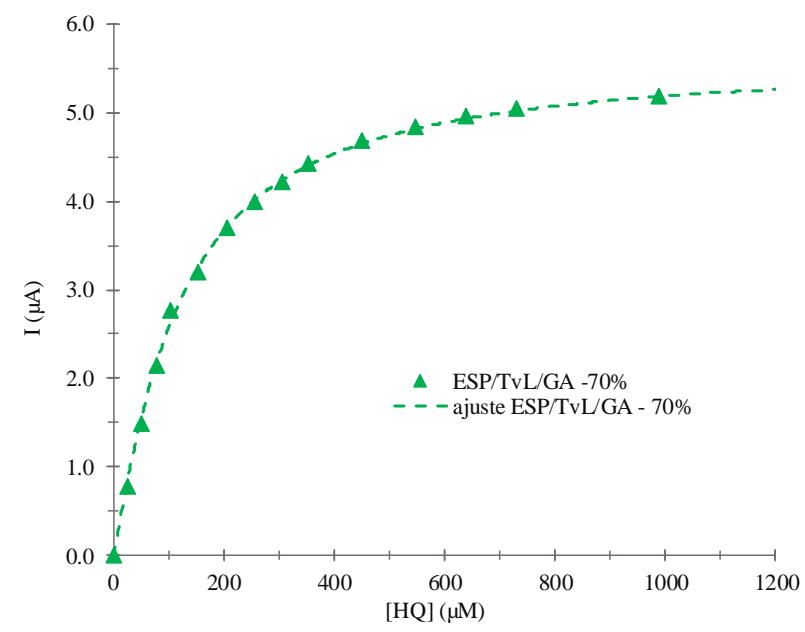

a)

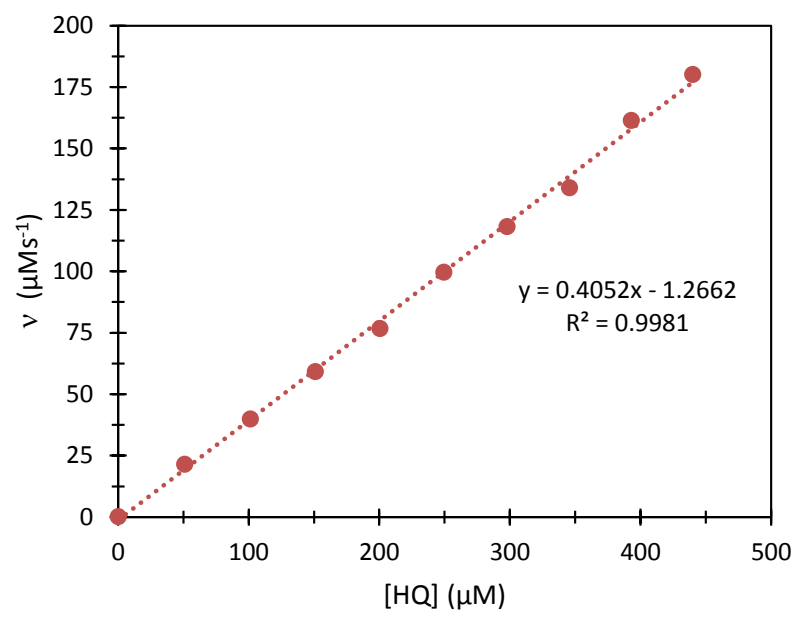

b)

Figura 4.9. Comportamiento cinético de LTv obtenido mediante a) voltamperometría cíclica, Ip obtenida para la reducción de Q a HQ, b) UV-Vis, utilizando el biosensor ESP/LTv/GA - 70\%, a diferentes concentraciones de HQ contenida en amortiguador de acetatos $0.1 \mathrm{M}$ a pH $4.70 \pm 0.01$ a $(30.0 \pm 0.5)^{\circ} \mathrm{C}$.

\subsection{Caracterización de biosensor con el $30 \%$ del área cubierta en el electrodo de trabajo}

Cuando se descubre el 70\% del área en el electrodo de trabajo, la diferencia de potencial entre los picos de reducción y oxidación se mantiene (Figura 4.10) sin embargo la intensidad en la corriente es similar a la obtenida por la enzima en solución, esto nos indica que la constante de velocidad de la reacción química se ha favorecido, sin embargo la constante de velocidad de transferencia electrónica se ve afectada. 


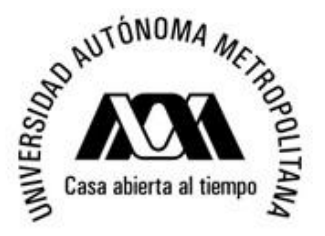

Universidad Autónoma Metropolitana Unidad Iztapalapa

División Ciencias Básicas e Ingeniería

Departamento de Química

Área de Química Analítica

Tesis de Doctorado

Q. Erika Rodríguez Sevilla

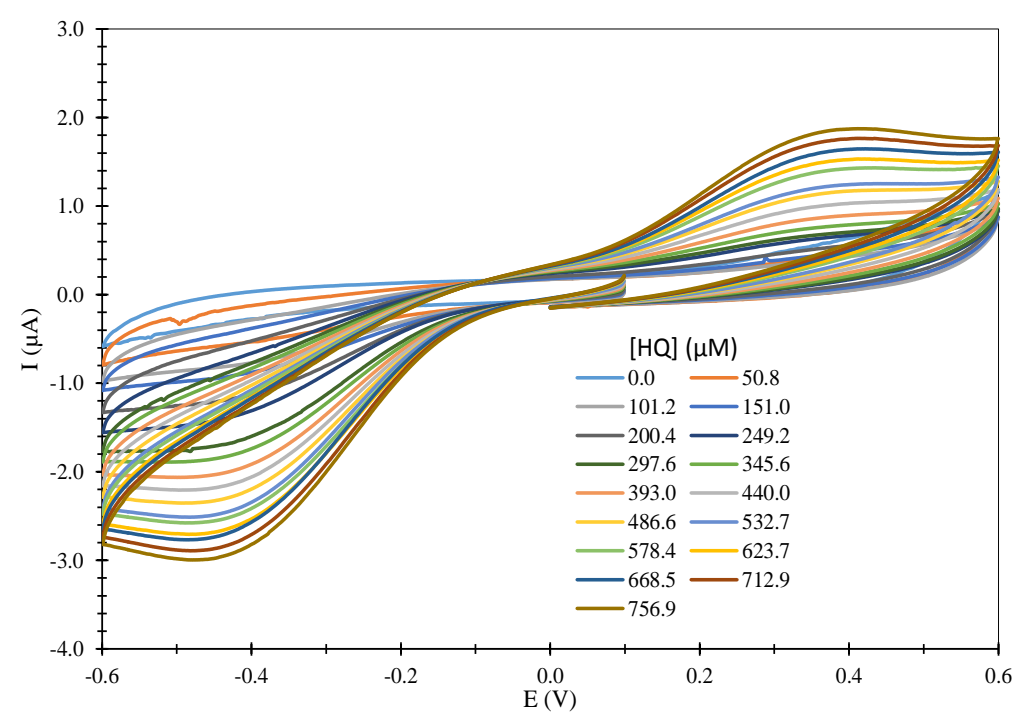

Figura 4.10. Voltamperogramas cíclicos obtenidos para el biosensor ESP/LTv/GA - 30\%, a diferentes concentraciones de $\mathrm{HQ}$ contenida en amortiguador de acetatos $0.1 \mathrm{M}$ a pH $4.70 \pm 0.01 \mathrm{a}(30.0 \pm 0.5)^{\circ} \mathrm{C}$, partiendo de un potencial de $0.1 \mathrm{~V}$ hacia reducción, a una velocidad de barrido de $100 \mathrm{mVs}^{-1}$.

La cinética descrita por el biosensor sigue siendo de tipo Michaeliano (Figura 4.11 a), los parámetros cinéticos del biosensor $K_{m}{ }^{\prime}=(171 \pm 6) \mu \mathrm{M}$ y $I_{\max }=$ (obtenidos indican que los sitios activos de la enzima son expuestos de manera adecuada, sin embargo la interacción de la hidroquinona con los sitios activos de la laccasa se ve afectada debido a el área reducida en el electrodo de trabajo obteniendo así una contante de Michaelis-Menten aparente mayor), y una intensidad en la respuesta menor comparado con el biosensor anterior.

La velocidad de reacción es medida de manera simultánea, en este caso no se observa la saturación de la enzima, debido a la saturación en la absorbancia del equipo (Figura 4.11 b), por lo que no pueden determinarse los parámetros cientos para el biosensor sin embargo se observa un incremento del $7.2 \%$ con respecto a la velocidad de reacción para la enzima en solución. 


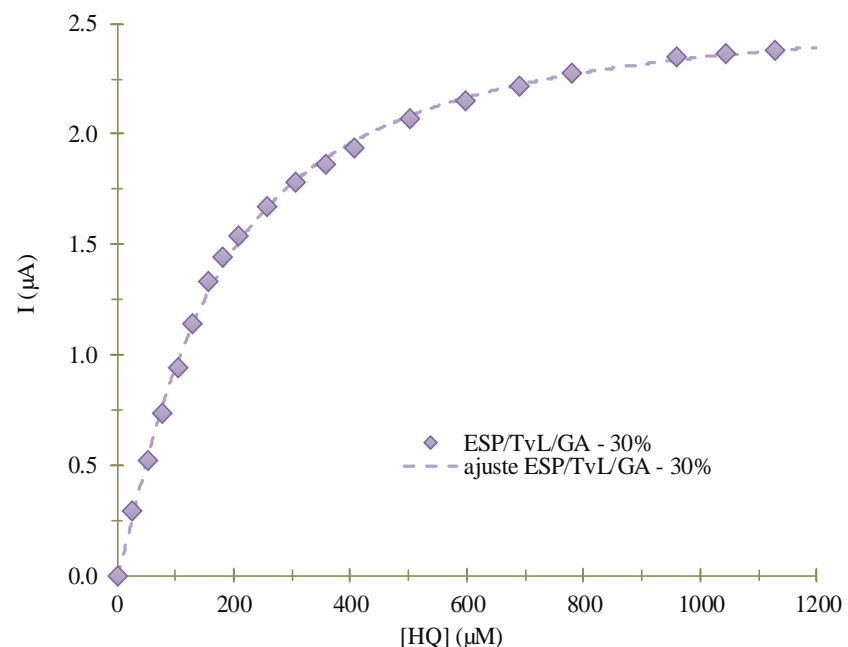

a)

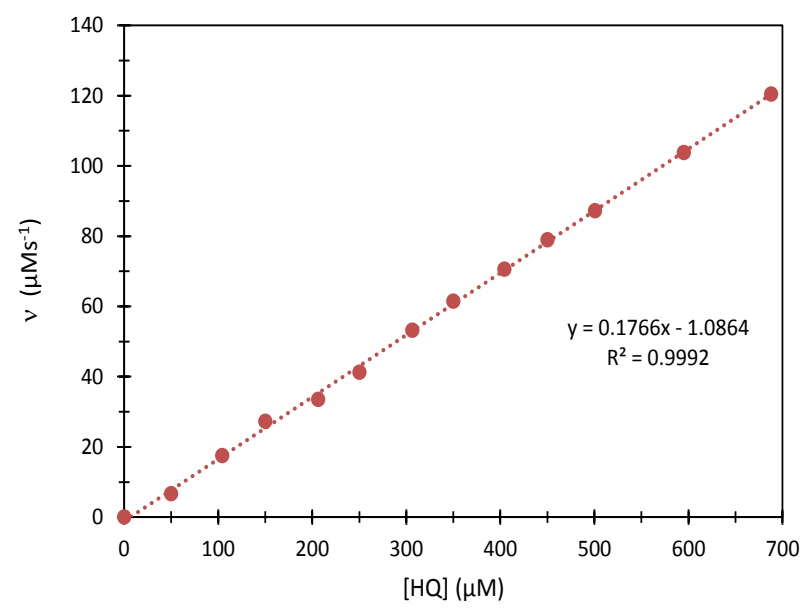

b)

Figura 4.11. Comportamiento cinético de LTv obtenido mediante a) voltamperometría cíclica, Ip obtenida para la reducción de Q a HQ, b) UV-Vis, utilizando el biosensor ESP/LTV/GA - 30\%, a diferentes concentraciones de HQ contenida en amortiguador de acetatos $0.1 \mathrm{M}$ a pH $4.70 \pm 0.01$ a $(30.0 \pm 0.5)^{\circ} \mathrm{C}$.

Para la caracterización amperométrica, se impone un potencial de reducción de $-0.300 \mathrm{~V}$, el comportamiento cinético del biosensor ESP/LTv/GA con distintas áreas cubiertas por la membrana en el electrodo de trabajo se observa en la Figura 4.12, cuando la superficie del electrodo de trabajo es cubierta en su totalidad (ESP/LTv/GA-100\%, Figura 4 marcadores ๑), se obtienen una corriente máxima $\left(I_{\max }\right)$ de $(2.13 \pm 0.02) \mu \mathrm{A}$, y una constante de Michaelis-Menten aparente $\left(\mathrm{Km}^{\prime}\right)$ de $(169 \pm 3) \mu \mathrm{M}$, dichos parámetros son obtenidos mediante la regresión no lineal basada en el modelo de Hill (anexo 2). Cuando el área del electrodo es cubierta en un 70\% (ESP/LTv/GA-70\%, Figura 4.12 marcadores $\mathbf{A}$ ), ) la respuesta se incrementa en un $263 \%$, obteniendo una $I_{\max }$ de $(5.61 \pm 0.03) \mu \mathrm{A}$ y una $K_{m}{ }^{\prime}=$ $(116 \pm 2) \mu \mathrm{M}$, la constante de Michaelis indica que si $K_{m}{ }^{\prime}$ es pequeña, la constante de formación del complejo enzima-sustrato $\left(k_{l}\right)$ y por lo tanto la constante de formación del producto $\left(k_{2}\right)$ en la reacción enzimática es grande.

Esta mejora en la respuesta del biosensor se debe a que la velocidad de transferencia de electrones se incrementa, debido a que la superficie descubierta del electrodo de trabajo 


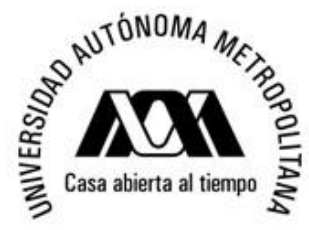

Universidad Autónoma Metropolitana Unidad Iztapalapa

División Ciencias Básicas e Ingeniería

Departamento de Química

Área de Química Analítica

Tesis de Doctorado

Q. Erika Rodríguez Sevilla

suministra los electrones de manera más rápida y por lo tanto los procesos redox de LTV con HQ, se llevan a cabo con mayor facilidad, de esta forma el los electrones son suministrados al closter T2/T3, de una forma más eficaz.

Sin embargo cuando la superficie del electrodo es cubierta en un $30 \%$ (biosensor ESP/LTv/GA-30\%, Figura 4.12 marcadores $\diamond$ ), la intensidad en la respuesta del biosensor incrementa un $122 \%$, la corriente máxima obtenida es de $I_{\max }=(2.60 \pm 0.02) \mu \mathrm{A}$, con una $K_{m}{ }^{\prime}=(159 \pm 3) \mu \mathrm{M}$, debido a que apresar de que la transferencia electrónica se lleva a cabo de forma eficaz, la interacción de la enzima con el sustrato es afectada debido al espesor de la membrana polimérica.

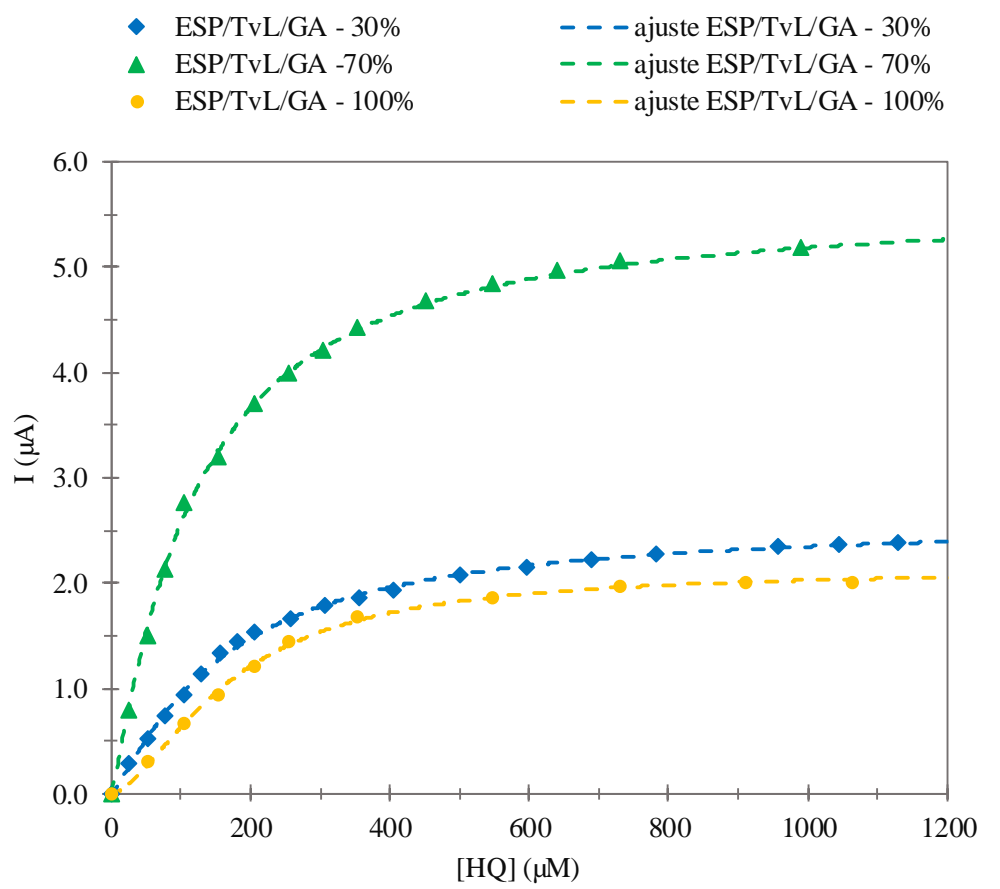

Figura 4.12. Comparación de los puntos experimentales, obtenidos para laccasa de Trametes versicolor inmovilizada mediante reticulado, en sensores de tipo screen-printed, cubriendo una área del $30 \%$ (ESP/LTv/GA-30\%, marcadores $\bullet$ ), 70\% (ESP/LTv/GA-60\%, marcadores $\mathbf{\Delta}$ ), y 100\% (ESP/LTv/GA$100 \%$, marcadores $\bullet$ ) del electrodo de trabajo respectivamente; siguiendo la respuesta en la corriente al imponer un potencial de $-0.300 \mathrm{~V}$ como función de la concentración de Hidroquinona (HQ) en amortiguador de acetatos $0.1 \mathrm{M}, \mathrm{pH} 4.7 \pm 0.01$ a $(30.0 \pm 0.5)^{\circ} \mathrm{C}$. Las líneas punteadas fueron obtenidas utilizando el modelo de Hill con los valores correspondientes de $K_{m}^{\prime}, I_{\max }$ y $h$ mostrados en la Tabla 5.2. 
División Ciencias Básicas e Ingeniería

Departamento de Química

Área de Química Analítica

Tesis de Doctorado

Q. Erika Rodríguez Sevilla

La Tabla 4.2 y 4.3 muestra una comparación de los parámetros cinéticos y analíticos respectivamente de cada biosensor, y puede observarse que cuando se obtiene un valor menor para la constante de Michaelis-Menten se obtienen los mejores parámetros analíticos, es decir una mayor sensibilidad, un menor límite de detección y cuantificación y una mayor respuesta electroquímica, con base en lo anterior se encuentra que el mejor biosensor se obtiene al cubrir el 70\% del área del electrodo de trabajo y dejar el 30\% libre para mantener un equilibrio entre la reacción enzimática y la electroquímica, manteniendo así una buena velocidad en la trasferencia de carga y una buena interacción de la enzima con su sustrato.

Tabla 4.2. Parámetros cinéticos obtenidos para la inmovilización de laccasa de Trametes versicolor, mediante reticulado utilizando glutaraldehído (GA) en biosensores con un electrodo de trabajo cubierto en un 30\%, $70 \%$ y $100 \%$ de su área por la membrana polimérica.

\begin{tabular}{|c|c|c|c|c|c|}
\hline $\begin{array}{c}\text { Biosensor - \% área } \\
\text { cubierta }\end{array}$ & $\begin{array}{c}K_{m}^{\prime} \\
(\mu \mathbf{M})\end{array}$ & $\begin{array}{c}I_{\max } \\
(\mu \mathbf{A})\end{array}$ & $\boldsymbol{h}$ & 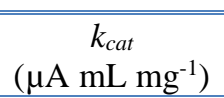 & $\begin{array}{c}k_{\text {cat }} / K_{m}^{\prime} \\
\left(\mu \mathrm{A} \mathrm{mL} \mathrm{mg^{-1 }} \mu \mathrm{M}^{-1}\right)\end{array}$ \\
\hline ESP/LTv/GA - 100\% & $170 \pm 3$ & $2.0 \pm 0.2$ & $1.7 \pm 0.2$ & 0.403 & 0.0024 \\
\hline ESP/LTv/GA - 70\% & $116 \pm 2$ & $5.61 \pm 0.03$ & $1.16 \pm 0.02$ & 1.12 & 0.0097 \\
\hline ESP/LTv/GA - 30\% & $169 \pm 3$ & $2.13 \pm 0.02$ & $1.64 \pm 0.05$ & 0.43 & 0.0025 \\
\hline
\end{tabular}

Tabla 4.3. Parámetros analíticos obtenidos para la inmovilización de laccasa de Trametes versicolor, mediante reticulado utilizando glutaraldehído (GA) en biosensores con un electrodo de trabajo cubierto en un 30\%, $70 \%$ y $100 \%$ de su área por la membrana polimérica.

\begin{tabular}{ccccccc}
\hline $\begin{array}{c}\text { Biosensor - \% área } \\
\text { cubierta }\end{array}$ & $\begin{array}{c}\boldsymbol{K}_{\boldsymbol{m}^{\prime}} \\
(\boldsymbol{\mu M})\end{array}$ & $\begin{array}{c}\text { Sensibilidad } \\
\left(\mathbf{n A} \boldsymbol{\mu M ^ { - 1 } )}\right.\end{array}$ & $\begin{array}{c}\text { LOD } \\
(\boldsymbol{\mu M})\end{array}$ & $\begin{array}{c}\text { LOQ } \\
(\boldsymbol{\mu M})\end{array}$ & $\begin{array}{c}\text { Intervalo Lineal } \\
(\boldsymbol{\mu M})\end{array}$ & $\mathbf{R}^{\mathbf{2}}$ \\
\hline \hline ESP/LTv/GA - 100\% & $170 \pm 3$ & $5.6 \pm 0.4$ & $14 \pm 5$ & $48 \pm 17$ & $26 \leq[\mathrm{HQ}] \leq 258$ & 0.9994 \\
ESP/LTv/GA - 70\% & $116 \pm 2$ & $26 \pm 2$ & $0.63 \pm 0.02$ & $2.1 \pm 0.8$ & $0 \leq[\mathrm{HQ}] \leq 103$ & 0.9973 \\
\hline ESP/LTv/GA - 30\% & $169 \pm 3$ & $5.7 \pm 0.7$ & $2.2 \pm 0.9$ & $7.6 \pm 0.3$ & $0 \leq[\mathrm{HQ}] \leq 255$ & 0.9937 \\
\hline \hline
\end{tabular}

La caracterización analítica de cada biosensor confirma que para la inmovilización mediante el método de reticulado, la mejor transferencia electrónica se lleva a cabo cuando la 


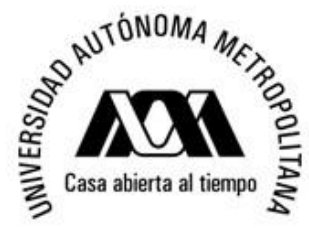

Universidad Autónoma Metropolitana Unidad Iztapalapa
División Ciencias Básicas e Ingeniería
Departamento de Química
Área de Química Analítica
Tesis de Doctorado
Q. Erika Rodríguez Sevilla

membrana solo cubre el 70\% del área del biosensor (ESP/LTv/GA - 70\%), pues se obtiene la mayor sensibilidad, así como menores límites de detección y cuantificación, y la mejor eficiencia catalítica, (ver Tabla 4.3) seguido por el biosensor ESP/LTv/GA - 30\%) y finalmente el biosensor ESP/LTv/GA - 100\%, que tienen un área cubierta del 30\% y 100\% respectivamente.

\subsection{Caracterización de biosensores de laccasa inmovilizada mediante atrapamiento a diferentes areaas del electrodo de trabajo.}

Para mejorar la respuesta generada por el biosensor amperométrico se evalúa el efecto del área cubierta por la red polimérica al momento de realizar la inmovilización de la enzima. Para la inmovilización mediante el método de reticulado, se utiliza glutaraldehído (GA) como agente reticulante y alcohol polivinílico (PVA) para la inmovilización por atrapamiento; en la Figura 4.12 se observa los voltamperogramas cíclicos de cada biosensor, cuando se lleva a cabo la inmovilización por reticulado utilizando el biosensor ESP/LTv/GA-100\% (línea punteada), partiendo de un potencial de corriente nula hacia valores negativos, se observa un pico de reducción a un potencial de $-0.370 \mathrm{~V}$ atribuido a la reducción de p-quinona $(\mathrm{Q})$ a hidroquinona (HQ); utilizada como sustrato afín a la enzima, al continuar el barrido de potencial hasta un valor de $-1.2 \mathrm{~V}$, se observa la presencia de algunos procesos de reducción atribuidos a la enzima, al invertir una vez más el barrido de potencial hacia valores positivos hasta $1.2 \mathrm{~V}$, se observa un pico de oxidación en un potencial de $0.150 \mathrm{~V}$ debido a la oxidación de HQ a Q.

Al caracterizar la membrana formada por la inmovilización de laccasa con PVA (Figura 4.13, línea en guiones), mediante atrapamiento con el biosensor ESP/LTV/PVA-100\% los picos de reducción de Q a HQ se observa ahora en un potencial de $-0.387 \mathrm{~V}$, mientras que la oxidación de HQ a Q se observa en un potencia de $0.100 \mathrm{~V}$, este desplazamiento es atribuido a la 


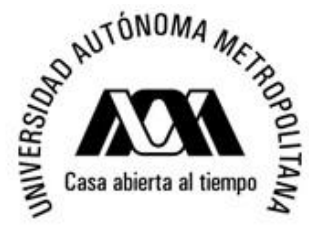

Universidad Autónoma Metropolitana Unidad Iztapalapa

División Ciencias Básicas e Ingeniería

Departamento de Química

Área de Química Analítica

Tesis de Doctorado

Q. Erika Rodríguez Sevilla

densidad de la membrana formada por el reticulante, lo cual acelera la transferencia electrónica.

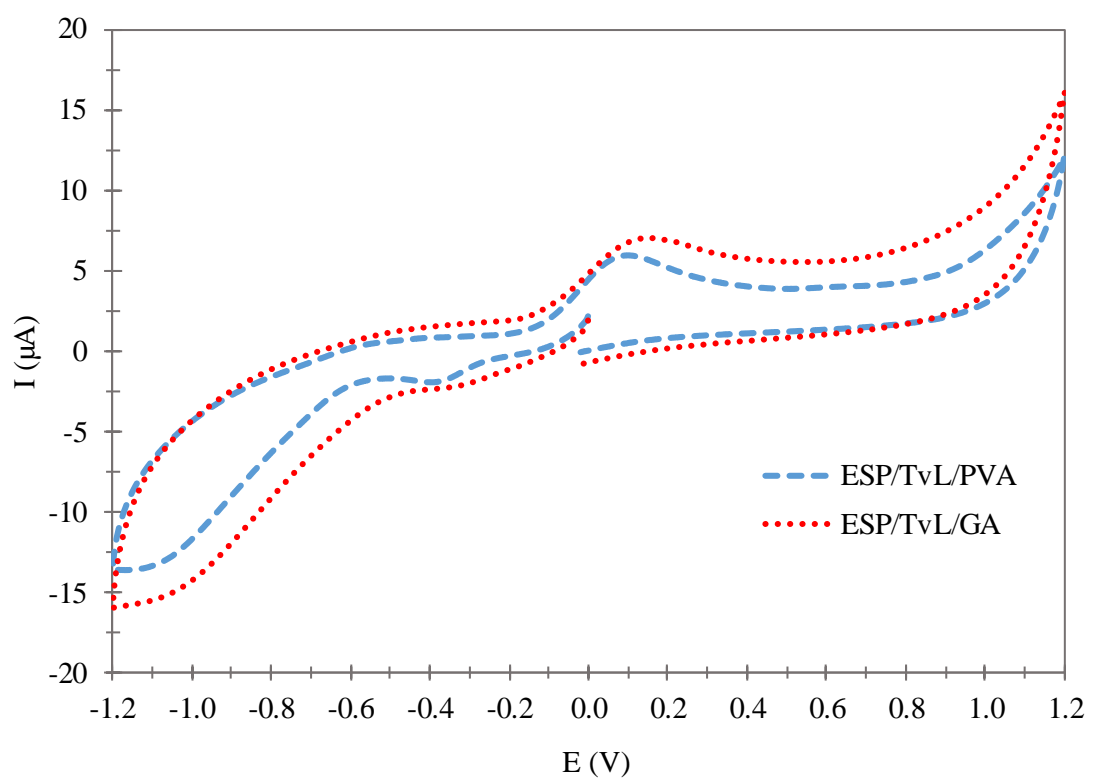

Figura 4.13.Voltamperogramas cíclicos de los biosensores ESP/LTv/GA-100\% (línea punteada) y ESP/LTv/PVA-100\% (línea con guiones), partiendo de un potencial corriente nula hacia valores negativos hasta $-1.2 \mathrm{~V}$, posteriormente se invierte el barrido de potencial hasta $1.2 \mathrm{~V}$, al llegar a este potencial el barrido se invierte una vez más hasta $0 \mathrm{~V}$, a una velocidad de $100 \mathrm{mVs}^{-1}$.

Cuando la enzima es inmovilizada mediante el método de atrapamiento, con alcohol polivinílico se forma una red polimérica característica de este tipo de inmovilización, el comportamiento cinético de la enzima se muestra en la Figura 4.14. Al igual que en la inmovilización por reticulado, al cubrir el $60 \%$ del área de la superficie del electrodo (ESP/LTv/PVA- 70\%, Figura 4.14 marcadores $\mathbf{\Delta}$ ) se obtienen los mejores parámetros cinéticos $\left(K_{m}{ }^{\prime}=(127 \pm 2) \mu \mathrm{M}, I_{\max }=(7.07 \pm 0.03) \mu \mathrm{A}\right)($ ver Tabla 4.4) y analíticos (ver Tabla 4.5), generando así un biosensor robusto cuya respuesta en la corriente mejora un $151 \%$ con respecto al biosensor ESP/LTv/PVA - 100\% que tiene el 100\% del área del electrodo de trabajo cubierta por la membrana polimérica, este resultado confirma una vez más que la 


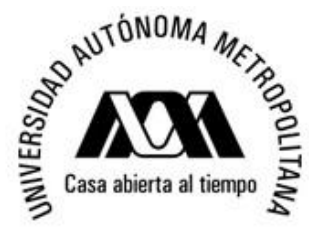

Universidad Autónoma Metropolitana Unidad Iztapalapa

División Ciencias Básicas e Ingeniería

Departamento de Química

Área de Química Analítica

Tesis de Doctorado

Q. Erika Rodríguez Sevilla

trasferencia electrónica entre la superficie del electrodo y el sitio activo de la enzima se lleva a cabo de manera más eficaz.

Sin embargo al cubrir el 30\% de la superficie del electrodo (ESP/LTv/PVA - 30\%), la interacción de la enzima con el sustrato se ve afectada por el espesor de la membrana polimérica, lo cual se ve relejado en el desempeño del biosensor, obteniendo mayores valores de $K_{m}{ }^{\prime}, I_{\max }$, límite de detección ( $\left.L O D\right)$ y límite de cuantificación $(L O Q)$, (ver Tabla 4.5) así como una mejor eficiencia catalítica.

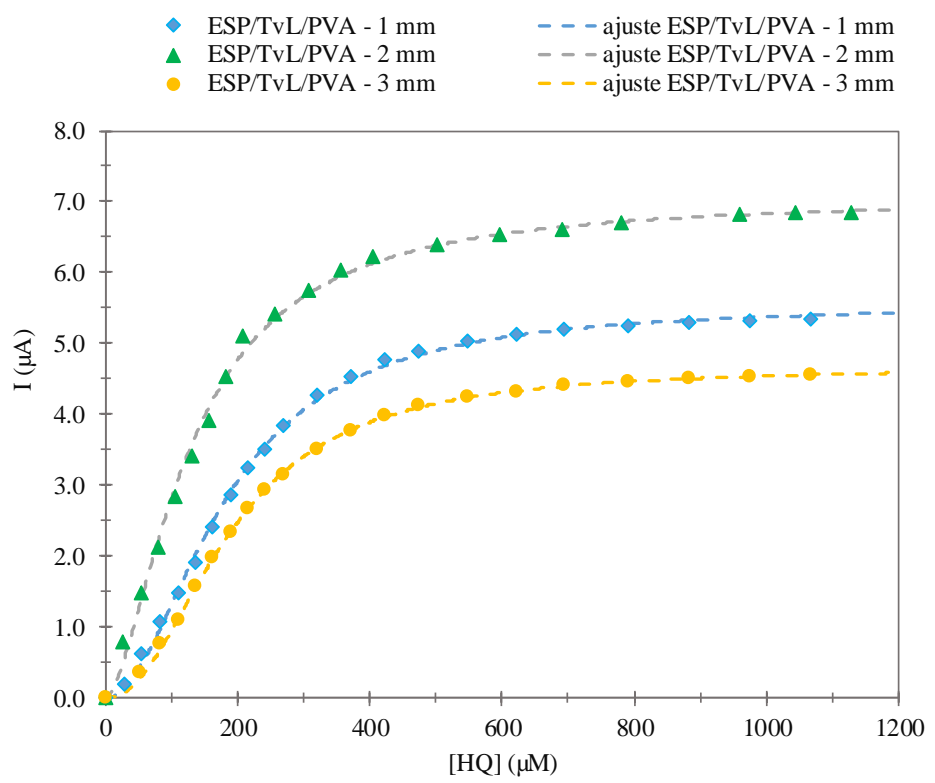

Figura 4.142. Comparación de los puntos experimentales, obtenidos para laccasa de Trametes versicolor inmovilizada mediante atrapamiento, en sensores de tipo screen-printed, cubriendo una área del 30\% (ESP/LTv/PVA-30\%, marcadores $\bullet$ ), 60\% (ESP/LTv/PVA-60\%, marcadores $\mathbf{\Delta}$ ), y 100\% (ESP/LTv/PVA$100 \%$, marcadores $\bullet$ ) del electrodo de trabajo respectivamente; siguiendo la respuesta en la corriente al imponer un potencial de $-0.300 \mathrm{~V}$ como función de la concentración de Hidroquinona (HQ) en amortiguador de acetatos $0.1 \mathrm{M}, \mathrm{pH} 4.7 \pm 0.01$ a $(30.0 \pm 0.5)^{\circ} \mathrm{C}$. Las líneas punteadas fueron obtenidas utilizando el modelo de Hill con los valores correspondientes de $K_{m}^{\prime}, I_{\max }$ y $h$ mostrados en la Tabla 4.3. 


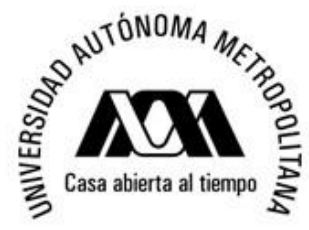

Universidad Autónoma Metropolitana Unidad Iztapalapa

División Ciencias Básicas e Ingeniería

Departamento de Química

Área de Química Analítica

Tesis de Doctorado

Q. Erika Rodríguez Sevilla

Un equilibrio entre las constantes de velocidad de la reacción enzimática y la constante de transferencia electrónica se encuentra al desarrollar biosensores con un área cubierta del 70\% del total del área del electrodo de trabajo, al inmovilizar la enzima mediante los métodos de atrapamiento y reticulado, siendo este último el mejor método para generar biosensores robustos.

Tabla 4.4. Parámetros cinéticos obtenidos para la inmovilización de laccasa de Trametes versicolor, mediante atrapamiento utilizando alcohol polivinílico (PVA) en biosensores con un electrodo de trabajo cubierto en un 30\%, $70 \%$ y $100 \%$ de su área por la membrana polimérica.

\begin{tabular}{|c|c|c|c|c|c|}
\hline $\begin{array}{c}\text { Biosensor - \% de } \\
\text { área cubierta } \\
\end{array}$ & $\begin{array}{c}K_{m}^{\prime} \\
(\mu \mathbf{M}) \\
\end{array}$ & $\begin{array}{l}I_{\max } \\
(\mu \mathrm{A}) \\
\end{array}$ & $h$ & 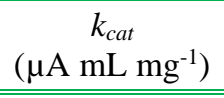 & $\begin{array}{c}k_{\text {cat }} / K_{m} \\
\left(\mu \mathrm{A} \mathrm{mL} \mathrm{mg}^{-1} \mu \mathrm{M}^{-1}\right)\end{array}$ \\
\hline $\begin{array}{c}\text { ESP/LTv/PVA - } \\
\mathbf{3 0 \%}\end{array}$ & $180 \pm 2$ & $5.56 \pm 0.04$ & $1.97 \pm 0.05$ & 1.11 & 0.0062 \\
\hline $\begin{array}{c}\text { ESP/LTv/PVA - } \\
70 \%\end{array}$ & $127 \pm 2$ & $7.07 \pm 0.03$ & $1.63 \pm 0.04$ & 1.41 & 0.0111 \\
\hline $\begin{array}{c}\text { ESP/LTv/PVA - } \\
100 \%\end{array}$ & $188 \pm 1$ & $4.66 \pm 0.01$ & $2.14 \pm 0.02$ & 0.944 & 0.0050 \\
\hline
\end{tabular}

Tabla 4.4. Parámetros analíticos obtenidos para la inmovilización de laccasa de Trametes versicolor, mediante atrapamiento utilizando alcohol polivinílico (PVA) en biosensores con un electrodo de trabajo cubierto en un 30\%, 70\% y 100\% de su área por la membrana polimérica.

\begin{tabular}{ccccccc}
\hline $\begin{array}{c}\text { Biosensor - \% de } \\
\text { área cubierta }\end{array}$ & $\begin{array}{c}\boldsymbol{K}_{\boldsymbol{m}}{ }^{\prime} \\
(\boldsymbol{\mu M})\end{array}$ & $\begin{array}{c}\text { Sensibilidad } \\
\left(\mathbf{n A} \boldsymbol{\mu} \mathbf{M}^{-1}\right)\end{array}$ & $\begin{array}{c}\text { LOD } \\
(\boldsymbol{\mu M})\end{array}$ & $\begin{array}{c}\text { LOQ } \\
(\boldsymbol{\mu M})\end{array}$ & $\begin{array}{c}\text { Intervalo lineal } \\
(\boldsymbol{\mu M})\end{array}$ & $\mathbf{R}^{\mathbf{2}}$ \\
\hline \hline $\begin{array}{c}\text { ESP/LTv/PVA }- \\
\mathbf{3 0 \%}\end{array}$ & $180 \pm 2$ & $15 \pm 1$ & $1.8 \pm 0.6$ & $6.0 \pm 0.2$ & $0 \leq[\mathrm{HQ}] \leq 268$ & 0.9954 \\
$\begin{array}{c}\text { ESP/LTv/PVA - } \\
\quad \mathbf{7 0 \%}\end{array}$ & $127 \pm 2$ & $24 \pm 1$ & $1.2 \pm 0.4$ & $4.1 \pm 0.1$ & $0 \leq[\mathrm{HQ}] \leq 207$ & 0.9967 \\
$\begin{array}{c}\text { ESP/LTv/PVA - } \\
\mathbf{1 0 0 \%}\end{array}$ & $188 \pm 1$ & $12 \pm 1$ & $2.7 \pm 0.3$ & $9.0 \pm 0.3$ & $0 \leq[\mathrm{HQ}] \leq 268$ & 0.9891 \\
\hline \hline
\end{tabular}

Es importante elaborar biosensores que mantengan un equilibrio entre la reacción electroquímica como en la reacción enzimática, de esta forma los parámetros cinéticos y analíticos obtenidos mejoran significativamente. 


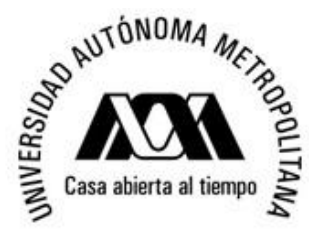

Universidad Autónoma Metropolitana Unidad Iztapalapa

División Ciencias Básicas e Ingeniería

Departamento de Química

Área de Química Analítica

Tesis de Doctorado

Q. Erika Rodríguez Sevilla
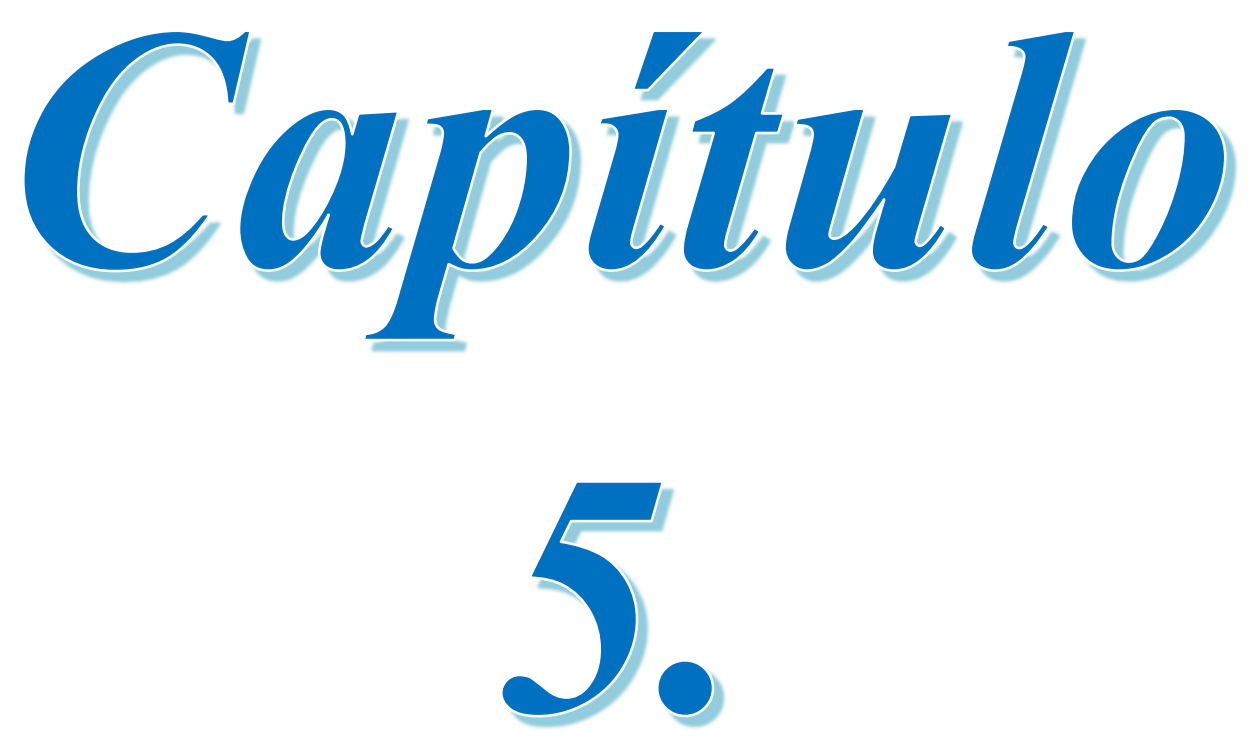

\section{Uso del radical DPPH para} determinar TEAC en plantas medicinales de la zona de "tierra caliente" en el estado de Guerrero. 


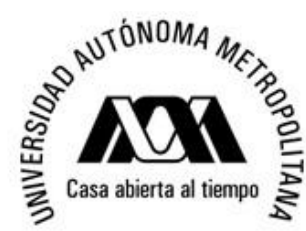

\subsection{Introducción}

Existen diversos métodos para conocer la capacidad antioxidante $[116,117,118]$, sin embargo en los últimos años se ha buscado elaborar dispositivos compactos y de bajo costo que permitan conocer la cantidad de antioxidantes presentes en los alimentos y los biosensores electroquímicos son uno de los dispositivos más utilizados para este fin [119].

Un antioxidante puede ser definido como una molécula capaz de prevenir o retardar la oxidación de otra [120], hay antioxidantes que normalmente se encuentran presentes en el organismo, tales como los antioxidantes enzimáticos como catalasa, o bien los antioxidantes no enzimáticos por ejemplo la Co-enzima Q, sin embargo mediante la dieta cotidiana pueden ser suministrados al organismo antioxidantes como vitaminas, carotenoides, flavonoides, polifenoles entre otros, por ello en los últimos años se ha determinado de la capacidad antioxidante en alimentos [121], jugos [122], vinos [123], cervezas [124], tés frutales [125], plantas medicinales [126], etcétera, con la finalidad de consumir una dieta balanceada y rica en antioxidantes.

Un gran porcentaje de la población mundial utiliza la herbolaria no solo para proveer antioxidantes al organismo sino como una opción alternativa en el tratamiento de enfermedades ya que en los últimos años se ha asociado a los antioxidantes no solo con la promesa de retardar en envejecimiento sino con el hecho de que al ser consumidos como alimentos pueden reducir el desarrollo de enfermedades cardiovasculares, neurodegenerativas e incluso tumorales.

México es un país que desde tiempos muy antiguos se ha caracterizado por el uso de plantas en el tratamiento de enfermedades, que pueden ser desde leves malestares hasta enfermedades crónicas, como son el cáncer, la diabetes, la hipertensión, etcétera. En la región de "Tierra caliente" en el estado de Guerrero, México, la gente utiliza Mirto (Salvia microphylla) para aliviar los dolores de cabeza, tomando una taza de té antes de dormir, o 


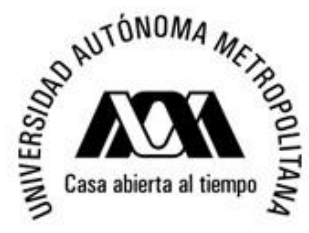

Universidad Autónoma Metropolitana Unidad Iztapalapa

División Ciencias Básicas e Ingeniería

Departamento de Química

Área de Química Analítica

Tesis de Doctorado

Q. Erika Rodríguez Sevilla

bien suelen hacerse pomadas para aliviar el dolor colocando un poco sobre la sien. El uso de Muicle (Justicia spicigera) como calmante del sistema nervioso es común también en esta zona, la población ingiere esta infusión las veces que sea necesario durante el día.

Para curar el malestar estomacal o la diarrea se utilizan Salve Real (Lippia alba) y/o Hierba dulce (Lippia dulcis) la gente consume una taza de té antes de cada alimento durante el día, esta infusión puede ser preparada utilizando alguna de las dos plantas medicinales o bien las dos al mismo tiempo. La Hierba de San Cayetano (Solanum rudepannum) es utilizada para controlar la presión arterial, así como para relajar el sistema nervioso, consumiendo una taza de té por las mañanas durante una semana, se suspende su toma por una semana y se retoma a la semana siguiente durante tres semanas, de esta forma la presión arterial suele mantener niveles estables. Estas plantas medicinales (Figura 5.1) son típicas de la región, son almacenadas y en algunos casos cultivadas por los pobladores para su uso cotidiano.

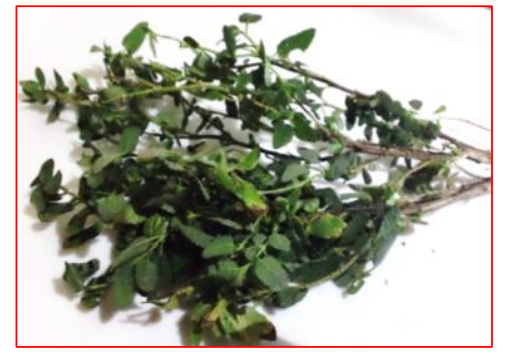

Mirto (Salvia microphylla)

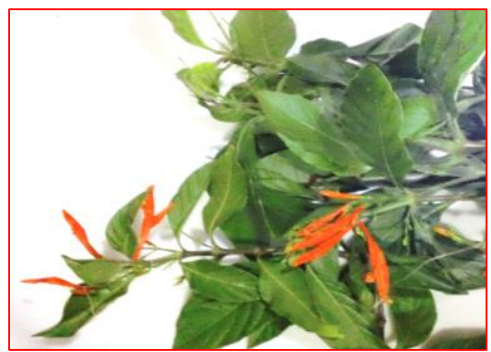

Muicle (Justicia spicigera)

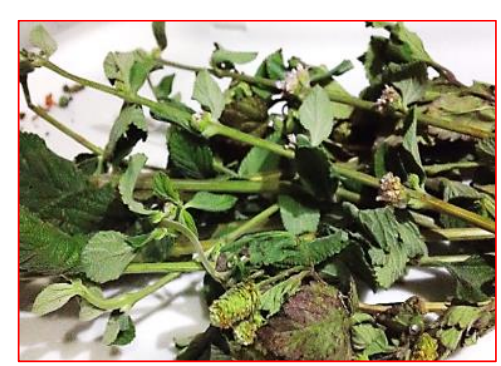

Salve real (Lippia alba)

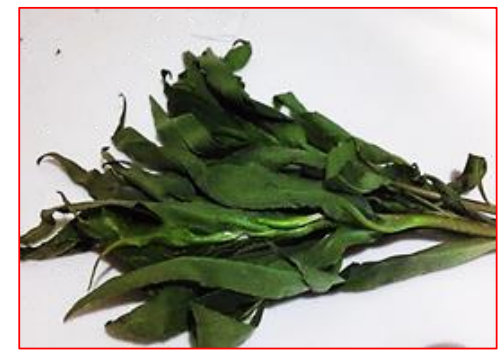

Hierba dulce (Lippia dulcis)

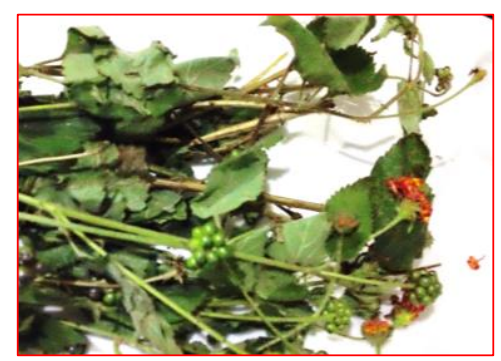

Hierba San Cayetano

(Solanum rudepannum)

Figura 5.1. Fotografía de Mirto (Salvia microphylla), Muicle (Justicia spicigera), Salve Real (Lippia alba), Hierba dulce (Lippia dulcis) y Hierba de San Cayetano (Solanum rudepannum), plantas medicinales pertenecientes a la herbolaria mexicana. 


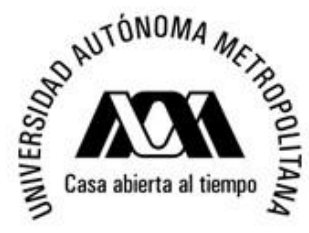

Universidad Autónoma Metropolitana Unidad Iztapalapa

División Ciencias Básicas e Ingeniería

Departamento de Química

Área de Química Analítica

Tesis de Doctorado

Q. Erika Rodríguez Sevilla

En este capítulo se presenta la determinación de la capacidad antioxidante de Mirto (Salvia microphylla), Muicle (Justicia spicigera), Salve Real (Lippia alba), Hierba dulce (Lippia dulcis) y Hierba de San Cayetano (Solanum rudepannum), utilizando biosensores amperométricos construidos con laccasa de Trametes versicolor y tirosinasa mushroom en sensores de tipo screen-printed, así como su comparación con el método de DPPH.

\subsection{Obtención de la capacidad antioxidante equivalente a Trolox mediante el método espectrofotométrico de DPPH.}

El efecto de los compuestos fenólicos sobre el DPPH (Figura 5.2) en solución es estimado por reacción directa y los resultados son expresados en equivalentes de TROLOX (TEAC) [127]. La curva de calibración se obtiene graficando la concentración de TROLOX (Figura 5.3) en función de la absorbancia después de la reacción. Inicialmente se colocan $100 \mu \mathrm{L}$ de DPPH $10^{-3} \mathrm{M}$ y se agregan distintos volúmenes de la solución $10^{-4} \mathrm{M}$ ó $10^{-5}$ de TROLOX ajustando en todos los casos un volumen final de celda de $1.0 \mathrm{~mL}$.

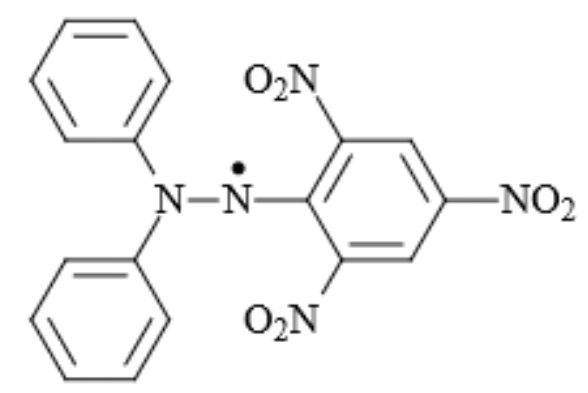

Figura 5.2. Estructura química de 2,2-difenil-1-picrilhidrazil (DPPH) 


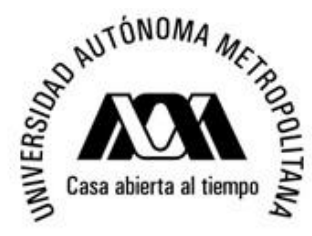

Universidad Autónoma Metropolitana Unidad Iztapalapa

División Ciencias Básicas e Ingeniería

Departamento de Química

Área de Química Analítica

Tesis de Doctorado

Q. Erika Rodríguez Sevilla

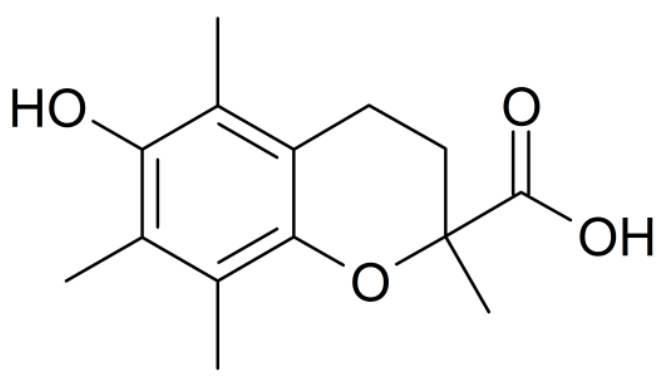

Figura 5.3. Estructura química de ácido 6-hidroxi-2,5,7,8-tetrametilcroman-2-carboxílico (TROLOX).

Tabla 5.1. Volúmenes de reacción para el sistema TROLOX-DPPH en etanol.

\begin{tabular}{ccccccc}
\hline Celda & $\begin{array}{c}\mathrm{V}_{\text {DPPH }} \\
10^{-3} / \mu \mathrm{L}\end{array}$ & $\begin{array}{c}\mathrm{V}_{\text {Etanol }} \\
/ \mu \mathrm{L}\end{array}$ & $\begin{array}{c}\mathrm{V}_{\text {TROLOX }} \\
10^{-5} / \mu \mathrm{L}\end{array}$ & $\begin{array}{c}\mathrm{V}_{\text {TROLOX }} \\
10^{-4} / \mu \mathrm{L}\end{array}$ & $\begin{array}{c}\text { [TROLOX }]_{\text {final }} \\
/ \mu \mathrm{M}\end{array}$ & $\mathrm{A}_{514}$ \\
\hline 1 & 100 & 900 & 0 & 0 & 0 \\
2 & 100 & 800 & 100 & 0 & 1 \\
3 & 100 & 400 & 500 & 0 & 5 \\
4 & 100 & 800 & 0 & 100 & 10 \\
5 & 100 & 700 & 0 & 200 & 20 \\
6 & 100 & 500 & 0 & 400 & 40 \\
7 & 100 & 400 & 0 & 500 & 50 \\
\hline
\end{tabular}

La concentración de TROLOX en las celdas se incrementa desde 1.0 hasta $50 \mu \mathrm{M}$ (ver Tabla 5.1), se registra la absorbancia de la mezcla en $514 \mathrm{~nm}$ a 5 minutos de iniciada la reacción usando etanol como blanco. En estas condiciones la absorbancia de DPPH $100 \mu \mathrm{M}$ en ausencia de TROLOX debe ser $\mathrm{A}_{\operatorname{máx}}=1.05 \pm 3 \%$.

La Figura 5.4 muestra el cambio en la absorbancia para diferentes concentraciones de Trolox, al incrementar la [Trolox] en el sistema la absorbancia disminuye, lo que implica que hay mayor cantidad de especies oxidantes. El sistema llega al equilibrio en un tiempo de 5 


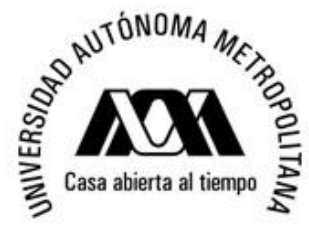

Universidad Autónoma Metropolitana Unidad Iztapalapa

División Ciencias Básicas e Ingeniería

Departamento de Química

Área de Química Analítica

Tesis de Doctorado

Q. Erika Rodríguez Sevilla

minutos por lo que se mide la absorbancia de la muestra a este tiempo para construir la curva de calibración de absorbancia vs [Trolox] (Figura 5.5).

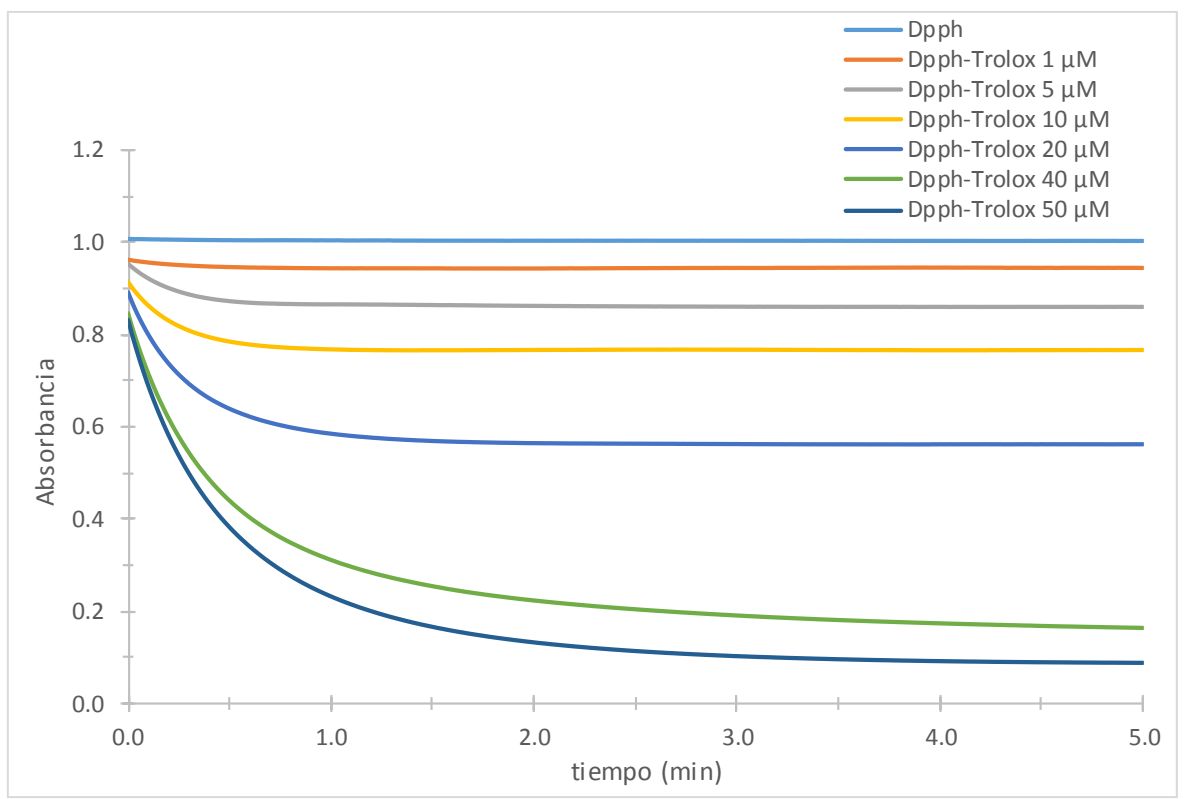

Figura 5.4. Absorbancia vs. Tiempo de los distintos sistemas descritos en la Tabla 5.1.

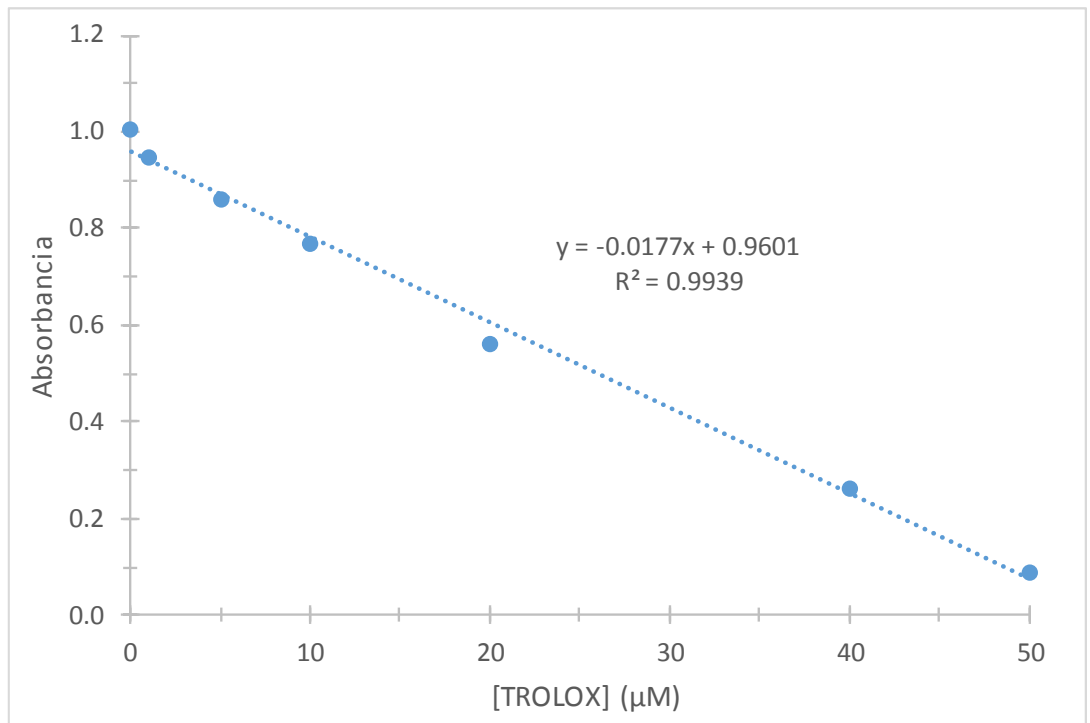

Figura 5.5. Curva de calibración espectrofotométrica para el sistema TROLOX-DPPH. 
Las plantas medicinales son obtenidas de la zona de "Tierra caliente" en el Estado de Guerrero, México. Las infusiones de Mirto (Salvia microphylla) Hierba San Cayetano (Solanum rudepannum), Muicle (Justicia spicigera), Hierba dulce (Lippia dulcis) y Salve Real (Lippia alba) se peparan siguiendo la metodología descrita en el apartado de materiales y métodos.

La concentración de Mirto, Muicle, Salve Real, Hierba dulce y Hierba de San Cayetano en las celdas se incrementa respectivamente y se registra la absorbancia de la mezcla en 514 $\mathrm{nm}$ a 5 minutos de iniciada la reacción usando etanol como blanco. En estas condiciones la absorbancia de la primera celda, DPPH $100 \mu \mathrm{M}$ en ausencia de la muestra debe ser $\mathrm{A}_{\text {máx }}=$ $1.05 \pm 3 \%$. En la Figura 5.6 se muestran dichas curvas de calibración.

Utilizando la pendiente de las curvas de calibración de la muestra y la pendiente de la curva de calibración con Trolox (TEAC), se obtiene la capacidad antioxidante equivalente a Trolox utilizando la ecuación

$$
\text { TEAC }=\frac{m_{\text {muestra }} / g \text { de muestra }}{m_{\text {Trolox }}}
$$

Estos resultados se muestran en la Tabla 5.2 la mayor cantidad de especies antioxidantes se encuentra en Mirto, seguido de Muicle y Hierba dulce, la infusión preparada con hierba de San Cayetano muestra el menor TEAC. 


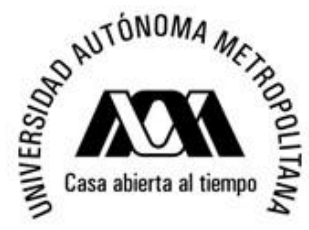

Universidad Autónoma Metropolitana Unidad Iztapalapa

División Ciencias Básicas e Ingeniería

Departamento de Química

Área de Química Analítica

Tesis de Doctorado

Q. Erika Rodríguez Sevilla

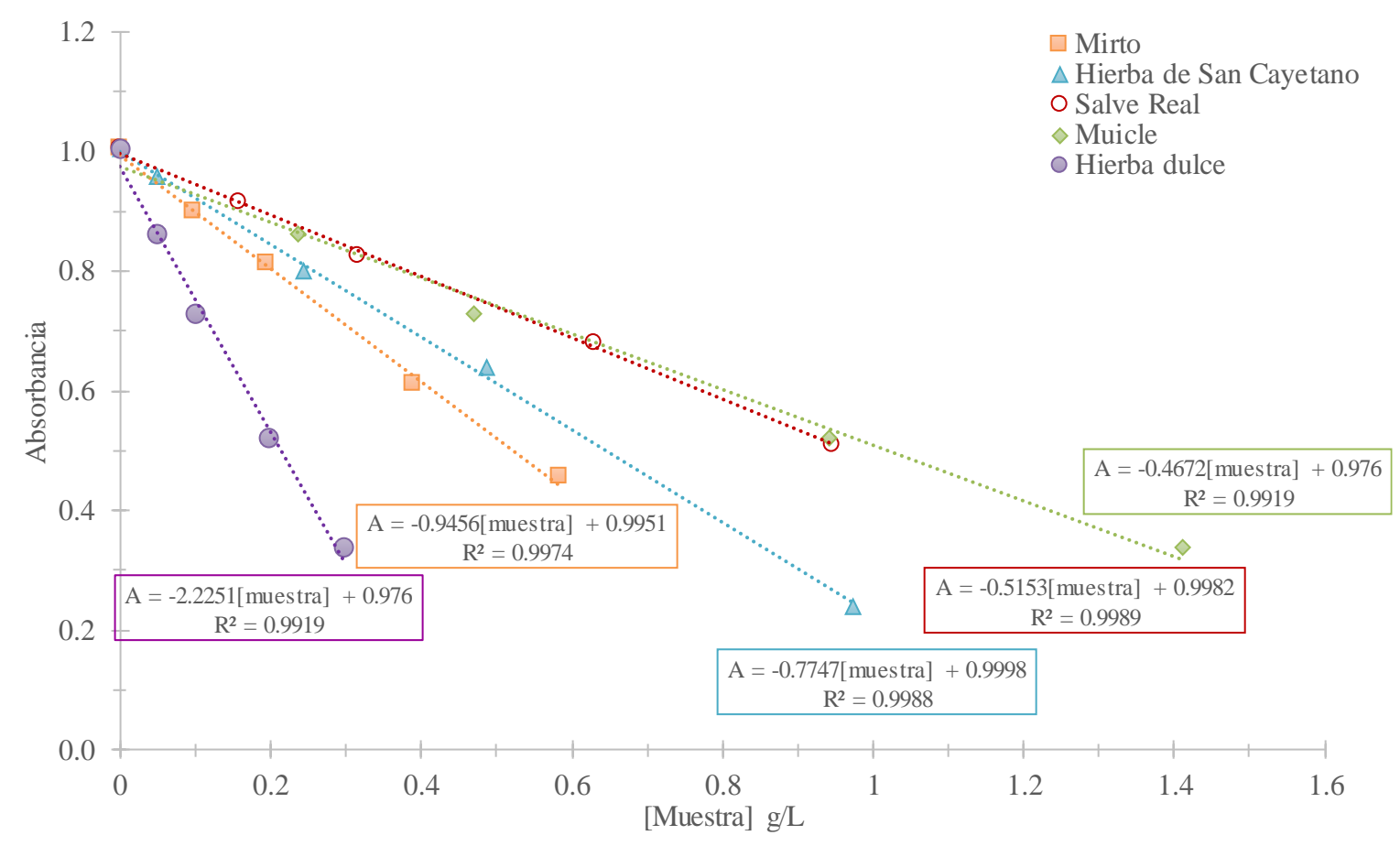

Figura 5.6. Curva de calibración espectrofotométrica para el sistema DPPH-Muestra.

De acuerdo con lo reportado en la literatura Mirto (Salvia microphylla) tiene propiedades bactericidas [128], Muicle (Justicia spicigera) presenta propiedades antidiabéticas [129] y antitumorales [130], Salve Real (Lippia alba) presenta efectos antiespasmódicos [131] y es utilizada en el tratamiento de la migraña en mujeres [132], Hierba dulce (Lippia dulcis) tiene propiedades antiinflamatorias [133] y antiespasmódicas [134]. La Hierba de San Cayetano ha sido poco estudiada, sin embargo todos estos resultados muestran la efectividad del estas plantas medicinales en el tratamiento y prevención de enfermedades como diarrea, tos, dolor de cabeza, hipertensión, entre otras. Los resultados obtenidos en este capítulo demuestran que dichas plantas medicinales poseen un alto grado de capacidad antioxidante. 


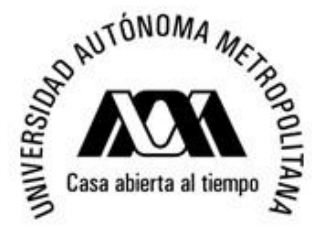
Universidad Autónoma Metropolitana Unidad Iztapalapa
División Ciencias Básicas e Ingeniería
Departamento de Química
Área de Química Analítica
Tesis de Doctorado
Q. Erika Rodríguez Sevilla

Tabla 5.2. Capacidad antioxidante equivalente a Trolox (TEAC) para diferentes infusiones de plantas medicinales obtenidas mediante el método espectrofotométrico con DPPH.

\begin{tabular}{cc}
\hline Muestra & $\begin{array}{c}\text { TEAC } \cdot \mathbf{D P P H} \\
\text { Mg } \\
\text { de } \text { Trolox } / \mathbf{m L}\end{array}$ \\
\hline Mirto (Salvia microphylla) & $620 \pm 38$ \\
Muicle (Justicia spicigera) & $519 \pm 24$ \\
Salve Real (Lippia alba) & $459 \pm 16$ \\
Hierba dulce (Lippia dulcis) & $519 \pm 23$ \\
Hierba San Cayetano (Solanum \\
rudepannum)
\end{tabular}

\subsection{Medición de la capacidad antioxidante de plantas medicinales del estado de Guerrero, utilizando un biosensor de laccasa de Trametes versicolor.}

Utilizando el biosensor ESP/LTv/GA 2.5\%, se obtienen las curvas de calibración, para Trolox, Las mediciones amperométricas se realizan en una celda temostatada a $30^{\circ} \mathrm{C}$ en 10 $\mathrm{mL}$ de amortiguador de acetatos $0.1 \mathrm{M} \mathrm{pH} 4.5$ bajo agitación constante e imponiendo un potencial de celda de $-300 \mathrm{mV}$ usando el método de adiciones estándar con un amperímetro BAS LC-4C conectado a una PC. La recopilación de datos se hace mediante el software especializado DAISY LAB 6.0.

La Figura 5.7 muestra la curva de calibración de ESP/LTv/GA 2.5\% con TROLOX, en ella se observa una dependencia lineal con una sensibilidad de $6.27 \mathrm{nA \mu M}^{-1}$, las curvas de calibración para cada muestra se construyeron agregando pequeñas alícuotas de la muestra y registrando la corriente obtenida (Figura 5.8), la mayor sensibilidad se observa para Mirto seguido por Hierba dulce y Hierba San Cayetano. 


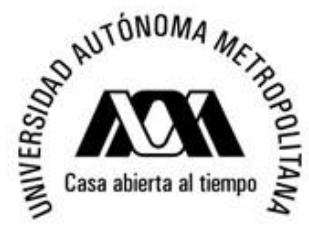

Universidad Autónoma Metropolitana Unidad Iztapalapa

División Ciencias Básicas e Ingeniería

Departamento de Química

Área de Química Analítica

Tesis de Doctorado

Q. Erika Rodríguez Sevilla

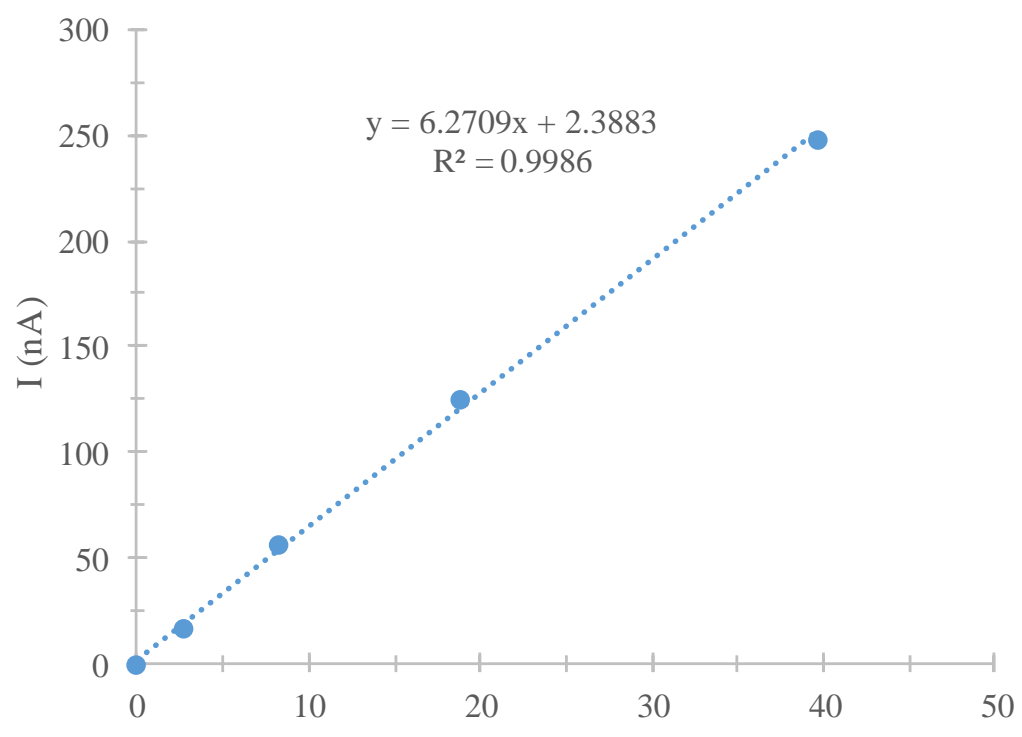

[Trolox] $(\mu \mathrm{M})$

Figura 5.7. Curva de calibración electroquímica para el sistema ESP/LTv/GA 2.5\% -TROLOX

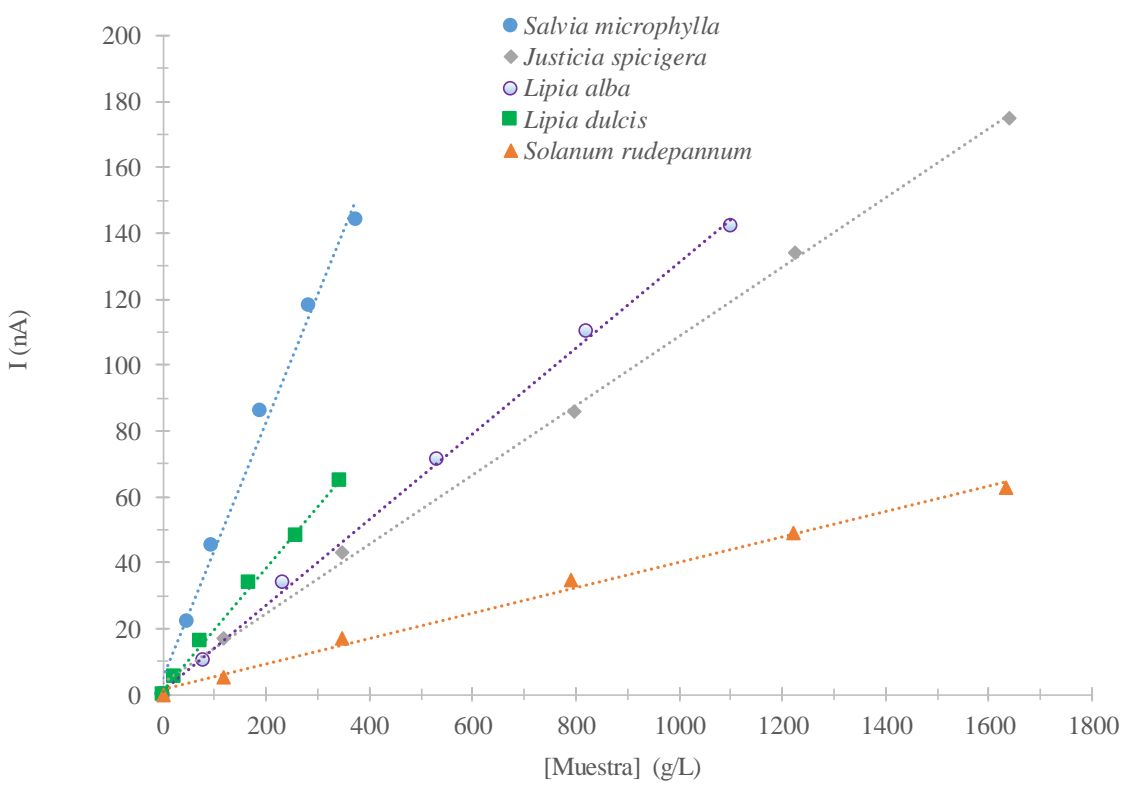

Figura 5.8. Curva de calibración electroquímica para el sistema ESP/LTv/GA 2.5\% - muestra 


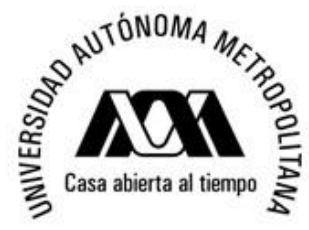

Universidad Autónoma Metropolitana Unidad Iztapalapa
División Ciencias Básicas e Ingeniería
Departamento de Química
Área de Química Analítica
Tesis de Doctorado
Q. Erika Rodríguez Sevilla

Utilizando el biosensor ESP/LTv/GA 2.5\%, considerado el mejor biosensor, se lleva a cabo la determinación de TEAC. La Tabla 5.3 muestra que utilizando el método espectrofotométrico de DPPH se obtiene un TEAC mayor para Mirto (Salvia microphylla), seguido por Muicle (Justicia spicigera) y finalmente Hierba San Cayetano (Solanum rudepannum), este resultado es consistente al hacer la determinación de TEAC utilizando el biosensor ESP/LTv/GA 2.5\%, lo cual demuestra que el sensor es aplicable a la determinación de antioxidantes en muestras reales. Dichas muestras tiene un TEAC cinco veces mayor comparado con otros extractos de plantas medicinales [135].

Tabla 5.3. Capacidad antioxidante equivalente a Trolox para diferentes muestras reales obtenidas mediante el método espectrofotométrico y utilizando el biosensor ESP/LTv/GA

\begin{tabular}{ccc}
\hline Muestra & $\begin{array}{c}\text { TEAC } \cdot \text { DPPH } \\
\boldsymbol{\mu g} \text { de Trolox/mL }\end{array}$ & $\begin{array}{c}\text { TEAC }_{\text {ESP/LTv/GA }} \\
\boldsymbol{\mu g} \text { of } \text { Trolox/ } \mathbf{~ m L}\end{array}$ \\
\hline Mirto (Salvia microphylla) & $620 \pm 38$ & $6.0 \pm 0.1$ \\
Hierba San Cayetano (Solanum rudepannum) & $102 \pm 41$ & $1.4 \pm 0.3$ \\
Muicle (Justicia spicigera) & $519 \pm 24$ & $3.9 \pm 0.1$ \\
\hline
\end{tabular}

\subsection{Medición de la capacidad antioxidante de plantas medicinales del estado de Guerrero. Usando el biosensor ESP/Tir/GA 2.5\%.}

Cuando se utiliza el biosensor modificado con glutaraldehído al $2,5 \%$ y $40{ }^{\circ} \mathrm{C}$ considerado como mejor método de inmovilización para tirosinasa, y siguiendo la metodología anterior, se obtiene la curva de calibración de ESP/Tir/GA 2.5\% con TROLOX (Figura 5.9), en ella

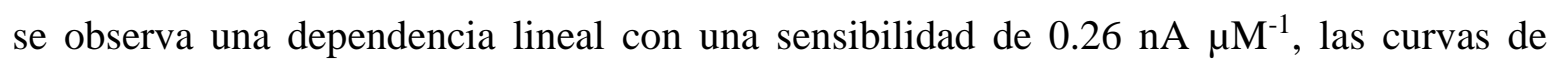
calibración para cada muestra se construyeron agregando pequeñas alícuotas de la solución y registrando la corriente (Figura 5.10), la mayor sensibilidad se observa para Mirto seguido por Hierba dulce y posteriormente Salve Real. 


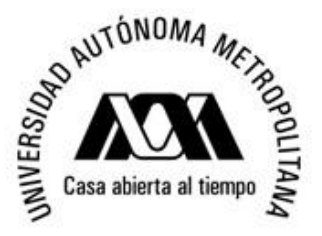

Universidad Autónoma Metropolitana Unidad Iztapalapa

División Ciencias Básicas e Ingeniería

Departamento de Química

Área de Química Analítica

Tesis de Doctorado

Q. Erika Rodríguez Sevilla

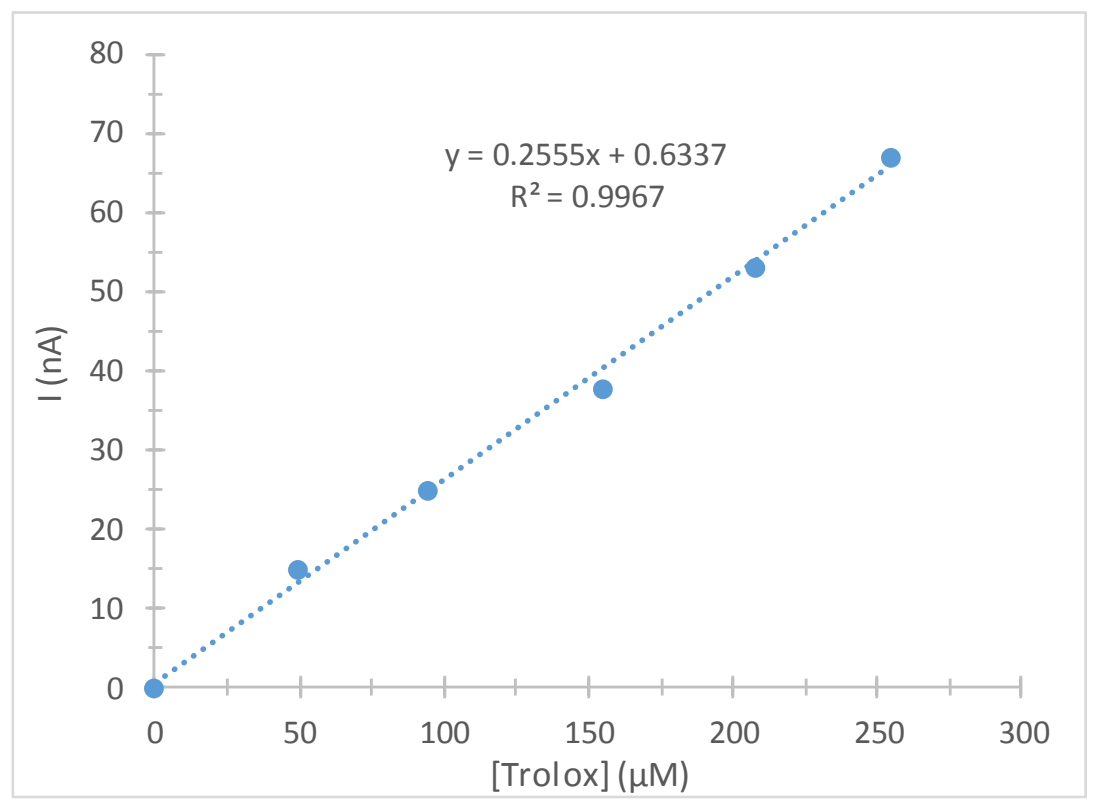

Figura 5.9. Curva de calibración electroquímica para el sistema ESP/Tir/GA 2.5\% -TROLOX

Usando este biosensor se determina la capacidad antioxidante equivalente a Trolox (TEAC, por sus siglas en ingles), la Tabla 5.4 muestra que utilizando el método espectrofotométrico de DPPH se obtiene un TEAC mayor para Mirto (Salvia microphylla), seguido por Hierba dulce (Lippia dulcis) y finalmente Salve Real (Lippia alba), estas muestras son parte de la herbolaria mexicana y tienen un TEAC cinco veces mayor comparado con otros extractos de plantas medicinales [135]. Esto demuestra que el sensor es aplicable a la determinación de antioxidantes. 


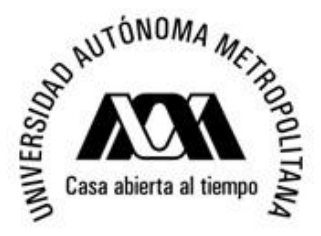

Universidad Autónoma Metropolitana Unidad Iztapalapa

División Ciencias Básicas e Ingeniería

Departamento de Química

Área de Química Analítica

Tesis de Doctorado

Q. Erika Rodríguez Sevilla

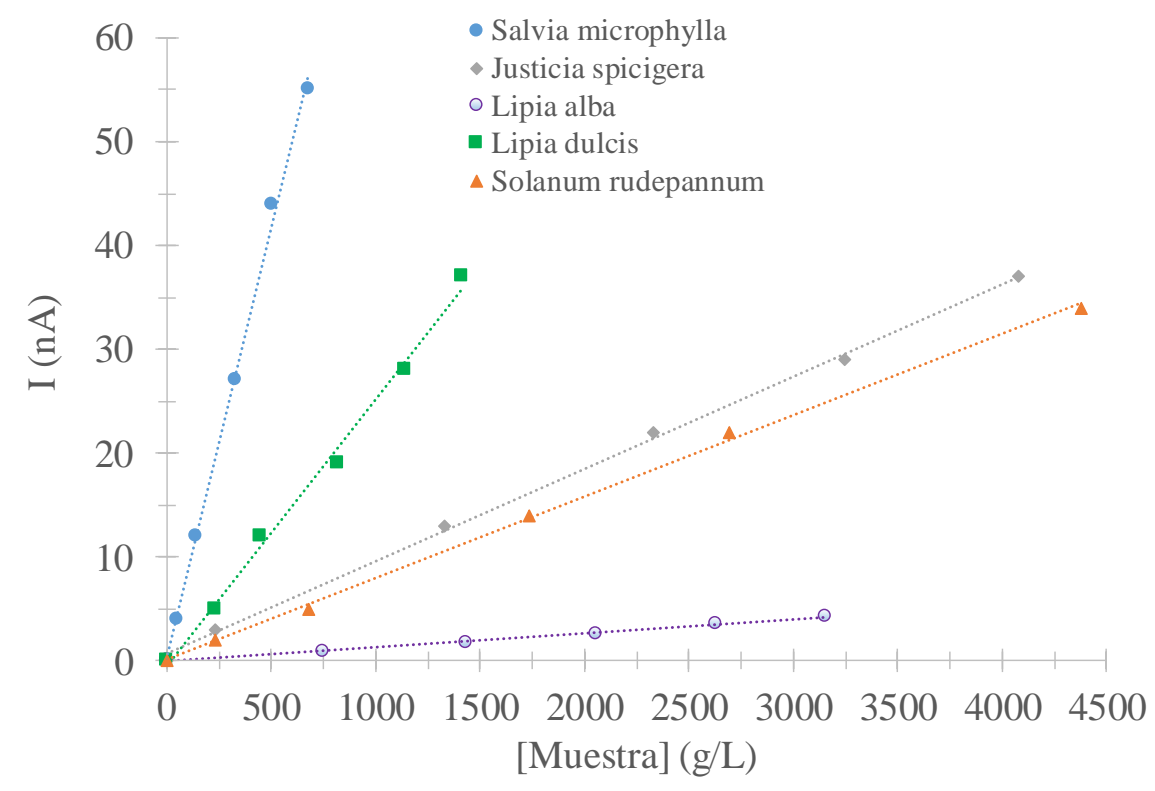

Figura 5.10. Curva de calibración electroquímica para el sistema ESP/Tir/GA 2.5\% - muestra

Tabla 5.4. Capacidad antioxidante equivalente a Trolox para diferentes muestras reales obtenidas mediante el método espectrofotométrico y utilizando el biosensor ESP/Tir/GA

\begin{tabular}{ccc}
\hline Muestra & $\begin{array}{c}\text { TEAC } \cdot \text { DPPH } \\
\boldsymbol{\mu g} \text { de } \text { Trolox/mL }\end{array}$ & $\begin{array}{c}\text { TEAC } \text { ESP/Tir/GA } \\
\boldsymbol{\mu g} \text { of } \text { Trolox/ } \mathbf{m L}\end{array}$ \\
\hline Mirto (Salvia microphylla) & $620 \pm 38$ & $31 \pm 1$ \\
Hierba dulce (Lippia dulcis) & $519 \pm 23$ & $4.9 \pm 0.2$ \\
Salve Real (Lippia alba) & $459 \pm 16$ & $0.82 \pm 0.03$ \\
\hline
\end{tabular}

La sensibilidad de cada biosensor con las diferentes muestras preparadas, se debe al contenido de compuestos fenólicos, en cada infusión, recordemos que la LTv es sensible a compuestos fenólicos para-sustituidos, mientras que Tir es más sensible a compuestos ortoy meta- sustituidos. Estos resultados demuestran la aplicabilidad de los sensores construidos en este trabajo para la determinación de capacidad antioxidante, y dan una descripción cualitativa de los componentes de la muestra. 


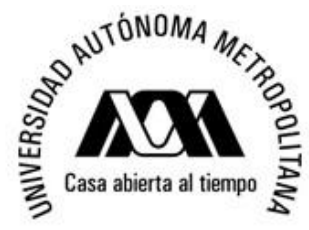

Universidad Autónoma Metropolitana Unidad Iztapalapa

División Ciencias Básicas e Ingeniería

Departamento de Química

Área de Química Analítica

Tesis de Doctorado

Q. Erika Rodríguez Sevilla

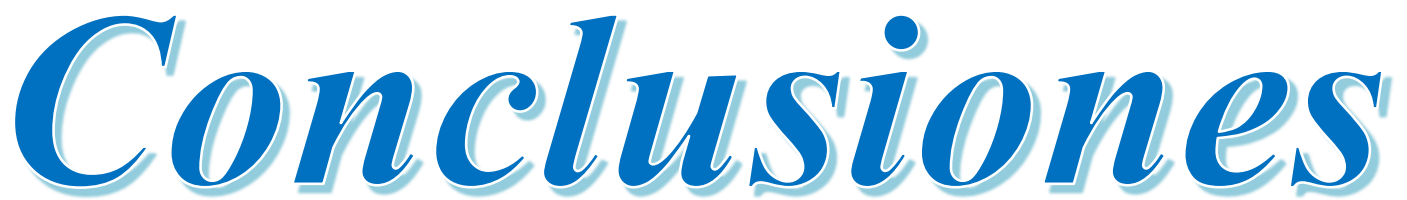




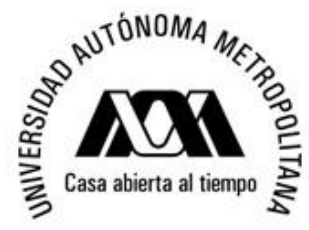
Universidad Autónoma Metropolitana Unidad Iztapalapa
División Ciencias Básicas e Ingeniería
Departamento de Química
Área de Química Analítica
Tesis de Doctorado
Q. Erika Rodríguez Sevilla

Se caracterizó electroquímica y espectrofotométricamente la hidroquinona y catecol, sustratos afines a laccasa de Trametes versicolor y tirosinasa mushroom respectivamente.

Se caracterizó la superficie del electrodo de trabajo, del screen-printed.

Se construyeron biosensores con laccasa de Trametes versicolor y tirosinasa mushroom inmovilizadas mediante los métodos de atrapamiento, reticulado, co-reticulado y enlace covalente.

La determinación de la constante de Michaelis-Menten se puede llevar a cabo al observar alguna propiedad del sistema que varíe directamente proporcional con la concentración del sustrato, en el caso de la laccasa de Trametes versicolor, el uso de la amperometría genera una descripción mayor del sistema obteniendo una $\mathrm{K}_{\mathrm{m}}$ apropiada, por lo tanto el método analítico utilizado para la determinación de dicho parámetro cinético, modifica la interacción enzima-sustrato.

Si la enzima es inmovilizada, el sistema tiene un grado de libertad menos, comparado con el sistema de la enzima en solución, por lo tanto la inmovilización por atrapamiento es, en este caso, el mejor método de inmovilización para laccasa de Trametes versicolor, lo cual se ve reflejado en la constante de Michaelis-Menten aparente, que indica mejor método de inmovilización y por consecuencia mejores parámetros analíticos para el sensor. Si se utiliza un proceso de termocurado el sensor obtendrá ventajas atribuidas a un método de atrapamiento exponiendo de manera considerable los sitios activos de la enzima.

La inmovilización de tirosinasa mediante el método de enlace covalente genera biosensores robustos con una mejora considerable en la actividad de la enzima, así como mayor sensibilidad, mejores límites de detección y cuantificación. Por otro lado la inmovilización mediante reticulado es considerado el peor método de inmovilización para tirosinasa, en el que existe la mayor pérdida de actividad enzimática, por ello la $K_{m}{ }^{\prime}$ es mayor. 
La inmovilización de tirosinasa mushroom mediante el método de reticulado sin albúmina, con glutaraldehído al $2.5 \%$ y a $40^{\circ} \mathrm{C}$ es considerado el mejor método de inmovilización dado que mejora la actividad enzimática, genera biosensores robustos con mejores límites de detección, cuantificación y sensibilidad; seguido de la inmovilización por atrapamiento, posteriormente el método de enlace covalente seguido por el método de reticulado puro reticulado utilizando ASH para la funcionalización de los sitios activos de la tirosinasa y finalmente el reticulado sin albúmina con glutaraldehído al 1\% donde existe la mayor pérdida de actividad enzimática.

Mediante la espectroscopia de impedancia electroquímica es posible evaluar el efecto en la doble capa en cada sistema así como la porosidad del sensor la cual tiene un efecto en la interacción de la enzima con el sustrato, comprobando de esta forma que la inmovilización por reticulado con GA a $40^{\circ} \mathrm{C}$ genera sensores rugosos que permiten una buena cooperatividad en el sistema, dando como resultado biosensores robustos, de bajo costo, fácil elaboración, y reutilizables.

Mediante la evaluación de método de inmovilización de enzimas puede diseñarse biosensores más robustos, de bajo costo y con un amplio tiempo de vida.

La aplicación de dicho biosensor en muestras reales indica que el biosensor propuesto en este trabajo es completamente útil en la determinación de la capacidad antioxidante y comparable con otros métodos ya establecidos.

Al dejar descubierta una parte proporcional a la cubierta por la membrana al momento de diseñar los biosensores se mejora la transferencia de carga en cada dispositivo y por lo tanto los equilibrios en las reacciones químicas y electroquímicas, se mantienen obteniendo mejores parámetros cinéticos y analíticos en cada biosensor. 


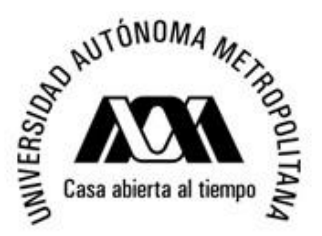

Universidad Autónoma Metropolitana Unidad Iztapalapa

División Ciencias Básicas e Ingeniería

Departamento de Química

Área de Química Analítica

Tesis de Doctorado

Q. Erika Rodríguez Sevilla

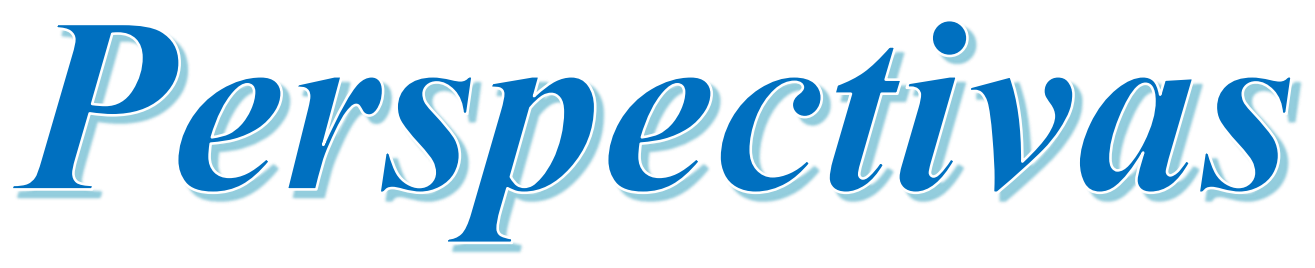

Este trabajo puede tomarse como base para el desarrollo de biosensores con características similares a los dispositivos de medición de glucosa en personas diabéticas, la cuantificación de antioxidantes en el cuerpo es un tema de interés y preocupación actual, desarrollando dispositivos que nos indiquen la cantidad de antioxidantes presentes en el organismo, daría a la población una ayuda en la prevención de enfermedades tales como el estrés oxidativo y por ende ayudaría a mantener una mejor calidad de vida.

Desarrollar dispositivos de bajos costo con mejores límites de detección y cuantificación, un amplio tiempo de vida, etcétera, caracterizar métodos de inmovilización de enzimas de grupos distintos a las oxidasas, utilizar nano materiales para mejorar el desempeño de biosensores con dispositivos más compactos, evaluar la respuesta de la enzima en condiciones fisicoquímicas cercanas a las del cuerpo humano, diseñar materiales no abrasivos permitirá cumplir con el objetivo anterior.

Analizar las infusiones herbales usando otros métodos de análisis químico tales como la cromatografía y la electroforesis capilar con el fin de cuantificar la cantidad de compuestos fenólicos presentes en cada muestra, con el fin de establecer una correlación con los resultados obtenidos con los biosensores propuestos en esta investigación. 


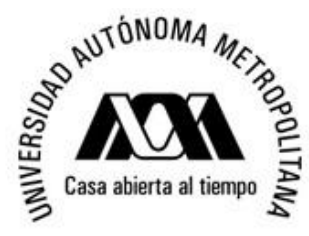

Universidad Autónoma Metropolitana Unidad Iztapalapa División Ciencias Básicas e Ingeniería

Departamento de Química

Área de Química Analítica

Tesis de Doctorado

Q. Erika Rodríguez Sevilla
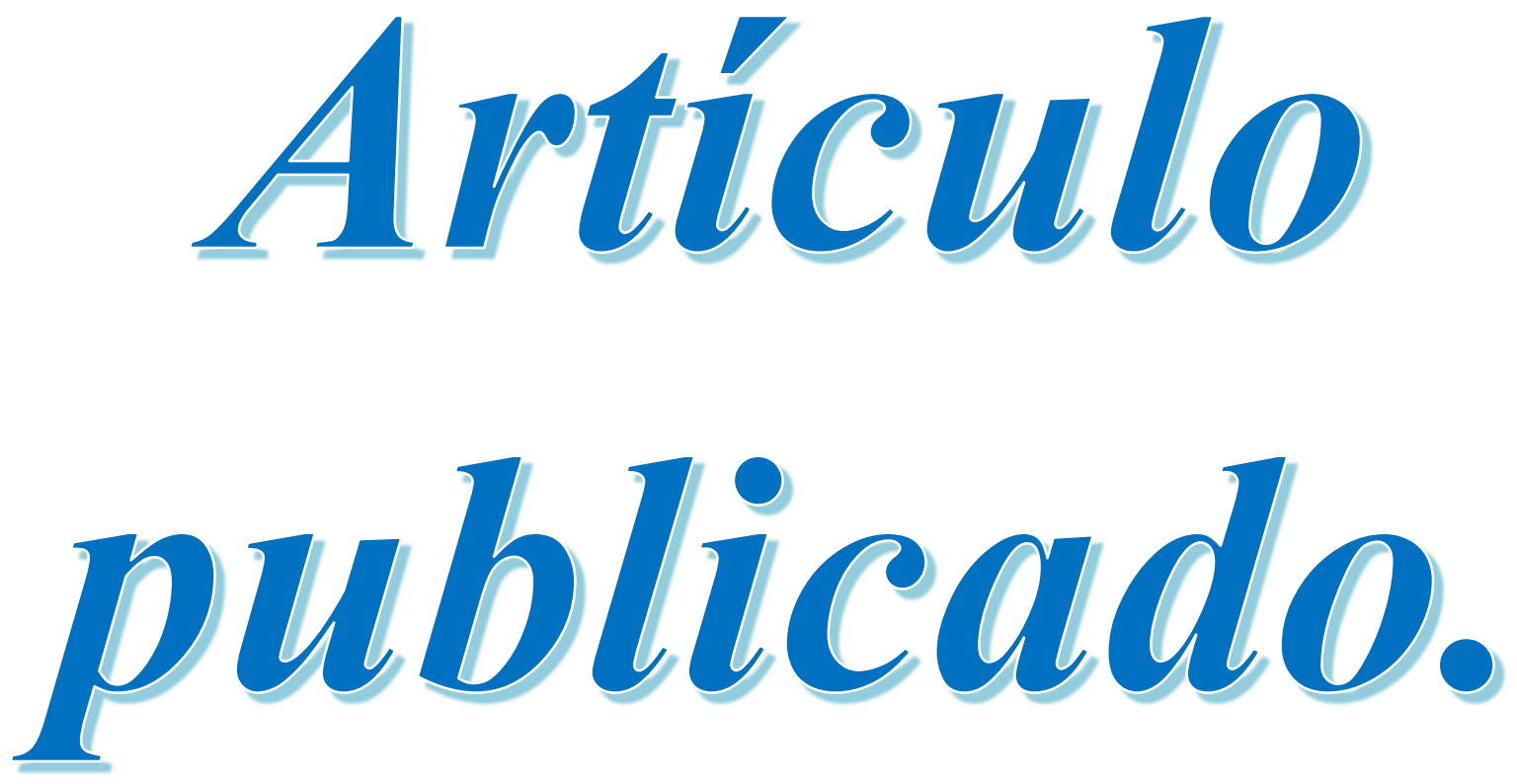


\title{
Electrochemical Quantification of the Antioxidant Capacity of Medicinal Plants Using Biosensors
}

\author{
Erika Rodríguez-Sevilla ${ }^{1, \dagger}$, María-Teresa Ramírez-Silva ${ }^{1, \dagger, *}$, Mario Romero-Romo ${ }^{2, \dagger}$, \\ Pedro Ibarra-Escutia ${ }^{3, \uparrow}$ and Manuel Palomar-Pardavé ${ }^{2, \uparrow, *}$
}

1 Departamento de Química, Universidad Autónoma Metropolitana-Iztapalapa, Área de Química Analítica, San Rafael Atlixco 186, Col. Vicentina, Del. Iztapalapa, México D.F., C.P. 09340, Mexico; E-Mail: chinita022001@yahoo.com.mx

2 Departamento de Materiales, Universidad Autónoma Metropolitana-Azcapotzalco, Área Ingeniería de Materiales, Av. San Pablo 180, Col. Reynosa-Tamaulipas, Del. Azcapotzalco, México, D.F., C.P. 02200, Mexico; E-Mail: mmrr@correo.azc.uam.mx

3 SEP-Instituto Tecnológico de Toluca. Departamento de Ingeniería Química y Bioquímica. Av, Tecnológico S/N. Fraccionamiento La Virgen, Metepec, Edo de México, C.P. 52149, Mexico; E-Mail: pedroibes@hotmail.com

$\uparrow \quad$ These authors contributed equally to this work.

* Authors to whom correspondence should be addressed; E-Mails: mtrs218@xanum.uam.mx (M.-T.R.-S.); mepp@correo.azc.uam.mx (M.P.-P.);

Tel.: +52-55-5804-4470 (M.-T.R.-S.); +52-55-5318-9472(M.P.-P.);

Fax: +52-55-5804-4466 (M.-T.R.-S.); +52-55-5318-9484 (M.P.-P.).

Received: 30 June 2014; in revised form: 28 July 2014 / Accepted: 30 July 2014 /

Published: 8 August 2014

\begin{abstract}
The working area of a screen-printed electrode, SPE, was modified with the enzyme tyrosinase (Tyr) using different immobilization methods, namely entrapment with water-soluble polyvinyl alcohol (PVA), cross-linking using glutaraldehyde (GA), and cross-linking using GA and human serum albumin (HSA); the resulting electrodes were termed SPE/Tyr/PVA, SPE/Tyr/GA and SPE/Tyr/HSA/GA, respectively. These biosensors were characterized by means of amperometry and EIS techniques. From amperometric evaluations, the apparent Michaelis-Menten constant, $K_{m}{ }^{\prime}$, of each biosensor was evaluated while the respective charge transfer resistance, Rct, was assessed from impedance measurements. It was found that the SPE/Tyr/GA had the smallest $K_{m}{ }^{\prime}(57 \pm 7) \mu \mathrm{M}$ and Rct values. This electrode also displayed both the lowest detection and quantification limits
\end{abstract}




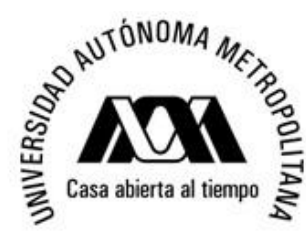

Sensors 2014, 14
Universidad Autónoma Metropolitana Unidad Iztapalapa

División Ciencias Básicas e Ingeniería

Departamento de Química

Área de Química Analítica

Tesis de Doctorado

Q. Erika Rodríguez Sevilla

for catechol quantification. Using the SPE/Tyr/GA, the Trolox Equivalent Antioxidant Capacity (TEAC) was determined from infusions prepared with "mirto" (Salvia microphylla), "hHierba dulce" (Lippia dulcis) and "salve real" (Lippia alba), medicinal plants commonly used in Mexico.

Keywords: medicinal plants; antioxidant capacity; biosensors; tyrosinase; immobilization; screen-printed electrodes; Michaelis-Menten constant

\section{Introduction}

Lately, enzymes have been used to manufacture biological sensors better known as biosensors [1,2], which are defined as compact analytical devices that incorporate a biological recognition element, like an acid, an enzyme, an antibody, a tissue, a cell, or a biomimetic, like molecular imprinted polymers or MIPs, aptamers, associated to a transduction system that performs signal processing as this is produced through interaction between the recognition element and the analyte.

The biosensor's detection principle is based on the specific interaction between the compound of interest and the recognition element. As result of such a bond there emerges a variation in one or more physicochemical properties, like $\mathrm{pH}$, heat, mass or electron transfer, potential difference, variation of optical properties, and others, detected by the transducer. This system transforms the recognition element's response into an electronic signal directly linked to the presence of the analyte or proportional to its concentration in the sample under scrutiny [3-5]. The enzymes' immobilization plays a truly relevant role in biosensor manufacture, since it is used as recognition element, whereby the useful life, the sensitivity, the detection and the quantification limits of each sensor depend on the enzyme. There are several methods to effect immobilization [6,7], some of which occur through physical interactions such as entrapment, the inclusion in membranes or through microencapsulation and others through chemical interactions between the support and the enzyme like in ionic adsorption, covalent bonding and cross-linking, such that the following questions arise: what's the best immobilization method? What happens to all the general features of a given enzyme upon immobilization through any of the said methods? Or for a particular enzyme, which immobilization method likely leads to the design and fabrication of a robust biosensor?

It is recommended to perform a good selection of the immobilization method depending on two basic factors to be economized: time and resources. Above all, to obtain good reproducible results, the methods most used are physical adsorption, entrapment, cross-linking and covalent bonding.

Tyrosinase (Tyr), is an enzyme of the oxidases group comprising two copper atoms at meta position, oxy and desoxy states in its active sites (T3 sites), their function being to catalyze the ortho-hydroxylation of monophenols and oxidation of $o$-diphenols to $o$-quinones [8-10]; therefore, it can be immobilized through diverse methods with the aim of improving the biosensor's catalytic properties [11-14]. There are several mathematical models to evaluate the kinetic, catalytic or physicochemical properties of each enzyme, one of which is the Hill's model, based on Equation (1): 


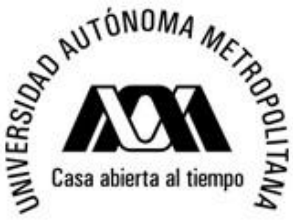

Sensors 2014, 14
Universidad Autónoma Metropolitana Unidad Iztapalapa

División Ciencias Básicas e Ingeniería

Departamento de Química

Área de Química Analítica

Tesis de Doctorado

Q. Erika Rodríguez Sevilla

$$
R=R_{\max } \frac{\left(\frac{[S]}{[S]_{0.5}}\right)^{h}}{1+\left(\frac{[S]}{[S]_{0.5}}\right)^{h}}
$$

where $R$ is the biosensor's response; [S] is the substrate's concentration; $R_{\max }$ is $R$ 's limiting value when $[\mathrm{S}] \rightarrow \infty ;[\mathrm{S}]_{0.5}$ is the media's saturation concentration, i.e., when $R=R_{\max } / 2$ and $h$ is Hill's coefficient [15-20], which when $h>1$ it implies cooperative kinetics, $h=1$ describes Michaelian kinetics and $h<1$ implies negative cooperativity between the enzyme and the substrate [21]. Whenever the Hill's coefficient = 1, Equation (1) becomes the Michaelis-Menten Equation (2), where $[S]_{0.5}=$ Michaelis-Menten $\left(K_{m}\right)$ constant:

$$
R=R_{\max } \frac{[S]}{K_{m}+[S]}
$$

In order to evaluate the features of an enzyme in solution the Michaelis-Menten model has been most used, where the reaction rates are measured as a function of the concentration of the substrate akin to the enzyme. In order to obtain the kinetic parameters like the $R_{\max }$ and the $K_{m}$ the Lineweaver-Burk model, see Equation (3), also known as double reciprocal is used, which is the linearization of Equation (2):

$$
\frac{1}{R}=\frac{K_{m}}{R_{\max }} \frac{1}{[S]}+\frac{1}{R_{\max }}
$$

Hence, this allows obtaining the $R_{\max }$ through the intercept while $K_{m}$ is associated to the slope of the straight line. If the Hill's coefficient differs from unit, then it is necessary to use a different model to that of Lineweaver-Burk. This model (see Equation (4)) results from the linearization of Hill's equation:

$$
\log \frac{R}{R_{\max }-R}=h \log [s]-h \log [S]_{0.5}
$$

This system of equations (Equations (1)-(4)) allows evaluation of the same parameters, even when the enzyme is immobilized, in which case the mathematical model is adequately fitted, though the only change refers to notation of the Michaelis constant, that now receives the name of apparent Michaelis-Menten constant, $K_{m}$ ' because the enzyme is not found in solution as in the original model. However, the use of these models (Equations (3) and (4)), generates kinetic constants with a large error, hence it is better to use constants, fitted by a non-linear regression method directly applied to Equation (1).

Either the Hill's or the Michaelis-Menten model is based on the reaction scheme (R1):

$$
E+S \stackrel{k_{1}}{\stackrel{k_{k-1}}{\longrightarrow}} E S \stackrel{k_{2}}{\longrightarrow} E+P
$$

where $E$ represents the enzyme, $S$ the substrate, $k_{I}$ is the enzyme-substrate's complex (ES) formation rate constant, $k_{2}$ is the product's $(P)$ formation rate constant and $k_{-1}$ is the enzyme-substrate's complex decomposition rate constant. The apparent Michaelis-Menten $\left(K_{m}{ }^{\prime}\right)$ constant is defined as:

$$
K_{m}^{\prime}=\frac{k_{-1}+k_{2}}{k_{1}}
$$




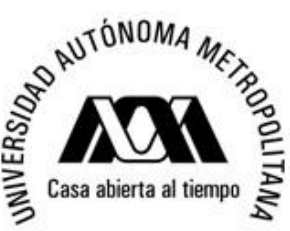

Sensors 2014, 14
Universidad Autónoma Metropolitana Unidad Iztapalapa

División Ciencias Básicas e Ingeniería

Departamento de Química

Área de Química Analítica

Tesis de Doctorado

Q. Erika Rodríguez Sevilla

which is inversely proportional to $k_{1}$, therefore, if the value of the apparent Michaelis-Menten constant is large, it is due to the enzyme-substrate's complex (ES) formation rate constant, therefore, the product's reaction rate is small.

It is through the apparent Michaelis-Menten constant that descriptive information on the system can be obtained and used as a descriptive parameter of the sensor's robustness, although up to now it has either been used as another feature of the sensor without fitting the mathematical model to the experimental results, or without mentioning the type of kinetics described in the reaction [22-25].

Electrochemical impedance spectroscopy is a noninvasive, linear response electrochemical technique, which involves the perturbation of the system under study by a current or potential sinusoidal signal with variable frequency, where the transfer function obtained from the perturbation-response relationship is known as impedance. Today this technique has been used as a tool in various study fields such as batteries, fuel cells electrode kinetics, biosensors and biological processes, among others [26-28].

The construction of a robust biosensor involves obtaining analytically important parameters like life span, sensitivity, detection and quantification limits, each of which are found directly linked to the system's immobilization and therefore to the apparent Michaelis-Menten constant, since the more effective the enzymes' immobilization, then the greater the formation rate of the products. The use of EIS leads to a description of the sensor's surface and the charge transfer resistance for each immobilization, which points out to the enzyme's interaction with the substrate.

Recently, different biosensors have been reported in order to measure the antioxidant capacity of wine [29], fruit [30], infusions [31] and medicinal plant extracts [32]. The present research work shows that after mushroom tyrosinase is immobilized through the entrapment and cross-linking methods, under three different experimental conditions, the apparent Michaelis-Menten constant for all of them is used as a parameter to establish the system's kinetic behavior, the reaction product's formation rate and other kinetic, physicochemical and analytic parameters. Above all, it allows establishing the effect of the enzyme's active sites upon its immobilization for each of the methods described through the determination of $K_{m}{ }^{\prime}$ for tyrosinase's and catechol enzymatic oxidation. Such results are reinforced when characterizing each biosensor through EIS, also aided by SEM. Further, the determination of the Trolox Equivalent Antioxidant Capacity (TEAC), using the best method of immobilization in infusions of medicinal plants from Mexico such as mirto (Salvia microphylla), which is used popularly to relieve headache, drinking a cup of infusion before bed, hierba dulce (Lippia dulcis) used to relieve coughs as well as stomach aches, also drinking a cup of infusion before breakfast, and salve real (Lippia alba), which is a plant used to alleviate stomach ache and diarrhea, taking two or three cups of infusion per day.

\section{Experimental Section}

\subsection{Reactants}

The $34 \mathrm{U} \mathrm{mg}^{-1}$ mushroom tyrosinase (EC 232-653-4) was from Sigma (St. Louis, MO, USA), the water-soluble polyvinyl alcohol polymer, PVA-AWP, from Toyo Gosei Co., Ltd. (Tokyo, Japan), the $99 \%$ pyrocatechol from Fluka (St. Louis, MO, USA), the $25 \%$ glutaraldehyde (GA), at and the human serum albumin (HSA), were from Aldrich (St. Louis, MO, USA). For the buffer solution, $99.6 \%$ purity potassium phosphate dibasic $\left(\mathrm{K}_{2} \mathrm{HPO}_{4}\right)(3252)$ and the $99.36 \%$ purity potassium phosphate monobasic 


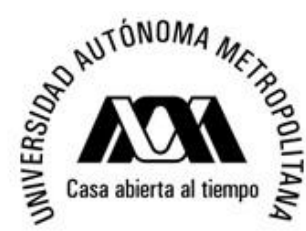

Sensors 2014, 14
Universidad Autónoma Metropolitana Unidad Iztapalapa

División Ciencias Básicas e Ingeniería

Departamento de Química

Área de Química Analítica

Tesis de Doctorado

Q. Erika Rodríguez Sevilla

$\left(\mathrm{KH}_{2} \mathrm{PO}_{4}\right)$ were from Baker Analyzed (Center Valley, PA, USA), as well as the potassium chloride $(\mathrm{KCl})$, the glacial acetic acid $\left(\mathrm{CH}_{3} \mathrm{COOH}\right)$, and the $99 \%$ purity sodium acetate $\left(\mathrm{NaCH}_{3} \mathrm{COO}\right)$. 2,2-Diphenyl-1-picryl-hydrazyl $(\cdot \mathrm{Dpph})$, and 6-hydroxy-2,5,7,8-tetrametyl choman-2-carboxylic acid (Trolox), and ethanol were from Aldrich. All solutions were prepared with deionized water type I.

\subsection{Methods}

\subsubsection{Spectrophotometric Characterization of Tyrosinase and Catechol in Solution}

The spectrophotometric studies were carried out putting $145 \mu \mathrm{g} \cdot \mathrm{mL}^{-1}$ mushroom tyrosinase and/or catechol $118 \mu \mathrm{M}$ in $0.1 \mathrm{M}$ acetate buffer at $\mathrm{pH} 4.50 \pm 0.01$ and at $(30.0 \pm 0.5)^{\circ} \mathrm{C}$, using a Perkin Elmer Lambda 20 spectrophotometer (Waltham, MA, USA).

\subsubsection{Electrochemical Characterization of Tyrosinase and Catechol in Solution}

An unmodified screen-printed electrode (SPE), having a $0.7 \mathrm{~cm}^{2}$ exposed surface area working electrode, was used for the amperometric determination of tyrosinase and catechol in solution, assessing the current as a function of the catechol's concentration at $5 \mu \mathrm{g} \cdot \mathrm{mL}^{-1}$ mushroom tyrosinase. Six different methods were followed in order to characterize the catechol's using the immobilized tyrosinase biosensors, although for both characterizations a BAS LC-4C detector (West Lafayette, IN, USA) was used, imposing a $-300 \mathrm{mV}$ constant potential using a $\mathrm{Ag} / \mathrm{AgCl}$ pseudoreference electrode [33], doing the determination in $0.1 \mathrm{M}$ acetate buffer at $\mathrm{pH} 4.50 \pm 0.01$ and at $(30.0 \pm 0.5){ }^{\circ} \mathrm{C}$, with constant stirring.

\subsection{Construction of the Biosensors}

\subsubsection{Entrapment}

Five $\mu \mathrm{L}$ of the mix $50 \% \mathrm{v} / \mathrm{v} 5 \mathrm{mg} \cdot \mathrm{mL}^{-1}$ mushroom tyrosinase (Tyr) solution and water-soluble polyvinyl alcohol (PVA) are deposited over the screen-printed working electrode; subsequently, the electrodes are left to photocure for $3 \mathrm{~h}$ at $4{ }^{\circ} \mathrm{C}$; this biosensor was labeled as SPE/Tyr/PVA [33]

\subsubsection{Cross-Linking with Albumin}

Five $\mathrm{mg} \cdot \mathrm{mL}^{-1}$ of an enzymatic solution is prepared from mushroom tyrosinase in $5 \mathrm{mg} \cdot \mathrm{mL}^{-1}$ has. This sort of albumin has been successfully used for biosensor fabrication [34], then a $50 \% \mathrm{v} / \mathrm{v}$ mix of the enzymatic solution with $2.5 \% \mathrm{GA}$ was prepared and $5 \mu \mathrm{L}$ of this solution were deposited over the working electrode and the membrane is left to polymerize at $4{ }^{\circ} \mathrm{C}$ for $3 \mathrm{~h}$; this sensor was labeled as $\mathrm{SPE} / \mathrm{Tyr} / \mathrm{HSA} / \mathrm{GA}$. The optimization of the enzyme concentration, crosslinking agent and serum albumin quantities was carried out, in terms of the biosensor sensitivity, through the use of a $2^{3}$ experimental factorial design see Table S1 in the Supplementary Information of this paper. 


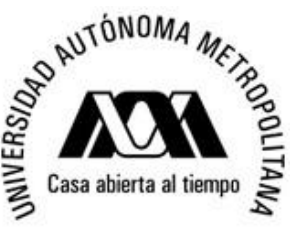

Sensors 2014, 14
Universidad Autónoma Metropolitana Unidad Iztapalapa

División Ciencias Básicas e Ingeniería

Departamento de Química

Área de Química Analítica

Tesis de Doctorado

Q. Erika Rodríguez Sevilla

\subsubsection{Cross-Linking without Albumin}

A $50 \% \mathrm{v} / \mathrm{v}$ mix of $5 \mathrm{mg} \cdot \mathrm{mL}^{-1}$ mushroom tyrosinase solution with $2.5 \%$ GA was prepared and then $5 \mu \mathrm{L}$ of the mixture were deposited over the working electrode and the membrane's polymerization is allowed at $40^{\circ} \mathrm{C}$ for $1 \mathrm{~h}$; this sensor was referred to as SPE/Tyr/GA.

\subsection{Determination of $K_{m}$ and $K_{m}^{\prime}$}

The Michaelis-Menten constant was obtained by fitting the Hill's and the Michaelis-Menten's models through non-linear regression with the aid of OriginLab 9. The apparent Michaelis-Menten's $\left(K_{m}\right)$ constant was evaluated following the o-quinone's potentiostatic reduction, also called benzoquinone, formed enzymatically by mushroom tyrosinase for different catechol's concentrations

\subsection{Sample Preparation}

The medicinal plants were obtained from the area known as the hotland of the state of Guerrero, Mexico (coordinates: $17^{\circ} 37^{\prime} \mathrm{N} 99^{\circ} 57^{\prime} \mathrm{W}$ ). The infusions were prepared as follows: for the mirto (Salvia microphylla) $4.8637 \mathrm{~g}$ of the plant including stem and leaves are placed in $50 \mathrm{~mL} \mathrm{H}_{2} \mathrm{O}$. For hierba dulce (Lippia dulcis) $2.4685 \mathrm{~g}$ of the plant including the stem, leaves and flowers, were placed in $50 \mathrm{~mL}$ $\mathrm{H}_{2} \mathrm{O}$. For the salve real (Lippia alba) $7.8930 \mathrm{~g}$ of the plant including the roots, stem, leaves and flowers were placed in $50 \mathrm{ml} \mathrm{H}_{2} \mathrm{O}$; all the solutions were prepared by infusing for $5 \mathrm{~min}$ in $\mathrm{H}_{2} \mathrm{O}$ at $100{ }^{\circ} \mathrm{C}$, later the solution is decanted and cooled at room temperature.

\subsection{Determination of the Antioxidant Capacity in Real Samples}

To determine the antioxidant capacity using $\cdot$ Dpph spectrophotometric method [35] and Trolox as standard, the $\cdot$ Dpph radical absorbance was measured at $514 \mathrm{~nm}$ by varying the concentration of Trolox in the system. Calibration curves were constructed of the real sample for the determination of the Trolox Equivalent Antioxidant Capacity (TEAC); the results are reported in $\mu \mathrm{g}$ of Trolox per $\mathrm{g}$ of sample.

\section{Results and Discussion}

\subsection{Evaluation of $K_{m}$}

In order to carry out the spectrophotometric characterization of mushroom tyrosinase, the spectra of the enzyme and catechol were obtained, to be used as the enzyme's akin substrate, in $0.1 \mathrm{M}$ acetate's buffer at $\mathrm{pH} 4.50 \pm 0.01$ and at $(30.0 \pm 0.5)^{\circ} \mathrm{C}$. The tyrosinase (see Figure 1, solid line) shows an absorption band at $289 \mathrm{~nm}$, and a shoulder at $388 \mathrm{~nm}$, see the inset in Figure 1, whereas the catechol (see Figure 1, dotted line) showed an absorption band at $275 \mathrm{~nm}$. The spectrum of the reacting system (Figure 1, dashed line) of tyrosinase (Tyr) with catechol (Cat), showed that the complex enzyme-substrate was formed, namely the tyrosinase-catechol (TyrCat), that dissociates afterwards to give the enzyme and the product: in this case benzoquinone $(o-Q)$. There were two absorption bands observed, one at 275 , which is attributed to the catechol that did not react in the system and another at $388 \mathrm{~nm}$, attributed to benzoquinone formation, as indicated by reaction scheme R2: 


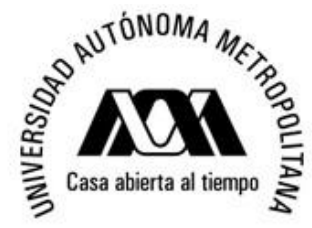

Sensors 2014, 14
Universidad Autónoma Metropolitana Unidad Iztapalapa

División Ciencias Básicas e Ingeniería

Departamento de Química

Área de Química Analítica

Tesis de Doctorado

Q. Erika Rodríguez Sevilla

$$
\operatorname{Tyr}_{(a q)}+\mathrm{Cat}_{(a q)} \Leftrightarrow \operatorname{TyrCat}_{(a q)} \rightarrow T y r_{(a q)}+o-Q_{(a q)}
$$

Figure 1. Absorption spectra of the mushroom tyrosinase (Tyr) $145 \mu \mathrm{g} \cdot \mathrm{mL}^{-1}$ (Solid line), catechol (Cat) $118 \mu \mathrm{M}$ (Broken line) and the reacting system Tyr + Cat; each spectrum was obtained in $0.1 \mathrm{M}$ acetates' buffer at $(30.0 \pm 0.5)^{\circ} \mathrm{C}$ and at $\mathrm{pH} 4.50 \pm 0.01$. The inset shows a close-up of the Tyr absorption spectrum.

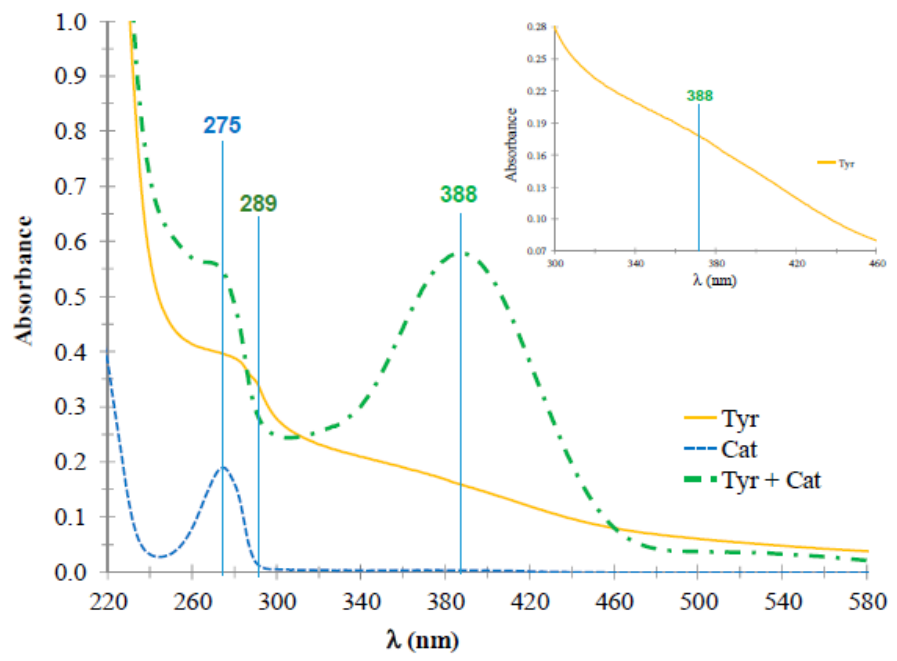

Figure 2. Enzymatic kinetics for catechol using mushroom tyrosinase in solution, in $0.1 \mathrm{M}$ acetates' buffer at $\mathrm{pH} 4.50 \pm 0.01$ and at $(30.0 \pm 0.5){ }^{\circ} \mathrm{C}$. Monitoring the enzymatic reaction rate as a function of the catechol's concentration; the dots are the experimental data while the line is the result of fitting the Hill's model Equation (1) to the data, using the values of $K_{m}=(0.46 \pm 0.02) \mathrm{mM}, v_{\max }=(174 \pm 4) \mathrm{mM} \mathrm{min}^{-1}$ and $h=1.33 \pm 0.04$. The linear fit of the trace and its corresponding equation are also shown in the figure.

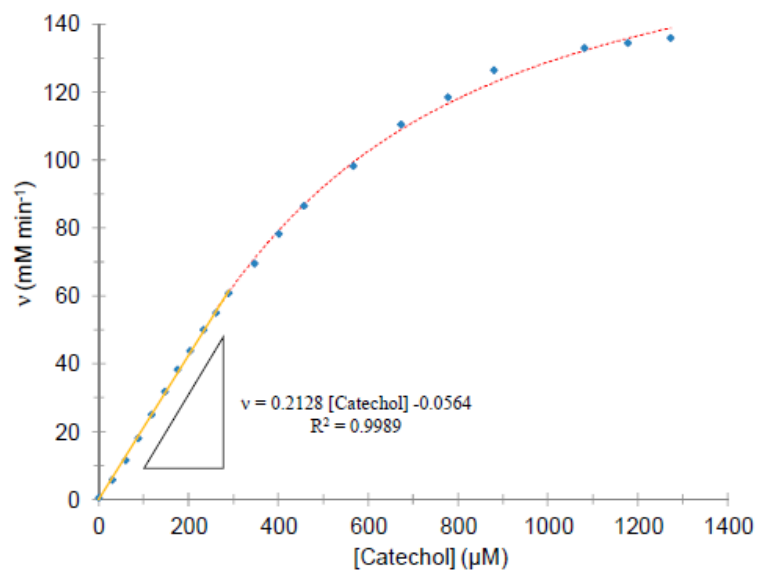




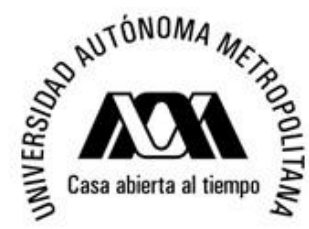

Sensors 2014, 14
Universidad Autónoma Metropolitana Unidad Iztapalapa

División Ciencias Básicas e Ingeniería

Departamento de Química

Área de Química Analítica

Tesis de Doctorado

Q. Erika Rodríguez Sevilla

In order to obtain the kinetic parameters of the enzyme, it is adequate to monitor the absorbance at $388 \mathrm{~nm}$, as a function of varying the catechol's concentrations. The reaction rate of the system formed by tyrosinase and catechol at $(30.0 \pm 0.5)^{\circ} \mathrm{C}$ in $0.1 \mathrm{M}$ acetates' buffer at $\mathrm{pH} 4.50 \pm 0.01$ as a function of the catechol concentration [Catechol] is shown in Figure 2. In this case a linear interval given was observed given by: $0 \mu \mathrm{M} \leq$ [Catechol] $\leq 289 \mu \mathrm{M}$ concentrations range with a linear regression coefficient of 0.9989. The corresponding kinetic parameters were also obtained through non-linear regression into the experimental data of the enzyme in solution $K_{m}=(460 \pm 20) \mu \mathrm{M}, v_{\max }=(174 \pm 4) \mu \mathrm{M} \cdot \min ^{-1}$ and $h=1.33 \pm 0.04$. It is important to state that the value for the Hill's coefficient obtained $(h)$ refers to the cooperativity of the system, in agreement with Coperland [21], the tyrosinase shows a positive cooperativity with the substrate, thus the Hill's coefficient is greater than 1 .

\subsection{Evaluation of $K_{m}$}

The amperometric evaluation of the tyrosinase in solution displayed a Michaelian-type kinetic behavior, (see Figure 3), where the current obtained due to the benzoquinone's reduction to catechol is monitored (inset Figure 3) at $-300 \mathrm{mV}$ imposed potential as a function of the catechol concentration, in $0.1 \mathrm{M}$ acetate buffer at $\mathrm{pH} 4.50 \pm 0.01$ and at $(30.0 \pm 0.5){ }^{\circ} \mathrm{C}$ using an unmodified screen-printed electrode, SPE.

Figure 3. Enzymatic kinetics for catechol using mushroom tyrosinase in solution, in $0.1 \mathrm{M}$ acetates' buffer at $\mathrm{pH} 4.50 \pm 0.01$ and at $(30.0 \pm 0.5)^{\circ} \mathrm{C}$. Following the measured current at $-300 \mathrm{mV}$ imposed potential as a function of the catechol's concentration. The dots are experimental data and the line is the fitting of the Hill's model of Equation (1), the best fit parameters were $\mathrm{Km}=(0.40 \pm 0.01) \mathrm{mM}, I_{\max }=(27.5 \pm 0.4) \mu \mathrm{A}$ and $h=1.35 \pm 0.03$. The inset shows the reaction scheme of catechol and benzoquinone catalyzed by tyrosinase. The linear fit of the trace and its corresponding equation are also shown in the figure.

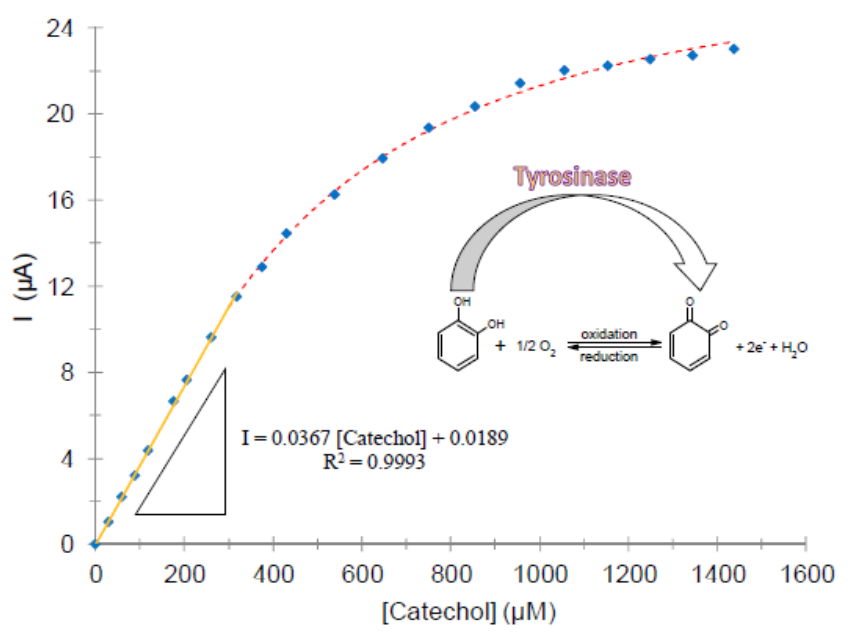

This electrode was used in order to study the kinetic behavior of the enzyme present in aqueous solution aiming to validate the estimation of the Michaelis-Menten constant using amperometry. Prior 


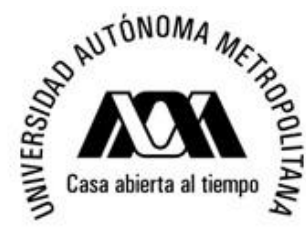

Sensors 2014, 14
Universidad Autónoma Metropolitana Unidad Iztapalapa

División Ciencias Básicas e Ingeniería

Departamento de Química

Área de Química Analítica

Tesis de Doctorado

Q. Erika Rodríguez Sevilla

to determining the best potential to be imposed in the amperometric technique, a cyclic voltammetry study was carried in the system SPE/150 $\mu \mathrm{M}$ catechol, see Figure S1 in the Supplementary Information of this article. From this electrochemical study it is plain that at $-300 \mathrm{mV}$ the reduction of $\mathrm{o}-\mathrm{Q}$ to catechol occurs with the maximum current; therefore, this potential was chosen to be applied during the amperometric study. In this case, the $K_{m}{ }^{\prime}=(404 \pm 11) \mu \mathrm{M}$ is similar to that obtained by means of UV-Vis spectroscopy, which allows neglecting a negative effect from the biosensor's material or from the pseudoreference used. However, the Michaelis-Menten constant was denoted as an apparent constant $\left(K_{m}\right)$ because it was not obtained by means of the original model; $I_{\max }=(27.5 \pm 0.4) \mu \mathrm{A}$ and $h=1.35 \pm 0.03$, which indicates that the system's cooperativity was not affected by the electrochemical technique used. The linear interval was: $0 \mu \mathrm{M} \leq$ [Catechol] $\leq 318 \mu \mathrm{M}$ concentration range with a linear regression coefficient of 0.9992 .

\subsubsection{Using the SPE/Tyr/PVA Biosensor}

The immobilization of enzymes through the entrapment method consists of physically retaining the enzyme into the inner pores' surfaces in a porous solid matrix, generally built by photo-inter-cross-linked prepolymers or polyacrylamide-type polymers, collagen, alginate, carrageenan or polyurethane resins. Two relevant advantages of this method are that it requires small quantities of the enzyme to obtain active derivatives, which makes it is much simpler from the experimental point of view and secondly, that the enzyme does not suffer any structural alteration.

Figure 4 shows the kinetic behavior of tyrosinase immobilized through entrapment; when the catechol concentration was varied in the system at $\mathrm{pH} 4.50 \pm 0.01$ imposed by means of $0.1 \mathrm{M}$ acetate buffer at $(30.0 \pm 0.5){ }^{\circ} \mathrm{C}$, in this case there was a linear interval of $0 \mu \mathrm{M} \leq$ [Catechol] $\leq 82 \mu \mathrm{M}$ with $\mathrm{R}^{2}=0.9995$, with a sensitivity of $(120 \pm 20) \mathrm{nA} \cdot \mu \mathrm{M}^{-1}$, a $\mathrm{LOD}=(9.5 \pm 0.4) \mu \mathrm{M}$ and a $\mathrm{LOQ}=(31 \pm 1) \mu \mathrm{M}$. In order to assess the immobilized enzyme's kinetic parameters the Hill's model is used as given in Equation (1); the type of kinetics for the enzyme and its substrate is cooperative with $h=1.35 \pm 0.23$. The kinetic parameters $I_{\max }=(16.8 \pm 0.2) \mu \mathrm{A}$ and the $K_{m}{ }^{\prime}=(65 \pm 2) \mu \mathrm{M}$ indicate that the enzyme's catalytic activity has been improved respect to the enzyme's in solution.

Table 1. Analytic parameters of the tyrosinase immobilized through entrapment, cross-linking and covalent bonding over screen-printed-type sensors.

\begin{tabular}{|c|c|c|c|c|c|c|c|c|}
\hline Method & $\begin{array}{c}K_{m}^{\prime} \\
(\mu \mathrm{M})\end{array}$ & $\begin{array}{l}\text { Sensitivity } \\
\left(\mathbf{n A} \cdot \mu \mathbf{M}^{-1}\right)\end{array}$ & $\begin{array}{l}\text { LOD } \\
/ \mu \mathbf{M}\end{array}$ & $\begin{array}{l}\text { LOQ } \\
/ \mu M\end{array}$ & Linear Range $(\mu \mathrm{M})$ & $I_{\max }(\mu \mathrm{A})$ & $h$ & $\begin{array}{c}\text { Useful Life } \\
\text { Span *(Days) }\end{array}$ \\
\hline $\begin{array}{c}\text { Entrapment } \\
\text { (SPE/Tyr/PVA) }\end{array}$ & $65 \pm 2$ & $120 \pm 2$ & $9.5 \pm 0.4$ & $31 \pm 1$ & $0 \leq[$ Catechol $] \leq 82$ & $16.80 \pm 0.23$ & $1.35 \pm 0.06$ & $>360$ \\
\hline $\begin{array}{l}\text { Cross-Linking } \\
\text { (SPE/Tyr/GA) }\end{array}$ & $57 \pm 7$ & $26 \pm 4$ & $1.5 \pm 0.6$ & $5.1 \pm 1.7$ & $0 \leq[$ Catechol $] \leq 136$ & $5.35 \pm 0.02$ & $1.56 \pm 0.03$ & $>165$ \\
\hline
\end{tabular}

* The biosensor was stored at room temperature conditions. 


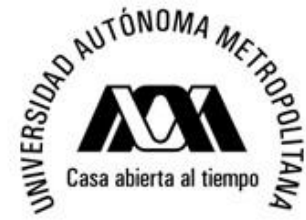

Sensors 2014, 14
Universidad Autónoma Metropolitana Unidad Iztapalapa

División Ciencias Básicas e Ingeniería

Departamento de Química

Área de Química Analítica

Tesis de Doctorado

Q. Erika Rodríguez Sevilla

Figure 4. Comparison of the enzymatic kinetics for catechol (dots) recorded using the different tyrosinase biosensors: (A) SPE/Tyr/PVA $(\bullet)$ SPE/Tyr/HAS/GA and $(\bullet)$ $\mathrm{SPE} / \mathrm{Tyr} / \mathrm{GA}$ in acetates' buffer $0.1 \mathrm{M}$ at $\mathrm{pH} 4.50 \pm 0.01$ a $(30.0 \pm 0.5){ }^{\circ} \mathrm{C}$. Following the measured current, at $-300 \mathrm{mV}$ imposed potential, as a function of catechol's concentration. The lines correspond to the fitting of the Hill's model of Equation (1), the best fit values for $K_{m}{ }^{\prime}, I_{\max }$ and $h$ are shown in Table 1.

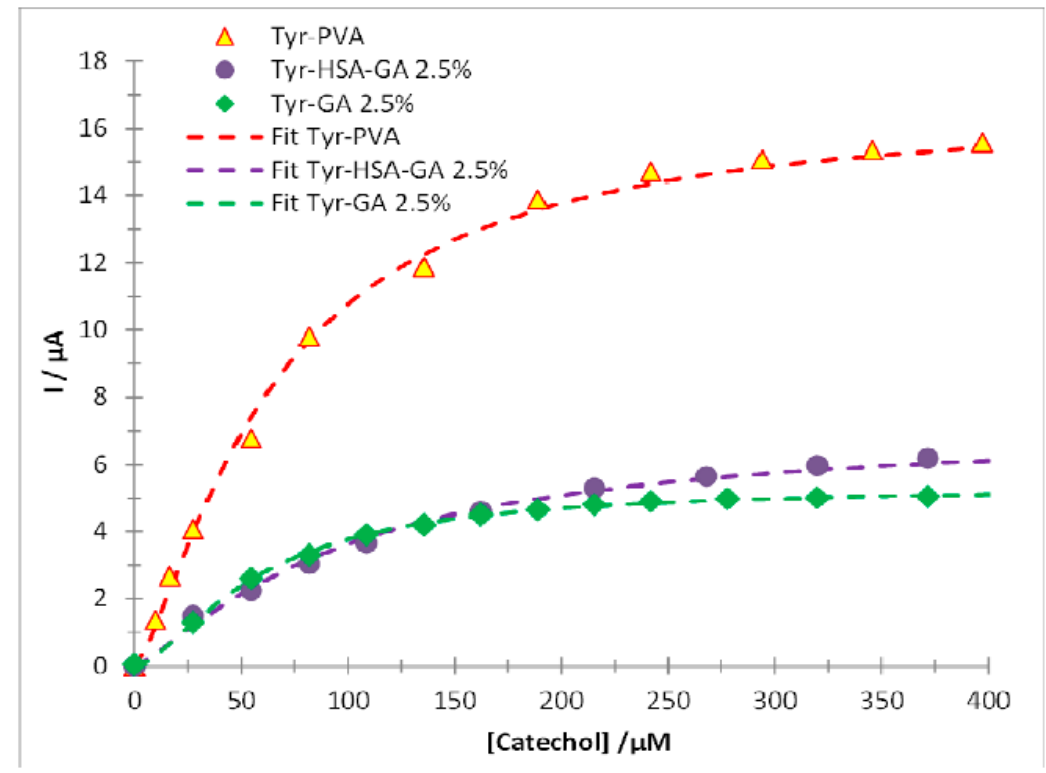

\subsubsection{Using the $\mathrm{SPE} / \mathrm{Tyr} / \mathrm{HSA} / \mathrm{GA}$ Biosensor}

Cross-linking is another immobilization method that is carried out in two different manners: one is known as pure cross-linking, that has been widely used to stabilize many enzymes; the method uses bifunctional reactants (for example: dialdehides, diimine-ethers, diisocyanates, bisdiazonium salts, including, diamines, provided they are activated with carbodiimide), that give rise to intermolecular bonds among the enzyme's molecules. Cross-linking gives as result enzymes bearing irreversible intermolecular bonds, capable of resisting $\mathrm{pH}$ and temperature extreme conditions.

The kinetic behavior of the tyrosinase after immobilization with $2.5 \%$ glutaraldehyde (GA) as cross-linking agent is shown in Figure 4; the use of human serum albumin (HSA) involves functionalization of the enzyme active sites to turn them even more reactive. In this case the linear interval for the biosensor $\mathrm{SPE} / \mathrm{Tyr} / \mathrm{HSA} / \mathrm{GA}$ is given as: $0 \mu \mathrm{M} \leq[$ Catechol] $\leq 109 \mu \mathrm{M}$ with $\mathrm{R}^{2}=0.9950$. The apparent Michaelis-Menten constant for the said sensor was $(98 \pm 6) \mu \mathrm{M}$, which either indicates that some of the enzyme's active sites are not adequately exposed or that that they have been blocked by the cross-linking agent. The sensor's analytical parameters are greater, $\mathrm{LOD}=(26 \pm 1) \mu \mathrm{M}$, LOQ $=(88 \pm 32) \mu \mathrm{M}$ and sensitivity $(32 \pm 1) \mathrm{nA} \cdot \mathrm{mM}^{-1}$, compared to the immobilization through entrapment. 


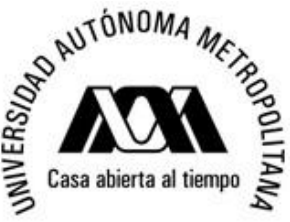

Sensors 2014, 14
Universidad Autónoma Metropolitana Unidad Iztapalapa

División Ciencias Básicas e Ingeniería

Departamento de Química

Área de Química Analítica

Tesis de Doctorado

Q. Erika Rodríguez Sevilla

\subsubsection{Using the $\mathrm{SPE} / \mathrm{Tyr} / \mathrm{GA}$ Biosensor}

Sensor fabrication aided by thermally assisted curing in the absence of HSA (SPE/Tyr/GA) process improved significantly the enzyme-substrate interaction (see Figure 4) thus increasing the sensor's enzymatic activity $K_{m}{ }^{\prime}=(57 \pm 7) \mu \mathrm{M}$, with a linear interval given as: $0 \mu \mathrm{M} \leq$ [Catechol] $\leq 136 \mu \mathrm{M}$, a linear regression coefficient $=0.9998$. In this case the enzymatic kinetics is cooperative $h=1.56 \pm 0.03$. The increase in enzyme activity affects the analytical parameters of the biosensor obtaining the lowest values of detection $((1.5 \pm 0.6) \mu \mathrm{M})$ and quantification $((5.1 \pm 1.7) \mu \mathrm{M})$ limits. This result proves that the apparent Michaelis-Menten constant is an indicative parameter of the sensor robustness, because lower values of $K_{m}{ }^{\prime}$ imply lower LOD and LOQ values. It is important to mention that the coefficient of variation (CV\%) of this biosensor was $3.4 \%$, estimated when the same biosensor was used to carry out 10 consecutive quantification measurements of a 50 M Catechol solution, and $3.9 \%$ when 3 different biosensors were used.

A comparison of the immobilization methods for the mushroom tyrosinase is shown in Table 1; note that the immobilization through HSA-less cross-linking, with $2.5 \%$ glutaraldehyde at $40{ }^{\circ} \mathrm{C}$ is considered the best immobilization method because it improved the enzymatic activity, followed by the entrapment immobilization, and finally the HSA cross-linking with $2.5 \%$ glutaraldehyde, which exhibited the greatest loss of enzymatic activity.

\subsection{Characterization of the Modified SPEs by Means of Electrochemical Impedance Spectroscopy, EIS and Scanning Electron Microscopy, SEM}

It becomes possible to evaluate the porosity of the electrode using EIS; the effect of the membrane in charge transport as well as in the formation of the electrochemical double layer and for the evaluation of the limiting factors with respect to the charge transfer and the diffusion of the system in each biosensor. Figure 5 (dots) shows the Nyquist's diagram for the different biosensors built over the SPE electrodes, as well as the fitting (solid line) carried out through Zview, using the Randles circuit and the model (inset Figure 5), where $R_{c t}$ is the charge transfer resistance, $R_{s}$ is the solution resistance, $Q$ is the electrochemical double layer's capacitance; the Nyquist's diagram shows the effect of adding each electrical component at the moment of fabricating the biosensor: it appeared that the capacitance has been considerably affected. The electrochemical impedance is calculated through Equation (6):

$$
Z=\frac{1}{C(j \omega)^{n}}
$$

where $Z$ is the impedance modulus, $C$ is the double layer's capacitance, $j=\sqrt{-1}, \omega$ is the frequence: in agreement with Pajkossy [36] $n$ is an indicative of rugosity or porosity inherent to the electrode that can adopt values from 0 to 1 , where zero indicates that the electrode is not porous, while 1 means that the reverse is true.

Modifying of the surface of the working electrode of the SPE, makes that the $R_{c t}$ changes; the $R_{c t}$ for the biosensor SPE/Tyr/HSA/GA exceeds that of SPE/Tyr/PVA and is greater than for $\mathrm{SPE} / \mathrm{Tyr} / \mathrm{GA}$ (see Table 2), confirming once again that the best analytical parameters are obtained when the resistance to charge transfer and $K_{m}{ }^{\prime}$ are lower (see Table 1). 


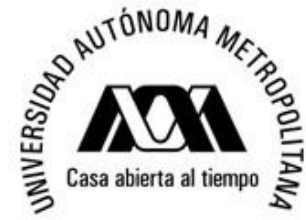

Sensors 2014, 14
Universidad Autónoma Metropolitana Unidad Iztapalapa

División Ciencias Básicas e Ingeniería

Departamento de Química

Área de Química Analítica

Tesis de Doctorado

Q. Erika Rodríguez Sevilla

Figure 5. Comparison of the experimental Nyquist diagrams (dots) recorded using each biosensor immersed in $0.1 \mathrm{M}$ phosphate's buffer at $\mathrm{pH} 7.00 \pm 0.01$, with $0.1 \mathrm{M} \mathrm{KCl}, 1 \mathrm{mM}$ $\mathrm{Fe}(\mathrm{CN})_{6}{ }^{3-/ 4-}$ at $(30.0 \pm 0.5)^{\circ} \mathrm{C}$, with the corresponding (broken line) obtained by fitting of the Randles' circuit, see the inset, to the experimental data using Zview software. With the best fit parameters the data shown in Table 2 were obtained.

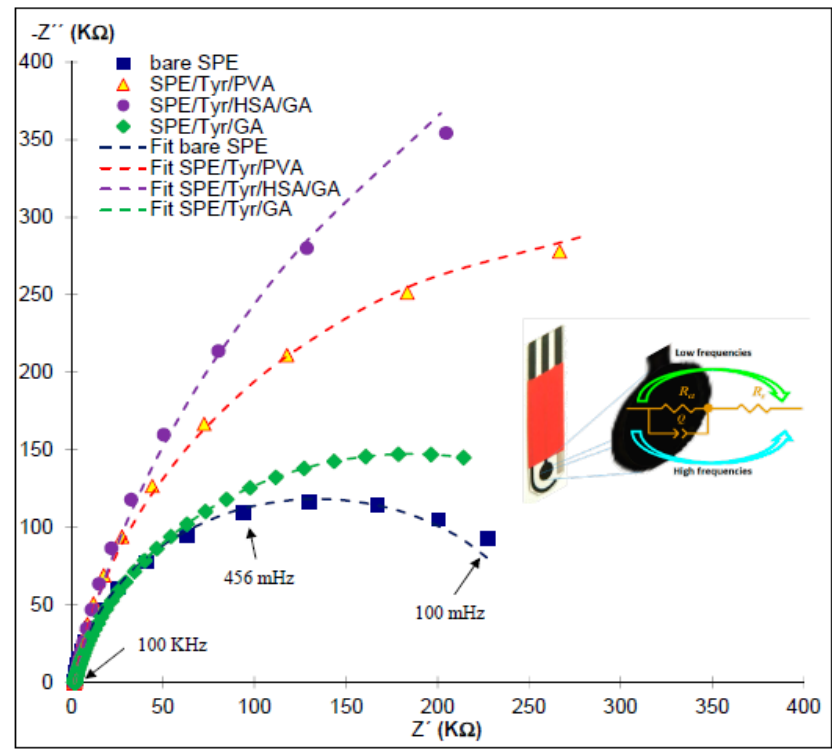

Table 2. Characterization by means of EIS of the bare SPE and the biosensors.

\begin{tabular}{ccccc}
\hline Biosensor & $\boldsymbol{R}_{s}(\mathbf{K} \boldsymbol{\Omega})$ & $\boldsymbol{R}_{c t}(\mathbf{K} \boldsymbol{\Omega})$ & $\boldsymbol{C}(\boldsymbol{\mu} \mathbf{F})$ & $\boldsymbol{n}$ \\
\hline $\mathrm{SPE}$ & 1.67 & 265 & 0.007 & 0.92 \\
$\mathrm{SPE} / \mathrm{Tyr} / \mathrm{GA}$ & 1.62 & 368 & 0.430 & 0.87 \\
$\mathrm{SPE} / \mathrm{Tyr} / \mathrm{PVA}$ & 1.62 & 680 & 0.740 & 0.91 \\
$\mathrm{SPE} / \mathrm{Tyr} / \mathrm{HSA} / \mathrm{GA}$ & 1.70 & 1359 & 0.552 & 0.88 \\
\hline
\end{tabular}

When the surface of the SPE (see Figure 6a) is modified with Tyr/PVA (Figure 6b), the immobilization is carried out by forming a polymer network; hence it becomes more rugose (see the $n$ values in Table 2), which affects directly the interaction between the enzyme and the substrate, thus the charge transfer resistance becomes larger (see the $R_{c t}$ values in Table 2). Modifying the sensor's surface with albumin makes it becomes more resistive, $R_{c t}=1359 \mathrm{~K} \Omega$, in spite of the porous surface (see Figure 6c), which had a direct impact on the biosensor's analytic parameters: this being the reason for obtaining highest LOD and LOQ compared to the previous case, while the interaction between the enzyme and the substrate becomes favored (see Table 1). Finally when the surface of the SPE is modified with GA, polymerized at $40^{\circ} \mathrm{C}$, the membrane loses porosity, however, it is uniform porosity (Figure 6d); a GA's relative proportion of $2.5 \%$, led to an improved enzyme's-substrate interaction, thus rendering biosensors with a smaller charge transfer resistance, namely $367 \mathrm{~K} \Omega$, providing hence robust sensors. 


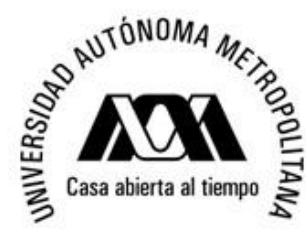

Sensors 2014, 14
Universidad Autónoma Metropolitana Unidad Iztapalapa

División Ciencias Básicas e Ingeniería

Departamento de Química

Área de Química Analítica

Tesis de Doctorado

Q. Erika Rodríguez Sevilla

Figure 6. Results of the SEM morphology analysis of the bare SPE (a) and tyrosinase immobilized through: (b) entrapment, SPE/Tyr/PVA, (c) pure cross-linking with HSA, $\mathrm{SPE} / \mathrm{Tyr} / \mathrm{HAS} / \mathrm{GA}$ and $(\mathbf{d})$ cross-linking at $(40.0 \pm 0.5)^{\circ} \mathrm{C}, \mathrm{SPE} / \mathrm{Tyr} / \mathrm{GA}$.
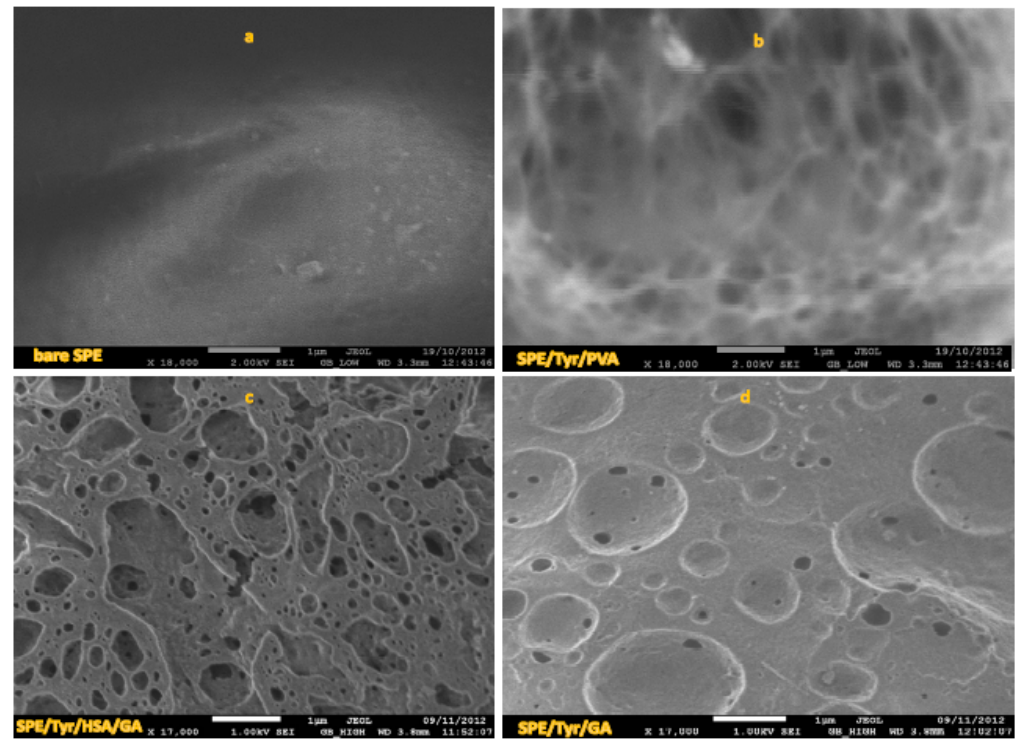

The Michaelis-Menten's constants values obtained are smaller than those reported in the literature for immobilization of tyrosinase immobilized through the same methods, including those that used nanoparticles [37-39], this indicates that the enzyme activity increases. Manufacturing these biosensors is simple and inexpensive because it does not use nanoparticles, Au electrodes, nanotubes, and so on. For example, the manufacture of robust biosensor prepared with glutaraldehyde is $80 \%$ cheaper compared to the other biosensors.

So far our results have shown that SPE/Tyr/GA displays the best attributes for a biosensor, namely: The smallest $K_{m}{ }^{\prime}$ and $R_{c t}$ values and the lowest detection and quantification limits for catechol quantification. Accordingly, this can be explained because the polymeric network formed by GA promotes two sorts of sites, one where the interaction between the enzyme and the substrate is favored, see reaction R2, thus giving the lowest $K_{m}$ ' values, and a second one where the electrochemical reduction of the enzymatic reaction product takes place easily, thereby lowering the $R_{c t}$ value. The synergy between these two kinds of sites provides the SPE/Tyr/GA biosensor with the best analytical performance.

\subsection{Quantification of the Trolox Equivalent Antioxidant Capacity}

The Trolox Equivalent Antioxidant Capacity (TEAC) of real medicinal plant samples commonly used in the Mexican herbalist, namely: "mirto" (Salvia microphylla), "hierba dulce" (Lippia dulcis) and "salve real" (Lippia alba) was estimated using two different methods: spectrophotometric with DPPH and using the biosensor SPE/Tyr/GA. Table 3 shows that using the spectrophotometric method with DPPH led to the following trend for the TEAC values: Salvia microphylla > Lippia dulcis > Lippia alba. When using the 


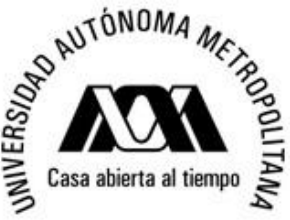

Sensors 2014, 14
Universidad Autónoma Metropolitana Unidad Iztapalapa

División Ciencias Básicas e Ingeniería

Departamento de Química

Área de Química Analítica

Tesis de Doctorado

Q. Erika Rodríguez Sevilla

biosensor the same trend was observed (see Table 3). It is important to mention that these plants exhibit TEAC values five times larger compared to other medicinal plant extracts [32]. This shows that the sensor is applicable to the determination of antioxidant capacity. Notwithstanding, it is relevant to note that for each sample the TEAC values estimated from DPPH method and using the biosensor are different. Diverse methodological approaches will provide information on different phsyiological aspects, see for instance the work of Kintzios et al. [40]. In the presence case the quantification of TEAC using the biosensor $\mathrm{SPE} / \mathrm{Tyr} / \mathrm{GA}$ is mainly given by the contribution of monophenolic compound.

Table 3. Quantification of the trolox equivalent antioxidant capacity of different real samples using the spectrophotometric method and the SPE-Tyr-GA $2.5 \%$ biosensor.

\begin{tabular}{ccc}
\hline Sample & TEAC .Dpph $\boldsymbol{\mu g}$ of Trolox/mL & TEAC SPE/Ty/GA $\boldsymbol{\mu g}$ of Trolox/mL \\
\hline "Mirto" (Salvia microphylla) & $620 \pm 38$ & $31 \pm 1$ \\
"Hierba dulce" (Lippia dulcis) & $519 \pm 23$ & $4.9 \pm 0.2$ \\
"Salve Real" (Lippia alba) & $459 \pm 16$ & $0.82 \pm 0.03$ \\
\hline
\end{tabular}

\section{Conclusions}

The immobilization of mushroom tyrosinase through the cross-linking method, with $2.5 \%$ glutaraldehyde at $40{ }^{\circ} \mathrm{C}$ is considered the best because it improved the enzymatic activity, generated robust biosensors having better LOD, LOQ and sensitivity. Then it followed the immobilization through entrapment; one but last, it was the pure cross-linking method using HSA to functionalize the tyrosinse's active sites. The last was the cross-linking albuminless method with $2.5 \% \mathrm{GA}$, which displayed the largest loss of enzymatic activity.

The use of EIS permitted to evaluate the effect of the double layer for each system as well as the porosity of the sensor, which exhibited an interaction level between the enzyme and the substrate, thus showing that immobilization through cross-linking with GA at $40{ }^{\circ} \mathrm{C}$ generated rugose sensors that displayed good cooperativity of the system and rendering robust, inexpensive, easy to fabricate, reusable biosensors. The application in real samples, indicates that the proposed biosensor in this work is useful for determining TEAC and comparable with well-established methods.

\section{Acknowledgments}

E. Rodríguez-Sevilla expresses her gratitude to CONACYT for financial support given to undertake doctorate studies, 229045, and to develop this research, well as to the Electron Microscopy Laboratory of UAM-I. MPP, MTRS and MRR gratefully thank the SNI for the distinction of their membership and the stipend received. This work was done in partial fulfillment of ERS's Ph.D. requirements.

\section{Author Contributions}

María Teresa Ramírez-Silva, Mario Romero-Romo and Manuel Palomar-Pardavé participated in the conception and design of the study. Erika Rodríguez-Sevilla carried out all the experiments. Erika Rodríguez-Sevilla, María Teresa Ramírez-Silva, Mario Romero-Romo, Pedro Ibarra-Escutia and Manuel Palomar-Pardavé participated in the analysis and discussion of results. 


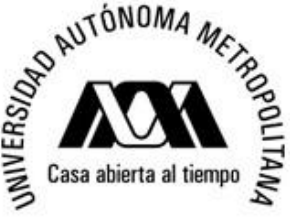

Sensors 2014, 14
Universidad Autónoma Metropolitana Unidad Iztapalapa

División Ciencias Básicas e Ingeniería

Departamento de Química

Área de Química Analítica

Tesis de Doctorado

Q. Erika Rodríguez Sevilla

\section{Conflicts of Interest}

The authors declare no conflict of interest.

\section{References}

1. Mello, L.D.; Kubota, L.T. Review of the use of biosensors as analytical tools in the food and drink industries. Food Chem. 2002, 77, 237-256.

2. Ma, Q.; Sun, H.; Hou, S. Application of graphene oxide sheets incorporated in the porous calcium alginate films on the glassy carbon electrode for biosensor construction based on myoglobin. J.Appl. Electrochem. 2013, 43, 975-984.

3. Pérez, S.; Bartrolí, J.; Fàbregas, E. Amperometric biosensor for the determination of histamine in fish samples. Food Chem. 2013, 141, 4066-4072.

4. Fatima, B.M.; Delerue-Matos, C.; Oliveira, M.B.P.P. Electrochemical evaluation of total antioxidant capacity of beverages using a purine-biosensor. Food Chem. 2012, 132, 1055-1062.

5. ElKaoutit, M.; Naranjo-Rodriguez, I.; Temsamani, K.R.; Hemández-Artiga, M.P.; Bellido-Milla, D.; Hidalgo-Hidalgo de, C.J.L. A comparison of three amperometric phenoloxidase-Sonogel-Carbon based biosensors for determination of polyphenols in beers. Food Chem. 2008, 110, 1019-1024.

6. Arroyo, R. Immobilized enzymes: Theory, methods of study and applications. Ars. Pharm. 1998, 39, 23-39.

7. García-Roig, M.; Bello-Estevez, F.; González-Velasco, F.; Ibrahim-Ghais, N.; Cachaza-Silverio, J.M. Methods for immobilizing enzymes. Biochem. Educ. 1986, 14, 180-185.

8. Espín, J.C.; García, R.P.A.; Tudela, J.; García-Cánovas, F. Study of stereospecificity in mushroom Tyrosinase. Biochem. J. 1998, 331, 547-551.

9. Lerch, K. Interrelations among metal ions, enzymes, and gene expression. Met. Ions Biol. Syst. 1981, 25, 143-186.

10. Shleev, S.; Tkac, J.; Christenson, A.; Ruzgas, T.; Yaropolov, A.I.; Whittaker, J.W.; Gorton, L. Direct electron transfer between copper-containing proteins and electrodes. Biosens. Bioelectron. 2005, 20, 2517-2554.

11. Karim, M.N.; Lee, H.J. Amperometric phenol biosensor based on covalent immobilization of tyrosinase on Au nanoparticle modified screen printed carbon electrodes. Talanta 2013, 116 , 991-996.

12. Mayorga-Martinez, C.C.; Cadevall, M.; Guix, M.; Ros, J.; Merkoçi, A. Bismuth nanoparticles for phenolic compounds biosensing application. Biosens. Bioelectron. 2013, 40, 57-62.

13. Bayramoglu, G.; Akbulut, A.; Arica, M.Y. Immobilization of tyrosinase on modified diatom biosilica: Enzymatic removal of phenolic compounds from aqueous solution. J. Hazard. Mater. 2013, 244-245, 528-536.

14. Apetrei, C.; Rodríguez-Méndez, M.L.; De Saja, J.A. Amperometric tyrosinase based biosensor using an electropolymerized phosphate-doped polypyrrole film as an immobilization support. Application for detection of phenolic compounds. Electrochim. Acta 2011, 56, 8919-8925.

15. Kurganov, B.I.; Lobanov, A.V.; Borisov, I.A.; Reshetilov, A.N. Criterion for Hill equation validity for description of biosensor calibration curves. Anal. Chim. Acta 2001, 427, 11-19. 


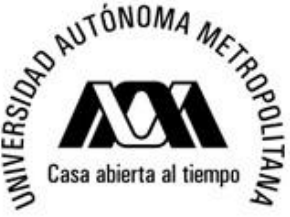

Sensors 2014, 14
Universidad Autónoma Metropolitana Unidad Iztapalapa

División Ciencias Básicas e Ingeniería

Departamento de Química

Área de Química Analítica

Tesis de Doctorado

Q. Erika Rodríguez Sevilla

16. Barbanti, L.; Damasceno, B.C. Control aspects in nonlinear Hill's equation. Comm. Nonlinear Sci. Numer. Simulat. 2011, 16, 2328-2331.

17. Johnson, K.A.; Goody, R.S. The original michaelis constant: Translation of the 1913 Michaelis-Menten paper. Biochemistry 2011, 50, 8264-8269.

18. Peterson, N.A. Analysis of dual transport systems by means of Hill plots. Anal. Biochem. 1981, $114,322-329$.

19. Stanca, S.E.; Popescu, I.C. Phenols monitoring and Hill coefficient evaluation using tyrosinase-based amperometric biosensors. Bioelectrochemistry 2004, 64, 47-52.

20. Goličnik, M. Evaluation of enzyme kinetic parameters using explicit analytic approximations to the solution of the Michaelis-Menten equation. Biochem. Eng. J. 2011, 53, 234-238.

21. Coperland, R.A. Enzymes: A Practical Introduction to Structure, Mechanism, and Data Analysis, 2nd ed.; Wiley-VCH. Inc.: Hoboken, NJ, USA, 2000; pp. 109-188.

22. Naish-Byfield, S.; Riley, P.A. Oxidation of monohydric phenol substrates by tyrosinase. An oximetric study. Biochem. J. 1992, 28, 63-67.

23. Cosnier, S.; Innocent, C. A new strategy for the construction of a tyrosinase-based amperometric phenol and o-diphenol sensor. Bioelectrochem. Bioenerg. 1993, 31, 147-160.

24. Chen, Q.; Kubo, I. Kinetics of mushroom tyrosinase inhibition by quercetin. J. Agric. Food Chem. 2002, 50, 4108-4112.

25. Fenoll, L.G.; Rodríguez-López, J.N.; García-Molina, F.; García-Cánovas, F.; Tudela, J. Michaelis constants of mushroom tyrosinase with respect to oxygen in the presence of monophenols and diphenols. Int. J. Biochem. Cell Biol. 2002, 34, 332-336.

26. Li, X.; Shen, L.; Zhang, D.; Qi, H.; Gao, Q.; Ma, F.; Zhang, C. Electrochemical impedance spectroscopy for study of aptamer-thrombin interfacial interactions. Biosens. Bioelectron. 2008, $23,1624-1630$.

27. Aaron, D.; Borole, A.P.; Yiacoumi, S.; Tsouris, C. Effects of operating conditions on internal resistances in enzyme fuel cells studied via electrochemical impedance spectroscopy. J. Power Sources 2012, 201, 59-65.

28. Bravo-Anaya, L.M.; Macías, E.R.; Carvajal, R.F.; Álvarez-Ramírez, J.G.; Casillas, N.; Soltero, J.F.A.; Larios-Durán, E.R. DNA Transitions by an Adsorption Impedance Study. J. Electrochem. Soc. 2013, 160, G69-G74.

29. Gil, D.M.A., Rebelo, M.J.F. Evaluating the antioxidant capacity of wines: A laccase-based biosensor approach. Eur. Food Res. Technol. 2010, 231, 303-308.

30. Wang, X., Jiao, C., Yu, Z. Electrochemical biosensor for assessment of the total antioxidant capacity of orange juice beverage based on the immobilizing DNA on apoly L-glutamic acid doped silver hybridized membrane. Sens. Actuators B Chem. 2014, 192, 628-633.

31. Ziyatdinova, G.K.; Nizamova, A.M.; Aytuganova, I.I.; Budnikov, H.C. Voltammetric evaluation of the antioxidant capacity of tea on electrodes modified with multi-walled carbon nanotubes. J. Anal. Chem. 2013, 68, 132-139.

32. Skotti, E.; Anastasaki, E.; Kanellou, G.; Polissiou, M.; Tarantilis, P.A. Total phenolic content, antioxidant activity and toxicity of aqueous extracts from selected Greek medicinal and aromatic plants. Ind. Crop. Prod. 2014, 53, 46-54. 
33. Ibarra-Escutia, P.; Juárez, G.J.; Calas-Blanchard, C.; Marty, J.L.; Ramírez-Silva, M.T. Amperometric biosensor based on a high resolution photopolymer deposited onto a screen-printed electrode for phenolic compounds monitoring in tea infusions. Talanta 2010, 81, 1636-1642.

34. Chuanga, M.H.; Liu, C.C.; Yang, M.C. An electrochemical tyrosinase-immobilized biosensor for albumin-toward a potential total protein measurement. Sens. Actuators B Chem. 2006, 114, 357-363.

35. Brand-Williams, W.; Cuvelier, M.E.; Berset, C. Use of a free radical method to evaluate antioxidant activity. Lebensm. Wiss. Technol. 1995, 28, 25-30.

36. Pajkossy, T. Impedance spectroscopy at interfaces of metals and aqueous solutions-Surface roughness, CPE and related issues. Solid State Ion. 2005, 176, 1997-2003.

37. Campanhã, V.F.; Janegitz, B.C.; Brett, C.M.A.; Fatibello-Filho, O. Tyrosinase biosensor based on a glassy carbon electrode modified with multi-walled carbon nanotubes and 1-butyl-3-methylimidazolium chloride within adihexadecylphosphate film. Sens. Actuators B Chem. 2013, 188, 1101-1108.

38. Pauliukaite, R.; Ghica, M.E.; Fatibello-Filho, O.; Brett, C.M.A. Electrochemical impedance studies of chitosan-modified electrodes for application in electrochemical sensors and biosensors. Electrochim. Acta 2010, 55, 6239-6247.

39. Lupu, S.; Lete, C.; Balaure, P.C.; del Campo, F.J.; Muñoz, F.X.; Lakard, B.; Hihn, J.-Y. In situ electrodeposition of biocomposite materials by sinusoidal voltages on microelectrodes array for tyrosinase based amperometric biosensor development. Sens. Actuators B Chem. 2013, 181, 136-143.

40. Kintzios, S.; Papageorgiou, K.; Yiakoumettis, I.; Barǐcevĩ, D.; Kŭsar, A. Evaluation of the antioxidants activities of four Slovene medicinal plant species by traditional and novel biosensory assays. J. Pharm. Biomed. Anal. 2010, 53, 773-776.

(C) 2014 by the authors; licensee MDPI, Basel, Switzerland. This article is an open access article distributed under the terms and conditions of the Creative Commons Attribution license (http://creativecommons.org/licenses/by/3.0/). 


\section{Anexo 1. Métodos de inmovilización}

Existen diversos métodos de inmovilización de enzimas, algunos de ellos son:

\section{Inmovilización por retención física:}

\section{Atrapamiento}

El atrapamiento consiste en la retención física de la enzima a las cavidades interiores de la matriz sólida porosa, constituida generalmente por prepolímeros fotoentrecruzables o polímeros del tipo poliacrilamida, colágeno, alginato, carraginato o resinas de poliuretano. Algunas de las ventajas de este método son que requiere poca cantidad de enzima para obtener derivados activos, es de gran sencillez desde el punto de vista experimental, como ventaja adicional, la enzima no sufre ninguna alteración en su estructura. Sin embargo también podemos encontrar algunas desventajas, por ejemplo, requiere un control riguroso de las condiciones de polimerización, así como la comprobación de que la naturaleza química del proceso no altera los grupos reactivos de la proteína [136].

\section{Inclusión en membranas}

La inclusión en membranas está dividida en dos partes:

\section{a) Microencapsulación}

La microencapsulación es una técnica en la que las enzimas están rodeadas de membranas semipermeables que permiten el paso de moléculas de sustrato y producto, pero no de la enzima (Figura A1.1). Estas membranas semipermeables, pueden ser también permanentes (originadas por la polimerización interfacial) o no permanentes (generadas por surfactantes, también llamadas "micelas inversas"). Las microcápsulas obtenidas son de forma esférica, con tamaños comprendidos entre 1 y $100 \mu \mathrm{m}$ de diámetro. Mediante este método se pueden encapsular simultáneamente una gran variedad de enzimas, células o biomoléculas, 


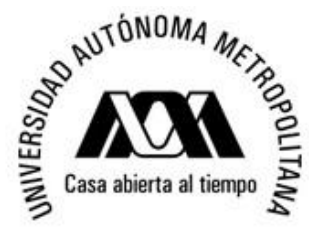
Universidad Autónoma Metropolitana Unidad Iztapalapa
División Ciencias Básicas e Ingeniería
Departamento de Química
Área de Química Analítica
Tesis de Doctorado
Q. Erika Rodríguez Sevilla

permitiendo que se lleven a cabo determinadas reacciones que suceden en múltiples pasos [137].

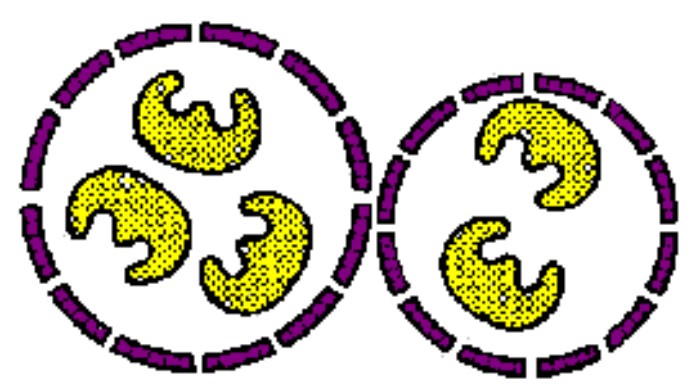

Figura A1.1 Inmovilización enzimática mediante microencapsulación.

\section{b) Reactores de membrana:}

El desarrollo de reactores o sistemas que contengan enzimas atrapadas ha despertado gran interés en la industria. Estos reactores emplean membranas permeables al producto final, permeables o no al sustrato inicial y obviamente impermeables a la enzima. Mediante una bomba se establece un flujo líquido de sustrato que traviesa el reactor.

En general, en esta metodología, se produce inicialmente a la adsorción de la enzima sobre la membrana que formará el reactor. Esta adsorción se puede realizar de dos formas

i. Mediante el paso de una solución tamponada de enzima a través de la membrana

ii. Por el contacto continuo de una solución de enzima con la membrana

\section{Inmovilización por unión química}

\section{Unión a soportes.}

Las enzimas se pueden unir químicamente a soportes. La unión a soportes es el método de inmovilización más utilizado y del que se dispone de una mayor información. La elección del soporte y del tipo de enlace resultan determinantes en el comportamiento posterior del biocatalizador. Se debe procurar que la inmovilización incremente la afinidad por el sustrato, disminuya la inhibición, amplíe el intervalo de pH óptimo y reduzca las posibles contaminaciones microbianas [138]. 


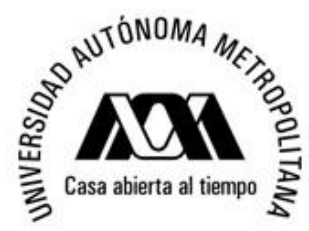

Universidad Autónoma Metropolitana Unidad Iztapalapa

División Ciencias Básicas e Ingeniería

Departamento de Química

Área de Química Analítica

Tesis de Doctorado

Q. Erika Rodríguez Sevilla

Además el soporte debe tener resistencia mecánica adecuada a las condiciones de operación del reactor y ser fácilmente separable del medio líquido para que pueda ser reutilizado. Se han usado una gran variedad de materiales como soportes para la inmovilización de numerosas enzimas. Estos materiales difieren en tamaño, densidad, porosidad y forma, aunque generalmente nos los encontramos en forma de cilindro, hojas, fibras y más corrientemente en forma de esferas.

\section{Tipos de soportes:}

Los soportes pueden clasificarse en dos grandes grupos:

\section{i. Soportes orgánicos:}

Los soportes orgánicos se pueden clasificar en:

- Polímeros naturales: a su vez divididos en:

polisacáridos (celulosa, almidón, etc).

proteínas fibrosas (colágeno, queratina, etc).

- Polímeros sintéticos: divididos en:

Poliolefinas (como el poliestireno)

Polímeros acrílicos (poliacrilatos, poliacrilamidas, polimetacrilatos, etc.)

Otros tipos (alcohol polivinílico, poliamidas, etc).

\section{ii. Soportes inorgánicos:}

Dentro de este grupo existe una gran variedad de soportes, que pueden ser

- naturales (arcillas como la bentonita, piedra pómez, sílice, etc.)

- materiales manufacturados (óxidos de metales y vidrio de tamaño de poro controlado, vidrio no poroso, alúmina, cerámicas, gel de sílice, etc.) 

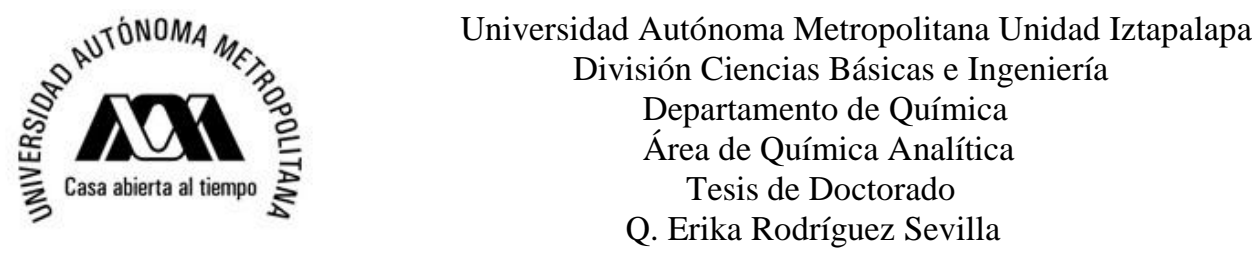

Las enzimas se pueden unir químicamente a estos soportes por adsorción iónica o por unión covalente

\section{a) Adsorción iónica}

En la adsorción iónica la enzima se une a un soporte sin funcionalizar mediante interacciones iónicas. Fuerzas de Van der Waals y por puentes de hidrógeno [139]. Esta técnica consiste en emplear resinas de intercambio iónico, las cuales contienen grupos funcionales y contraiones móviles. Estos contraiones se pueden intercambiar reversiblemente por otros iones de la misma carga, sin que se produzcan cambios en la matriz insoluble. Los principales factores que influyen en la adsorción son:

$\oplus$ el pH del medio: controla el número y la naturaleza de las cargas que presenta la superficie de la proteína y del sólido;

† la fuerza iónica: al aumentar la fuerza iónica se produce la desorción de la enzima, ya que los iones inorgánicos se unen con más fuerza al soporte que la proteína;

Ф el diámetro de poro: debe ser aproximadamente dos veces el tamaño del eje mayor de la enzima;

$\oplus$ la presencia de iones que actúen como cofactores de la enzima, ya que pueden incrementar la carga enzimática del derivado.

En este caso las ventajas son: su preparación sencilla, su bajo costo, no hay cambios de especificidad enzimática, los derivados son estables en medios de trabajo con bajo contenido en agua. Mientras que las desventajas encontradas son, la optimización de las variables que controlan la adsorción, los derivados obtenidos son poco estables desde el punto de vista mecánico, y la unión al soporte es débil.

\section{b) Unión covalente.}

La unión covalente (Figura A1.2) de una enzima a un soporte es quizá el método más interesante desde el punto de vista industrial. La metodología de la unión covalente se basa en la activación de grupos químicos del soporte para que reaccionen con nucleófilos de las proteínas. De entre los 20 aminoácidos diferentes que se encuentran en la estructura de las 


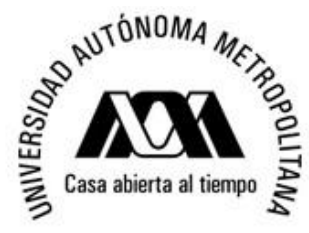
Universidad Autónoma Metropolitana Unidad Iztapalapa
División Ciencias Básicas e Ingeniería
Departamento de Química
Área de Química Analítica
Tesis de Doctorado
Q. Erika Rodríguez Sevilla

enzimas, los más empleados para la formación de enlaces con el soporte son principalmente la lisina, la cisteína, la tirosina y la histidina, y en menor medida la metionina, el triptófano, la arginina y el ácido aspártico y glutámico.

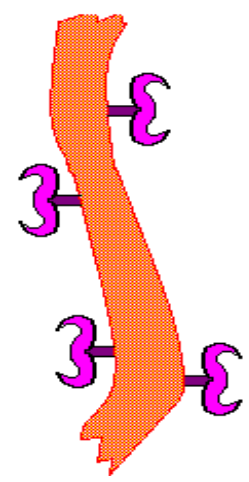

Figura A1.2 Inmovilización de enzimas mediante unión covalente.

\section{Reticulado:}

$\oplus$ Reticulado puro

Otro método de inmovilización es el reticulado, el cual puede llevarse a cabo mediante dos formas distintas, una de ellas es el reticulado puro, también denominado entrecruzamiento o cross-linking, es una técnica que ha sido ampliamente utilizada en la estabilización de muchas enzimas (Figura A1.3). Este método consiste en uso de reactivos bifuncionales (por ejemplo: dialdehídos, diiminoésteres, diisocianatos, sales de bisdiazonio e, incluso, diaminas si están activadas con carbodiimida), que originan uniones intermoleculares entre las moléculas de enzima.

El resultado del reticulado son enzimas con enlaces intermoleculares irreversibles capaces de resistir condiciones extremas de $\mathrm{pH}$ y temperatura. 


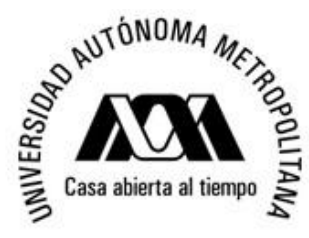

Universidad Autónoma Metropolitana Unidad Iztapalapa

División Ciencias Básicas e Ingeniería

Departamento de Química

Área de Química Analítica

Tesis de Doctorado

Q. Erika Rodríguez Sevilla

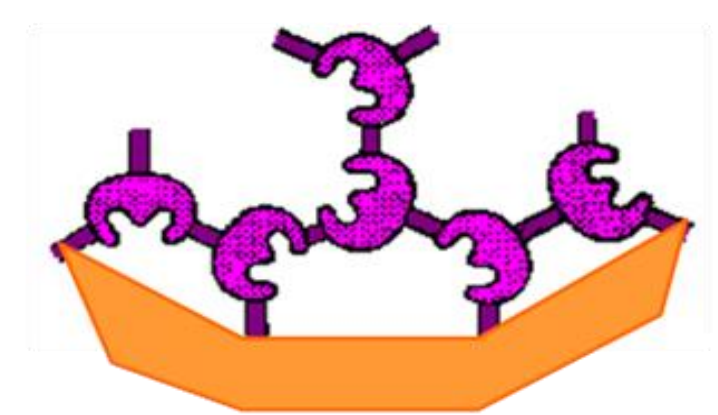

Figura A1.3 Inmovilización de enzimas mediante cross-linking, o entrecruzamiento o reticulado.

\section{$\oplus$ Co-reticulado}

El co-reticulado es un procedimiento mixto de inmovilización muy común consiste en inmovilizar la enzima por adsorción sobre una resina de intercambio iónico o un soporte polimérico (con lo que se consigue una elevada carga enzimática) y posteriormente añadir el reactivo bifuncional. Actualmente el método más novedoso de cross-linking consiste en la cristalización de enzimas y su posterior reticulado con glutaraldehído (Cross-Linked Enzyme Crystals o CLECs) [140].

El aumento de estabilidad se basa en la obtención de un entramado cristalino, donde las moléculas de enzima están rodeadas exclusivamente por otras moléculas de proteína. De esta manera la propia enzima actúa como soporte, y su estructura terciaria está estabilizada por las uniones covalentes intermoleculares. La estructura cristalina posee canales microscópicos (20-50 A) que permiten el paso de sustratos hasta el centro activo de la enzima donde se cataliza la reacción. Estos cristales pueden soportar temperaturas elevadas y pH extremos, así como la acción de las proteasas. Esta tecnología se ha aplicado a enzimas muy diferentes [141], las cuales se han utilizado en la obtención de compuestos enatioméricamente puros y en la síntesis de péptidos.

El co-reticulado, permite eliminar las pérdidas de actividad enzimática debidas a efectos difusionales, mediante el entrecruzamiento de las enzimas con una proteína sin actividad enzimática y rica en residuos de lisina (por ejemplo, la albúmina bovina). 


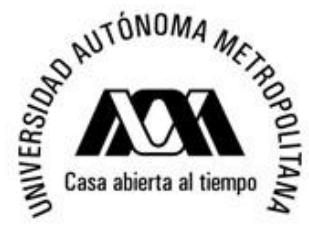

Universidad Autónoma Metropolitana Unidad Iztapalapa

División Ciencias Básicas e Ingeniería

Departamento de Química

Área de Química Analítica

Tesis de Doctorado

Q. Erika Rodríguez Sevilla

La Tabla A1.1 nos muestra algunas de las características de cada método para llevar a cabo una buena elección del método de inmovilización.

Tabla A1.4. Elección del método de inmovilización

\begin{tabular}{|c|c|c|c|c|c|}
\hline Método & $\begin{array}{l}\text { Inclusión en } \\
\text { Membranas }\end{array}$ & Atrapamiento & Reticulado & $\begin{array}{l}\text { Adsorción } \\
\text { química }\end{array}$ & $\begin{array}{c}\text { Unión } \\
\text { covalente }\end{array}$ \\
\hline Preparación & Intermedia & Difícil & Intermedia & Sencilla & Difícil \\
\hline Fuerza de unión & Débil & Media & Débil-Media & Media & Fuerte \\
\hline $\begin{array}{c}\text { Actividad } \\
\text { enzimática }\end{array}$ & Media-Alta & Baja & Baja & Media & Alta \\
\hline $\begin{array}{c}\text { Regeneración del } \\
\text { soporte }\end{array}$ & Posible & Imposible & Imposible & Posible & Difícil \\
\hline Costo del proceso & Medio-Alto & Medio & Medio & Bajo & Alto \\
\hline Estabilidad & Media & Alta & Alta & Baja & Alta \\
\hline Validez & General & General & Limitada & General & Limitada \\
\hline $\begin{array}{l}\text { Resistencia } \\
\text { microbiana }\end{array}$ & Sí & Sí & Sí & No & No \\
\hline
\end{tabular}




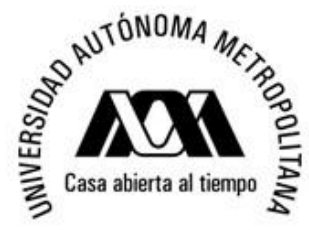

División Ciencias Básicas e Ingeniería

Departamento de Química

Área de Química Analítica

Tesis de Doctorado

Q. Erika Rodríguez Sevilla

\section{Anexo 2. Modelos matemáticos para estudiar la cinética enzimática.}

Los modelos matemáticos más relevantes en el estudio de la cinética enzimática son el modelo de Michaelis-Menten [142] y el modelo o la ecuación de Hill [143]. Ambos modelos estudian la cinética enzimática mediante ecuaciones del tipo,

$$
R=R_{\operatorname{máx}} \frac{\left(\frac{[S]}{[S]_{0.5}}\right)^{h}}{1+\left(\frac{[S]}{[S]_{0.5}}\right)^{h}}
$$

Donde $R$ es la respuesta del biosensor; $[S]$ es la concentración del sustrato; $[S]_{0.5}$ es la concentración de media saturación, es decir cuando $R=R_{\text {lim }} / 2 ; R_{\text {lim }}$ es el valor límite de $R$ cuando $[S] \rightarrow \infty$, y $h$ es el coeficiente de Hill.

Cuando el coeficiente de Hill tiene un valor de 1, la ecuación A2.1 se convierte en la ecuación de Michaelis-Menten, donde $[S]_{0.5}=K_{m}$. por lo tanto la ecuación es:

$$
R=\frac{R_{\text {máx }}[S]}{K_{m}+[S]}
$$

La energía de los sistemas biológicos, se describe en función de la energía libre de Gibbs $(\Delta G)$. Al punto de partida tanto para la reacción hacia productos como hacia reactivos se denomina estado basal, que es la contribución a la energía libre del sistema de una molécula promedio $(S$ o $P$ ) bajo un conjunto de condiciones dadas.

Para un sistema: 


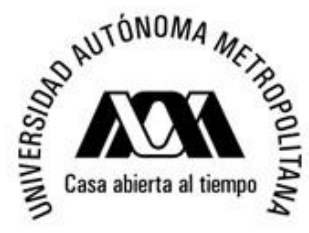

Universidad Autónoma Metropolitana Unidad Iztapalapa

División Ciencias Básicas e Ingeniería

Departamento de Química

Área de Química Analítica

Tesis de Doctorado

Q. Erika Rodríguez Sevilla

$$
E+S \underset{k_{-1}}{\stackrel{k_{1}}{\rightleftarrows}} E S \underset{k_{-2}}{\stackrel{k_{2}}{\rightleftarrows}} E P \underset{k_{-3}}{\stackrel{k_{3}}{\rightleftarrows}} E+P
$$

Donde $E$ es la enzima, $S$ es el sustrato, $P$ es el producto, $E S$ y $E P$ son los complejos enzimasustrato y enzima-producto respectivamente, las $k_{i}$ son las constantes de velocidad para cada reacción.

Debido a que la inter-conversión de dos intermediarios de reacción secuenciales constituyen un paso de la reacción; la reacción R.A2.2 se simplifica como:

$$
E+S \underset{k_{-1}}{\stackrel{k_{1}}{\rightleftarrows}} E S \underset{k_{-2}}{\stackrel{k_{2}}{\rightleftarrows}} E+P
$$

Un equilibrio tal como

$$
E+S \underset{k_{-1}}{\stackrel{k_{1}}{\rightleftarrows}} E S
$$

Viene descrito por una constante de equilibrio $K_{e q}$. En las condiciones biológicas se denota como $K^{\prime}$ eq. Por lo tanto:

$$
K_{e q}^{\prime}=\frac{[E S]}{[E][S]}
$$

De la termodinámica puede describirse

$$
\Delta G^{\prime 0}=-R T \ln K_{e q}^{\prime}
$$

donde $\mathrm{R}$ es la constante de los gases $(8.314 \mathrm{~J} / \mathrm{mol} \mathrm{K})$, T es la temperatura absoluta (298 K).

De la ecuación A2.4 es posible conocer que $\Delta G^{0} \propto K_{e q}^{\prime}$. Para la reacción R.1.4 se tiene que

$$
v=k[E][S]
$$

Para estudiar el cambio de la velocidad inicial $\left(\mathrm{V}_{0}\right)$ con respecto a la concentración del sustrato, se tiene: 


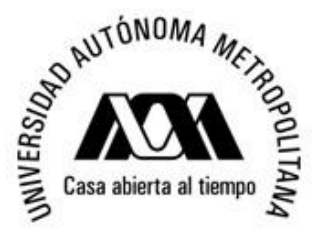

Universidad Autónoma Metropolitana Unidad Iztapalapa

División Ciencias Básicas e Ingeniería

Departamento de Química

Área de Química Analítica

Tesis de Doctorado

Q. Erika Rodríguez Sevilla

$$
v_{0}=k[S]
$$

En 1913, Michaelis y Menten [144], postularon que la velocidad de reacción (v) es relativamente rápida,

$$
E S \underset{k_{-2}}{\stackrel{k_{2}}{\rightleftarrows}} E+P
$$

La velocidad de reacción $\left(v_{2}\right)$ es más lenta que $v_{1}$.Por lo tanto R.A2.5 se convierte en la etapa limitante de la reacción, de aquí, se desprende que

\section{$v \propto[$ especie que reacciona en el segundo paso de la reacción]}

es decir, $v \propto[E S]$. En cualquier momento $E$ existe en dos formas, la forma libre o sin combinar $[E]$ y la forma combinada $[E S]$.

A baja $[S]$ la mayor parte del enzima está sin combinar, $[E]$ y por lo tanto $v \propto[S]$ (ver reacción R.4). Sin embargo la $V_{\text {máx }}$ se observará cuando toda la enzima esté en forma de complejo $E S$ y $[E]$ será extremadamente pequeña (la enzima está saturada).

De acuerdo con la reacción R.A2.5 en los primeros minutos de reacción, $[P]$ es despreciable y se hace la suposición de que puede ignorarse la reacción inversa descrita por $k_{-2}$ obteniendo así

$$
E S \longleftarrow k_{-2} E+P
$$

Por lo tanto el sistema queda como:

$$
E+S \stackrel{k_{1}}{\stackrel{k_{-1}}{\longrightarrow}} E S \stackrel{k_{2}}{\longrightarrow} E+P
$$

La velocidad inicial $\left(v_{0}\right)$ se determina por la descomposición de ES para dar P es decir,

$$
\mathrm{v}_{0}=k_{2}[E S]
$$




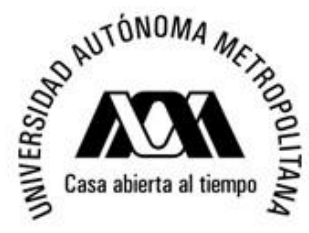
Universidad Autónoma Metropolitana Unidad Iztapalapa
División Ciencias Básicas e Ingeniería
Departamento de Química
Área de Química Analítica
Tesis de Doctorado
Q. Erika Rodríguez Sevilla

Dado que $[E S]$ no se puede medir experimentalmente con facilidad, se busca una expresión alternativa para $[E S]$.

1. Se introduce el término $[E]_{T}$ que es la concentración total de la enzima que es igual a

$$
\begin{aligned}
& {[E]_{T}=[E]+[E S]} \\
& {[E]=[E]_{T}-[E S]}
\end{aligned}
$$

2. Debido que $[S]$ es normalmente mucho mayor que $[E]_{T}$, la cantidad de sustrato fija por la enzima en cualquier momento de la reacción es despreciable, comparada con $[S]_{\text {TOTAL. }}$

Se deduce entonces una expresión para $v_{0}=f$ (parámetros que se miden fácilmente).

a) Para un sistema descrito por la reacción 7 (R.A2.7)

$$
v_{\text {formación }}^{E S}=k_{1}[E][S]
$$

Sustituyendo la ecuación A2.9, en la ecuación anterior se obtiene,

$$
v_{\text {formación }}^{E S}=k_{1}[E][S]=k_{1}\left([E]_{T}-[E S]\right)[S]
$$

Mientras que la velocidad de descomposición es:

$$
v_{\text {descomposioón }}^{E S}=k_{-1}[E S]+k_{2}[E S]
$$

b) Si se asume que: vinicial refleja un estado estacionario en que [ES] es constante, es decir

$$
v_{\text {formación }}^{E S}=v_{\text {descompositión }}^{E S}
$$

A lo que se le conoce como la hipótesis del estado estacionario. Por lo tanto

$$
k_{1}\left([E]_{T}-[E S]\right)[S]=k_{-1}[E S]+k_{2}[E S]
$$

c) Si se resuelve la ecuación A2.14 resulta. 


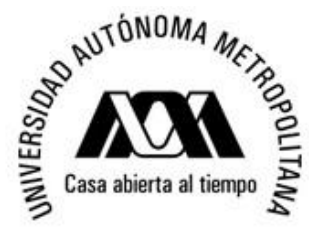

Universidad Autónoma Metropolitana Unidad Iztapalapa

División Ciencias Básicas e Ingeniería

Departamento de Química

Área de Química Analítica

Tesis de Doctorado

Q. Erika Rodríguez Sevilla

$$
\begin{aligned}
& k_{1}\left([E]_{T}-[E S]\right)[S]=k_{-1}[E S]+k_{2}[E S] \\
& \left(k_{1}[E]_{T}-k_{1}[E S]\right)[S]=k_{-1}[E S]+k_{2}[E S] \\
& k_{1}[E]_{T}[S]-k_{1}[E S][S]=k_{-1}[E S]+k_{2}[E S]
\end{aligned}
$$

Sumando $k_{1}[E S][S]$ en ambos lados de la ecuación A2.16 se tiene:

$$
k_{1}[E]_{T}[S]=k_{-1}[E S]+k_{2}[E S]+k_{1}[E S][S]
$$

Agrupando resulta:

$$
k_{1}[E]_{T}[S]=[E S]\left(k_{-1}+k_{2}+k_{1}[S]\right)
$$

Despejando $[E S]$ se obtiene

$$
[E S]=\frac{k_{1}[E]_{T}[S]}{\left(k_{-1}+k_{2}+k_{1}[S]\right)}
$$

Combinando las constantes de velocidad resulta:

$$
\begin{gathered}
{[E S]=\frac{\frac{k_{1}[E]_{T}[S]}{k_{1}}}{\left(\frac{k_{-1}+k_{2}+k_{1}[S]}{k_{1}}\right)}} \\
{[E S]=\frac{[E]_{T}[S]}{[S]+\left(\frac{k_{-1}+k_{2}}{k_{1}}\right)}}
\end{gathered}
$$

De donde se define la constante de Michaelis-Menten $\left(K_{m}\right)$ como:

$$
K_{m}=\frac{k_{-1}+k_{2}}{k_{1}}
$$

Por lo tanto 


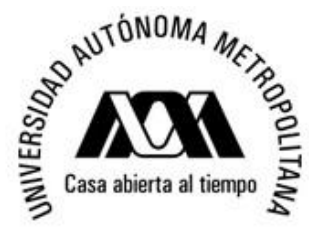

Universidad Autónoma Metropolitana Unidad Iztapalapa

División Ciencias Básicas e Ingeniería

Departamento de Química

Área de Química Analítica

Tesis de Doctorado

Q. Erika Rodríguez Sevilla

$$
[E S]=\frac{[E]_{T}[S]}{K_{m}+[S]}
$$

d) Ahora es posible expresar $v_{0}$ como función de $[E S]$, sustituyendo la ecuación A2.23 en la ecuación A2.7

$$
v_{0}=k_{2} \frac{[E]_{T}[S]}{K_{m}+[S]}
$$

Dado que $v_{\text {máx }}$ se obtiene cuando la enzima está saturada, es decir cuando $[E S]=[E]_{T}$, entonces $v_{\text {máx }}=k_{2}[E]_{T}$ de esta forma se obtiene la ecuación de Michaelis-Menten para describir la cinética enzimática:

$$
V_{0}=\frac{v_{\max }[S]}{K_{m}+[S]}
$$

Como es posible observar, $K_{m}$ está relacionada con las constantes de velocidad de cada paso de la reacción $\left(k_{i}\right)$, es decir $K_{m}$ está relacionada con la formación y/o descomposición del producto.

Es posible obtener una constante de Michaelis-Menten como se ha descrito o bien de manera gráfica (Figura A2.1) linealizando la ecuación de Michaelis-Menten para obtener una ecuación del tipo Lineweaver-Burk [145].

$$
\frac{1}{V_{0}}=\frac{K_{m}}{V_{\text {máx }}} \frac{1}{[\mathrm{~S}]}+\frac{1}{V_{\text {máx }}}
$$

Si se lleva a cabo dicha linealización, la ecuación de la recta seria de la forma $y=m x+b$ donde la pendiente es $\left(\frac{K_{m}}{V_{\text {máx }}}\right)$ y la ordenada al origen es $\frac{1}{V_{\text {máx }}}, y$ sería el inverso de la velocidad $\left(\frac{1}{V_{0}}\right)$ y $x$ seria el inverso de la concentración de sustrato $\left(\frac{1}{[\mathrm{~S}]}\right)$. De acuerdo con esta linealización se puede obtener la velocidad máxima como el inverso de la ordenada al origen 


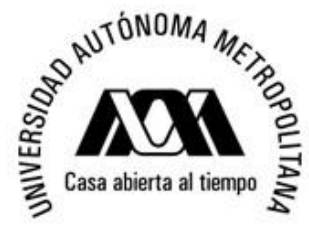

Universidad Autónoma Metropolitana Unidad Iztapalapa

División Ciencias Básicas e Ingeniería

Departamento de Química

Área de Química Analítica

Tesis de Doctorado

Q. Erika Rodríguez Sevilla

y la $K_{m}$ ' utilizando el valor de la pendiente de la recta o bien hacer la extrapolación para encontrar el valor de $\mathrm{x}$ cuando $y=0$.

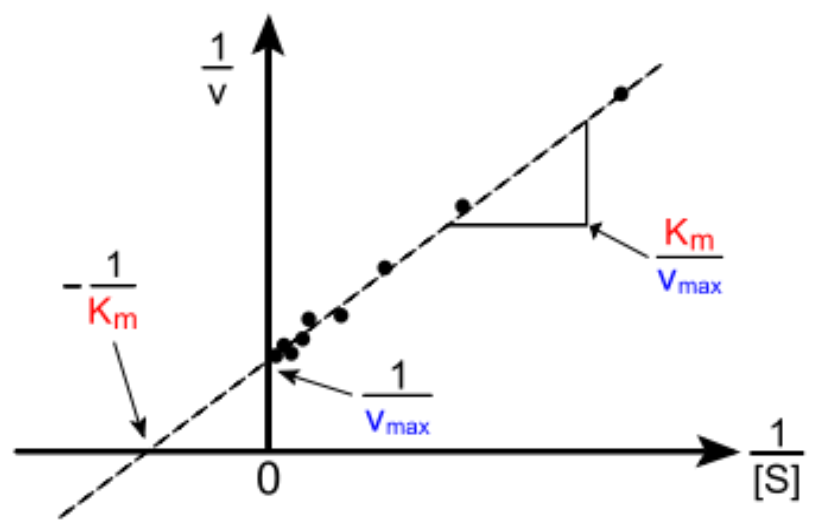

Figura A2.1. Diagrama de Lineweaver-Burk, trazando la inversa de la concentración de sustrato frente a la inversa de la velocidad inicial

Por analogía con las gráficas de Lineweaver-Burk, que son usadas para la determinación de los parámetros de la ecuación de Michaelis-Menten, este método de representación da una clara conformidad para la aplicabilidad de la ecuación de Hill para describir la dependencia experimental de $R$ con respecto a [S], donde $R$ es la respuesta medida para la enzima en estudio [146]. 


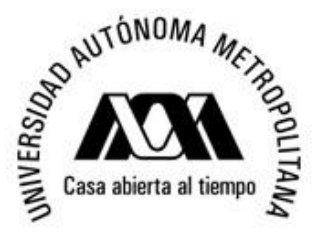

Universidad Autónoma Metropolitana Unidad Iztapalapa

División Ciencias Básicas e Ingeniería

Departamento de Química

Área de Química Analítica

Tesis de Doctorado

Q. Erika Rodríguez Sevilla

\section{Anexo 3. Fabricación de biosensores.}

\section{Biosensores con laccasa de Trametes versicolor (LTv).}

\section{os Biosensor de LTv con PVA (método de atrapamiento)}

Sobre el electrodo de trabajo del ESP se depositan $5 \mu \mathrm{L}$ de una mezcla $50 \%$ v/v de una solución de laccasa de Trametes versicolor (LTv) $170 \mathrm{Umg}^{-1} \mathrm{~mL}^{-1}$ y alcohol polivinílico soluble en agua (PVA-WAP por simplicidad PVA), posteriormente el biosensor se somete a un proceso de fotocurado por 3 horas a $4^{\circ} \mathrm{C}$, este biosensor es etiquetado como ESP/LTv/PVA.

os Biosensor de laccasa de Trametes versicolor con albúmina y glutaraldehído (método de reticulado)

Reticulado con albúmina: se prepara una solución enzimática de LTv $170 \mathrm{Umg}^{-1} \mathrm{~mL}^{-1}$ en Albúmina de Suero Humano $5 \mathrm{mgmL}^{-1}$ (ASH), posteriormente se prepara una mezcla 50\% v/v de la solución enzimática con glutaraldehído (GA) al 2.5\%, se depositan $5 \mu \mathrm{L}$ de esta solución sobre el electrodo de trabajo y se permite la polimerización de la membrana a una temperatura de $4^{\circ} \mathrm{C}$ por 3 horas, este sensor se etiqueta como ESP/LTv/ASH/GA $2.5 \%$. Utilizando el mismo procedimiento se preparan biosensores inmovilizados con GA al 1.0\%, los cuales son etiquetados como ESP/LTv/ASH/GA 1.0\%

os Biosensor de laccasa de Trametes versicolor y glutaraldehído (método de coreticulado) 


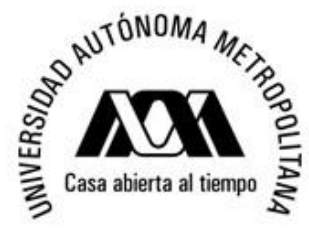
Universidad Autónoma Metropolitana Unidad Iztapalapa
División Ciencias Básicas e Ingeniería
Departamento de Química
Área de Química Analítica
Tesis de Doctorado
Q. Erika Rodríguez Sevilla

Reticulado sin albúmina o co-reticulado: Se prepara una mezcla 50\% v/v de la solución enzimática de LTv $170 \mathrm{Umg}^{-1} \mathrm{~mL}^{-1}$ con glutaraldehído al $2.5 \%$ se depositan $5 \mu \mathrm{L}$ de esta solución sobre el electrodo de trabajo y se permite la polimerización de la membrana a $40^{\circ} \mathrm{C}$ por 1 hora, este biosensor es etiquetado como ESP/LTv/GA 2.5\%. Utilizando GA al 1.0\% y siguiendo el mismo procedimiento se prepara el biosensor etiquetado como ESP/LTv/GA $1.0 \%$.

\section{ç Biosensor de laccasa de Trametes versicolor y EDC (método de enlace covalente)}

Antes de modificar la superficie del electrodo de trabajo ésta se activa con $5 \mu \mathrm{L}$ de una solución amortiguadora que contiene acido 2-(N-morfolino)- etano sulfónico, MES, 0.1 M y $\mathrm{NaCl} 0.5 \mathrm{M}$ a pH $=6$. Después de 15 minutos se extrae el exceso de amortiguador y se colocan $3 \mu 1$ de una solución que contiene clorhidrato de N-etil-N'-(3dimetilaminopropil) carbodimida (EDC) $2 \mathrm{mM}$ y hidroxi-2,5-dioxopirrolidina-3- sal sulfónica ácida de sodio (sulfo-NHS) $5 \mathrm{mM}$, el sistema se deja reaccionar durante $15 \mathrm{~min}$ a temperatura ambiente, posteriormente se colocan $5 \mu \mathrm{L}$ de una solución de LTv $170 \mathrm{Umg}^{-1} \mathrm{~mL}^{-1}$ y se deja reaccionar el sistema durante 1 hora a temperatura ambiente. Finalmente el biosensor se enjuaga con amortiguador de fosfatos $0.1 \mathrm{M}$, a $\mathrm{pH}=7.00 \pm 0.01$ para eliminar la enzima no inmovilizada [55]. Este biosensor es etiquetado como ESP /LTv/EDC.

\section{Biosensores con tirosinasa mushroom (Tir).}

Para fabricar biosensores con tirosinasa mushroom como elemento de reconociomiento se sigue la metodología descrita anteriormente para cada método de inmovilización, utilizando ahora una solución enzimática de tirosinasa mushroom $170 \mathrm{Umg}^{-1} \mathrm{~mL}^{-1}$. 


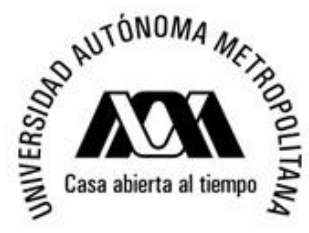

Universidad Autónoma Metropolitana Unidad Iztapalapa

División Ciencias Básicas e Ingeniería

Departamento de Química

Área de Química Analítica

Tesis de Doctorado

Q. Erika Rodríguez Sevilla

\section{Caracterización electroquímica}

La caracterización mediante voltamperometría cíclica y amperometría de cada biosensor se

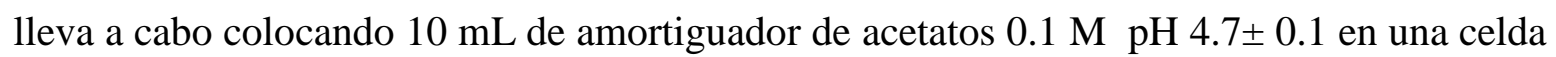
termostatada a $30^{\circ} \mathrm{C}$; en la determinación amperométrica se impone un potencial de -0.300 $\mathrm{V}$ manteniendo la agitación constante.

\section{Caracterización analítica.}

Para la caracterización analítica de cada biosensor se utiliza el software OriginLab, con los modelos de Hill y Michaelis-Menten, aplicando una regresión no lineal para obtener los parametros cinéticos $\left(K_{m}^{\prime}\right.$ y $\left.I_{m a ́ x}\right)$. Tomando los puntos experimentales correspondientes a el intervalo lineal, de cada cinetica, se determina la sensibilidad (pendiente de la recta), el limite de detección y cuantificación como la concentración correspondiente a la corriente dada por $\mathrm{I}=\mathrm{b}+3 \delta \mathrm{y} \mathrm{I}=\mathrm{b}+10 \delta$ respectivamente [147]; donde I es la corriente, b es la ordenada al origen y $\delta$ es la desviación estándar o error típico de la regresión lineal. 


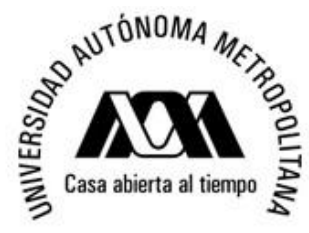

Universidad Autónoma Metropolitana Unidad Iztapalapa

División Ciencias Básicas e Ingeniería

Departamento de Química

Área de Química Analítica

Tesis de Doctorado

Q. Erika Rodríguez Sevilla

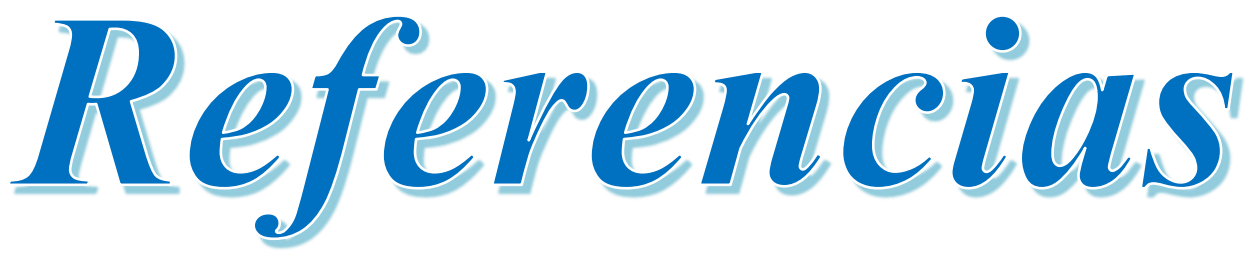




\section{Capítulo 1.}

1 Charles Darwin, M.A., F.R.S., The Origin of Species by means of Natural Selection or,The Preservation of Favoured Races in the Struggle for Life, 6 Edición, DB Publishing House, 2012.

2 Cristopher K. Mathews, Kensal E. Van Holde, Kevin G. Ahern, Bioquímica, 3 Edición, Pearson 2006.

3 Robert A. Coperland, Enzymes: A Practical Introduction to Structure, Mechanism, and Data Analysis, 2 Edición. Wiley-VCH, Inc. 2000.

4 http://www.iubmb.org/index.php?id=33; http://www.enzyme-database.org/class.php

5 Elizabeth A. H Hall, Biosensors, 1 Edción, Prentice Hall, 1991.

6 Alam Fersht, Estructura y mecanismo de las enzimas, 1 Edición en español, Editorial Reverté, 1980.

7 J. Maria Medicina, F. Sanchez de Medicina, A. Vargas, Bioquímica, 2da Edición, editorial Sintesis. 2003.

8 David L. Nelson y Michael M. Cox, Lenhinger Principios de bioquímica, 4 Edición, Editorial Omega, 2005.

9 Julio Polaina, Andrew P. MacCabe, Industrial Enzymes, Structure, Function and Applications, publicado por Springer, 2007.

10 Gordon F. Bickerstaff, Immobilization of Enzymes and Cells, en Methods in Biotechnology Vol. $1,1997$.

11 García-Roig M.; Bello-Estevez F.; González-Velasco F.; Ibrahim-Ghais N.; Cachaza-Silverio J.M. Methods for Immobilizing Enzymes. Biochemical Education 1986, 14, 180-185.

12 Taylor, R.F. Protein Immobilization: fundamentals and applications: (Bioprocess Technology Series/14), página 71, en Journal of Pharmacy and Pharmacology, book review, 1992.

13 Dmitry Murzin, Tapio Salmi, Chapter 6. Enzymatic kinetics in Catalytic Kinetics, Elsevier, 2005, $189-224$

14 John D. Enderle, Chapter 8 - Biochemical Reactions and Enzyme Kinetics, Introduction to Biomedical Engineering (Third Edition), A volume in Biomedical Engineering, Elsevier, 2012, páginas 447-508.

15 Arroyo R. Inmobilized enzymes: Theory, methods of study and applications. Ars. Pharmaceutica. 1998, 39, 23-39.

16 Vladimir Leskovac, Comprehensive Enzyme Kinetics, Kluwer Academic Publishers, New York, 2004. 
17 Ahmet R. Özdurala, Deniz Tanyolaç, Zafer Demircan, 'Ismail H. Boyaci, Mehmet Mutlu, Colin Webb, A new method for determination of apparent kinetics parameters in recirculating packedbed immobilized enzyme reactors, Chemical Engineering Science 56 (2001) 3483-3490.

18 Jeffrey A. Cohlberg, $\mathrm{K}_{\mathrm{m}}$ as an Apparent Dissociation Constant, Journal of Chemical Education 56 (8), (1979), 512-514.

19 D.R. Thévenot, K. Toth, R.A. Durst, G.S. Wilson. ELECTROCHEMICAL BIOSENSORS: RECOMMENDED DEFINITIONS AND CLASSIFICATION Pure Appl Chem. 71, 2333-2348 (1999).

20 F. Ivanauskas, I. Kaunietis, V. Laurinavičius, J. Razumienè, R. Šimkus, Apparent Michaelis constant of the enzyme modified porous electrode, Journal of Mathematical Chemistry, 43 (4), 2008, 1516-1526

21 F. Ivanauskas, I. Kaunietis, V. Laurinavičius, J. Razumienè, R. Šimkus, Computer simulation of the steady state currents at enzyme doped carbon paste electrodes, Journal of Mathematical Chemistry 38 (3), 2005, 355-366.

22 R. Baronas, F. Ivanauskas, J. Kulys, M. Sapagovas, Modelling of amperometric biosensors with rough surface of the enzyme membrane, Journal of Mathematical Chemistry 34, (3-4), 2003, 227-242.

23 I. Kaunietis, R. Šimkus, V. Laurinavičius, F. Ivanauskas, Apparent Parameters of Enzymatic PlateGap Electrode, Nonlinear Analysis: Modelling and Control, 10 (3), 2005, 211-221

24 Lurdes I.B. Silva, Filipe D.P. Ferreira, Ana C. Freitas, Teresa A.P. Rocha-Santos, A.C. Duarte, Optical fiber biosensor coupled to chromatographic separation for screening of dopamine, norepinephrine and epinephrine in human urine and plasma, Talanta 80 (2009) 853-857

25 Javier Gonzalo Ruiz, Desarrollo de biosensores enzimáticos miniaturizados para su aplicación en la industria alimentaria, Tesis doctoral, Universidad de Barcelona, 2006.

26 Pingarrón, J.M. Sánchez Batanero, P “Química electroanalítica, Fundamentos y aplicaciones”. Ed. Síntesis. . (1999).

27 Jane E. Frew, H. Allen 0. Hill, Electrochemical Biosensors, Analytical Chemistry, 59 (15), 1987, 933-944.

28 Danielle W. Kimmel, Gabriel LeBlanc, Mika E. Meschievitz, and David E. Cliffel, Electrochemical Sensors and Biosensors, Anal. Chem. 2012, 84, 685-707

29 S.V. Dzyadevych, V.N. Arkhypova, A.P. Soldatkin, A.V. El'skaya, C. Martelet, N. Jaffrezic Renault Amperometric enzyme biosensors: Past, present and future, ITBM-RBM 29 (2008) 171180

30 Jiř́ Janata, Principles of Chemical Sensors, Second Edition, Springer,. 2009.

31 Pedro Ibarra Escutia, Determinación del contenido fenólico en extractos naturales mediante sensores enzimáticos", Tesis doctoral 2010. 


\section{CAPÍtUlo 2.}

32 Kurt Kalcher, Ivan Svancara, Marijo Buzuk, Karel Vytras, Alain Walcarius, Electrochemical sensors and biosensors based on heterogeneous carbon materials, Monatsh Chem 140, 2009, 861-889.

33 Zahra Taleat, Alireza Khoshroo, Mohammad Mazloum-Ardakani, Screen-printed electrodes for biosensing: a review (2008-2013), Microchim Acta 181, 2014, 865-891.

34 Yongsang Kim, Hyejung Kim, and Hoi-Jun Yoo, Electrical Characterization of Screen-Printed Circuits on the Fabric, IEEE Transactions on Advanced Packaging, 33 (1), 2010, 196-205.

35 R. G. Guevara-González and I. Torres-Pacheco, Laccases, Advances in Agricultural and Food Biotechnology (2006) 323-340.

36 N. Duran and E. Eposito, Potential applications of oxidative enzymes and phenoloxidase-like compounds in wastewater and soil treatment: a review Applied Catalysis B: Environmental (2000), 28, 83-99

37 C. Raghukumar, Mycological Research (2000), 104, 1222-1226

38 S. Larsson, P. Cassland, L. J. Jonsson, Fungi from marine habitats : an application in bioremediation, Applied and Environmental Microbiology (2001), 67, 1163-1170

39 M. Servili, G. DeStefano, P. Piacquadio and V. Sciancalepore, A Novel Method for Removing Phenols from Grape Must, American Journal of Enology and Viticulture (2000), 51, 357-361

40 R. Cohen, L. Persky, Y. Hadar, Biotechnological applications and potential of wood-degrading mushrooms of the genus Pleurotus, Applied Microbiology and Biotechnology (2002), 58, 582594.

41 C. Mougin, A. Kollmann, C. Jolivat, Enhanced production of laccase in the fungus Trametes versicolor by the addition of xenobiotics, Biotechnology Letters (2002), 24, 139-142.

42 A. Kunamneni, A. Ballesteros, F. J. Plou and M. Alcalde, Fungal laccase - a versátil enzyme for biotechnological applications, Communicating Current Research and Educational Topics and Trends in Applied Microbiology (2007), 233-245.

43 K. Piontek, M. Antorini and T. Choinowski, Crystal Structure of a Laccase from the Fungus Trametes versicolor at 1.90- $\AA$ Resolution Containing a Full Complement of Coppers, The Journal of Biological Chemistry (2002), 277, 40, 4, 37663-37669.

44 Loera Corral Octavio, Pérez Pérez Ma. Cristina Irma, Barbosa Rodríguez Juan Ricardo and Villaseñor Ortega Francisco, Laccases, Advances in Agricultural and Food Biotechnology, 2006, 323-340. 
45 Upendra N. Dwivedi, Priyanka Singh, Veda P. Pandey, Anoop Kumar, Structure-function relationship among bacterial, fungal and plant laccases, Journal of Molecular Catalysis B: Enzymatic 68 (2011) 117-128.

46 María Fernández-Fernández, M. Ángeles Sanromán, Diego Moldes, Recent developments and applications of immobilized Laccase, Biotechnology Advances 31 (2013) 1808-1825.

47 Audrey Sassolas, L. J. Blum, B. D. Leca-Bouvier, Immobilization strategies to develop enzymatic biosensors, Biotechnology Advances 30 (2012) 489-511.

48 García-Roig M.; Bello-Estevez F.; González-Velasco F.; Ibrahim-Ghais N.; Cachaza-Silverio J.M. Methods for Immobilizing Enzymes. Biochemical Education 1986, 14, 180-185.

49 Jagriti Narang, Sheetal Chawla, Nidhi Chauhan, Monika Dahiya, Chandra Shekhar Pundir, Construction of an amperometric polyphenol biosensor based on PVA membrane, Food Measure (2013) 7:22-28.

50 K. Rasera, J. Ferla, A.J.P. Dillon, R. Riveiros, Mara Zeni, Immobilization of laccase from Pleurotus sajor-caju in polyamide membranes, Desalination 245 (2009) 657-661. 43ew2

51 De-Sheng Jiang, Sheng-Ya Long, Jun Huang, Hai-Yan Xiao, Ju-Ying Zhou, Immobilization of Pycnoporus sanguineus laccase on magnetic chitosan microspheres, Biochemical Engineering Journal 25 (2005) 15-23

52 X. Hai-yan, H. Jun, L. Cheng, J. De-sheng, Immobilization of laccase on amine-terminated magnetic nano-composite by glutaraldehyde crosslinking methodTrans. Nonferrous Met. Soc.China (2006), 16, s414-s4 18.

53 G. Alarcón-Ángeles, M. Guix, W.C. Silva, M.T. Ramírez-Silva, M. Palomar-Pardavé, M. RomeroRomo, A. Merkoci, Enzyme entrapment by $\beta$-cyclodextrin electropolymerization onto a carbón nanotubes-modified screen-printed electrode, Biosensors and Bioelectronics 26 (2010) 17681773.

54 L. F. Bautista, G. Morales, R. Sanz, Immobilization strategies for laccase from Trametes versicolor on mesostructured silica materials and the application to the degradation of naphthalene, Bioresource Technology 101 (2010) 8541-8548.

55 D. Fink, I. Klinkovich, O. Bukelman, R. S. Marks, A. Kiv, D. Fuks, W. R. Fahrner, L. Alfonta, Glucose determination using a re-usable enzyme-modified ion track membrane sensor, Biosensors and Bioelectronics 24 (2009) 2702-2706

56 B.I. Kurganov, A.V. Lobanov, I.A. Borisov, A.N. Reshetilov, Criterion for Hill equation validity for description of biosensor calibration curves, Analytica Chimica Acta 427 (2001) 11-19.

57 Stuart J. Edelstein and William G. Bardsley, Contributions of Individual Molecular Species to the Hill Coefficient for Ligand Binding by an Oligomeric Protein, J. Mol. Biol. (1997) 267, 10-16. 
58 Ivanauskas F, Kaunietis I, Laurinavičius V, Razumienė J, R. Šimkus, Apparent Michaelis constant of the enzyme modified porous electrode, Journal of Mathematical Chemistry, 43 (2008) 15161526.

59 Lorenzo Di Bari, Silvia Ripoli and Piero Salvadori, Serum Albumin and Natural Products, in Progress in Biological Chirality, G. Palyi, C. Zucchi and L. Caglioti (Editors), 2004, Elsevier Ltd

60 Lorena Betancor, Fernando López-Gallego, Aurelio Hidalgo, Noelia Alonso-Morales, Gisela Dellamora-Ortiz Cesar Mateo, Roberto Fernández-Lafuente, Jose M. Guisán, Different mechanisms of protein immobilization on glutaraldehyde activated supports: Effect of support activation and immobilization conditions, Enzyme and Microbial Technology 39 (2006) 877882

61 Isabelle Migneault, Catherine Dartiguenave, Michel J. Bertrand, and Karen C. Waldron Glutaraldehyde: behavior in aqueous solution, reaction with proteins, and application to enzyme crosslinking BioTechniques 37:790-802 (November 2004

62 Gabriella Fanali, Alessandra di Masi, Viviana Trezza, Maria Marino, Mauro Fasano, Paolo Ascenzi, Human serum albumin: From bench to bedside, Molecular Aspects of Medicine 33 (2012) 209-290.

63 Claudia M. Rivera-Hoyos, Edwin David Morales-Alvarez, Raul A. Poutou-Piñales, Aura Marina Pedroza-Rodríguez, Refugio Rodríguez-Vázquez, Julio M. Delgado-Boada, Fungal laccases, Fungal Biology Reviews 27 (2013) 67-82.

64 M.R. Montereali, L. Della Seta,W. Vastarella, R. Pilloton, A disposable Laccase-Tyrosinase based biosensor for amperometric detection of phenolic compounds in must and wine, Journal of Molecular Catalysis B: Enzymatic 64 (2010) 189-194.

65 A.T. Lawal, S.B. Adeloju, Comparison of enzyme immobilisation methods for potentiometric phosphate biosensors, Biosensors and Bioelectronics 25 (2009) 406-410.

66 Gülay Bayramoğlu, M. Yakup Arıca, Immobilization of Laccase onto poly(glycidylmethacrylate) brush grafted poly(hydroxyethylmethacrylate) films: Enzymatic oxidation of phenolic compounds, Materials Science and Engineering C 29 (2009) 1990-1997.

67 Suellen Cadorin Fernandes, Inés RosaneW.Z. de Oliveira, Orlando Fatibello-Filho, Almir Spinelli, Iolanda Cruz Vieira, Biosensor based on laccase immobilized on microspheres of chitosan crosslinked with tripolyphosphate, Sensors and Actuators B 133 (2008) 202-207.

68 Yuanyuan Liu, Zhuotong Zeng, Guangming Zeng, Lin Tang, Ya Pang, Zhen Li, Can Liu, Xiaoxia Lei, Mengshi Wu, Pinyun Ren, Zhifeng Liu, Ming Chen, Gengxin Xie, Immobilization of laccase on magnetic bimodal mesoporous carbon and the application in the removal of phenolic compounds, Bioresource Technology 115 (2012) 21-26. 
69 Cristina Tortolini, Sara Rea, Eleonora Carota, Salvatore Cannistraro, Franco Mazzei, Influence of the immobilization procedures on the electroanalytical performances of Trametes versicolor laccase based bioelectrode, Microchemical Journal 100 (2012) 8-13.

70 E. Casero, M.D. Petit-Domínguez, L. Vázquez, I. Ramírez-Asperilla, A.M. Parra-Alfambra, F. Pariente, E. Lorenzo, Laccase biosensors based on different enzyme immobilization strategies for phenolic compounds determination, Talanta 115 (2013) 401-408.

71 Renato S. Freire, Nelson Durán, Lauro T. Kubota, Effects of fungal laccase immobilization procedures for the development of a biosensor for phenol compounds, Talanta 54 (2001) 681686.

\section{Capítulo 3.}

72 María Elisa Marín-Zamora, Francisco Rojas-Melgarejo, Francisco García-Cánovas, Pedro Antonio García-Ruiz, Production of o-diphenols by immobilized mushroom Tyrosinase, Journal of Biotechnology 139 (2009) 163-168.

73 J. C. Espín, P. A. García Ruiz, J. Tudela and F. García-Cánovas, Study of stereospecificity in mushroom Tyrosinase, Biochemical Journal, (1998), 331, 547-551.

74 K. Lerch, Metal Ions in Biological Systems (Sigel, H., ed.), (1981) 143-186.

75 Sung-Yum Seo, Vinay K. Sharma, Niti Sharma, Mushroom Tyrosinase: Recent Prospects, J. Agric. Food Chem. 2003, 51, 2837-2853.

76 K. S. Abhijith, P. V. Sujith Kumar. M. A. Kumar, M. S. Thakur, Immobilised tyrosinase-based biosensor for the detection of tea polyphenols, Anal Bioanal Chem (2007) 389:2227-2234.

77 E.A. Cummings, S. Linquette-Mailley, P. Mailley, S. Cosnier, B.R. Eggins, E.T. McAdams, A comparison of amperometric screen-printed, carbon electrodes and their application to the analysis of phenolic compounds present in beers, Talanta 55 (2001) 1015-1027.

78 Engin Asav, Emine Yorganci, Erol Akyilmaz, An inhibition type amperometric biosensor based on tyrosinase enzyme for fluoride determination, Talanta 78 (2009) 553-556.

79 M. Portaccio, S. Di Martino, P. Maiuri, D. Durante, P. De Luca, M. Lepore, U. Bencivenga, S. Rossi, A. De Maio, D.G. Mita, Biosensors for phenolic compounds: The catechol as a substrate model, Journal of Molecular Catalysis B: Enzymatic 41 (2006) 97-102.

80 S. Naish-Byfield, P. A. Riley, Oxidation of monohydric phenol substrates by Tyrosinase, An oximetric study Biochemical Journal, 28, (1992), 63-67. 
81 S. Cosnier, C. Innocent, A new strategy for the construction of a Tyrosinase-based amperometric phenol and o-diphenol sensor, Bioelectrochemistty and Bioenergetics, 31, (1993), 147-160.

82 Q. Chen and I. Kubo, Kinetics of Mushroom Tyrosinase Inhibition by Quercetin, J. Agric. Food Chem., 50, (2002), 4108-4112.

83 L. G. Fenoll, J. N. Rodríguez-López, F. García-Molina, Francisco García-Cánovas, and J. Tudela, Michaelis constants of mushroom tyrosinase with respect to oxygen in the presence of monophenols and diphenols, The International Journal of Biochemistry \& Cell Biology, 34, (2002), 332-336.

84 G. Rivas and V.M. Solis, Electrochemical determination of the kinetic parameters of mushroom Tyrosinase, Bioelectrochemis\&y and Bioenergetics, 29 (1992) 19-28.

85 Li, X.; Shen, L.; Zhang, D.; Qi, H.; Gao, Q.; Ma, F.; Zhang, C. Electrochemical impedance spectroscopy for study of aptamer-thrombin interfacial interactions. Biosensors and Bioelectronics 2008, 23, 1624-1630

86 Aaron, D.; Borole, A.P.; Yiacoumi, S.; Tsouris, C. Effects of operating conditions on internal resistances in enzyme fuel cells studied via electrochemical impedance spectroscopy, Journal Power Sources 2012, 201, 59-65.

87 Bravo-Anaya, L.M.; Macías, E.R.; Carvajal, R.F.; Álvarez-Ramírez, J.G.; Casillas, N.; Soltero, J.F.A.; Larios-Durán, E.R. DNA Transitions by an Adsorption Impedance Study. Journal Electrochemical Society, 2013, 160, G69-G74.

88 T. Pajkossy, Impedance spectroscopy at interfaces of metals and aqueous solutions - Surface roughness, CPE and related issues, Solid State Ionics 176 (2005) 1997 - 2003.

89 Fernando Campanhã Vicentini, Bruno C. Janegitz, Christopher M.A. Brett, Orlando FatibelloFilho, Tyrosinase biosensor based on a glassy carbon electrode modifiedwith multi-walled carbon nanotubes and1-butyl-3-methylimidazolium chloride within adihexadecylphosphate film, Sensors and Actuators B 188 (2013) 1101- 1108.

90 Carmen C. Mayorga-Martinez, Miquel Cadevall, Maria Guix, Josep Ros, Arben Merkoçi, Bismuth nanoparticles for phenolic compounds biosensing application, Biosensors and Bioelectronics 40 (2013) 57-62.

\section{Capítulo 4.}

$91 \mathrm{Hu}$, S., Lu, Q., Xu, Y., 2008. Biosensors based on direct electron transfer of protein, in: Zhang, X., Ju, H., Wang, J. (Eds.), Electrochemical Sensors, Biosensors and Their Biomedical Applications, Elsevier Inc. pp. 531-581. 
92 Roy, J. J., Abraham, T. E. Abhijith, K.S., Sujith Kumar, P.V., Thakur, M.S., Biosensor for the determination of phenols based on Cross-Linked Enzyme Crystals (CLEC) of laccase, Biosensors and Bioelectronics 21 (2005) 206-211.

93 Portaccio, M., Di Martino, S., Maiuri, P., Durante, D., De Luca, P., Lepore, M., Bencivenga, U., Rossi, S., De Maio, A., Mita, D.G., Biosensors for phenolic compounds: The catechol as a substrate model, Journal of Molecular Catalysis B: Enzymatic 41 (2006) 97-102.

94 Mousty, C., Vieille, L., Cosnier, S., Laccase immobilization in redox active layered double hydroxides: A reagentless amperometric biosensor, Biosensors and Bioelectronics 22 (2007) $1733-1738$.

95 Montereali, M.R., Della Seta, L., Vastarella, W., Pilloton, R., A disposable Laccase-Tyrosinase based biosensor for amperometric detection of phenolic compounds in must and wine, Journal of Molecular Catalysis B: Enzymatic 64 (2010) 189-194.

96 Rawal, R., Chawla, S., Devender, Pundir, C.S., An amperometric biosensor based on laccase immobilized onto $\mathrm{Fe}_{3} \mathrm{O}_{4} \mathrm{NPs} / \mathrm{cMWCNT} / \mathrm{PANI} / \mathrm{Au}$ electrode for determination of phenolic content in tea leaves extract, Enzyme and Microbial Technology 51 (2012) 179- 185.

97 Narang, J., Chawla, S., Chauhan, N., Dahiya, M., Pundir, C.S., Construction of an amperometric polyphenol biosensor based on PVA membrane Food Measure. 7 (2013) 22-28.

98 Das, P., Barbora, L., Das, M., Goswami, P., Highly sensitive and stable laccase based amperometric biosensordeveloped on nano-composite matrix for detecting pyrocatechol inenvironmental samples, Sensors and Actuators B 192 (2014) 737- 744.

99 Lötzbeyer, T., Schuhmann, W., Schmidt, H-L. Electron transfer principles in amperometric biosensors: direct electron transfer between enzymes and electrode surface, Sensors and Actuators B 33, (1996), 50-54.

100 Ying Li, Jiwei Zhang, Xirong Huang, Tianhong Wang, Construction and direct electrochemistry of orientation controlled laccase electrode, Biochemical and Biophysical Research Communications 446 (2014) 201-205.

101 Yaropolov, A.I., Skorobogat'ko, O.V., Vartanov, S.S., Varfolomeyev, S.D., Laccase Properties, Catalytic .Mechanism, and Applicability Applied Biochemistry and Biotechnology 49 (1994) 257-280.

102 Solomon, E.I., Sundaram, U.M., Machonkin, T.E., Multicopper Oxidases and Oxygenases, Chemical Review 96 (1996) 2563-2605.

103 Shleev, S., Tkac, J., Christenson, A., Ruzgas, T., Yaropolov, A.I., Whittaker, J.W., Gorton, L., Direct electron transfer between copper-containing proteins and electrodes Biosensors and Bioelectronics 20 (2005) 2517-2554.

104 Xu, F., Shin, W., Brown, S.H., Wahleithner, J.A., Sundaram U.M., Solomon,E.I., A study of a series of recombinant fungal laccases and bilirubin oxidase that exhibit significant differences in 
redox potential, substrate specificity, and stabilit, Biochimica et Biophysica Acta 1292 (1996) 303-311.

105 Ferapontova, E.E., Shleev, S., Ruzgas, T., Stoica, L., Christenson, A., Tkac, J., Yaropolov, A.I., Gorton, L., 2005. Direct Electrochemistry of Proteins and Enzymes, in Palecek, E., Scheller, F., Wang, J. (Eds.), Perspectives in Bioanalysis 1, Elsevier Inc, pp. 517-598.

106 Xu, F., Kulys, J.J., Duke, K., Li, K., Krikstopaitis, K., Deussen, H.J., Abbate, E., Galinyte, V., Schneider, P., Redox Chemistry in Laccase-Catalyzed Oxidation of N-Hydroxy Compounds, Applied and Environmental Microbiology, 66 (2000) 2052-2056.

107 Ducros, V., Brzozowski, A.M., Wilson, K.S., Brown, S.H., Østergaard, P., Schneider, P., Yaver, D.S., Pedersen, A.H., Davies, G.J., Crystal structure of the type-2 $\mathrm{Cu}$ depleted laccase from Coprinus cinereus at $2.2 \AA$ resolution, Nature Structural \& Molecular Biology 5 (1998) 310 316.

108 Lee, S-K., DeBeer, G.S., Antholine, W.E., Hedman, B., Hodgson K.O., Solomon, E.I., Nature of the Intermediate Formed in the Reduction of $\mathrm{O}_{2}$ to $\mathrm{H}_{2} \mathrm{O}$ at the Trinuclear Copper Cluster Active Site in Native Laccase, Journal of American Chemical Society 124 (21) (2002), 6180-6193.

109 Tarasevich, M.R., Bogdanovskaya, V.A., Fridman V.A., Kuznetsova, L.N., Kinetics and Mechanism of the H2O2 Electroreduction on the Peroxidase-Promoted Electrodes, Russian Journal of Electrochemistry, 37 (2001a) 7-14.

110 Shlev, S.V., Zaitseva, E.A., Gorshina, E.S., Morozova, O.V., Serezhenkov, V.A., Burbaev, D.S., Kuznetsov, B.A., Yaropolov, A.I., Spectral and electrochemical study of laccases from basidiomycetes, Moscow University Chemistry Bulletin 44 (2003) 35-39.

111 Shleev, S., Jarosz-Wilkolazka A., Khalunina, A., Morozova, O., Yaropolov, A., Ruzgas T., Gorton, L., Direct electron transfer reactions of laccases from different origins on carbon electrodes, Bioelectrochemistry 67 (2005) 115 - 124.

112 Tarasevich, M.R., Bogdanovskaya, V.A., Kuznetsova, L.N., Bioelectrocatalytic Reduction of Oxygen in the Presence of Laccase Adsorbed on Carbon Electrodes, Russian Journal of Electrochemistry, 37 (2001b) 833-837.

113 Marcus, R.A., Sutin, N., Electron transfers in chemistry and biology, Biochimica et Biophysica Acta 811 (1985) 265-322.

114 Allen J. Bard, Larry R. Faulkner, ELECTROCHEMICAL METHODS Fundamentals and Applications, segunda edicion, JOHN WILEY \& SONS, INC. New York.

115 Sabine Borgmann, Gerhard Hartwich, Albert Schulte, Wolfgang Schuhmann, Amperometric Enzyme Sensors based on Direct and Mediated Electron Transfer, Perspectives in Bioanalysis 1, (2005), 599-655 


\section{Capítulo 5.}

116 Michael Antolovich, Paul D. Prenzler, Emilios Patsalides, Suzanne McDonald, Kevin Robards, Methods for testing antioxidant activity, Analyst, 127, 2002, 183-198

117 Ayse Karadag, Beraat Ozcelik, Samim Saner, Review of Methods to Determine Antioxidant Capacities, Food Anal. Methods 2, (2009), 41-60.

118 Mustafa Özyürek, Kubilay Güçlü, Esma Tütem, Kevser Sözgen Başkan, Erol Erçăg, S. Esin Çelik, Sefa Baki, Leyla Yıldız, Şeyda Karaman, Reşat Apak, A comprehensive review of CUPRAC methodology, Anal. Methods, 3, 2011, 2439-2453.

119 L.D. Mello, L.T. Kubota, Biosensors as a tool for the antioxidant status evaluation, Talanta 72 (2007) 335-348.

120 David E. Goodney, Todd P. Silverstein, Using the Tyrosinase-Based Biosensor To Determine the Concentration of Phenolics in Wine, J. Chem. Educ. 90, 2013, 1710-1712

121 Mustafa Bener, Mustafa Özyürek,* Kubilay Güçlü, Reşat Apak, Novel Optical Fiber Reflectometric CUPRAC Sensor for Total Antioxidant Capacity Measurement of Food Extracts and Biological Samples, J. Agric. Food Chem. 61, 2013, 8381-8388.

122 Wang, X., Jiao, C., Yu, Z. Electrochemical biosensor for assessment of the total antioxidant capacity of orange juice beverage based on the immobilizing DNA on apoly L-glutamic acid doped silver hybridized membrane. Sens. Actuators B Chem. 2014, 192, 628-633.

123 Lismery P. Souza, Francyelle Calegari, Aldo J. G. Zarbin, Luiz Humberto Marcolino-Júnior, Márcio F. Bergamini, Voltammetric Determination of the Antioxidant Capacity in Wine Samples Using a Carbon Nanotube Modified Electrode, J. Agric. Food Chem. 59, 2011, 76207625.

124 Mohammed Elkaoutit, Ignacio Naranjo-Rodriguez, Khalid Riffi Temsamani, Manuel Domínguez De La Vega, Jose Luis Hidalgo-Hidalgo De Cisneros, Dual Laccase-Tyrosinase Based SonogelCarbon Biosensor for Monitoring Polyphenols in Beers, J. Agric. Food Chem. 55, 2007, 80118018.

125 Saliha Şahin, Evaluation of Antioxidant Properties and Phenolic Composition of Fruit Tea Infusions, Antioxidants 2, 2013, 206-215.

126 Lakshi Prasad Bhuyan, Santanu Sabhapondit, Binoti Devi Baruah, Cinmoy Bordoloi, Ramen Gogoi, Pradip Bhattacharyya, Polyphenolic compounds and antioxidant activity of CTC black tea of North-East India, Food Chemistry 141 (2013) 3744-3751.

127 W. Brand-Williams, M. E. Cuvelier and C. Berset, Use of a Free Radical Method to Evaluate Antioxidant Activity, Lebensm.-Wiss. u.-Technol., 28, 1995, 25-30. 
128 Rafaela K. Lima, Maria das Graças Cardoso, Milene A. Andrade, Paula L. Guimarães, Luís R. Batista, David L. Nelson, Bactericidal and Antioxidant Activity of Essential Oils from Myristica fragrans Houtt and Salvia microphylla H.B.K, J Am Oil Chem Soc 89, (2012) 523-528.

129 Rolffy Ortiz-Andrade, Angel Cabañas-Wuan, Víctor E. Arana-Argáez a, Angel Josabad AlonsoCastro, Rocio Zapata-Bustos, Luis A. Salazar-Olivo, Fabiola Domínguez, Marco Chávez, Candy Carranza-Álvarez, Alejandro García-Carrancá, Antidiabeticeffectsof Justicia spicigera Schltdl(Acanthaceae), Journal of Ethnopharmacology 143 (2012) 455-462.

130 Angel Josabad Alonso-Castro, Elizabeth Ortiz-Sánchez, Fabiola Domínguez, Victor AranaArgáez, Maria del Carmen Juárez-Vázquez, Marco Chávez, Candy Carranza-Álvarez, Octavio Gaspar-Ramírez, Guillermo Espinosa-Reyes, Gabriela López-Toledo, Rolffy Ortiz-Andrade, Alejandro García-Carrancá, Antitumor and immunomodulatory effects of Justicia spicigera Schltdl (Acanthaceae), Journal of Ethnopharmacology 141 (2012) 888- 894.

131 Marcos A. Blanco, Germán A. Colareda, Catalina van Baren, Arnaldo L. Bandoni, Jorge Ringuelet, Alicia E. Consolini, Antispasmodic effects and composition of the essential oils from two South American chemotypes of Lippia alba, Journal of Ethnopharmacology 149(2013)803809.

132 Fabio Carmona, Mateus A. Angelucci, Débora S. Sales, Telma M. Chiaratti, Fernando B. Honorato, Randal V. Bianchi, Ana M.S. Pereira, Lippia alba (Mill.) N. E. Brown hydroethanolic extract of the leaves is effective in the treatment of migraine in women, Phytomedicine 20 (2013) 947-950.

133 S. Pérez, M. Meckes, C. Pérez, A. Susunaga, M.A. Zavala, Anti-inflammatory activity of Lippia dulcis, Journal of Ethnopharmacology 102 (2005) 1-4.

134 T. Görnemann, R. Nayal, H.H. Pertz, M.F. Melzig, Antispasmodic activity of essential oil from Lippia dulcis Trev., Journal of Ethnopharmacology 117 (2008) 166-169.

135 E. Skotti, E. Anastasaki, G. Kanellou, M. Polissiou, P. A. Tarantilis, Total phenolic content, antioxidant activity and toxicity of aqueousextracts from selected Greek medicinal and aromatic plants, Ind. Crop. Prod. 53, 2014, 46-54.

\section{ANEXo 1}

136 Beatriz M. Brena and Francisco Batista-Viera, Immobilization of Enzymes: A Literature Survey, Inmobilization of enzymes and cells, Ed. Guisán J. M., 2006, Hardcover, A production of Humana Press

137 Klei, H.E.; Sundstrom, D.W.; Shim, D. (1985) Immobilization of enzymes by microencapsulation en Immobilized cells and enzymes: a practical approach J. Woodward, ed. IRL Press, pág. 49-54. 
138 Cesar Mateo, Jose M. Palomo, Gloria Fernandez-Lorente, Jose M. Guisan *, Roberto FernandezLafuente, Improvement of enzyme activity, stability and selectivity via immobilization techniques, Enzyme and Microbial Technology 40 (2007) 1451-1463

139 Veronika Stepankova, Sarka Bidmanova, Tana Koudelakova, Zbynek Prokop, Radka Chaloupkova, Jiri Damborsky, Strategies for Stabilization of Enzymes in Organic Solvents, ACS Catal. 2013, 3, 2823-2836.

140 J. Jegan Roy, T. Emilia Abraham, Strategies in Making Cross-Linked Enzyme Crystals, Chemical Reviews, 2004, Vol. 104, No. 9, 3705-3721.

141 Margolin, A.L. (1996) Novel crystalline catalysts. Trends Biotechnol. 14: 223-230.

ANEXO 2.

142 Kenneth A. Johnson and Roger S. Goody, The Original Michaelis Constant: Translation of the 1913 Michaelis-Menten Paper, Biochemistry 50, (2011), 8264-8269

143 B.I. Kurganov, A.V. Lobanov, I.A. Borisov, A.N. Reshetilov, Criterion for Hill equation validity for description of biosensor calibration curves, Analytica Chimica Acta, (2001), 427, 11-19.

144 Kenneth A. Johnson and Roger S. Goody, The Original Michaelis Constant: Translation of the 1913 Michaelis-Menten Paper, Biochemistry 50, (2011), 8264-8269

145 Hans Lineawere and Dean Burk, The Determination of Enzyme Dissociation Constants J. Am. Chem. Soc., 1934, 56 (3), pp 658-666

146 Javier Gonzalo Ruiz, Desarrollo de biosensores enzimáticos miniaturizados para su aplicación en la industria alimentaria, Tesis doctoral, Universidad de Barcelona 2006.

147 J.C. Miller, J.N. Miller, Estadistica para quimica analitica, segunda edición, Addison-Wesley Iberoamerican, 1993, USA. 